\title{
The effect of a home exercise program on health status and depression level during Corona pandemic
}

\section{Dr. Ahmed Mohamed Abdelaziz Ahmed}

Exercises and gymnastics department, faculty of physical education, Sadat city university

\section{Dr. Ibrahim Mahmoud Mohammed Deyab}

Exercises and gymnastics department, faculty of physical education, Sadat city university

\section{Introduction and Research Problem :}

There's no doubt that human being, recently, needs some regular exercises to overcome so many health problems that have emerged because of the overuse of modern technological means and lack of movements. Recent studies have shown that regular physical exercises and sports activities achieve a lot of positive benefits for both the individual and society. (15: 215)

Low and moderate intensity of physical exercises raise the level of health and play a fundamental role in alleviating health problems and improving the function of internal organs such as the heart and lungs. (14: 299)

Depression is one of the oldest disorders known to the human community, and the world has witnessed a tremendous increase in the prevalence of depressive disorders. The World Health Organization stated that (2\%: 5\%) of the world's population suffers from a severe or moderate state of depression. (16:17)

The researchers believe that there are some social and psychological changes accompanying to home isolation during the curfew period due to the pandemic of Corona which causes loss of social relations, loss of doing activities and interests, dependence on others, and many problems that hinder the psychological and social compatibility.

The big point is that integration into exercise programs improve the person's healthy lifestyle and makes him enjoy his life naturally, as good fitness gives our bodies the opportunity to function with the highest possible efficiency. Therefore, it has become necessary to pay attention to the importance of sport as an essential part of the individual's lifestyle. (5:51)

Exercises relieve stress and anxiety, and renew physical and mental activity. In addition to preserving the body physiologically and psychologically.

From the above, the researchers believe that physical exercises aim to create a general positive participation and break the barrier of isolation because of its profound effect on the participants through increasing attention and interaction with others into the teamwork, and developing a sense of self-esteem, vitality and positive energy, which reduce depression and psychological loneliness.

Through the researchers' field experience as fitness trainers in the Platinum Sports Club in Hail, Saudi Arabia, and because of the curfew due to Corona pandemic and the closure of clubs and health centers, the researchers conducted personal interviews on social media with some participants of common age (40:50) of men. He notes that there are some problems this group suffers from, which are depression, psychological loneliness, low level of fitness and general health due to the imposition of curfews, staying at home and lack of exercise. Since then, the idea of this research crystallized in an attempt to design a home exercise program to raise the level of health and get out of the state of depression that dominated on most people, and to 
unload the stored energy inside the individual through the performance of exercises at home on a regular basis.

\section{Study objective :}

Designing a home exercise program to raise the level of some health status (weight - body mass - pulse rate - blood pressure - vital capacity - cardiorespiratory fitness - muscle fitness) and the level of depression for the research sample.

\section{Hypotheses:}

1- There are statistically significant differences between the pre and post measurements in the level of some health status (weight - body mass - pulse - blood pressure - vital capacity - cardiac fitness - muscle fitness) and in favor of the post measurement.

2- There are statistically significant differences between the pre and post measurement in the degree of depression in favor of the post measurement.

\section{key words :}

\section{home exercise program :}

It is a set of movements based on scientific and educational foundations that are applied inside the home with the aim of physically for reaching the best level of health .(procedural definition)

\section{health status :}

It is a state of complete physical, mental and social integrity and not merely the absence of disease or infirmity. (procedural definition).

\section{Depression :}

A mood state characterized by sadness, pessimism and fatigue as a result of traumatic experiences and frustrations that an individual faces in his life. (procedural definition).

\section{Procedures:}

\section{Research method:}

The researchers used the experimental design for the current study.

\section{Research sample :}

The sample was chosen deliberately among (39) persons (30) as a basic sample and (9) persons as an exploratory sample.

\section{Sample Conditions:}

- They should have the desire to participate in the experience and train regularly.

- $\quad$ The sample should be in a good health and non-smokers.

- All members of the sample live in similar environmental conditions of economic and social terms. 


\section{Homogeneity of the research sample:}

Table (1)

Arithmetic mean, standard deviation and torsion value of the total research sample (weight - Bmi - pulse - blood pressure - vital capacity - cardiac fitness muscle fitness) $\mathbf{n}=30$

\begin{tabular}{|c|c|c|c|c|c|}
\hline serial & The variables & $\begin{array}{c}\text { Measurement } \\
\text { unit }\end{array}$ & mean & Std-v & skewnes: \\
\hline 1 & Age & Year & 45.06 & 2.63 & .164 . \\
\hline 2 & Length & $\mathrm{cm}$ & $179,7$. & $1, V V$ & $-\cdot, \leqslant Y \wedge$ \\
\hline 3 & the weight & $\mathrm{Kg}$ & 84.46 & 1.224 & $-\cdot .038$ \\
\hline 4 & $\mathrm{BMI}$ & $\mathrm{Kg} / \mathrm{m} 2$ & 27.40 & 1.643 & $-\cdot, 797$ \\
\hline 5 & Pulse rate & $\mathrm{N} / \mathrm{s}$ & 79.70 & 1.643 & $\cdot, \leqslant 19$ \\
\hline 6 & $\begin{array}{c}\text { Systolic blood } \\
\text { pressure }\end{array}$ & $\mathrm{Mm} / \mathrm{Hg}$ & 139.00 & .830 & $\cdot, \cdots$ \\
\hline 7 & $\begin{array}{c}\text { Diastolic blood } \\
\text { pressure }\end{array}$ & $\mathrm{Mm} / \mathrm{Hg}$ & 86.86 & 1.995 & $\cdot, 19 V$ \\
\hline 8 & Vital capacity & Milliliter & 2711.70 & 1.704 & $r, \vee \wedge T$ \\
\hline 9 & Cardiac fitness & mile & 1.64 & .0294 & $\cdot, r 99$ \\
\hline 10 & Muscle fitness & Number & 13.30 & 1.087 & $\cdot, Y) \cdot$ \\
\hline 11 & Depression & Degree & 35.13 & 35.00 & $-\cdot, Y \wedge Y$ \\
\hline
\end{tabular}

Table (1) shows the values of the torsion coefficient for the variables are limited to \pm 3 which indicates the homogeneity of the sample members.

\section{Data collection, Tools and systems of measurement:}

- Restameter to measure height - Spirometer device - Medical scale calibrated to measure weight.

- A stop watch to count the time - mattresses - treadmill - weights - bounce ropes sticks.

\section{Attachments used in the research:}

- The names of the experts are in attached (1).

- The personal data registration form and the pre and post tests of the sample attached (2)

- A questionnaire for surveying experts' opinions on determining the degree of importance of the proposed exercises and their suitability for the members of the research sample, as well as the time period required to apply the program attached (3)

Tests and measures used in research :

Health variables tests: Attachment (4)

Weight - Body Mass - Pulse Rate - Blood Pressure - Vital Capacity - 
Cardiorespiratory Fitness - Muscle Fitness .

\section{Depression Scale : Attachment (5)}

It was prepared by Amal Abd al-Sami Meliji Baza (1999 CE), but the researchers made some adjustment to it .The test consists of (30) statements to be answered (yes or no) if the answer matches the correction key, it takes one score, and if it does not match it takes two scores.

\section{Procedures' adjustment :}

The researchers used the following scientific transactions of the scale .

\section{- coefficient of stability}

The researchers extracted the stability factor using the Test and Retest method with an interval of (15) days on a sample consisting of (9) individuals, not from the main research sample, but from the same research population. The following table shows that :

Table No. (2)

The correlation coefficient between the first and

second application of the depression scale $n=9$

\begin{tabular}{|c|c|c|c|}
\hline application & mean & Stdev. & Correlation coefficient \\
\hline The First & ro, & $\varepsilon, \Gamma$ & \multirow{2}{*}{$\cdot, \wedge 1$} \\
\hline The second & $r 0, \wedge q$ & $\Gamma, \wedge r$ & \\
\hline
\end{tabular}

the tabular " $\mathrm{t}$ " value at the level of $(0.05)=0.582$

It is clear from Table (3) that the calculated value of " $r$ " is greater than the tabular " $\mathrm{t}$ " value, which indicates the stability of the scale.

\section{- The validity of the scale}

The researchers used terminal comparison to calculate the validity of differentiation.

Table No. (3)

The significance of the differences between the upper and lower quartiles to find the validity of the differentiation for the depression scale $n=9$

\begin{tabular}{c|c|c|c|c|c}
\hline \hline variable & the group & Average ranks & Total ranks & )Z( & Error potential \\
\hline \multirow{2}{*}{ Depression } & the highest & $r$ & 7 & \multirow{2}{*}{1,99} &,,$\cdot 57$ \\
\cline { 2 - 5 } & The lowest & 0 & 10 & & \\
\hline \hline
\end{tabular}

The tabular $(\mathrm{Z})$ value at the level of $(0.05)=1.96$

It is clear from Table (3) that there are statistically significant differences 
between the upper and lower quartiles in the depression variable, which indicates the validity of the scale.

\section{Assistants :}

A number of (2) fitness trainers in the Platinum Club, who hold a Bachelor's degree in Physical Education, were selected to assist the researchers in implementing and conducting the measurements and tests used in the research.

\section{Exploratory study :}

The researchers conducted an exploratory study from $1 / 6 / 2020$ to $8 / 6 / 2020$ on a sample consisting of (5) from outside the main research sample and represents the research community in order to :

- Determine the time of the tests.

- Verify the validity of the devices and tools used in the measurement.

- Identify the willingness of the members of the research sample to submit to the conditions of conducting the experiment.

- Identify any obstacles and try to avoid them .

- $\quad$ Find the best arrangement for taking the measurements.

\section{Home exercise program:}

The researchers designed the home exercise program by referring to scientific references and previous studies, as well as referring to the opinions of experts in the field of physical education to express their opinion on the extent to which the designed program is related and the extent of its comprehensiveness to the objectives of the research and determine the total duration of exercise, the number of training units, number of times of practice per week and The time for the daily training unit, The researchers has satisfied the approval of the experts by a percentage of $75 \%$ Attachment (1)

According to the above, the researchers designed a home exercise program according to the following conditions :

- The number of training times is (3) units per week.

- Unit content includes (warm-up - main exercise - cool down).

- Free home exercises with the use of appropriate tools and recreational games. Attachment (6)

- The duration of the program is three months, with 36 training units. Attachment (7)

\section{Program Aims :}

- Improving physical fitness and general health of the body.

- Reducing the degree of depression among the research sample.

- Spending an enjoyable and healthy leisure time.

\section{The principles of Building the program:}

- Taking into account the health and physical condition of the participants in the program.

- Focusing on the spirit of fun and recreation within the program.

- Choosing exercises that involve the large muscles of the body.

- The intensity of the load ranges from (50: 70\%) of the maximum heart rate during performance. 
- Taking into account the security and safety factors.

- Taking into account the sample's desire to participate in the program.

\section{Program content:}

To achieve the research objectives, the researchers designed the program according to the following parts:

1- Warm-up: Its duration is $10-15 \mathrm{~m}$ that includes simple exercises with the aim of raising the body temperature, such as (walking exercises in place recreational games - lateral movements - moving the joints in circular motions).

2- Basic exercises: its duration is $30-40 \mathrm{~m}$, and it includes a group of various exercises and recreational games with the aim of increasing periodic endurance and raising the level of fitness through strengthening large muscles (walking in place - running in place - jumping - recreational games -

\section{Basic study :} competitions - resistance exercises for the arms, a torso and two legs).

\section{Before implementing the program}

- Conducting an initial medical examination on the research sample to ensure the general health status to participate in the program.

- Use the heart rate to determine the intensity of the program and calculate the maximum heart rate for each individual according to the equation (maximum heart rate $=220$ - age).

- Training the sample to calculate the pulse rate for each individual in the range from 50 to $70 \%$ of the maximum pulse rate through the carotid artery in the neck.

- Paying the attention of the participants to stop exercising when feeling exhausted or noticing abnormal changes.

\section{Pre measurements:}

The pre-measurement of health variables was performed using health variables tests and the level of depression was measured for the research sample by applying the scale (level of depression) at the period from 10/2/2020 AD: 11/2/2020 AD.

\section{Application of training program:}

The researchers implemented the program during the period from 12/2/2020 to $11 / 5 / 2020$ at Platinum Club in Hail.

\section{post measurements:}

The researchers conducted the post measurement by re-applying the depression scale and health variables tests for the study sample on 12/5/2020: 13/5/2020 AD.

\section{Statistical Processes:}

The researchers processed the data statistically using the following statistical analysis methods: Mean - Standard Deviation "Stdev".- Median - Skewness - Test (T) Improvement percentage. 
View and discuss the results:

Showing results: -

Table (4)

The significance of the differences between the two measures (pre - post) and the rate of improvement in Health status $N=(30)$

\begin{tabular}{|c|c|c|c|c|c|c|c|}
\hline \multirow{2}{*}{ Variables } & \multirow{2}{*}{$\begin{array}{c}\text { Unit of } \\
\text { Measure }\end{array}$} & \multicolumn{2}{|c|}{ pre } & \multicolumn{2}{|c|}{ post } & \multirow{2}{*}{ T - Test } & \multirow{2}{*}{$\begin{array}{c}\text { Improvement } \\
\%\end{array}$} \\
\hline & & mean & Stdev. & mean & Stdev. & & \\
\hline the weight & $\mathrm{Kg}$ & $\wedge \varepsilon, \varepsilon\rceil$ & $1, Y Y \leq$ & $\vee \wedge, \Sigma$. & $1, \wedge 71$ & $1 r, 19$ & $\% \vee, I \vee$ \\
\hline $\mathrm{BMI}$ & $\mathrm{Kg} / \mathrm{m} 2$ & $Y V, \varepsilon$. & $1, \leqslant Y \wedge$ & YO, M & $1,10 \leqslant$ & T,AY & $\% \vee, 00$ \\
\hline Pulse rate & $\mathrm{N} / \mathrm{s}$ & $\vee q, \vee$. & $1,7 \leqslant r$ & $V Y, 1 T$ & $1, \leqslant 17$ & $r \cdot, \wedge T$ & $\% 9, \leq 7$ \\
\hline $\begin{array}{l}\text { Systolic blood } \\
\text { pressure }\end{array}$ & $\mathrm{Mm} / \mathrm{Hg}$ & $1 \Gamma q, \ldots$ & Аঙ. & $1 Y \leq, 7 T$ & ११ะ. & $71, \wedge \wedge$ & $\% 1 \cdot, r r$ \\
\hline $\begin{array}{l}\text { Diastolic blood } \\
\text { pressure }\end{array}$ & $\mathrm{Mm} / \mathrm{Hg}$ & $\wedge \neg, \wedge \uparrow$ & 1,990 & А.,人 & 1,941 & 11,91 & $\% ч, 9 \leq$ \\
\hline Vital capacity & Milliliter & $r v \|, V$. & $1, V \cdot \varepsilon$ & $r \leqslant Y V, Y$. & $1, T Y V$ & $1711,7-$ & $\% r 7, r q$ \\
\hline Cardiac fitness & Tendency & $1,7 \varepsilon$ &. $\mathrm{rq}^{9}$ & Y,OA & IVY. & $r q, \vee \leqslant-$ & $\%$ \%ч, \& \\
\hline $\begin{array}{l}\text { Muscular } \\
\text { fitness }\end{array}$ & Number & .r., & $1, \cdot \wedge V$ & דוץ, & $1, \lambda \leq V$ & $1 \cdot, \leq \leq-$ & \% \\
\hline
\end{tabular}

The value of the table "T" (1.761) at the level of 0.05

Table (4) shows statistically significant differences (0.05) between the pre and post measurements on the body composition variables (the weight, BMI, Pulse rate , Systolic blood pressure

Diastolic blood pressure, Vital capacity, Cardiac fitness, Muscular fitness) and for the benefit of the post ones. It's shown that the rate of improvement ranged between $(7.17 \%: 36.43 \%)$.

Table (5)

Indication of differences between the median of the measures (pre - post) and the rate of improvement in depression rate $\mathrm{N}=(30)$

\begin{tabular}{c|r|r|r|r|r|r||c}
\hline \hline \multirow{2}{*}{ variables } & Unit of & \multicolumn{2}{|c|}{ pre } & \multicolumn{2}{c||}{ post } & \multirow{2}{*}{ T - Test } & \multirow{2}{*}{ Improvement\% } \\
\cline { 3 - 5 } & Measure & mean & Stdev & mean & Stdev. & & \\
\hline \hline Depression & degree & 35.13 & 1.074 & 21.70 & 2.215 & 30.268 & $38.23 \%$ \\
\hline \hline
\end{tabular}

The $t$-value of the table (1.761) is at the level of 0.05

Table (5) shows statistically significant differences (0.05) in the pre and post measurements on the sample in the Depression level. The improvement rate ranged $(38.23 \%)$.

\section{Discuss the results}

\section{** The results of Table (4) indicate:}

Table No. (4) shows that there are statistically significant differences at the level of $(0.05)$ between the mean of the two measurements (pre-post) of the experimental group in the level of the variables under search and in favor of the post 
measurement.

Table No. (4) also shows that there are improvement rates in the postmeasurement over the pre-measurement in the indicators of health variables, and these differences are attributed to the benefit of the higher measurement, the average calculation, which is the post-measurement, as it was higher than the premeasurement in all health variables indicators, and this is an indication of The effectiveness of the proposed training program using home exercises in improving health status.

The researchers attributes this positive effect of the program on health status to the regular exercise of the program, as the program led to weight loss, improvement in cardiac and respiratory variables, as well as increasing muscle strength and improving flexibility of the spine and body mass.

These results are agreeable with the researches of Hussein Zaidan and Jamal Maqrani (2015) (11), who indicated that physical activity improves the level of fitness by practicing various appropriate activities in intensity.

And what Hani Hajar and Walid El-Demerdash (2015) (9) indicated that the positive effect of exercise programs on cardiorespiratory variables is through improving pulse rate and blood pressure.

And what was indicated by Medhat Qassem (2007) (17) study, citing James who confirmed that exercise helps in improving the functional capabilities of the heart muscle, the heart's ability to pump blood, flexibility, the vital capacity of the lungs, and raising the level of health and physical .

As well as the study of Yasser Muhammad Eid and Samira Muhammad Orabi (2019) (30), which confirmed the positive effect of the sports program on improving the work of the heart, as well as improving the work of the respiratory system by increasing the vital capacity.

Thus, the first hypothesis is fulfilled, which states: The training program using home exercises positively affects the health variables (weight, body mass index, pulse rate, systolic blood pressure, diastolic blood pressure, vital capacity) of the sample in question.

\section{** The results of Table (5) indicate:}

Table No. (5) shows that there are statistically significant differences at the level of (0.05) between the mean of the two measures (pre-post) for the experimental group in the level of depression and in favor of the post measurment in Table No. (5). There is an improvement rate in the post measurement than The pre-one in depression indicators by $38.23 \%$ due to using a home exercise program. These differences are in favor of the post-measurement, in the level of depression, and this is an indication of the effectiveness of the proposed home exercise program in improving depression level.

These results indicate a decrease in the level of depression when the individual practices healthy habits such as practicing physical activity, adopting healthy eating habits, avoiding harmful habits and following the health status. 
This is consistent with the study of Ashraf Mahmoud Morsi (2013 CE) (4), which confirmed that exercising leads to general improvement in health, controlling of emotions, and a reduction in the level of depression, and leads to relaxation.

Likewise, Hussein Zaidan and Jamal Maqrani (2015) (11) pointed out the necessity of improving the functional condition by practicing sports activities, which has an effective impact on their healthy lives.

This is consistent with so many studies that dealt with health and positive thinking, with the psychological state and its impact on the quality of life as the study of Ali Alij Khadr (2012) (2) as well as health awareness and its relationship to life satisfaction as the study of Noha Saadi and Ahmed Maghazi (2013 CE) (21) The rationalist and its relationship on dealing with life pressures, and a study on health care services and improving the quality of life.

The study of Noha Saadi Ahmed Maghazi (2013) has confirmed (21) that practicing sports activity through codified programs is one of the most important ways to bring positive changes in an individual's life and reduce the degree of depression.

The researchers believe that practicing sports is an important part of an individual's life, as it works to renew mental and physical activity, achieve the ability to make decisions, develop emotional health, restore psychological balance, get rid of life pressures, increase a sense of self-confidence, and help form social relationships and friends.

Thus, the second hypothesis is fulfilled, which states that the training program using the proposed home exercises has a positive effect on reducing the degree of depression of the sample in question.

\section{Conclusions and recommendations}

\section{Conclusions :}

1. The training program using home exercises positively affects the health variables (weight, body mass index; pulse rate, systolic blood pressure, diastolic blood pressure, vital capacity) of the sample under investigation.

2. The training program using the suggested home exercises has a positive

\section{Recommendations:} effect on reducing the degree of depression for the sample in question.

1. Building sports programs that care about the health status of individuals and rely on the diversity of methods used.

2. Studying many other variables related to health and ways to improve them.

3. Linking psychological variables with physical variables.

Applying similar programs to different age groups.

\section{References:}

1. Abdullah bin Ahmed Al-Zahrani (2019 AD): The global structure and short psychometric properties of the Depression, Anxiety and Stress Scale (DASS-21) in a Saudi environment. College of Education / King Saud University / Issue 42

2. Ali Alij Khader (2012): The effectiveness of a counseling program in reducing the 
level of depression among depressed students, College of Education, University of Mosul.

3. Amer Othman Abdel-Basit. (2019): The effectiveness of a program of walking and running using a treadmill with resistance exercises on some health, physiological and physical variables for the elderly. Assiut Journal of Physical Education Sciences and Arts.

4. Ashraf Mahmoud Morsi (2013): The effect of a water sports recreational program on some psychological variables among the elderly, Journal of Physical Education Research, College of Physical Education, Zagazig University.

5. Barbara, Isaacs,( 1997) : " Routines out mind bodies " Washington Lexington Herald .

6. Carolin, E. Layde, (1999): " Dance therapy " New York, http/ www.

7. Dee Smith (2000) : "What is the Dance Movement therapy" Annual conference, Washington IDTI

8. Fran J. levy (2000) :" Dance Movement therapy" Washington Eric Clearing house.

9. Hani Hajar and Walid Al-Demerdash (2015 AD): The Impact of a Proposed Sports Recreation Program on Some Physiological Variables and Sleep Disorders in Elderly People with Depression, Journal of the College of Education, Al-Azhar University, p. 162.

10. https://www.feedo.net/Fitness/PatientFitness/FitnessForDepressionAndAniety.h tm

11. Hussein Zaidan and Gamal Maqrani (2015 AD): Physical variables the way to a healthy life for adults, International Conference on Sport and Health Sciences, Faculty of Physical Education, Assiut University, Egypt.

12. Ibrahim Abd Rabbo Khalifeh (2000): Walking Sport: Importance, Application and Future Directions, The Arab Regional Conference for Elderly Care, Part Two, Helwan University.

13. Ibrahim Abdul Sattar (1998) Depression: Disorder of the Modern Age, Its Understanding and Treatment Methods, Kuwait, The World of Knowledge.

14. Idris Ahmed Karim (2014): A comparative study of the level of depression among female students who practice and non-practice in sports activity in the College of Basic Education, Sulaymaniyah University. Journal of Physical Education Sciences, University of Babylon.

15. JONNE THATEHE, MELISSA DAY, RACHEL RAHMAN, SPORT AND EXERCISE

16. Mahmoud Naguib Mahmoud (2009 AD): The effect of an exercise program on the lung capacity of the elderly, The Scientific Journal of Physical Education and Sports, Egypt, p. 58.

17. Medhat Qassem (2007 AD): The effect of using healthy fitness exercises on the degree of concentration, stress, and quality of life for the elderly, Journal of Sciences of Sports Arts, Egypt, Volume 27,

18. Nabil Jabrin Al-Jundi (2008 AD): The Arabic Image of Testing for Depression in Old Age, a global study on a sample of Palestinian elderly, Al-Aqsa University Journal, Volume 12, Issue 1.

19. NAIL J.SALKIND, ENEYELOPIDEA OF HUMAN DEVELOPMENT, SAGE

20. Nemat Salah Al-Sayed (2011): Physical responses to specific exercise and quality of life among the elderly. Sports - Sciences and Arts: Helwan University - College 
of Physical Education for Women,

21. Noha Saadi Ahmed Maghazi (2013 AD): The Impact of a Proposed Recreation Program on Some Social and Psychological Variables Accompanying Older Elderly Women in Residential Homes, Higher Institute of Social Service in Alexandria.

22. PSYCHOLOGY, LEARNIG MATERS LTD, UNITED KINGDOM, 2011.

23. PUBLICATIONS, UNITED STATES OF AMERICA, 2006.

24. Saif Muhammad Radif (2013): Self-image and its relationship to depression in the elderly, Journal of Educational and Psychological Research, Sadr City.

25. Salem Hamid Obaid, Saif Muhammad Radif (2019 AD): Life satisfaction and its relationship to existential anxiety among the elderly, Psychological Research Center.

26. Samah Hassan Farag (2019): The effect of various exercise on physical fitness elements related to health and quality of life for women who do not practice sports. The Scientific Journal of Sport Sciences and Arts, Helwan University.

27. Samah Sami Suleiman, Samira Muhammad Orabi, Hussein Hassan Muhammad (2015): The effect of the rhythmic aerobic exercise program on the degree of depression and the level of endorphins in the blood of a group of women with depression in Jordan - Journal of Humanities and Social Sciences - University of Jordan.

28. Sayyidah Ali Abdel-Aal (2012): The effect of using some special exercises for ballet on the level of motor and static balance and the degree of depression among students of the Faculty of Sports Education, Beni Suef University, during the menstrual cycle. Assiut Journal of Physical Education Sciences and Arts.

29. WHO Report (2007) ,www.who.com/ . [Accessed on 3 April, 2007] r)

30. Yasser Muhammad Eid and Samira Muhammad Orabi (2019): Aerobic exercise and its effect on some physiological and physical variables among people with depression. Studies - Educational Sciences: The University of Jordan - Deanship of Scientific Research. 


\section{A training program using pilates and its effect on some physical variables And some kicks for taekwondo junior players}

\section{Dr. Ali Nour Eldin Ali Moustafa}

Self-defense instractuor, Department of Athletic Training and Movement Science Faculty of Physical Education - Assiut University

\section{Introduction \& Research problem:}

Attention to the physical, skillful, and planning requirements is one of the most important things that coaches must consider in preparing the players. This is due to the importance of these factors and the extent of their impact on the athletic performance of the players, as the extent of winning many sporting championships and competitions depends on the extent of the integrated interest with the athletic preparation of players in these various aspects.

Essam El-Din Abdel-Khalek (2003) also indicates that upgrading the level of skillful performance is through training, which is a process of repetition of the performance of skills in different circumstances to reach the player to the stage of competition. Each of the games and the level of mastery depend heavily on their basic skills. Skillful performance is an important factor for players, and this requires continuous and regular practice, while correcting what might hinder the reasons for the way of the right performance.(10:197.198)

Hatem Al- Shaloul et al (2008) believe that taekwondo is one of the martial arts that requires many physical capabilities that must be available in the junior and agree with the nature of performance. There is a great importance of the elements of physical fitness in the effectiveness of performance when meeting with the opponent, because the taekwondo game depends greatly on the physical fitness and its various elements, and for this, good physical fitness training is an integral part of skilled and tactical training in taekwondo, where coaches today use many methods of physical training and have even been interested in finding theories and scientific foundations for sports training to prepare an integrated player to face sports competitions.(8: 1195).

Amer Allah Albasaty(1996) states that mathematical training is characterized by the feature of relying on scientific research to achieve the highest levels of achievement, depending on theories and 
knowledge extracted from the results of the scientific research for many sciences related to the sports field (3:6).

Yahia Alhawy notes that sports training science is one of the applied sciences that depends on science and its innovations, which aims to provide the sports coach with information and knowledge that helps him to achieve the best results with his players through his using for the best available methods, and means by a scientific way (20:39).

Ahmed Saeed Zahran(2004) also states that victory can only be achieved through the special physical preparation, which plays an important role in raising the level of the technical and planning performance of taekwondo players, because the lack of physical taekwondo players required for the game works impede him to perform the required skill and planning side(2:195.194).

Mechail King (2001) indicates that there is a type of aerobic exercise that has been reached and is known as Pilates exercises, which is an organized exercise for a group of exercises with an organization for the breathing process that depends on the various muscle groups together. This type of exercises aims to find a balance in the normal shape of the body, taking into account all factors involved in obtaining a healthy body(32:1).

Pilates's movements are attributed to the German Joseph H. Pilates who invented and developed this type of movement through his experiences in gymnastics, exercises, yoga and martial sports(33:280).

Pilates movements are one of the methods of modern physical preparation for training the muscles of the body as one unit. Pilate's movements are distinguished by the ability to exercise men and women of different ages, in addition to that it can be practiced anywhere with or without tools(28:32).

Kadry Morsy(2014) indicates that the success of the skill performance needs to develop the necessary special physical characteristics that contribute in its performance ideally. As the special physical characteristics do not appear separately when implementing the skillful performance of the game, as this contributes in developing the type and nature of work required in the performance Skillful (13:20)

Pilates movements are considered among the prevalent modern methods in the sports field, which aim to develop the muscle strength and the ability to control performance through the various muscles of the body in general and the muscles of the trunk in particular through compatibility and accuracy between both the nervous and muscular systems. As the Pilates movements mobilize the largest number of 
muscle groups through continuous movement in a streamlined manner and the precise focus in the strength and balance of the various trunk muscles such as the abdominal and back muscles and the pelvic joint muscles.(25:318)(38).

There are several basic principles for Pilates exercises:

1- Focus: Pilates exercises work by recognizing each movement and controlling it through the mind, which must be in a state of permanent total focus on the goal of performance

2-Center: Pilates exercises help build a strong center for the body while reducing the waist circumference, flat abdomen and move easily with movement flowing from the inside to outside, as all movements start from the center as the center muscles support the spine and internal organs and improve performance

3-Breathing: Pilates exercises help control and continue breathing, which is reflected in improved performance and efficiency in the use of body energy, and breathing properly helps get rid of psychological stress, tension, energy enhancement, and increased body activity

4-precision : It is the use of muscles to be developed in a consistent and correct exercise, as Pilates exercises help to move more accurately and reveal the natural dimensions of the body

Control : In Pilates exercises, the practitioner learns to control the abdominal muscles first and then begins to learn more advanced serious movements, while controlling the body during the performance and the movements are performed slowly and controlled

Kinetic flow: It is an internal control through the mind in all the parts used in the exercise where the transition from one movement to another easily and easily without stopping during the performance until completing the movement.

The benefits of Pilates exercises are to improve both strength and elongation and muscle balance. Muscle balance on both sides of the body is the actual basis for a good strength. Pilate's exercises increase the awareness, awareness and sense of the individual of the ideal position of the muscles and joints of the body starting from the neck, spine and pelvis through the legs to the feet. Pilates training also adjusts the body shape from the current position to the ideal situation should to be (21:28).

The problem appears through the researcher's observation of the low level of kicks performance among students in the specialization of taekwondo, especially those that depend on strength and control of body parts during the performance. This is evident during the 
performance of some kicks, such as "Bek Chagi", "Abtulio Chagie" and "Te Chagie", as these kicks require the player to control the performance during all parts of the body, and that the interest in the first place in the lectures on the skill side and learn different skills with Lack of focus on the physical side, especially exercises that are concerned with strengthening the trunk muscles that affect performance control. As the university semester does not allow large training periods and this is clearly consistent with Pilates training as you do not need a large time to influence the physical side of the player.

Both Christine Roman and Ben Roter (2006) have indicated that the Pilates method is an integrated program for training the muscles of the body through the performance of movements whose primary goal is to develop and increase the strength of the deep muscles of the trunk in particular such as the abdominal and back muscles and the pelvic joint muscles and responsible for control and muscular stabilization to improve the position, balance and compatibility of the body. Pilates movements depend on the neuromuscular compatibility between the hands, eyes and legs, as Pilates exercises using the gravity and body weight as resistance to increase the intensity of training during performance (22:149) (27:18).

Through the importance of Pilates exercises in developing strength and lengthening the abdominal, back and pelvic muscles, and it is commensurate with the short period of time during the semester, the researcher used these exercises in an attempt to develop some elements of physical fitness and improve the level of performance of some kicks, which is commensurate with the goal of Pilates exercises.

\section{Research importance}

It contributes in developing some of the physical variables of players and their impact on some kicks in taekwondo in the least time possible.

\section{Research objective}

The research aims to design a training program using "pilates" training for taekwondo players and know its effect on:

1- Some physical variables related to taekwondo (muscle strength muscular endurance - flexibility).

2- Some kicks for taekwondo, including (DOLLYO chagi - Te Olgul Dollyo chagi - DWI Chagi ).

\section{Research hypotheses:}

In light of the research objectives, the researcher sets the following hypotheses

1-There are statistically significant differences between the averages of 
the pre and post measurements in some physical variables under consideration in favor of the post measurement.

2-There are statistically significant differences between the averages of the pre and post measurements in some kicks under consideration in favor of the post measurements.

\section{Research Terms:}

\section{Pilates}

It is a group of physical movements designed to develop flexibility, strength and endurance of the body and achieve balance accompanied by patterns of breathing. Its effect is not limited to the physical side only, but extends to the rehabilitation of the body in all respects (23:17).

\section{Some previous studies}

The researcher examined the studies and researches that were conducted on Pilates training, such as the study of Ghaidaa Abdel Shakour Mohamed(2009)(12), Nahid Khairy Abdullah(2010)(18), Atef Rashad Khalil(2008)(9), Muhammad Abulhamd Abdel Wahab(2019)(14), Maja Bučar Pajek(2009)(31), Ahmed Hussein Muhammad Ali(2016)(1), Amal Al-Sayed Salim Ibrahim(2016)(4), Ehab Ahmad Al-Metwally Mansour(2013)(5), Atef Rashad Khalil, Moushera Ibrahim Al-Ajmi (2008)(9), Manal Talaat Muhammed.

These studies have proven the effectiveness of Pilates training in developing the physical side of the player, which positively affects the skillful level.

\section{Research plan and procedures}

\section{Research Methodology}

The researcher used the experimental method using one experimental group by conducting pre and post measurement as an experimental design due to its relevance to the nature of this research.

\section{Research community}

The research community included students of the Faculty of Physical Education for emerging Taekwondo students, whose number was (40) students, Table (1).

\section{The research sample}

The research sample was chosen intentionally among the students of the Faculty of Physical Education for Taekwondo for the academic year2018/2019 and whose number was (15) students who are regular in attendance. 


\section{Table(1)}

Characterization of the research population and sample

\begin{tabular}{|c|c|c|c|c|}
\hline & $\begin{array}{c}\text { Research community\& } \\
\text { sample }\end{array}$ & number & Why you choose it & percentage \\
\hline 1 & Experimental group & 15 & The basic research sample & $37.5 \%$ \\
\hline 2 & $\begin{array}{c}\text { Scientific coefficients } \\
\text { for tests }\end{array}$ & 20 & $\begin{array}{c}\text { To calculate the scientific coefficients for } \\
\text { tests (honesty and stability) }\end{array}$ & $50 \%$ \\
\hline 3 & Exploratory sample & 5 & $\begin{array}{c}\text { To ensure suitability of tools and equipment, } \\
\text { to pilot training units and to codify the } \\
\text { proposed program }\end{array}$ & $12.5 \%$ \\
\hline
\end{tabular}

Table (1) show the research community and its number.

Homogeneity of the research sample

The researcher has made homogeneity to the research sample to ensure that the research sample is distributed fairly in all variables under consideration as shown in table (2).

Table (2)

Arithmetic mean, standard deviation, and torsion coefficient of variables ( age, height, weight, and training age) of the sample members in question $\mathrm{N}=15$

\begin{tabular}{|c|c|c|c|c|}
\hline The variables & $\begin{array}{c}\text { Measurement } \\
\text { unit }\end{array}$ & $\begin{array}{c}\text { Arithmetic } \\
\text { mean }\end{array}$ & $\begin{array}{c}\text { standard } \\
\text { deviation }\end{array}$ & $\begin{array}{c}\text { torsion } \\
\text { coefficient }\end{array}$ \\
\hline Age & Year & 22.4 & 0.79 & -0.04 \\
\hline Height & $\mathrm{Cm}$ & 171.1 & 6.49 & 2.06 \\
\hline weight & $\mathrm{kg}$ & 64.1 & 8.15 & 0.18 \\
\hline
\end{tabular}

It is clear from table (2) that all the coefficients of the sample were confined between(-0.004 and 2.06) that is, they were confined between $(3 \pm)$, which means that there is homogeneity among the members of the research sample in variables (age, height and weight).

\section{Data collection tools}

The researcher relied on collecting research data and measurements on many tools, devices and forms, summarized as follows:

\section{A- Tools and Devices:}

Stopwatch to calculate time. - A medical scale for measuring weight-Rustemeter for measuring length. -Small and large hand tools (sponge bags).

Sandbag tools (sponge bags). $\quad$-2Legal chest protectors.-

-Divided boxes

-elastic rubber . . Medical balls. 


\section{B- Data collection forms}

-The anthropometric measurements and the special physical tests under consideration registration form.

Skillful tests under consideration registration form.-

-Data collection form (name - weight - length - training age) for the individuals of the research sample under consideration.

Results of a questionnaire to determine the most important kicks in taekwondo

The researcher designed a questionnaire containing the kicks in the sport of taekwondo extracted by analyzing the references and presenting them to experts in order to choose and determine the most important kicks that suit the stage of the research sample.

Table(3)

The percentage of expert opinions on the most appropriate kicks for a sample

\begin{tabular}{|l|c|c|c|}
\hline & The kick & $\begin{array}{c}\text { Exports } \\
\text { opinions }\end{array}$ & percentage \\
\hline $\mathbf{1}$ & DOLLYO Chagi & 10 & $100 \%$ \\
\hline $\mathbf{2}$ & Te Olgul Dollyo chagi & 10 & $100 \%$ \\
\hline $\mathbf{3}$ & Chagi DWI & 9 & $90 \%$ \\
\hline $\mathbf{4}$ & Naeryeo chagi & 7 & $60 \%$ \\
\hline $\mathbf{5}$ & Ap chagi & 5 & $50 \%$ \\
\hline $\mathbf{6}$ & HOORYO chagi & 4 & $40 \%$ \\
\hline $\mathbf{7}$ & 360 & 3 & $30 \%$ \\
\hline
\end{tabular}

Table (3) clear the expert opinions in determining the most important kicks for taekwondo players. The researcher was satisfied with choosing the kicks that achieved a percentage (90\%)and more, as follows: DOLLYO chagi, Te Olgul Dollyo Chagi DWI

Results of a questionnaire to determine the most important physical variables in taekwondo:

The researcher designed a questionnaire containing physical variables extracted by analyzing the references and presenting them to experts to choose and define the most important physical variables that fit with the research sample. 
Table(4)

The percentage of expert opinions on the most important physical variables associated with kicks

\begin{tabular}{|c|c|c|}
\hline $\begin{array}{l}\text { Variables } \\
\text { Physical variables }\end{array}$ & Exports opinions & percentage \\
\hline Flexibility & 10 & $100 \%$ \\
\hline Muscular strength & 9 & $90 \%$ \\
\hline Muscular endurance & 8 & $80 \%$ \\
\hline Agility & 6 & $60 \%$ \\
\hline Balance & 6 & $60 \%$ \\
\hline Compatibility & 5 & $50 \%$ \\
\hline Kinetic speed & 5 & $50 \%$ \\
\hline Responsiveness & 4 & $40 \%$ \\
\hline
\end{tabular}

Table (4) clear the expert opinions in determining the most important physical variables associated with kicks. The researcher was satisfied with choosing the physical variables that achieved (70\%) and more, as follows:

Flexibility (100\%)

Muscular strength (90\%)

Muscular endurance (80\%)

\section{Scientific coefficients for tests used in research}

\section{Honesty}

The researcher used the honesty of differentiation, by conducting tests on a distinct sample which is the exploratory research sample from the field of taekwondo. The most important thing that distinguishes them is the study of taekwondo course over the course of three academic years and the distinctive group who are students of the second year. The researcher has calculated the significance of the differences between the two distinct and non-distinct groups to ensure the validity of the tests. Table (5) shows this: 
Table(5)

Significance of the differences between the averages for the individuals of the distinct and non-distinct group for Physical variables tests and kicks $\mathrm{N}=\mathbf{2 0}$

Table $(T)$ value at a level $0.05=1.86$

\begin{tabular}{|c|c|c|c|c|c|c|c|c|}
\hline \multicolumn{2}{|c|}{ variables } & \multirow{2}{*}{$\begin{array}{c}\begin{array}{c}\text { Measurement } \\
\text { unit }\end{array} \\
\text { Time }\end{array}$} & \multicolumn{2}{|c|}{$\begin{array}{l}\text { Distinct } \\
\text { group }\end{array}$} & \multicolumn{2}{|c|}{$\begin{array}{c}\text { Non-distinct } \\
\text { group }\end{array}$} & \multirow{2}{*}{$\begin{array}{c}\begin{array}{c}\text { Calculated(T) } \\
\text { value }\end{array} \\
6.30\end{array}$} & \multirow{2}{*}{$\begin{array}{c}\begin{array}{c}\text { Significance } \\
\text { level }\end{array} \\
\text { signify }\end{array}$} \\
\hline \multirow{6}{*}{ 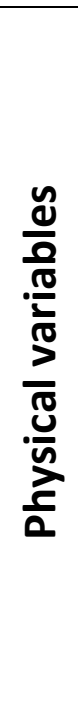 } & $\begin{array}{l}\text { Sit from lying } \\
\text { down(30 Sec) }\end{array}$ & & 29.60 & 6.97 & 16.00 & 2.73 & & \\
\hline & $\begin{array}{l}\text { Wide jump of } \\
\text { stability }\end{array}$ & meter & 2.11 & 7.41 & 1.81 & 29.02 & 2.23 & signify \\
\hline & $\begin{array}{l}\text { Trunk lift test } \\
\text { from flatness }\end{array}$ & Number & 45.60 & 6.06 & 24.40 & 4.39 & 6.32 & signify \\
\hline & $\begin{array}{l}\text { Bend the arms } \\
\text { from oblique } \\
\text { flatness }\end{array}$ & Number & 33.20 & 4.43 & 20.00 & 4.61 & 3.34 & signify \\
\hline & $\begin{array}{l}\text { Bend the torso } \\
\text { forward to stand }\end{array}$ & $\mathrm{Cm}$ & 18.80 & 3.03 & 7.80 & 5.26 & 4.04 & signify \\
\hline & $\begin{array}{l}\text { Bend the back of } \\
\text { the trunk } \\
\text { Lift the arms out } \\
\text { of flatness }\end{array}$ & $\mathrm{Cm}$ & 25.60 & 3.64 & 13.40 & 4.21 & 4.89 & signify \\
\hline$\frac{n}{\underline{u}}$ & $\begin{array}{l}\text { DWI Chagi, then } \\
\text { DOLLYO Chagi, } \\
\text { then Te Olgul } \\
\text { Dollyo chagi. }\end{array}$ & degree & 27.40 & 6.38 & 11.00 & 3.80 & 4.93 & signify \\
\hline
\end{tabular}

Table (5) shows that there are statistically significant differences between the distinct and non-distinct groups in favor of the distinct group, which indicates the validity of the test in measuring what was set for it.

\section{Stability}

The researcher used the Re-Test method after (10) days from applying the first test on the non-distinct group to calculate the stability of the test by calculating the correlation coefficient between the two applications, on the same exploratory group, and this is shown in table (6). 


\section{Table (6)}

The mean, standard deviation, and correlation coefficient for physical variables tests and kicks $\mathrm{N}=10$

\begin{tabular}{|c|c|c|c|c|c|c|c|c|}
\hline \multicolumn{2}{|c|}{ variables } & \multirow{2}{*}{$\begin{array}{l}\text { Measurement } \\
\text { unit }\end{array}$} & \multicolumn{2}{|c|}{$\begin{array}{l}\text { First } \\
\text { application }\end{array}$} & \multicolumn{2}{|c|}{$\begin{array}{l}\text { Second } \\
\text { application }\end{array}$} & \multirow{2}{*}{$\begin{array}{l}\text { (R) value } \\
0.985\end{array}$} & \multirow{2}{*}{$\begin{array}{l}\begin{array}{l}\text { Significance } \\
\text { level }\end{array} \\
\text { Non-signify }\end{array}$} \\
\hline \multirow{6}{*}{ 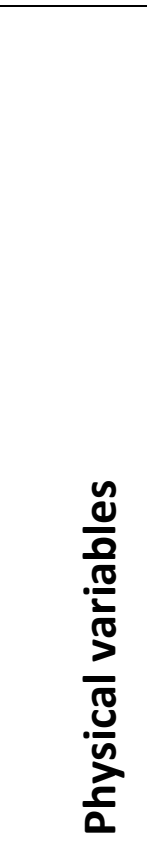 } & $\begin{array}{l}\text { Sit from lying } \\
\text { down }(30 \mathrm{Sec})\end{array}$ & & 29.60 & 3.97 & 29.40 & 4.39 & & \\
\hline & $\begin{array}{l}\text { Wide jump of } \\
\text { stability }\end{array}$ & meter & 2.11 & 7.41 & 2.08 & 6.76 & 0.927 & Non-signify \\
\hline & $\begin{array}{l}\text { Trunk lift test } \\
\text { from flatness }\end{array}$ & Number & 45.60 & 6.06 & 45.60 & 5.54 & 0.974 & Non-signify \\
\hline & $\begin{array}{l}\text { Bend the } \\
\text { arms from } \\
\text { oblique } \\
\text { flatness }\end{array}$ & Number & 33.20 & 4.43 & 33.40 & 4.61 & 0.959 & Non-signify \\
\hline & $\begin{array}{l}\text { Bend the } \\
\text { torso forward } \\
\text { to stand }\end{array}$ & $\mathrm{Cm}$ & 18.80 & 3.03 & 19.00 & 3.08 & 0.882 & Non-signify \\
\hline & $\begin{array}{l}\text { Bend the back } \\
\text { of the trunk } \\
\text { Lift the arms } \\
\text { out of } \\
\text { flatness }\end{array}$ & $\mathrm{Cm}$ & 25.60 & 3.64 & 25.00 & 3.24 & 0.994 & Non-signify \\
\hline$\frac{\underline{v}}{\underline{u}}$ & $\begin{array}{l}\text { DWI Chagi, } \\
\text { then DOLLYO } \\
\text { Chagi, then Te } \\
\text { Olgul Dollyo } \\
\text { chagi. }\end{array}$ & degree & 27.40 & 6.38 & 27.60 & 6.22 & 0.941 & Non-signify \\
\hline
\end{tabular}

Table $(\mathrm{T})$ value at a level $0.05=0.549$

Table (6) shows that the correlation coefficient between the first and second applications are statistically significance at significance level of 0.05 , which indicates the stability of the used test.

\section{Time distribution of the program}

Determine the total time for training during the program followed according to the following:

Number of weeks $=8$ weeks

The number of training units per week $=2$ training units

Training unit time $=120$ minutes

The total time of the training program $=8$ weeks $\times 2$ training units $\times 120$ minutes. Training unit time $=1920$ minutes 120

Pilates training time from the total time of the training program

Through the form that was presented to the experts, it was reached:

Pilates workout time $=15: 30$ minutes during the program.- 
The total time of Pilates training during the training program $=480$ minutes.-

\section{Steps to implement the training program}

The researcher implemented the training program as follows

The researcher conducted the survey study on a survey sample from the original community whose number was (5) students, which includes students from outside the main sample, on Sunday $24 / 2 / 2019$. The study targeted the following:

Selection and training of assistants to make measurements.Learn about available tools and devices and their suitability.-Accuracy of organization and workflow in measurement.

-Determine the timing and procedures of the tests and how they are serialized.

-Identify the difficulties that the researcher may face when applying tests and measurements and how to overcome them.

The study resulted in the following

-Validity of measuring instruments and devices for use:

Training assistants in applying tests-

-Knowing the time of the tests and their order

-Overcome some difficulties that may constitute a disability during applying.

-Coordinate the appointments to implement the program with the players.

\section{Pre measurements of the group in question:}

Pre measurements were performed on the research group for some of the kicks variables, as well as the physical variables under investigation, on Mondays and Tuesday 25,26/2/2019.

\section{Homogeneity of the research sample}

The researcher has made homogeneity to the research sample in order to ensure that the research sample is distributed fairly in all variables under investigation. 


\section{Table(7)}

Arithmetic mean, median, standard deviation, and torsion coefficient value in Kicks and physical variables of the sample in question $\mathrm{N}=15$

\begin{tabular}{|c|c|c|c|c|c|c|c|}
\hline \multicolumn{2}{|c|}{ variables } & element & $\begin{array}{c}\text { Measurement } \\
\text { unit }\end{array}$ & $\begin{array}{c}\text { Arithmetic } \\
\text { mean }\end{array}$ & median & $\begin{array}{l}\text { standard } \\
\text { deviation }\end{array}$ & $\begin{array}{c}\text { torsion } \\
\text { coefficient }\end{array}$ \\
\hline \multirow{7}{*}{ 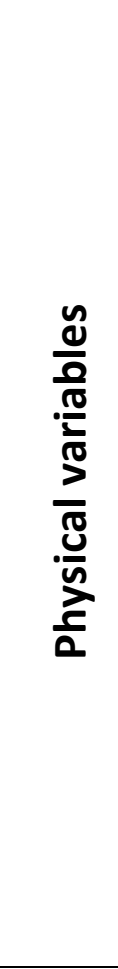 } & $\begin{array}{l}\text { Sit from lying } \\
\text { down(30 Sec) }\end{array}$ & $\begin{array}{c}\text { Muscle } \\
\text { strength }\end{array}$ & Time & 26.6 & 26 & 2.56 & 0.62 \\
\hline & $\begin{array}{c}\text { Wide jump of } \\
\text { stability }\end{array}$ & $\begin{array}{c}\text { Muscle } \\
\text { strength }\end{array}$ & meter & 213.1 & 212.5 & 6.61 & 0.07 \\
\hline & $\begin{array}{l}\text { Trunk lift test } \\
\text { from flatness }\end{array}$ & $\begin{array}{l}\text { Bearing } \\
\text { strength }\end{array}$ & Number & 32.8 & 30 & 9.45 & 0.31 \\
\hline & $\begin{array}{l}\text { Bend the } \\
\text { arms from } \\
\text { oblique } \\
\text { flatness }\end{array}$ & $\begin{array}{l}\text { Bearing } \\
\text { strength }\end{array}$ & Number & 39.8 & 40 & 15.30 & -0.24 \\
\hline & $\begin{array}{c}\text { Bend the } \\
\text { torso forward } \\
\text { to stand }\end{array}$ & flexibility & $\mathrm{Cm}$ & 15.3 & 16.5 & 9.05 & -0.71 \\
\hline & $\begin{array}{l}\text { Bend the } \\
\text { back of the } \\
\text { trunk }\end{array}$ & flexibility & $\mathrm{Cm}$ & 21.0 & 20 & 5.29 & 0.51 \\
\hline & $\begin{array}{c}\text { Lift the arms } \\
\text { out of } \\
\text { flatness }\end{array}$ & flexibility & degree & 18.4 & 17.50 & 6.74 & 0.59 \\
\hline kicks & $\begin{array}{c}\text { DWI Chagi, } \\
\text { then DOLLYO } \\
\text { Chagi, then } \\
\text { Te Olgul } \\
\text { Dollyo chagi. }\end{array}$ & & Time & 5.9 & 6 & 0.52 & -0.39 \\
\hline
\end{tabular}

Table (7) clear that all torsional coefficients have been confined between $( \pm 3)$, which means that there is homogeneity among the members of the research sample in the kicks and physical variables.

\section{Program implementation}

The proposed training program was applied for(8) weeks on the research sample and implementing the training units in the hall of the Faculty of Physical Education, Assiut University in the period from3/3/2019 until 22/4/2019

\section{Post measurements of the group in question}

The researcher made the post measurements of the variables under investigation on Sunday28/4/2019 for all the tests under consideration (kicks and physical variables) in the same manner of applying the premeasurement and under the same conditions, then the data was collected, classified, tabulated and then statistically processed 


\section{Statistical treatments used in the research}

The researcher prepared, tabulated and analyzed the data statistically, with the results being extracted and interpreted for each of the following statistical methods: arithmetic mean, median, standard deviation, torsional coefficient, correlation coefficient and "T" test.

View and discuss the results

\section{Show the results of the first hypothesis}

Which states that there are statistically significant differences between the pre and post measurements in some physical variables of the research sample in favor of the post measurements.

\section{Table (8)}

Significances of the differences between the averages of the pre and post measurements for the research sample in the physical variables

$$
\mathrm{N}=15
$$

\begin{tabular}{|c|c|c|c|c|c|c|c|c|}
\hline \multicolumn{2}{|c|}{ variables } & \multirow{2}{*}{$\begin{array}{c}\text { Measurement } \\
\text { unit }\end{array}$} & \multicolumn{2}{|c|}{$\begin{array}{c}\text { Pre } \\
\text { measurements }\end{array}$} & \multicolumn{2}{|c|}{$\begin{array}{c}\text { Post } \\
\text { measurements } \\
\end{array}$} & $\begin{array}{l}\text { Calculated } \\
(\mathrm{T}) \text { value }\end{array}$ & $\begin{array}{l}\text { Improvement } \\
\text { percentage\% }\end{array}$ \\
\hline \multirow{7}{*}{ 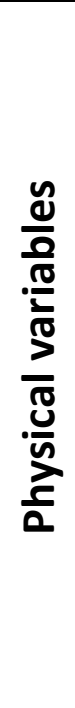 } & $\begin{array}{l}\text { Sit from lying } \\
\text { down(30 Sec) }\end{array}$ & & 26.62 & 2.55 & 36.50 & 8.97 & -3.46 & 37.11 \\
\hline & $\begin{array}{c}\text { Wide jump of } \\
\text { stability }\end{array}$ & meter & 2.13 & 9.61 & 2.30 & 10.50 & -4.78 & 7.98 \\
\hline & $\begin{array}{c}\text { Trunk lift test from } \\
\text { flatness }\end{array}$ & Number & 42.25 & 6.25 & 66.87 & 14.90 & -4.95 & 58.27 \\
\hline & $\begin{array}{c}\text { Bend the arms from } \\
\text { oblique flatness }\end{array}$ & Number & 39.75 & 16.31 & 50.87 & 16.03 & -4.32 & 27.97 \\
\hline & $\begin{array}{l}\text { Bend the torso } \\
\text { forward to stand }\end{array}$ & $\mathrm{Cm}$ & 16.00 & 7.87 & 19.75 & 7.70 & -11.96 & 23.43 \\
\hline & $\begin{array}{c}\text { Bend the back of the } \\
\text { trunk }\end{array}$ & $\mathrm{Cm}$ & 21.00 & 5.29 & 32.62 & 4.27 & -6.75 & 55.33 \\
\hline & $\begin{array}{l}\text { Lift the arms out of } \\
\text { flatness }\end{array}$ & & 18.4 & 6.74 & 31.62 & 10.30 & -4.43 & 72.12 \\
\hline
\end{tabular}

\section{Table $(\mathrm{T})$ value at a level $\mathbf{0 . 0 5}=\mathbf{1 . 8 6}$}

It is clear from table (8) that there are statistically significant differences between the mean scores of the pre and post measurements in some physical variables of the research sample in favor of the post measurement, where the calculated value of $(T)$ was greater than its tabled value at significance level of 0.05 in all the variables. As the calculated value of ( T) ranged between(3.46: 11.96). Also the improvement rate ranged between (7.98: 72.12\%). 


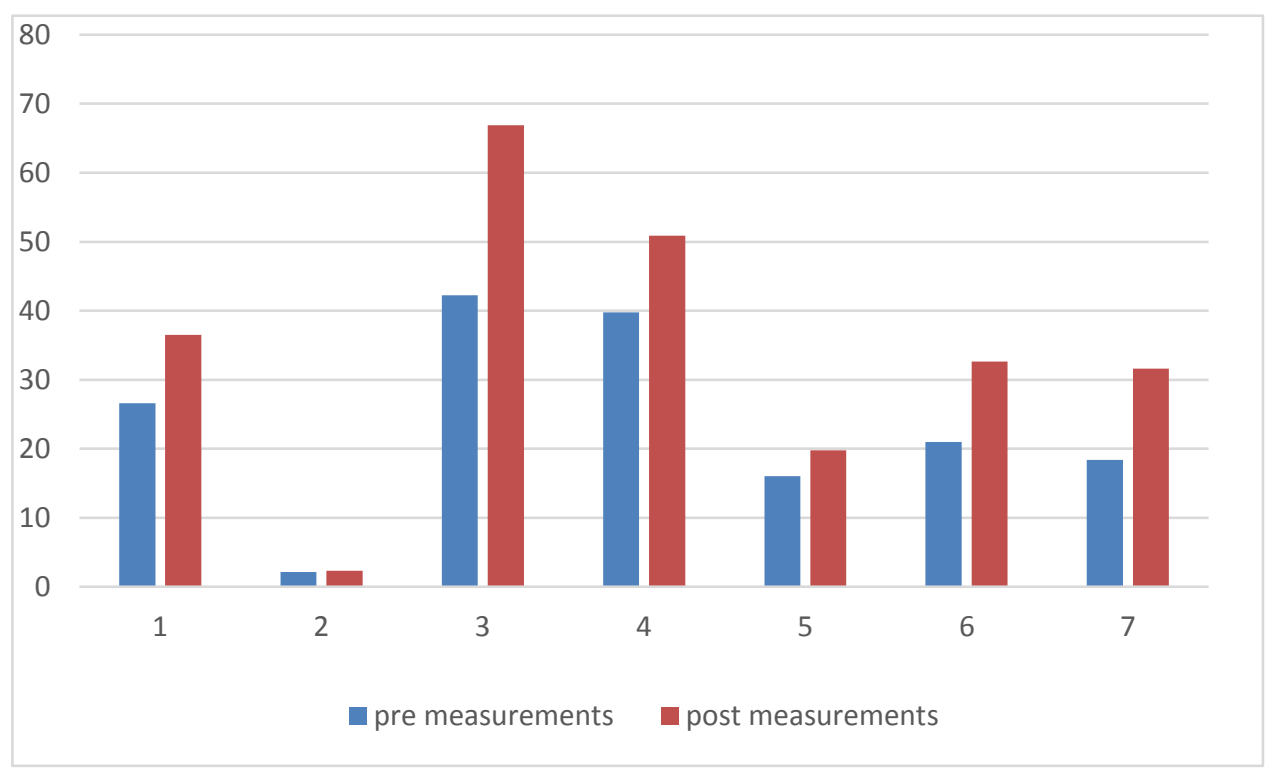

Show the results of the second hypothesis

Which states that there are statistically significant differences between the averages of the pre and post measurements in some kicks under consideration in favor of the averages of the post measurements. Table (9)

Significances of the differences between the averages of the pre and post measurements for the research sample in kicks $\mathrm{N}=15$

\begin{tabular}{|c|c|c|c|c|c|c|c|c|}
\hline \multicolumn{2}{|c|}{ variables } & $\begin{array}{l}\text { Measurement } \\
\text { unit }\end{array}$ & \multicolumn{2}{|c|}{$\begin{array}{c}\text { Pre } \\
\text { measurements }\end{array}$} & \multicolumn{2}{|c|}{$\begin{array}{c}\text { Post } \\
\text { measurements }\end{array}$} & $\begin{array}{c}\text { Calculated(T) } \\
\text { value }\end{array}$ & $\begin{array}{l}\text { Improvement } \\
\text { percentage\% }\end{array}$ \\
\hline$\frac{\tilde{v}}{\underline{x}}$ & $\begin{array}{l}\text { DWI Chagi, } \\
\text { then } \\
\text { DOLLYO } \\
\text { Chagi, then } \\
\text { Te Olgul } \\
\text { Dollyo } \\
\text { chagi. }\end{array}$ & degree & 5.87 & 0.517 & 8.50 & 0.755 & -16.75 & 44.80 \\
\hline
\end{tabular}

Table $(T)$ value at a level $0.05=1.86$

It is clear from table (9) that there are statistically significant differences between the mean scores of the pre and post measurements in the level of kicks of the experimental group in favor of the post measurements. As the calculated value of $(T)$ was greater than the tabled value of $(T)$ at the significance level of 0.05 . As the calculated value of $(T)$ was (16.75) and the rate of improvement was (44.80). 


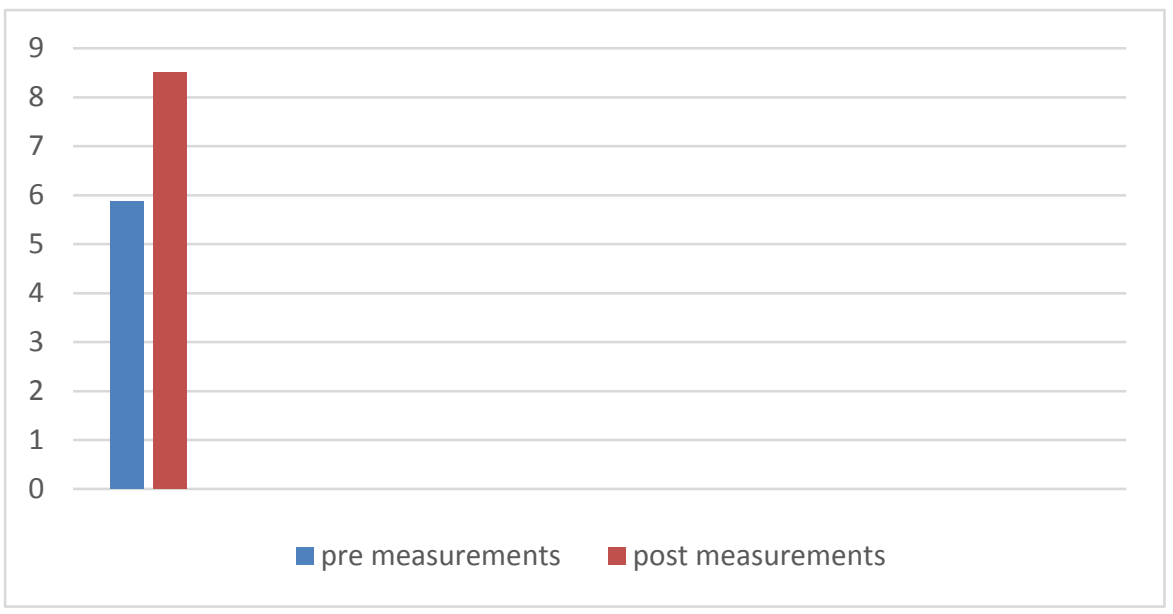

\section{Discuss the results}

It is clear from table (8) that there are statistically significant differences between the mean scores of the pre and post measurements in some physical variables of the research sample in favor of the post measurement, where the calculated value of $(T)$ was greater than its tabled value at significance level of 0.05 in all the variables. As the calculated value of $(T)$ ranged between (3.46: 11.96). Also the improvement rate ranged between (7.98: 72.12\%).

The researcher attributes the reason for these differences in the physical variables to the effect of codified exercises according to the modern scientific methods used by the researcher during the proposed training program, which had an effective effect in improving the physical variables.

"Ehab Ahmed Al-Metwally's study" (2013)(5) also confirms that the program, which included Pilates exercises, led to a noticeable improvement in some elements of fitness (muscle strength - flexibility). And "Caron Carter " (2001)notes that pilates training is characterized by its ability to develop muscle strength without the appearance of muscle mass of the various muscles of the body and without the clear increase of the physiological section of the muscles; thus it gives a better shape and strength to the body.(28.21)

This is confirmed by "Scott " (2007) (34) that Pilates training improves the rate of muscle stretch when performing the required image and by following its training principles.

It also indicates the study of both "Manal Talaat" (2014)(17) and "Ahmed Hussein Mohamed" (2016)(1) that pilates exercises increase the muscular strength, especially the muscles of the onyx, because when controlling the pilates exercises, they mobilize the largest amount of muscle fibers in the area that performs the exercise, which increases the 
muscle strength of this region.

The researcher believes that Pilates exercises work to improve the muscle strength of the onyx muscles better than regular exercises, especially in the onyx area. This is evident through the results of the tests where the improvement rate was noticeable in some tests such as lifting the onyx from flatness $(58.27 \%)$, as well as a marked improvement in the degree of flexibility of the joints where some exercises were applied on it, including the shoulder joint, as the improvement rate reached (72.12).

Thus, the first hypothesis is achieved. "There are statistically significant differences between the averages of the pre and post measurements in some physical variables (muscle strength - muscular endurance flexibility) for the individuals of the sample in question, in favor of the averages of the post measurements.

It is clear from table (9) that there are statistically significant differences between the mean scores of the pre and post measurements in the level of kicks of the experimental group in favor of the post measurements. As the calculated value of $(T)$ was greater than the tabled value of $(T)$ at the significance level of 0.05 . As the calculated value of (T) was (16.75) and the rate of improvement was (44.80).

The researcher attributes the improvement in the level of kicks performance in question to the training program using Pilates exercises, where these results are consistent with the study "Nahid Khairi" (2010)(18), as the training program is based on scientific foundations that suit the level and capabilities of female students and works to improve the level of their performance.

Ghaida Abdel Shakour's study (2009)(12) also confirms that the training program using Pilates exercises has a positive effect in improving the level of motor skills, as a result of strengthening the large muscles, including the muscles of the legs, abdomen, back, and arms, which are the most important muscles working in the motor performance of the skills.

Aml Alsayed Seleem (2016)(4) has reached that the proposed Pilates training program has a positive role in improving the skill level.

Therefore, the researcher believes that the Pilates training has had an effective impact on developing the level of kicks under consideration as it does not need long periods of training and this is what fits with the time allocated to students during the semester.

Thus, the second hypothesis is achieved. "There are statistically significant differences between the averages of the pre and post 
measurements in some kicks for the individuals of the sample in question, in favor of the averages of the post measurements.

\section{Conclusions and recommendations}

\section{Conclusions}

In light of the research objectives, hypotheses and statistical treatments used by the researcher and based on what the research results showed, the researcher reached the following conclusions

1-The training program using Pilates exercises led to an improvement in the level of muscle strength, muscular endurance and flexibility, and this was demonstrated by the difference between the pre and post measurements

2-The training program using Pilates exercises led to an improvement in the level of kicks performance, as demonstrated by the difference between the pre and post measurements.

\section{Recommendations}

Within the limits of the research community and the selected sample, in light of the research objectives and hypotheses, and through the results, the researcher recommends the following:

1-Conducting similar studies to use Pilates exercises on different age stages and on other kicks.

2-The necessity of using Pilates training for juniors in taekwondo to develop fitness elements, especially muscle strength and flexibility

3- Conducting similar studies to compare pilates training with other training programs.

\section{List of references}

\section{First: Arabic References}

1-Ahmed Hussein Mohamed Ali: The effect of blending between pilates and plyometric training on the muscular ability and accuracy of shooting in the handball players, published research, Scientific Journal of Physical Education and Sports 2016..

2-Ahmed Saeed Zahran: Scientific and Technical Grammar for Taekwondo Sports, Dar Al-Kutub, Cairo,2004.

3-Amr Allah Ahmed Al-Bassati: Training and physical preparation in football. Alexandria, Dar Al-Maaref,1996.

4-Amal Al-Sayed Salim Ibrahim: The Effectiveness of Pilates Training Program on Stress, Nerve Stress and Performance Level in Technical and Rhythmic Exercises, Published Research, Scientific Journal of Physical and Sports Education,2016.

5-Ehab Ahmed El-Metwally Mansour: The effectiveness of Pilates exercises on some physical variables and breathing functions for boxers, 
published research, the scientific journal of physical and sports education, 2013.

6-Tamer Mohamed Mohamed El-Sayed: The effect of a training program to develop the basic skills of the parallel system on the level of skill performance of the youth gymnastics, Master Thesis, Faculty of Physical Education for Boys, Helwan University,2015.

7-Tamara Al Homsi: Pilates and Yoga: Mind meeting with the body, Journal of Physical and Mental Health, Faculty of Arts, Tishreen University, Lattakia, Syria, July 2010.

8- Hatem Al-Shloul et al .: The effect of palladium exercises on skillful performance and some physiological variables among taekwondo, published scientific research, An-Najah University Journal for Research (Humanities), volume(7) issue (32), college of physical education, Yarmouk University 2018.

9- Atef Rashad Khalil, Ibrahim Ibrahim Al-Ajmi: Developing strength and stretching the muscles of the trunk using the Pilates method and its effect on the level of performance of some gymnastics skills, published research, Journal of Sports Science Applications, 2008

10- Essam El-Din Abdel-Khaleq Mustafa: Mathematical Training (Theories - Applications), Al-Maaref Establishment, Alexandria, 11 th, 2003.

11-Alaa El-Sayed Mohamed Tantawy: The effect of a specific training program on the performance of the straight-back aerodynamic cycle skill as a kinetic end on the parallel system, Master Thesis, Faculty of Physical Education, Sadat University,2017

12-Ghaidaa Abdel Shakour Mohamed, Walid Ahmed Gabr: The Effectiveness of a Pilates Exercise Program on Some Physical and Psychological Variables and the Level of Skill Performance on the Earth Movements Machine, Published Research, Journal of Sports Science and Arts, 2009

13-Qadry Sayed Morsi: Sports Training Planning, Unpublished Study Lectures, International Handball Federation, Cairo (2008).

14-Mohamed Abulhamd Abdel-Wahab: The effect of using Pilates training on some physical variables and skill level performance on Parallel device, published research, Scientific Journal of Physical and Sports Education,2019.

15-Mohamed Hassan Allawi: The Science of Athletic Training, Al-Maarif Dar, Cairo, 1997.

16-Muhammad Ali Anis Ali: The effect of some qualitative training on the level of performance of the parallel system, Master Thesis, Faculty of 
Physical Education, Helwan University,2015.

17-Manal Talaat Mohamed: The Effectiveness of Pilates Exercises in the Swiss Ball on the Kinetic Abilities of Women, published research, the Scientific Journal of Physical and Sports Education,2014.

18-Nahed Khairy Abdullah: The effect of a training program using Pilates exercises on some physical, physiological, self-confidence variables and the level of skill performance of the ground movements device, published research, the thirteenth international scientific conference (Physical Education Challenges of the Third Millennium)2010.

19-Nahed Khairy Fayyad, Nadia Abdel Qader Hamad, Ibrahim Saad Zaghloul: Female Gymnastics, G.M.S House, Benha 2000.

20-Yahia Al-Sayed Al-Hawi: Sports Coach between Traditional Method and Modern Technology in Training, Cairo, Arab Center for Publishing, 2002.

\section{Second: Foreign References:}

1. Anmore, Tia. The Pilates Back Book: Heal Neck, Back, and Shoulder Pain With Easy Pilates Stretches. Gloucester, MA: Fair Winds Press. 2004 ISBN 978-1931412896.

2. Christine Romani-Ruby, and Ben Reuter . Front, long stretch and hundredexercises on the Pilates reformer and mat.Journal of Orthopaedic \& Sports PhysicalTherapy: VOLUME 30 | NUMBER 2,2006. 


\title{
Physical Activity Levels among Male and Female Undergraduate Students at Umm Al-Qura University
}

\author{
Faisal Awad Barwais \\ * Department of Physical Education, Faculty of Education, Umm Al-Qura University, \\ Makkah, Saudi Arabia \\ Corresponding author: Faisal Awad Barwais (B.Sc., M.Sc., Ph.D.)
}

\section{Abstract}

Physically inactive is a significant problem in modern society worldwide. One of the primary reasons for this problem is that technological advances have allowed a reduction in energy expenditure for most individuals in habitual daily tasks. This study aimed to assess the levels of physical activity among male and female students at Umm Al-Qura University (UQU) in the Kingdom of Saudi Arabia (KSA). This research is a cross-sectional study conducted at UQU between September and December 2019 that investigated the levels of physical activity in a sample of 968 male and female students (452 males and 516 females), (mean age \pm SD, $22.1 \pm 1.7$ years). The Arabic short version of the International Physical Activity Questionnaire (IPAQ) was used to assess physical activity levels. The majority of students (54\%) were observed to be at a light-intensity physical activity level $(238.0 \pm 143$ METminutes/week), $38.4 \%$ were achieving the recommended daily levels of moderateintensity physical activity (1470 \pm 701 MET-minutes/week), and 7.6\% were achieving vigorous-intensity physical activity (3903 \pm 1043 MET-minutes/week). The independent samples t-test indicated no significant differences in light-intensity physical activities between males (240.4 \pm 147 MET-minutes/week) and females $(236.6 \pm 141$ MET-minutes/week) $t(519)=.287 ; p<0.167$. The present study concluded that $54 \%$ of the participants were failing to meet the physical activity recommendations of the WHO; this is a key public health concern. National campaigns with collaborations of various government and public sectors in KSA are needed to increase physical activity in different domains.

Keywords: IPAQ; body mass index, subjective assessment, metabolic equivalent of task, college students 


\section{Introduction}

In modern society, physical inactivity poses a significant problem worldwide (Lee et al., 2012). A primary reason for this problem is that technological advances have reduced the energy expenditure required for everyday tasks. There is consensus across several areas of health that physical inactivity is one of the most important contributors to increased rates of numerous diseases (Grøntved \& Hu, 2011). Physical inactivity is defined as a level of activity that does not meet one of three minimum standards: "30 minutes of moderate-intensity physical activity on 5 days or more every week, 20 minutes of vigorous-intensity physical activity on 3 days or more every week, or an equivalent combination achieving more than 600 metabolic equivalents (MET)-minutes/week" (Hallal et al., 2012). A recent study by Guthold et al. (2018) sed countries' measurements of local compliance with World Health Organization (WHO) guidelines for adults to examine the global prevalence of sufficient physical activity. The study, which ran from 2001 to 2016, included about two million participants, representing more than $90 \%$ of the world's population. The study found that more than a quarter of all adults engaged in inadequate levels of physical activity; this means that more than 1.4 billion adults are at increased risk of chronic disease (Guthold et al., 2018). In contrast, an active lifestyle offers considerable protection from chronic disease, and this relationship may be dosedependent. Strategies to prevent chronic disease must focus on lifestyle changes, beginning with encouraging physical activity among young people and extending to all ages.

A substantial body of literature confirms the positive relationship between daily physical activity and overall health benefits, including decreased risk of cardiovascular disease, high blood pressure, type 2 diabetes, and stroke (Dunstan, Howard, Healy, \& Owen, 2012; Gill \& Cooper, 2008). Moreover, otherwise healthy participants who are more physically active generally report higher total wellness. For example, Barwais et al. (2014) compared the total wellness of adults who engage in sufficient and insufficient physical activity and found that $72 \%$ of participants who self-reported high levels of physical activity also reported moderate to high levels of total wellness. Even half of the recommended level of physical activity may have significant health benefits (Warburton \& Bredin, 2016). Wen et al. (2011) found that 
participants who engaged in as little as 15 minutes a day (90 minutes a week) of moderately intense physical activity could increase their life expectancy by three years. Physical activity may also decrease the risk of increased body mass index (BMI) and of being overweight or obese, which can also pose severe health concerns (Sims et al., 2012).

Physical inactivity is one of the leading risk factors of disease in the Kingdom of Saudi Arabia (KSA); $60 \%$ of the Saudi adult population do not meet current WHO physical activity guidelines (WHO, 2017). A systematic review showed a low prevalence of physical activity in the KSA: $6.1 \%$ for males and $1.9 \%$ for females (Mabry, Koohsari, Bull, \& Owen, 2016). Levels of physical activity in the KSA are lower than in other Gulf Cooperation Countries, where levels vary (males $=85 \%$, females $=91 \%$ ) depending on demographics and other statistical factors (Al-Hazzaa, 2018). A study of physical inactivity among students at King Khalid University in the KSA found that approximately 58\% were inactive (Awadalla et al., 2014). Furthermore, physical activity declines significantly as young people transition from high school to university (Bray \& Born, 2004); this is attributed to university requirements, which may include sitting for long periods.

Therefore, enhancing physical activity and encouraging healthy lifestyles is a prime intervention strategy in the KSA and one of the key performance indicators of Saudi Arabia's Vision 2030. Since June 2017, numerous projects and initiatives have been launched throughout the KSA via the Quality of Life Program. Increasing levels of physical activity is a primary goal of these initiatives. Therefore, the objective of this study was to assess the levels of physical activity among male and female undergraduate students at Umm Al-Qura University (UQU) in the KSA.

\section{Methods}

This research is a cross-sectional study conducted at UQU in the KSA between September and December 2019 that investigated the levels of physical activity (light-, moderate-, and vigorous-intensity physical activity) in a sample of 968 male and female students (452 males and 516 females) who were 18-28 years old (mean age \pm $\mathrm{SD}, 22.1 \pm 1.7$ years) and had a BMI range of $15.5-46 \mathrm{~kg} / \mathrm{m}^{2}$ (mean $\mathrm{BMI} \pm \mathrm{SD}, 26.3$ $\left.\pm 5.1 \mathrm{~kg} / \mathrm{m}^{2}\right)$. 
An online survey was randomly distributed through email invitations and WhatsApp groups. Participants took approximately 15 to 25 minutes to complete three sections (covering general characteristics, social status and educational level, and physical activity levels). Participation was completely voluntary, and the study was approved by the Officer of Graduate Studies and Scientific Research of the College of Education at UQU.

\section{Measures}

The Arabic short version of the International Physical Activity Questionnaire (IPAQ) was used to assess physical activity levels (light-, moderate-, and vigorous-intensity physical activity) following the IPAQ protocol, which is available at www.ipaq.ki.se. The IPAQ contains questions about the frequency (days per week), duration (hours and minutes), and level of intensity (light, moderate, and vigorous) of physical activity during the last seven days. This study used the metabolic equivalent of task (MET) method, in which different activities and levels of intensity are assigned different MET estimates. Weekly total physical activity (MET- minutes/week) of the students was calculated. According to the IPAQ protocol, participants were classified into three different categories: (1) light-intensity physical activity $(<600$ METminutes/week), (2) moderate-intensity physical activity $(\geq 600$ to $<3000$ METminutes/week), and (3) high-intensity physical activity ( $\geq 3000$ MET-minutes/week). The IPAQ showed acceptable validity and reliability in previous research and has become widely used to assess 18 to 65 - years old adults' physical activity levels (AlHazzaa, 2007; Craig et al., 2003).

\section{Statistical Analyses}

Data were entered into Google Forms before being transferred into Microsoft Excel sheets by an independent research assistant. To be included in the analyses, undergraduate students and students who returned a complete IPAQ or whose questionnaires had no missing values. All statistical analyses were carried out using SPSS statistical software version 26.0 for Windows (IBM SPSS Inc., Chicago, IL). Descriptive statistics (mean $\pm \mathrm{SD}$ ) were initially calculated for all variables. The differences in physical activity levels between male and female students were tested using the independent samples t-test. Effect sizes for mean differences were expressed 
as Cohen's d (difference in means divided by the standard deviation of the difference) and interpreted as small (i.e., negligible practical importance), moderate, (i.e., moderate practical importance), or large (i.e., crucial practical importance), based on values of $0.2,0.5$, and 0.8 , respectively (Cohen, 1988).

\section{Results}

The general characteristics, social status, and educational levels (mean \pm SD and percentages) of the sample are shown in Table 1. A total of 968 students (452 males and 516 females) participated, and their age range was $18-28$ years (mean age \pm SD, $22.1 \pm 1.7$ years). The majority (60.6\%) of students were in the $20-23$ year age group. The BMI range was $15.5-46 \mathrm{~kg} / \mathrm{m}^{2}$ (mean $\mathrm{BMI} \pm \mathrm{SD}, 26.3 \pm 5.1 \mathrm{~kg} / \mathrm{m}^{2}$ ). Based on BMI categorization, 368 students $(38.0 \%)$ were found to be of normal weight, whereas $331(34.2 \%)$ were overweight and 228 (23.6\%) were obese. More male students were found to be slightly overweight than female students (193 [37.4\%] versus 138 [30.5\%], respectively), and more female students (206 [45.6\%]) were found to have a lower normal weight than male students (162 [31.4\%]). More male students were found to be slightly obese (146 [28.3\%]) compared with female students $(82[18.1 \%])$. More than $91.3 \%$ of respondents reported that they were single at the time of the study, and $75(7.7 \%)$ were married. Finally, $86 \%$ of respondents reported that they were bachelor's degree students, and $14 \%$ were in a diploma program.

Table 1: Participants' demographic characteristics $(n=968)$

\begin{tabular}{cccc}
\hline Variables & $\begin{array}{c}\text { Males } \\
(\boldsymbol{n}=\mathbf{4 5 2})\end{array}$ & $\begin{array}{c}\text { Female } \\
(\boldsymbol{n}=\mathbf{5 1 6})\end{array}$ & $\begin{array}{c}\text { Overall } \\
(\boldsymbol{n}=\mathbf{9 6 8})\end{array}$ \\
\hline Age (years) mean \pm SD & $21.94 \pm 1.5$ & $22.22 \pm 1.7$ & $22.1 \pm 1.7$ \\
Height $(\mathrm{cm})$ mean \pm SD & $173.81 \pm 10.5$ & $171.90 \pm 8.4$ & $172.82 \pm 9.5$ \\
Weight $(\mathrm{kg})$ mean \pm SD & $75.96 \pm 10.5$ & $80.20 \pm 14.7$ & $78.22 \pm 13.1$ \\
BMI $\left(\mathrm{kg} \cdot \mathrm{m}^{-2}\right)$ mean $\pm \mathrm{SD}$ & $25.41 \pm 4.7$ & $27.24 \pm 5.2$ & $26.38 \pm 5.2$ \\
Age groups $($ years $) \boldsymbol{n}(\boldsymbol{\%})$ & & & \\
$18-20$ & $123(27.2 \%)$ & $118(22.9 \%)$ & $241(24.9 \%)$ \\
$21-23$ & $276(61.1 \%)$ & $311(60.3 \%)$ & $587(60.6 \%)$ \\
$24-26$ & $49(27.2 \%)$ & $118(22.9 \%)$ & $130(13.4 \%)$
\end{tabular}




$\begin{array}{llll}>27 & 4(0.9 \%) & 6(1.2 \%) & 10(1.0 \%)\end{array}$

\section{Body mass index category $n(\%)$}

$\begin{array}{cccc}\text { Underweight } & 26(5.8 \%) & 15(2.9 \%) & 41(4.2 \%) \\ \text { Normal weight } & 206(45.6 \%) & 162(31.4 \%) & 368(38.0 \%) \\ \text { Overweight } & 138(30.5 \%) & 193(37.4 \%) & 331(34.2 \%) \\ \text { Obese } & 82(18.1 \%) & 146(28.3 \%) & 228(23.6 \%)\end{array}$

\section{Social status}

$\begin{array}{cccc}\text { Single } & 411(90.9 \%) & 473(91.7 \%) & 884(91.3 \%) \\ \text { Married } & 41(9.1 \%) & 34(6.6 \%) & 75(7.7 \%) \\ \text { Other } & 0(0 \%) & 9(1.7 \%) & 9(1.7 \%)\end{array}$

\section{Educational level}

$\begin{array}{lccc}\text { Bachelor } & 373(82.5 \%) & 459(89.0 \%) & 832(86.0 \%) \\ \text { Diploma } & 79(17.5 \%) & 57(11.0 \%) & 136(14.0 \%)\end{array}$

Table 2 shows that, as determined by IPAQ physical activity levels, the majority $(54 \%)$ of students were observed to be at a light-intensity physical activity level (238.0 \pm 143 MET-minutes/week), 38.4\% were achieving the recommended daily levels of moderate-intensity physical activity (1470 \pm 701 MET-minutes/week), and 7.6\% were achieving vigorous-intensity physical activity $(3903 \pm 1043$ METminutes/week).

Table 2: Physical activity levels as reflected by MET-minutes/week $(\mathrm{n}=968)$.

\begin{tabular}{cccc}
\hline Physical activity levels & Males & Female & Overall \\
& $\boldsymbol{n}($ Mean \pm SD) & $\boldsymbol{n}($ Mean \pm SD $)$ & $\boldsymbol{n}$ (Mean \pm SD) \\
\hline Light-intensity & $199(240.4 \pm 147)$ & $322(236.6 \pm 141)$ & $521(238.0 \pm 143)$ \\
Moderate-intensity & $191(1632.6 \pm 742)$ & $184(1301 \pm 613)$ & $375(1470 \pm 701)$ \\
Vigorous-intensity & $62(4017 \pm 1068)$ & $10(3193.7 \pm 218)$ & $72(3903 \pm 1043)$ \\
\hline
\end{tabular}

Table 3 shows the differences in the total MET-minutes/week of physical activity between male and female students. The independent samples t-test indicated no significant differences in light-intensity physical activities between males $(240.4 \pm$ 147 MET-minutes/week) and females (236.6 \pm 141MET-minutes/week) $t(519)=$ 
$.287 ; p<0.167$, with a small effect size $(d=0.03)$. However, a significant difference in moderate-intensity physical activity was found between males (1632.6 \pm 742 METminutes/week) and females $(1301 \pm 613$ MET-minutes/week) $t(373)=4.694 ; p<$ 0.001 , with a medium effect size $(d=0.50)$. Likewise, there was a significant difference in vigorous-intensity physical activities between males $(4017 \pm 1068$ METminutes/week) and females (3193.7 \pm 218 MET-minutes/week) $t(70)=2.417 ; p<$ 0.001 , with a large effect size $(d=1.28)$.

Table 3: Differences in total MET-minutes/week of physical activity levels between male and female students.

\begin{tabular}{cccccc}
\hline $\begin{array}{c}\text { Physical activity } \\
\text { levels }\end{array}$ & Males & Female & $\boldsymbol{t}$ & $\boldsymbol{p}$-value & Cohen \\
\hline Light-intensity & $199(240.4 \pm 147)$ & $322(236.6 \pm 141)$ & .287 & $p<0.167$ & $d=0.03$ \\
Moderate-intensity & $191(1632.6 \pm 742)$ & $184(1301 \pm 613)$ & 4.69 & $p<0.001$ & $d=0.50$ \\
Vigorous-intensity & $62(4017 \pm 1068)$ & $10(3193.7 \pm 218)$ & 2.41 & $p<0.001$ & $d=1.28$ \\
\hline
\end{tabular}

\section{Discussion}

The purpose of this study was to assess the physical activity levels of male and female students at UQU in the KSA. The results of this study showed that $54 \%$ of students engaged in light-intensity physical activity. No significant differences in lightintensity physical activity between males and females were found. The findings of the current study are consistent with Awadalla et al.'s (2014) study, which evaluated the pattern of physical activity among 1257 health college students (426 males and 831 females) in King Khalid University in southwestern KSA by using the Arabic short version of the IPAQ; that study found that $58.0 \%$ of the students were physically inactive, with no statistically significant difference between males and females. Likewise, a recent study that assessed the physical activity level of 278 health science students (205 males and 73 females) at King Faisal University in Al-Ahsa in KSA using the Global Physical Activity Questionnaire found that $44.6 \%$ of the students were physically inactive, with higher physical activity among female students $(51.71 \%)$ than male students $(24.66 \%)$ (Al-Hassan, Fabella, Estrella, Al-Ramadan, \& Bujbara, 2020). The results of this study support previous research into the prevalence of physical inactivity among university-age students in KSA. Additionally, since 
2005, physical inactivity has been highly prevalent in the Saudi population-67.6\%, according to a national study conducted by the Saudi Ministry of Health, which involved 3,547 males and females aged 18-64 (Saudi Ministry of Health, 2005).

No significant difference $(p<0.167)$ with a small effect size $(d=0.03)$ was observed between males $(240.4 \pm 147$ MET-minutes/week) and females $(236.6 \pm 141$ METminutes/week) for light-intensity physical activities. These results were not in line with previous research, which has shown that females are relatively more physically inactive than males, with inactivity levels reaching $43 \%-91 \%$ versus $26 \%-85 \%$, respectively (Al-Hazzaa, 2018). The different result with the current study may relate to the measurement instrument, the range of ages, and the region of Saudi Arabia. However, a more recent study that assessed levels of physical activity among 505 participants from UQU in KSA found no significant difference between males (48.5\%) and females (45.1\%) for light-intensity physical activities (Bardisi et al., 2020).

The results indicated that $54 \%$ of participants were failing to meet the WHO's physical activity recommendations; this is a key public health concern. In the general population, physical inactivity has been identified as an independent risk factor for diabetes, cardiovascular disease, weight gain, and obesity. This study indicates a rising physical inactivity trend in KSA that contrasts starkly with the WHO's worldwide goal to see a $10 \%$ decrease in the prevalence of physical inactivity by 2025 and a $15 \%$ decrease by 2030 (WHO, 2018).

Results showed that $38.6 \%$ of students were engaged in moderate-intensity physical activity and there were significant differences between males and females. Moreover, results showed that $7.4 \%$ of students were engaged in vigorous-intensity physical activity and that there were significant differences between males and females, with large effect sizes $(d=1.28)$. Recent systematic review research by Sharara et al. (2018) showed that males were more engaged in moderate- to vigorous-intensity physical activity than females. They found that lower physical activity among females has been attributed to socio-cultural factors that discourage physical activity (Sharara et al., 2018). Similarly, numerous studies have indicated that females were less likely to engage in moderate- and vigorous-intensity physical activities than were males (AlHazzaa, Abahussain, Al-Sobayel, Qahwaji, \& Musaiger, 2011; Awadalla et al., 2014; 
Irwin, 2004). Health education efforts and collaborations of various government and public sectors in KSA are needed to make people physically active in different domains (work, transportation, home, schools, universities, and leisure time).

\section{Limitations of the Study}

Although this is a cross-sectional study on physical activity levels and it used a sample of 968 males and female student respondents, certain limitations are present. The IPAQ, which was used to measure levels of physical activity, has some limitations. Students may have had difficulty recalling and describing their behaviors. All responses were self-reported, which may have resulted in biased conclusions. Multiple precautions were taken to minimize bias, including deleting participants with unrealistic responses and incomplete questionnaires. Future studies should include objective measures (e.g., accelerometer) directly assess physical activity levels. Data collected should include details of the academic path and socio-economic level, which affect differences in physical activity levels.

\section{Conclusions}

The present study concluded that no significant difference was observed between males and females for light-intensity physical activities and that $54 \%$ of the participants were failing to meet the WHO's physical activity recommendations; this is a key public health concern. National campaigns with collaborations of various government and public sectors in KSA are needed to increase physical activity in different domains.

\section{Acknowledgments}

The author would like to thank the research participants for their involvement in the study.

\section{References}

Al-Hassan, Y. T., Fabella, E., Estrella, E., Al-Ramadan, H. A., \& Bujbara, A. H. (2020). Utilizing the Health Belief Model in Determining the Association between Perceptions on Obesity and Exercise Behavior of Saudi University Students. The Open Public Health Journal, 13(1).

Al-Hazzaa. (2007). Health-enhancing physical activity among Saudi adults using the International Physical Activity Questionnaire (IPAQ). Public health nutrition, 10(1), 59-64.

Al-Hazzaa. (2018). Physical inactivity in Saudi Arabia revisited: a systematic review 
of inactivity prevalence and perceived barriers to active living. International journal of health sciences, 12(6), 50.

Al-Hazzaa, Abahussain, N. A., Al-Sobayel, H. I., Qahwaji, D. M., \& Musaiger, A. O. (2011). Physical activity, sedentary behaviors and dietary habits among Saudi adolescents relative to age, gender and region. International Journal of Behavioral Nutrition and Physical Activity, 8(1), 140.

Awadalla, N., Aboelyazed, A., Hassanein, M., Khalil, S., Aftab, R., Gaballa, I., \& Mahfouz, A. (2014). Assessment of physical inactivity and perceived barriers to physical activity among health college students, south-western Saudi Arabia. Eastern Mediterranean Health Journal, 20(10), 596-604.

Bardisi, B. M., Halawani, A. K., Bakhsh, A. Y., Alnajdi, M. A., Fouda, H. M., \& Sulaimani, M. M. (2020). Assessment of physical activity among students of Umm Al-Qura University in Makkah, Saudi Arabia.

Barwais, F. A., Cuddihy, T. F., \& Tomson, L. M. (2014). Adult total wellness: group differences based on sitting time and physical activity level. BMC public health, 14(1), 234.

Bray, S. R., \& Born, H. A. (2004). Transition to university and vigorous physical activity: Implications for health and psychological well-being. Journal of American College Health, 52(4), 181-188.

Cohen, J. (1988). Statistical power analysis for the behavioral sciences (2 ed.): Hillsdale, NJ: Lawrence Erlbaum.

Craig, C. L., Marshall, A. L., Sjöström, M., Bauman, A. E., Booth, M. L., Ainsworth, B. E., . . . Sallis, J. F. (2003). International physical activity questionnaire: 12country reliability and validity. Medicine and Science in Sports and Exercise, 35(8), 1381-1395.

Dunstan, D. W., Howard, B., Healy, G. N., \& Owen, N. (2012). Too much sitting-A health hazard. Diabetes Research and Clinical Practice, 97(3), 368-376.

Gill, J. M., \& Cooper, A. R. (2008). Physical activity and prevention of type 2 diabetes mellitus. Sports Medicine, 38(10), 807-824.

Grøntved, A., \& Hu, F. B. (2011). Television viewing and risk of type 2 diabetes, cardiovascular disease, and all-cause mortality. JAMA: Journal of the American Medical Association., 305(23), 2448-2455.

Guthold, R., Stevens, G. A., Riley, L. M., \& Bull, F. C. (2018). Worldwide trends in insufficient physical activity from 2001 to 2016: a pooled analysis of 358 population-based surveys with 1. 9 million participants. The Lancet Global Health, 6(10), e1077-e1086.

Hallal, P. C., Andersen, L. B., Bull, F. C., Guthold, R., Haskell, W., Ekelund, U., \& Group, L. P. A. S. W. (2012). Global physical activity levels: surveillance progress, pitfalls, and prospects. The Lancet, 380(9838), 247-257.

Irwin, J. D. (2004). Prevalence of university students' sufficient physical activity: a systematic review. Perceptual and Motor Skills, 98(3), 927-943.

Lee, I.-M., Shiroma, E. J., Lobelo, F., Puska, P., Blair, S. N., Katzmarzyk, P. T., \& Group, L. P. A. S. W. (2012). Effect of physical inactivity on major noncommunicable diseases worldwide: an analysis of burden of disease and life expectancy. The Lancet, 380(9838), 219-229.

Mabry, R., Koohsari, M. J., Bull, F., \& Owen, N. (2016). A systematic review of physical activity and sedentary behaviour research in the oil-producing countries of the Arabian Peninsula. BMC public health, 16(1), 1003.

Saudi Ministry of Health. (2005). Saudi Ministry of Health / World Health 
Organization. WHO Stepwise approach to NCD Surveillance. Country Specific Standard Report: Saudi Arabia. MoH/WHO:2005. Available from: http://www.who.int/chp/steps/2005_SaudiArabia_STEPS_Report_EN.pdf

Sharara, E., Akik, C., Ghattas, H., \& Obermeyer, C. M. (2018). Physical inactivity, gender and culture in Arab countries: a systematic assessment of the literature. BMC public health, 18(1), 639.

Sims, S. T., Larson, J. C., Lamonte, M. J., Michael, Y. L., Martin, L. W., Johnson, K. C.,Stefanick, M. L. (2012). Physical activity and body mass: changes in younger versus older postmenopausal women. Medicine and Science in Sports and Exercise, 44(1), 89-97.

Warburton, D. E., \& Bredin, S. S. (2016). Reflections on physical activity and health: what should we recommend? Canadian Journal of Cardiology, 32(4), 495-504.

Wen, C. P., Wai, J. P. M., Tsai, M. K., Yang, Y. C., Cheng, T. Y. D., Lee, M.-C., . . Wu, X. (2011). Minimum amount of physical activity for reduced mortality and extended life expectancy: a prospective cohort study. The Lancet, 378(9798), 1244-1253.

WHO. (2017). The Investment Case for Noncommunicable Disease Prevention and Control in the Kingdom of Saudi Arabia: https://www.undp.org/content/dam/saudi arabia/docs/Publications/180326\%20MOH $\% 20 \mathrm{KSA} \% 20 \mathrm{NCDs} \% 202017 . \mathrm{pdf}$.

WHO. (2018). The global action plan on physical activity 2018-2030. World Health Organization. http://www.who.int/ncds/prevention/physical-activity/gappa/actionplan. Accessed 25 Sep 2020. 


\title{
Health-related physical fitness among adolescent school boys in Madinah city, western Saudi Arabia
}

\section{Mohammad Ali Alahmadi}

Institutional affiliation: Department of Physical Education and Sport Sciences, College of Education, Taibah University, Saudi Arabia

\begin{abstract}
:
This study aimed to measure health-related physical fitness components (cardiorespiratory fitness, body fat, muscle strength, flexibility) among adolescent school boys in Madinah, western Saudi Arabia. The participants comprised 36 male students who performed a maximal multistage $20-\mathrm{m}$ shuttle run test to estimate maximal oxygen consumption $\left(\mathrm{VO}_{2} \mathrm{max}\right)$. Body fat percentage $(\mathrm{BF} \%)$ was determined using the bioelectrical impedance scale; hand grip strength was measured using a hand grip dynamometer; and flexibility was determined using the sit and reach test. The results of the health-related physical fitness tests reveal that the mean $( \pm$ SD) value of estimated $\mathrm{VO}_{2} \max$ was $41.1 \pm 6.9$ (ml.kg.min). The mean $( \pm \mathrm{SD})$ values of $\mathrm{BF} \%$, right-hand grip strength, left-hand grip strength, and flexibility were $18.7 \pm 8.6$ $(\%), 33.3 \pm 5.6(\mathrm{~kg}), 32.8 \pm 5.7(\mathrm{~kg})$, and $15.8 \pm 3.9(\mathrm{~cm})$, respectively. With the exception of flexibility, we conclude that it is necessary to improve health-related physical fitness components, particularly muscle strength, among Saudi adolescent school boys in Madinah city.
\end{abstract}

\section{Keywords: Exercise training; Physical activity; Body fat; Overweight; Obesity.}

\section{Introduction:}

Physical fitness is defined as the ability to achieve certain performance standards in physical activity and is an outcome of habitual physical activity or exercise (Freedson, Cureton, \& Heath, 2000; Tuero-del-Prado, de paz, \& Márquez, 2001). Evaluation of physical fitness in young adults is particularly important, as low fitness levels may indicate the potential for several health problems in later adulthood (Chen et al., 2005; Cheng et al., 2004; fu \& Hao, 2002; Heitzler, Martin, Duke, \& Huhman, 2006; Ready, Naimark, Tate, \& Boreskie, 2005; Sato, Demura, Murase, \& Kobayashi, 2005). Higher levels of physical fitness are associated with a lower risk of cardiovascular disease (CVD) and cancer (Guerra et al., 2006; Lacombe, Armstrong, Wright, \& Foster, 2019). Moreover, there is a substantial body of scientific evidence to show that risk factors for adult CVD are present from childhood, and preventive measures taken during childhood and adolescence may be key in mitigating these risk factors in later life (Shrestha \& Copenhaver, 2015). Risk factors for atherosclerotic CVD can develop during childhood and adolescence, and these risk factors are likely to be seen in adults, continuing to make them more susceptible (Daniels, Pratt, \& Hayman, 2011). Moreover, physical fitness has been demonstrated to be potentially beneficial in helping high school students cope with stress (Guszkowska, 2005). Earlier studies have defined several health-related components of physical fitness, including cardiorespiratory fitness, body composition, muscle strength, and flexibility (Cvejic, Pejović, \& Ostojic, 2013; Secchi, García, España-Romero, \& Castro-Piñero, 2014). A 
recent study found that high cardiorespiratory fitness combined with high muscular fitness was positively associated with improved health-related quality of life in adolescents (Evaristo et al., 2019). Moreover, several earlier studies have measured cardiorespiratory fitness among adolescents (Ekblom, Oddsson, \& Ekblom, 2005; Morinder, Mattsson, Marcus, \& Larsson, 2007). Enhancement of cardiorespiratory fitness during adolescence is known to be associated with better cardiovascular health indicators in adulthood (Harber et al., 2017; Lang et al., 2017). Moreover, the measurement of body composition, particularly fat percentage, is important, because the prevalence of obesity and overweight status in Saudi Arabia has increased dramatically in recent decades (DeNicola, Aburizaiza, Siddique, Khwaja, \& Carpenter, 2015) and has become a major public health problem among Saudi adolescents (Habbab \& Bhutta, 2020). Moreover, decreased muscular strength is a risk factor for major causes of death in the early stages of adulthood, such as CVD (Ortega, Silventoinen, Tynelius, \& Rasmussen, 2012). This is why hand grip strength is a popular means of predicting health throughout an individual's lifetime (Cooper et al., 2011) and is a field test that measures muscular strength among school adolescents (Saint-Maurice, Laurson, Karsai, Kaj, \& Csányi, 2015). Flexibility is also regarded as an important component of physical fitness and has several positive effects on overall health (Fleg et al., 2000; Mikkelsson et al., 2006; Okuda, Horii, \& Kano, 2005).

Earlier studies in the Saudi Arabian context have assessed only individual component of health-related physical fitness in isolation (Albawardi, Jradi, Almalki, \& AlHazzaa, 2017; Alqarni, 2016). However, reliance on one or two components of health-related physical fitness is unlikely to provide a complete picture of an individual's health status. It has been recommended that various components of health-related physical fitness should be measured and then considered individually because all the outcomes of these components are complex entities, involving several different characteristics (Kiernan, 2000). Moreover, no study has measured the main components of health-related physical fitness among Saudi male school adolescents. Only one study to date has assessed the components of health-related physical fitness in a sample of Saudi girls aged 8-15 years (Al-Asiri \& Shaheen, 2015), In addition, although few studies of health-related physical fitness have been conducted in Saudi Arabia (H. Al-Hazzaa, 1993; H. M. Al-Hazzaa, 2002), most studies conducted in Saudi Arabia have focused on physical activity rather than health-related physical fitness (H. M. Al-Hazzaa \& Albawardi, 2019; Al-Nozha et al., 2007; Albawardi et al., 2017; Aljuhani \& Sandercock, 2019; Almutairi et al., 2018; AlQuaiz, Siddiqui, Kazi, Batais, \& Al-Hazmi, 2019; Awadalla et al., 2014; Khalaf et al., 2013; Samara, Nistrup, Al-Rammah, \& Aro, 2015; Yahia, Wang, Rapley, \& Dey, 2016; Zaidi, 2020). A study conducted among schoolboys in Riyadh found that Saudi children and adolescents do not meet the minimal weekly requirement of moderate to vigorous physical activity necessary for an effectively functioning cardiorespiratory system and that $16 \%$ of them are considered obese (i.e., their fat content constitutes over $25 \%$ of their body mass) (H. Al-Hazzaa, 1993). It is thus critically important to distinguish between physical activity and physical fitness. To the best of our knowledge, no study hitherto has assessed physical fitness among young students in Madinah. Therefore, further research is necessary to assess health-related physical fitness in Saudi youth in Madinah more comprehensively, assessing measures of fitness for which an association with health outcomes has been demonstrated and to provide information about current fitness status. This may help to improve or evaluate health status among school-aged adolescents and to establish health programs within the school 
environment or as part of the physical education curriculum. Therefore, the present study aimed to measure the key health-related physical fitness components (cardiorespiratory fitness, body fat, muscle strength, flexibility) among adolescent school boys in Madinah city, western Saudi Arabia.

\section{Methods:}

1- Participants and study procedure:

This study was a descriptive-analytic study consisting of 36 male students (mean \pm $\mathrm{SD}$, age, $17.4 \pm 0.9$ years; body mass, $63.1 \pm 11.2 \mathrm{~kg}$; height, $169.6 \pm 5.7 \mathrm{~cm}$ ). Students were selected from a public school, and one class from each educational level (grades 10-12) was randomly chosen from the selected high school in Madinah city (Prince Nayef bin Abdulaziz Secondary School-East Madinah Education Office-General Administration of Education in Madinah Region. Madinah). The study was conducted in April, the second semester of the academic year 2018-2019. All health related physical fitness tests were performed in the morning $(8: 00 \mathrm{am})$. All physical fitness tests for all participants were performed in one day. Anthropometric and body composition measurements were performed first, followed by sit and reach test, hand grip strength test, and cardiorespiratory test. The study protocol and procedures conformed to the International Ethical Guidelines, and all participants signed an informed consent form. Participants were included if they answered "No" to all questions in the Physical Activity Readiness Questionnaire (Warburton, 211). Participants suffering from any musculoskeletal disorders and those with a history of CVD or other serious health concerns were excluded.

\section{2- Measurements:}

\section{2-1 Anthropometry and Body Composition:}

Body weight was measured to the nearest $100 \mathrm{~g}$ using a portable digital scale (Seca, Germany), and height was measured to the nearest $0.1 \mathrm{~cm}$ using a portable stadiometer (Seca, Germany). Body mass index (BMI) was calculated from height and weight measurements (mass/height ${ }^{2}$ ). Body fat percentage was measured using a bioimpedance analyzer (OMRON, BF511 body composition monitor). In accordance with the manufacturer's instructions, the participants dressed in light indoor clothes and wore no shoes, and the bioelectric impedance measurement was taken by placing the feet together on the foot electrodes with the weight equally distributed. The participants' knees and backs were straight; they extended their arms forward and held the grip electrodes for a few seconds. The fat percentage readings appeared on the display unit and were recorded.

2-2 A maximal multistage $20-\mathrm{m}$ shuttle run test to estimate maximal oxygen consumption $\left(\mathrm{VO}_{2} \max \right)$

Each participant performed a shuttle run test in accordance with Leger et al. (1988). The shuttle run test consisted of 20-m sprints with increasing speed in each run, the pace indicated with audible signals. Participants had to run back and forth along a 20$\mathrm{m}$ course in the gymnasium and touch the $20-\mathrm{m}$ line. The test began at a speed of 8.5 $\mathrm{km} / \mathrm{h}$ and was increased by $0.5 \mathrm{~km} / \mathrm{h}$ at one-minute intervals. Participants were verbally encouraged throughout the test, and they continued until they were unable to 
reach the cones three times consecutively after the signals. The $\mathrm{VO}_{2}$ max was estimated based on the speed reached by the participants during the last period until fatigue using the following equation (Leger \& Lambert, 1982):

$\mathrm{VO}_{2} \max =5.857 \mathrm{x}$ speed $(\mathrm{km} / \mathrm{h})-19.458$.

\section{2-3 Hand grip strength:}

Maximal isometric hand grip strength was measured using a hand grip dynamometer (Takei Kiki Kogyo® dynamometer) adjusted to hand size. A single measurement was taken for each hand to obtain the maximal isometric hand grip strength values. Each subject was instructed to maintain maximal isometric contraction during each measurement for three to six seconds (Kamimura \& Ikuta, 2001; Trossman \& Li, 1989). The participants contracted each of their hands with both feet placed on the floor, their shoulders bent by $90^{\circ}$, and their elbows completely extended.

\section{2-4 Flexibility:}

Flexibility was determined using the sit and reach test (Liemohn, Sharpe, \& Wasserman, 1994; Mayorga-Vega, Merino-Marban, \& Viciana, 2014). In this test, participants sat with knees straight, feet pressed flat against a box, one hand placed on top of the other with palms facing downwards. Each participant then gradually inclined his trunk forward as far as possible. Participants were not permitted to bounce or lunge: they reached forward and held that position for two seconds, and the distance was then recorded in centimeters $(\mathrm{cm})$.

\section{3- Statistical analysis:}

Data were analyzed using the statistical software package SPSS, version 21. Descriptive statistics were presented as mean values and standard deviation (SD).

\section{Results:}

A total of 36 adolescent school boys were measured for attributes of health-related physical fitness. Table 1 presents the participants' results of tests used to measure health-related physical fitness components (cardiorespiratory fitness [ $\left.\mathrm{VO}_{2} \mathrm{max}\right]$, body composition, muscle strength, and flexibility).

Table 1. Physical characteristics and health-related physical fitness components of Saudi adolescent school boys.

\begin{tabular}{|c|c|}
\hline Variables & Mean ( \pm SD) \\
\hline BMI $\left(\mathrm{kg} / \mathrm{m}^{2}\right)$ & $22.0 \pm 3.7$ \\
\hline $\mathrm{VO}_{2}$ max $(\mathrm{ml} . \mathrm{kg} \cdot \mathrm{min})$ & $41.1 \pm 6.9$ \\
\hline Body fat percentage $(\%)$ & $18.7 \pm 9.0$ \\
\hline Right-hand grip strength $(\mathrm{kg})$ & $33.3 \pm 5.6$ \\
\hline Left-hand grip strength $(\mathrm{kg})$ & $32.8 \pm 5.7$ \\
\hline Flexibility $(\mathrm{cm})$ & $15.8 \pm 3.9$ \\
\hline
\end{tabular}




\section{Discussion:}

Assessment of the components of health-related physical fitness in adolescents and young adults has received little scholarly attention. To the best of our knowledge, this is the first study to describe multiple aspects of health-related physical fitness in a sample of adolescent school boys in Madinah, western Saudi Arabia. Improvement in cardiorespiratory fitness during adolescence is known to be associated with improved cardiovascular health indicators, such as healthy blood pressure levels, favorable lipid profiles, and reduced risk of morbidity and mortality in adulthood (Harber et al., 2017; Lang et al., 2017). The present study's main finding was that cardiorespiratory fitness was 41 (ml.kg.min) and almost comparable with earlier studies' outcomes. For example, the cardiopulmonary fitness results in the present study were close to those previously recorded in young adults ( $37 \mathrm{ml} . \mathrm{kg} . \mathrm{min})$ (Ekblom et al., 2005; Morinder et al., 2007; Sallis, Patterson, Buono, \& Nader, 1988). New research has also suggested that cardiorespiratory fitness levels are related to brain properties and cognitive functions in adolescents (Ruotsalainen et al., 2020). This suggests that physical fitness in young people should receive more attention because adolescence is a critical life stage that can significantly influence adult life and may therefore be a crucial period for intervention. $\mathrm{VO}_{2} \mathrm{max}$ is a standard measure associated with cardiorespiratory fitness levels, with values expected to increase as cardiorespiratory fitness level improves, and an important indicator of successful physical activity interventions. However, many methods for directly or indirectly determining $\mathrm{VO}_{2} \mathrm{max}$ are available, making it more difficult to compare outcomes and indicating that the results should be interpreted with caution.

In addition to cardiorespiratory fitness, body fat was found to correlate positively with systolic blood pressure and blood lipids, such as triglycerides, in Saudi children $(\mathrm{H}$. Al-Hazzaa, 1993). Obesity and overweight status contribute to metabolic disease and are linked to increased risk of several chronic diseases, such as diabetes, heart disease, and cancer (Deckelbaum \& Williams, 2001). The prevalence of obesity and overweight status in Saudi Arabia has increased dramatically in recent decades and has become one of the highest overweight and obesity prevalence rates worldwide (DeNicola et al., 2015). The prevalence of overweight status and obesity among Saudi adolescents is a major public health problem that is growing at an alarming rate (Habbab \& Bhutta, 2020). However, most studies conducted in Saudi Arabia have examined obesity among children and adolescents based on waist-to-hip ratio (WHR) and/or BMI (Alqarni, 2016). In the present study, body fat was measured directly using bioelectrical impedance analysis, which provides a more accurate assessment than BMI of overweight status or obesity in adolescents (Albawardi et al., 2017). Saudi adolescent school boys' average body fat percentage (19\%) in our study was similar to that reported by Taylor et al. (2003) (21\%), though Taylor et al. (Taylor et al., 2003) used dual-energy X-ray absorptiometry to estimate body fat percentage. It is well known that BMI is widely used and accepted as indicative of body fat, however, more accurate methods, such as bioelectrical impedance analysis, can yield lower values than BMI. In a cross-sectional study (Shaikh et al., 2016) conducted among Saudi male and female students (aged 12-14 years) from three large cities in Saudi Arabia's Qassim region, the prevalence of overweight status and obesity was studied using three different methods (BMI, skin fold thickness, and bioelectrical impedance analysis), and the results showed that the obesity prevalence estimated using a bioelectrical impedance analyzer was lower than that measured using the other 
methods.

The third component of health-related physical fitness among Saudi adolescents evaluated in our study is muscle strength. Research has shown that low muscular strength is a risk factor for major causes of death in the early stages of adulthood, such as CVD (Ortega et al., 2012). Hand grip strength is a particularly popular means of predicting health throughout an individual's lifetime and is a field test that measures the maximum isometric strength of both hands' grip strengths (Cooper et al., 2011) . Our results showed that the average hand grip strength of Saudi school adolescents (33 kg) was similar to that reported ( $31.4 \mathrm{~kg}$ ) by Saint-Maurice et al. (2015), whereby the $50^{\text {th }}$-percentile values resulted in a score of $42.6 \mathrm{~kg}$ for boys aged 17 years.

In addition to muscle strength, flexibility in the lower back and hamstring areas was linked to reduced risk of lower back pain and other musculoskeletal injuries (Battié et al., 1990; Pollock et al., 1998). Adequate flexibility reduced the risk of lesions, prevented and reduced pain, and improved motor coordination (Fleg et al., 2000). High flexibility in adolescence has also been found to reduce the risk of neck tension in older men (Mikkelsson et al., 2006). Moreover, research suggests that children who have high adiposity or low levels of flexibility are more likely to continue to do so into adolescence, putting them at greater risk for developing diseases later in life (Marshall, Sarkin Ja Fau - Sallis, Sallis Jf Fau - McKenzie, \& McKenzie, 1998). Although flexibility is regarded as an important component of physical fitness, it has been reported that genetic influences can account for about $18-55 \%$ of variations in flexibility, as measured by the sit and reach test, in children and young adults (Okuda et al., 2005). The results of the present study showed that the average flexibility value in Saudi school adolescents was $15.8 \pm 3.9 \mathrm{~cm}$, which is lower than that found in a large study $(19.8 \pm 10.1 \mathrm{~cm})$ conducted among 243 male children and young adults (mean age 17.2 \pm 1.2 ) (Schutte, Nederend, Hudziak, de Geus, \& Bartels, 2016). The flexibility scores of Saudi school adolescents obtained in this study are considered to indicate high flexibility levels based on normative data from schoolchildren aged between 7 and 19 years developed by Dobosz, Mayorga-Vega, and Viciana (2015). The $50^{\text {th }}$-percentile values for flexibility, measured using the sit and reach test, resulted in $7.1 \mathrm{~cm}$ for boys aged 17 years old (Dobosz et al., 2015).

\section{Limitations:}

This study has several key limitations, including the low sampling power of the health-related physical fitness components. Further research involving larger samples that include both boys and girls is recommended. Another limitation of this study concerns physical fitness test motivation. Tests of this nature usually depend on the adolescent's motivation to perform them at maximum effort. For this reason, our results may be impacted by some participants' potential lack of motivation. These limitations notwithstanding, our study is the first conducted among school adolescents in Madinah using validated measurements for data collection and providing greater assurance of the findings' accuracy.

\section{Conclusion:}

Based on our findings, with the exception of the high flexibility score, we conclude that health-related physical fitness components, particularly muscle strength, should 
be improved among Saudi school adolescents. Moreover, like most adolescents, Saudi male adolescents in Madinah may benefit from additional fitness programs and opportunities that allow them to increase their components of health-related physical fitness. This may be achieved through participation in programs run by local health organizations or universities.

\section{References:}

Al-Asiri, Z., \& Shaheen, A. (2015). Body Mass Index and Health Related Physical Fitness in Saudi Girls and Adolescents Aged 8 - 15 Years. Open Journal of Therapy and Rehabilitation, 03, 116-125. doi: 10.4236/ojtr.2015.34016

Al-Hazzaa, H. (1993). Maximal Oxygen Uptake and Daily Physical Activity in 7- to 12-Year-Old Boys. Pediatric exercise science, 5, 357-366. doi: 10.1123/pes.5.4.357

Al-Hazzaa, H. M. (2002). Physical activity, fitness and fatness among Saudi children and adolescents: implications for cardiovascular health. Saudi Med J, 23(2), 144-150.

Al-Hazzaa, H. M., \& Albawardi, N. M. (2019). Activity energy expenditure, screen time and dietary habits relative to gender among Saudi youth: interactions of gender with obesity status and selected lifestyle behaviours. Asia Pac J Clin Nutr, 28(2)(1440-6047 (Electronic)), 389-400.

Al-Nozha, M. M., Al-Hazzaa Hm Fau - Arafah, M. R., Arafah Mr Fau - Al-Khadra, A., Al-Khadra A Fau - Al-Mazrou, Y. Y., Al-Mazrou Yy Fau - Al-Maatouq, M. A., Al-Maatouq Ma Fau - Khan, N. B., . . . Al-Shahid, M. S. (2007). Prevalence of physical activity and inactivity among Saudis aged 30-70 years. A population-based cross-sectional study. Saudi Med J, 28(4)(0379-5284 (Print)), 559-568.

Albawardi, N. M., Jradi, H., Almalki, A. A., \& Al-Hazzaa, H. M. (2017). Level of Sedentary Behavior and Its Associated Factors among Saudi Women Working in Office-Based Jobs in Saudi Arabia. Int J Environ Res Public Health, 14(6). doi: 10.3390/ijerph14060659

Aljuhani, O., \& Sandercock, G. (2019). Contribution of Physical Education to the Daily Physical Activity of Schoolchildren in Saudi Arabia. LID 10.3390/ijerph16132397 [doi] LID - 2397. nt J Environ Res Public Health, 16(13):2397.

Almutairi, K. M., Alonazi, W. B., Vinluan, J. A.-O., Almigbal, T. H., Batais, M. A., Alodhayani, A. A., . . Alhoqail, R. I. (2018). Health promoting lifestyle of university students in Saudi Arabia: a cross-sectional assessment. BMC Public Health, 18(1):1093.

Alqarni, S. (2016). A Review of Prevalence of Obesity in Saudi Arabia. Journal of Obesity \& Eating Disorders, 02. doi: 10.21767/2471-8203.100025

AlQuaiz, A. M., Siddiqui, A. R., Kazi, A. A.-O., Batais, M. A., \& Al-Hazmi, A. M. (2019). Sedentary lifestyle and Framingham risk scores: a population-based study in Riyadh city, Saudi Arabia. BMC Cardiovasc Disord, 19(1):88. 
Awadalla, N. J., Aboelyazed, A. E., Hassanein, M. A., Khalil, S. N., Aftab, R., Gaballa, II, \& Mahfouz, A. A. (2014). Assessment of physical inactivity and perceived barriers to physical activity among health college students, south-western Saudi Arabia. East Mediterr Health J, 20(10), 596-604.

Battié, M. C., Bigos, S. J., Fisher, L. D., Spengler, D. M., Hansson, T. H., Nachemson, A. L., \& Wortley, M. D. (1990). The role of spinal flexibility in back pain complaints within industry. A prospective study. Spine (Phila Pa 1976), 15(8), 768-773.

Chen, X., Sekine, M., Hamanishi, S., Wang, H., Gaina, A., Yamagami, T., \& Kagamimori, S. (2005). Lifestyles and health-related quality of life in Japanese school children: a cross-sectional study. Prev Med, 40(6), 668-678. doi: 10.1016/j.ypmed.2004.09.034

Cheng, K. Y., Cheng, P., Mak, K., Wong, S., Wong, Y. K., \& Yeung, E. (2004). Relationships of perceived benefits and barriers to physical activity, physical activity participation and physical fitness in Hong Kong female adolescents. The Journal of sports medicine and physical fitness, 43, 523-529.

Cooper, R., Kuh, D., Cooper, C., Gale, C. R., Lawlor, D. A., Matthews, F., \& Hardy, R. (2011). Objective measures of physical capability and subsequent health: a systematic review. Age Ageing, 40(1), 14-23. doi: 10.1093/ageing/afq117

Cvejic, D., Pejović, T., \& Ostojic, S. (2013). Assessment of physical fitness in children and adolescents. Facta universitatis - series: Physical Education, 11, 135145 .

Daniels, S. R., Pratt, C. A., \& Hayman, L. L. (2011). Reduction of risk for cardiovascular disease in children and adolescents. Circulation, 124(15), 1673-1686. doi: 10.1161/circulationaha.110.016170

Deckelbaum, R. J., \& Williams, C. L. (2001). Childhood obesity: the health issue. Obes Res, 9 Suppl 4, 239S-243S. doi: 10.1038/oby.2001.125

DeNicola, E., Aburizaiza, O. S., Siddique, A., Khwaja, H., \& Carpenter, D. O. (2015). Obesity and public health in the Kingdom of Saudi Arabia. Rev Environ Health, 30(3), 191-205. doi: 10.1515/reveh-2015-0008

Dobosz, J., Mayorga-Vega, D., \& Viciana, J. (2015). Percentile Values of Physical Fitness Levels among Polish Children Aged 7 to 19 Years--a Population-Based Study. Cent Eur J Public Health, 23(4), 340-351. doi: 10.21101/cejph.a4153

Ekblom, O., Oddsson, K., \& Ekblom, B. (2005). Physical performance and body mass index in Swedish children and adolescents. Food \& Nutrition Research, 49. doi: 10.3402/fnr.v49i4.1545

Evaristo, S., Moreira, C., Lopes, L., Oliveira, A., Abreu, S., Agostinis-Sobrinho, C., . 
. . Mota, J. (2019). Muscular fitness and cardiorespiratory fitness are associated with health-related quality of life: Results from labmed physical activity study. Journal of Exercise Science \& Fitness, 17(2), 55-61. doi: https://doi.org/10.1016/j.jesf.2019.01.002

Fleg, J. L., Piña, I. L., Balady, G. J., Chaitman, B. R., Fletcher, B., Lavie, C., . . . Bazzarre, T. (2000). Assessment of functional capacity in clinical and research applications: An advisory from the Committee on Exercise, Rehabilitation, and Prevention, Council on Clinical Cardiology, American Heart Association. Circulation, 102(13), 1591-1597. doi: 10.1161/01.cir.102.13.1591

Freedson, P., Cureton, K., \& Heath, G. (2000). Status of Field-Based Fitness Testing in Children and Youth. Preventive Medicine, 31. doi: 10.1006/pmed.2000.0650

fu, F., \& Hao, X. (2002). Physical Development and Lifestyle of Hong Kong Secondary School Students. Preventive Medicine, 35, 499-505. doi: 10.1006/pmed.2002.1104

Guerra, S., Teixeira-Pinto, A., Ribeiro, J. C., Ascensão, A., Magalhães, J., Andersen, L. B., . . . Mota, J. (2006). Relationship between physical activity and obesity in children and adolescents. J Sports Med Phys Fitness, 46(1), 79-83.

Guszkowska, M. (2005). Physical fitness as a resource in coping with stress among high school students. J Sports Med Phys Fitness, 45(1), 105-111.

Habbab, R. M., \& Bhutta, Z. A. (2020). Prevalence and social determinants of overweight and obesity in adolescents in Saudi Arabia: A systematic review. Clin Obes, 10(6), e12400. doi: 10.1111/cob.12400

Harber, M., Kaminsky, L., Arena, R., Blair, S., Franklin, B., Myers, J., \& Ross, R. (2017). Impact of Cardiorespiratory Fitness on All-Cause and Disease-Specific Mortality: Advances Since 2009. Progress in Cardiovascular Diseases, 60. doi: 10.1016/j.pcad.2017.03.001

Heitzler, C. D., Martin, S. L., Duke, J., \& Huhman, M. (2006). Correlates of physical activity in a national sample of children aged 9-13 years. Prev Med, 42(4), 254-260. doi: 10.1016/j.ypmed.2006.01.010

Kamimura, T., \& Ikuta, Y. (2001). Evaluation of grip strength with a sustained maximal isometric contraction for 6 and 10 seconds. $J$ Rehabil Med, 33(5), 225-229.

Khalaf, A., Ekblom Ö Fau - Kowalski, J., Kowalski J Fau - Berggren, V., Berggren V Fau - Westergren, A., Westergren A Fau - Al-Hazzaa, H., \& Al-Hazzaa, H. (2013). Female university students' physical activity levels and associated factors--a crosssectional study in southwestern Saudi Arabia. Int J Environ Res Public Health, 10(8), 3502-3517.

Kiernan, M. (2000). Methodologic issues in measuring physical activity and physical fitness when evaluating the role of dietary supplements for physically active people. 
The American journal of clinical nutrition, 72, 541S-550S. doi: 10.1093/ajcn/72.2.541S

Lacombe, J., Armstrong, M. E. G., Wright, F. L., \& Foster, C. (2019). The impact of physical activity and an additional behavioural risk factor on cardiovascular disease, cancer and all-cause mortality: a systematic review. BMC Public Health, 19(1), 900. doi: 10.1186/s12889-019-7030-8

Lang, J., Belanger, K., Poitras, V., Janssen, I., Tomkinson, G., \& Tremblay, M. (2017). Systematic review of the relationship between $20 \mathrm{~m}$ shuttle run performance and health indicators among children and youth. Journal of Science and Medicine in Sport, 21. doi: 10.1016/j.jsams.2017.08.002

Leger, L., \& Lambert, J. A. (1982). A maximal multistage 20-m shuttle run test to predict VO2 max. European journal of applied physiology and occupational physiology, 49, 1-12. doi: 10.1007/bf00428958

Leger, L., Mercier, D., Gadoury, C., \& Lambert, J. (1988). The multistage 20 metre Shuttle Run test for aerobic fitness. J Sports Sci 6 (2) 93-101 1988. Journal of sports sciences, 6, 93-101. doi: 10.1080/02640418808729800

Liemohn, W., Sharpe, G. L., \& Wasserman, J. F. (1994). Criterion Related Validity of the Sit-and-Reach Test. The Journal of Strength \& Conditioning Research, 8(2).

Marshall, S. J., Sarkin Ja Fau - Sallis, J. F., Sallis Jf Fau - McKenzie, T. L., \& McKenzie, T. L. (1998). Tracking of health-related fitness components in youth ages 9 to 12. Med Sci Sports, Exerc, 30(6), 910-916.

Mayorga-Vega, D., Merino-Marban, R., \& Viciana, J. (2014). Criterion-Related Validity of Sit-and-Reach Tests for Estimating Hamstring and Lumbar Extensibility: a Meta-Analysis. Journal of sports science \& medicine, 13(11-14).

Mikkelsson, L. O., Nupponen, H., Kaprio, J., Kautiainen, H., Mikkelsson, M., \& Kujala, U. M. (2006). Adolescent flexibility, endurance strength, and physical activity as predictors of adult tension neck, low back pain, and knee injury: a 25 year follow up study. British journal of sports medicine, 40(2), 107-113. doi: 10.1136/bjsm.2004.017350

Morinder, G., Mattsson, E., Marcus, C., \& Larsson, U. (2007). Age and gender differences in VO2 max in Swedish obese children and adolescents. Acta paediatrica (Oslo, Norway : 1992), 96, 567-571. doi: 10.1111/j.1651-2227.2007.00139.x

Okuda, E., Horii, D., \& Kano, T. (2005). Genetic and Environmental Effects on Physical Fitness and Motor Performance. International Journal of Sport and Health Science, 3, 1-9. doi: 10.5432/ijshs.3.1

Ortega, F. B., Silventoinen, K., Tynelius, P., \& Rasmussen, F. (2012). Muscular strength in male adolescents and premature death: cohort study of one million participants. $B M J, 345$, e7279. doi: 10.1136/bmj.e7279 
Pollock, M., Gaesser, G., Butcher, J., Després, J.-P., Dishman, R., Franklin, B., \& Garber, C. (1998). ACSM Position Stand: The Recommended Quantity and Quality of Exercise for Developing and Maintaining Cardiorespiratory and Muscular Fitness, and Flexibility in Healthy Adults. Medicine \& Science in Sports \& Exercise, 30, 975991. doi: 10.1097/00005768-199806000-00032

Ready, A. E., Naimark, B. J., Tate, R., \& Boreskie, S. (2005). Fitness centre membership is related to healthy behaviours. The Journal of sports medicine and physical fitness, 45, 199-207.

Ruotsalainen, I., Gorbach, T., Perkola, J., Renvall, V., Syväoja, H. J., Tammelin, T. H., . . . Parviainen, T. (2020). Physical activity, aerobic fitness, and brain white matter: Their role for executive functions in adolescence. Developmental cognitive neuroscience, 42, 100765-100765. doi: 10.1016/j.dcn.2020.100765

Saint-Maurice, P. F., Laurson, K. R., Karsai, I., Kaj, M., \& Csányi, T. (2015). Establishing Normative Reference Values for Handgrip Among Hungarian Youth. Res Q Exerc Sport, 86 Suppl 1, S29-36. doi: 10.1080/02701367.2015.1042354

Sallis, J. F., Patterson, T. L., Buono, M. J., \& Nader, P. R. (1988). Relation of cardiovascular fitness and physical activity to cardiovascular disease risk factors in children and adults. Am J Epidemiol, 127(5), 933-941. doi: 10.1093/oxfordjournals.aje.a114896

Samara, A., Nistrup, A., Al-Rammah, T. Y., \& Aro, A. R. (2015). Lack of facilities rather than sociocultural factors as the primary barrier to physical activity among female Saudi university students. Int $J$ Womens Health, 7, 279-286. doi: 10.2147/ijwh.s80680

Sato, T., Demura, S., Murase, T., \& Kobayashi, Y. (2005). Quantification of relationship between health status and physical fitness in middle-aged and elderly males and females. The Journal of sports medicine and physical fitness, 45, 561-569.

Schutte, N. M., Nederend, I., Hudziak, J. J., de Geus, E. J. C., \& Bartels, M. (2016). Differences in Adolescent Physical Fitness: A Multivariate Approach and Metaanalysis. Behavior genetics, 46(2), 217-227. doi: 10.1007/s10519-015-9754-2

Secchi, J. D., García, G. C., España-Romero, V., \& Castro-Piñero, J. (2014). Physical fitness and future cardiovascular risk in argentine children and adolescents: an introduction to the ALPHA test battery. Arch Argent Pediatr, 112(2), 132-140. doi: 10.5546/aap.2014.132

Shaikh, M. A., Al Sharaf, F., Shehzad, K., Shoukat, F., Naeem, Z., Al Harbi, S., . . Al Motairi, S. (2016). Prevalence and trends of overweight and obesity amongst Saudi school children, a study done by using three noninvasive methods. International journal of health sciences, 10(3), 381-387.

Shrestha, R., \& Copenhaver, M. (2015). Long-Term Effects of Childhood Risk 
Factors on Cardiovascular Health During Adulthood. Clinical medicine reviews in vascular health, 7, 1-5. doi: 10.4137/cmrvh.s29964

Taylor, R. W., Falorni, A., Jones, I. E., \& Goulding, A. (2003). Identifying adolescents with high percentage body fat: a comparison of BMI cutoffs using age and stage of pubertal development compared with BMI cutoffs using age alone. Eur $J$ Clin Nutr, 57(6), 764-769. doi: 10.1038/sj.ejcn.1601608

Trossman, P. B., \& Li, P.-W. (1989). The Effect of the Duration of Intertrial Rest Periods on Isometric Grip Strength Performance in Young Adults. The Occupational Therapy Journal of Research, 9(6), 362-378. doi: 10.1177/153944928900900604

Tuero-del-Prado, C., de paz, j. a., \& Márquez, S. (2001). Relationship of measures of leisure time physical activity to physical fitness indicators in Spanish adults. The Journal of sports medicine and physical fitness, 41, 62-67.

Warburton, D. E., Jamnik, V. K., Bredin, S. S., Gledhill, N. (211). The physical activity readiness questionnaire for everyone (PAR-Q+) and electronic physical activity readiness medical examination (ePARmed-X+). The Health and Fitness Journal of Canada, 4(2), 3-17.

Yahia, N., Wang, D., Rapley, M., \& Dey, R. (2016). Assessment of weight status, dietary habits and beliefs, physical activity, and nutritional knowledge among university students. Perspect Public Health, 136(4), 231-244.

Zaidi, U. (2020). Health and Rehabilitation Science specialities, physical activity and dimensions of wellness among the students of PNU. Heliyon, 6(1):e03204(2405-8440 (Print)). 


\title{
Physiological Profiles of Saudi Elite Judo Athletes
}

\section{Mohammad Ali Alahmadi}

${ }^{1}$ Department Physical Education and Sport Sciences, College of Education, Taibah University, Madinah, Saudi Arabia

\begin{abstract}
:
One of the most highly physiologically demanding combat sports is judo, which requires an excellent level of physical fitness to be successful in international competitions. Although the physical and physiological characteristics of high-ranked judo athletes are well established, the characteristics of Saudi judo athletes have not been determined. Therefore, the aim of this study was to assess the physiological profiles of Saudi elite judo athletes. Fourteen judo athletes (mean \pm standard deviation (SD) for age, $17 \pm 4$ years; body mass, $66.7 \pm 21 \mathrm{~kg}$; height, $160.2 \pm 13.6 \mathrm{~cm}$ ) performed a special judo fitness test (SJFT). Body fat percentage (BF\%) was determined using the bioelectrical impedance scale. Handgrip strength was measured using a handgrip dynamometer, and flexibility was determined by using a sit-andreach test. The mean \pm SD of the index of the SJFT was $16.2 \pm 1.6$. The means \pm SD of $\mathrm{BF} \%$, handgrip strength, and flexibility were $24.1 \pm 7.2(\%), 31.4 \pm 11.5(\mathrm{~kg})$, and $34.6 \pm 6.7(\mathrm{~cm})$, respectively. We concluded that the SJFT performance and handgrip strength were lower, and BF\% was higher in Saudi judo athletes compared to international elite judo athletes.
\end{abstract}

Keywords: Physical fitness, cardiovascular fitness, aerobic fitness, judo sport, combat sports

\section{Introduction}

One of the most highly physiologically demanding combat sports is judo, which requires an excellent level of physical fitness for success international competitions (Franchini et al. 2011a). It is well known that understanding the characteristics of elite athletes can provide insightful to determine what is required for competitive success (Agostinho et al. 2018; Callister et al. 1991; Franchini et al. 2011a; Franchini et al. 2007). The physical and physiological characteristics of high ranked judo athletes are well established (Franchini et al. 2011c; Torres-Luque et al. 2016). For example, physical fitness levels of judo athletes are evaluated using a special judo fitness test (SJFT). SJFT is the most common test used to evaluate judo athletes, allowing coaches to classify their athletes according to a classification levels developed for both male and female judo athletes (Franchini et al. 2011b; Franchini et al. 2009; Franchini, Takito and Bertuzzi 2005; Sterkowicz-Przybycień and Fukuda 2014). Physical fitness is related to SJFT performance (Lopes-Silva et al. 2018). Thus, highly ranked Judo athletes must achieve an excellent SJFT index, where the lower the index level the better the physical fitness level. For example, judo elite athletes typically have a low SJFT index, which is a positive combination of aerobic and anaerobic contributions (Franchini et al. 2017). Strength is also an important component of physical fitness and has been found to be critical in Judo sport, determining the results of judo competitions (Ache Dias et al. 2011; Blais and Trilles 2006; Franchini, 
Schwartz and Takito 2018; Franchini, Schwartz and Takito 2020; Kons et al. 2018). Flexibility is also a crucial component of physical fitness in Judo competitions because of the great neuromuscular demand involved in this type of combat sport (Fukuda et al. 2011; Sertić, Sterkowicz and Vuleta 2009). Moreover, body composition is regarded as a key element for competing at an international level in the judo sport. Therefore, judo athletes are recommended to obtain a target range of body fat percentage values to maximize their physiological capacity and performance (Franchini et al. 2011a; Franchini, Takito and Bertuzzi 2005).

However, although the physical and physiological characteristics of highly ranked judo athletes are well established, the characteristics of Saudi judo athletes have not been determined. Therefore, the aim of this study was to assess the physiological profiles of Saudi elite judo athletes.

\section{Methods}

Fourteen Saudi male judo athletes (mean \pm standard deviation (SD) for age, $17 \pm 4$ years; body mass, $66.7 \pm 21 \mathrm{~kg}$; height, $160.2 \pm 13.6 \mathrm{~cm}$ ) participated in this study. The study protocol and procedures conformed to International Ethical Guidelines. All participants signed an informed consent form.

\section{Anthropometry and Body Composition}

Body weight was measured to the nearest $100 \mathrm{~g}$ using a portable digital scale (Seca, Germany), and height was measured to the nearest $0.1 \mathrm{~cm}$ using a portable stadiometer (Seca, Germany). Body mass index (BMI) weight/stature2) was calculated from height and weight measurements.

Body fat percentage was measured without shoes in light indoor clothes using a bioimpedance analyser (OMRON, BF511 body composition monitor). According to the manufacturer's instruction manual with the participants in light clothes and without shoes, the bioelectric impedance measurement was performed by placing the feet together on foot electrodes with the weight equally distributed. The participant's knees and back were in a straightened position with their arms extended forward and holding the grip electrodes for a few seconds. The fat percentage reading appeared on the display unit and was then recorded.

\section{SJFT}

SJFT has been well described by Franchini et al. (1998) and Artioli et al. (2005). Briefly, three athletes in the same weight class and of similar heights are needed to perform the SJFT, which is composed of three periods (A, $15 \mathrm{~s}$; B and C, $30 \mathrm{~s}$ ) separated by 10 -s recovery intervals. The athlete begins the test in a position between two partners who are standing three meters away from each other. During each period, the athlete being evaluated throws the two partners as many times as possible using the "ippon-seoi-nage" technique. The athlete must complete as many throws as possible within the tested time. The heart rate was measured immediately after the end of the test and was measured again $1 \mathrm{~min}$ after completion of the test. A heart rate monitor (Polar RS400) was used to measure the heart rate. Then, the SJFT index was calculated as follows:

Index $=($ Heart rate after + Heart rate $1 \mathrm{~min}$ after $) /$ total number of throws.

Of note, the lower the index, the better the result.

\section{Handgrip strength}

Maximal isometric handgrip strength was measured using a handgrip dynamometer (Takei Kiki Kogyo ${ }^{\circledR}$ dynamometer) adjusted to the hand size. A single measurement was taken for each hand to obtain the maximal isometric handgrip strength value. Each subject was instructed to maintain maximal isometric contraction during each 
measurement for 3 to 6 s (Kamimura and Ikuta 2001; Trossman and Li 1989). Contractions were made using each hand with both feet on the floor, the shoulder bent by $90^{\circ}$, and the elbow completely extended.

\section{Flexibility}

Flexibility was determined by using the sit-and-reach test. In this test, athletes sat with knees straight, feet flat on the bench, and both hands on top of each other with palms facing downwards. Then, each participant gradually inclined his trunk forward as far as possible. The athletes were not allowed to bounce or lunge. Athletes reached out and held that position for $2 \mathrm{~s}$, and then, the distance was recorded in centimetres $(\mathrm{cm})$.

\section{Statistical analysis}

Data were analysed by using the statistical software package SPSS, version 21. Descriptive statistics was presented as mean values with SD.

\section{Results}

Descriptive characteristics and physiological responses for all participants are shown in Table 1. The mean $( \pm$ SD) for the SJFT index was $16.2 \pm 1.6$. Of note, the lower the value for this component, the higher the elite judo athlete's performance.

Table 1 Physiological profiles of Saudi judo athletes

\begin{tabular}{|c|c|}
\hline Variables & Means ( \pm SD) \\
\hline Number of throws & $21.5 \pm 2.1$ \\
\hline Heart rate after the test (beats/min) & $186 \pm 12$ \\
\hline Heart rate 1 min after the test (beats/min) & $161 \pm 17$ \\
\hline SJFT index & $16.2 \pm 1.6$ \\
\hline Body fat percentage (\%) & $24.1 \pm 7.2$ \\
\hline Right handgrip strength (kg) & $31.4 \pm 11.5$ \\
\hline Left handgrip strength (kg) & $30.5 \pm 12.0$ \\
\hline Flexibility (cm) & $34.6 \pm 6.7$ \\
\hline
\end{tabular}

\pm SD: standard deviation; STJF: special judo fitness test; kg: kilogram; cm: centimetre

\section{Discussion}

To our knowledge, this is the first study to use the SJFT test to evaluate judo athletes in Saudi Arabia. The SJFT is the most common test used to evaluate judo athletes, allowing coaches to classify their athletes according to classification levels developed for both male and female judo athletes (Franchini et al. 2011b; Franchini et al. 2009; Franchini, Takito and Bertuzzi 2005; Sterkowicz-Przybycień and Fukuda 2014). The smaller the index value, the better the test performance. The current study showed that the mean $( \pm$ SD) SJFT index for the tested Saudi judo athletes was $16.2 \pm 1.6$, and when, we compared this SJFT value to international elite judo athletes, our determined SJFT index value was higher (SJFT = 12.7-13.2) (Casals et al. 2017). The lower performance in the SJFT in relation to international elite judo athletes is probably related to the lower aerobic power capacity of the tested Saudi judo athletes. The higher maximal oxygen consumption performance $\left(\mathrm{VO}_{2 \max }\right)$ found in judo athletes (Agostinho et al. 2018; Sterkowicz-Przybycień, Miarka and Fukuda 2016) may be an important factor contributing to the higher performance in the SJFT. It has been found that $\mathrm{VO}_{2 \max }$ is related to both an increased aerobic contribution to sprintrecovery bouts and the enhanced ability to resist fatigue during intense intermittent exercise (Tomlin and Wenger 2002). Most judo athletes have $\mathrm{VO}_{2 \max }$ values between 44 and $65\left(\mathrm{ml} / \mathrm{kg} / \mathrm{min}^{-1}\right)$, regardless of the protocols and exercise modes (Franchini et 
al. 2011a; Franchini et al. 2007; Nikolova, Dimitrova and Mladenov 2020; TorresLuque et al. 2016). A further study is required to investigate the relationship between SJFT index and aerobic fitness and to explain why SJFT index found in the current study was poor. Moreover, poor index SJFT of our judo athletes may suggests that Judo as combat sport seems to be anaerobic in nature rather than aerobic. Therefore, it is recommended for future research to investigate the relationship between anaerobic fitness such as Wingate test with SJFT. This relationship may explain partially the poor SJFT index found in the current study.

The average body fat percentage for the Saudi judo athletes in this study was higher (24.1\%) than those of international judo athletes (range of approximately $7 \%$ to $14 \%$ ) (Franchini et al. 2011a; Franchini, Takito and Bertuzzi 2005). Of note, body fat percentage may differ between heavyweight and non-heavyweight judo athletes. A recent Japanese study found that heavyweight judo athletes had a higher body fat percentage $(23.2 \%)$ compared to non-heavyweight judo athletes (13.0\%) (Murata et al. 2016). Body fat percentage has been found to negatively influence the physiological capacity and performance in judo athletes (Franchini, Takito and Bertuzzi 2005). For instance, body fat percentage was negatively correlated with the number of throws in the SJFT $(r=-0.69)$ (Katralli and Goudar 2012). Moreover, the body fat percentage for higher ranked elite judo players compared with lower ranked elite judo players differed significantly (Callister et al. 1991). Therefore, to maximize the physiological capacities and performances of Saudi judo athletes, a target range of body fat percentage should be obtained.

Additionally, handgrip strength is critical in judo and may determine the result of judo bouts because the gripping method (kumi-kata) is the first contact between two judo players, (Ache Dias et al. 2011; Blais and Trilles 2006; Kons et al. 2018). Fatigue in the upper limbs, especially in the hands, is common in judo. In fact, an overall decrease in the maximal isometric strength has been found during judo bouts because of fatigue in each hand (Bonitch-Góngora et al. 2011). Handgrip strength was not found to differ between judo athletes and non-judo athletes in absolute terms (peak grip force); however, judo athletes have been found to be more resistant to fatigue (Ache Dias et al. 2011). Generally, no difference has been found between elite and non-elite judo athletes (Franchini, Takito and Bertuzzi 2005). Our study showed that the handgrip strength of these Saudi judo athletes was $31.4 \mathrm{~kg}$, which is lower than that of international judo athletes for handgrip strength (ranges from 38 to $65 \mathrm{~kg}$ ) (Franchini et al. 2011a; Franchini, Schwartz and Takito 2018; Franchini, Schwartz and Takito 2020).

In addition to handgrip strength, flexibility is a crucial component of physical fitness in judo competitions because of the high neuromuscular demand involved in this type of combat sport (Fukuda et al. 2011; Sertić, Sterkowicz and Vuleta 2009). It has been shown that there is an inverse relationship between flexibility and SJFT index, meaning that the higher the flexibility, the better the performance in SJFT (Arazi, Noori and Izadi 2017). Although insufficient information exists regarding the flexibility of judo athletes, the flexibility the Saudi judo athletes determined in this study $(35 \mathrm{~cm})$ was similar to those reported by Marques et al. (2019). However, Arazi et al. (2017) found greater values for the flexibility in their judo athletes $(48 \mathrm{~cm})$ than of those in our study. 
To conclude, the SJFT performance and handgrip strength were lower and the BF\% was higher in Saudi judo athletes compared to international elite judo athletes. In the future, we would like to investigate the relationship between aerobic and anaerobic fitness with SJFT. This relationship could explain why the SJFT index found in this study was poor for these Saudi judo athletes compared to their peers. Thus, the results of this study suggest the need for more studies to investigate the influence of aerobic and anaerobic fitness variables on the judo-related performance in Saudi judo athletes.

\section{References:}

1- Ache Dias, Jonathan, M. Wentz, Wladymir Külkamp, Daniela Mattos, Márcio Goethel, and N. Júnior (2011): Is the handgrip strength performance better in judokas than in non-judokas?. Science \& Sports 27:e9-e14.

2- Agostinho, M. F., J. A. O. Junior, N. Stankovic, R. Escobar-Molina, and E. Franchini (2018): Comparison of special judo fitness test and dynamic and isometric judo chin-up tests' performance and classificatory tables' development for cadet and junior athletes. J Exerc Rehabil 14(2):244-52.

3- Arazi, Hamid, Mohsen Noori, and Mani Izadi (2017): Correlation of anthropometric and bio-motor attributes with Special Judo Fitness Test in senior male judokas. Ido Movement for Culture 17:19-24.

4- Artioli, Guilherme, Desiré Coelho, Fabiana Benatti, Alessandra Gailey, Patrícia Berbel, Thomás Adolpho, and Antonio Lancha (2005): Relationship Between Blood Lactate And Performance In A Specific Judo Test. Medicine \& Science in Sports \& Exercise 37:S99.

4- Blais, Laurent, and Francis Trilles (2006): The progress achieved by judokas after strength training with a judo-specific machine. Journal of sports science \& medicine 5(CSSI):132-35.

5- Bonitch-Góngora, Juan, Juan Bonitch-Domínguez, Paulino Padial, and Belen Feriche (2011): The Effect of Lactate Concentration on the Handgrip Strength During Judo Bouts. Journal of strength and conditioning research / National Strength \& Conditioning Association 26:1863-71.

6- Callister, R., R. J. Callister, R. S. Staron, S. J. Fleck, P. Tesch, and G. A. Dudley (1991): Physiological characteristics of elite judo athletes. Int J Sports Med 12(2):196-203.

7- Casals, Cristina, Jesús Huertas, Emerson Franchini, Katarzyna SterkowiczPrzybycień, Stanisław Sterkowicz, Carlos Gutiérrez-García, and Raquel EscobarMolina (2017): Special Judo Fitness Test Level and Anthropometric Profile of Elite Spanish Judo Athletes. Journal of strength and conditioning research / National Strength \& Conditioning Association 31:1229-35.

8- Franchini, E., F. B. Del Vecchio, K. A. Matsushigue, and G. G. Artioli (2011a): Physiological profiles of elite judo athletes. Sports Med 41(2):147-66.

9- Franchini, E., S. Sterkowicz, U. Szmatlan-Gabrys, T. Gabrys, and M. Garnys. (2011b): Energy system contributions to the special judo fitness test. Int J Sports Physiol Perform 6(3):334-43.

10- Franchini, Emerson, Fabrício Abcde, Fabricio Del Vecchio, Vecchio, Stanislaw Cde, Stanisław Sterkowicz, and Acde (2009): A special judo fitness test classificatory table. Archives of Budo 5:127-29.

11- Franchini, Emerson, Fabricio Del Vecchio, Karin Matsushigue, and Guilherme Artioli (2011c): Physiological Profiles of Elite Judo Athletes. Sports medicine 
(Auckland, N.Z.) 41:147-66.

12- Franchini, Emerson, U. F. Julio, Valéria Panissa, Fabio Lira, Marcus Agostinho, and Braulio Branco (2017): Short-term low-volume high-intensity intermittent training improves judo-specific performance. Archives of Budo 12:219-29.

13- Franchini, Emerson, Fabio Nakamura, Monica Takito, Marian Kiss, and Stanisław Sterkowicz (1998): Specific fitness test developed in Brazilian judoists. Biology of Sport 15:165-70.

14- Franchini, Emerson, Alexandre Nunes, Josué Moraes, and Fabricio Del Vecchio (2007): Physical Fitness and Anthropometrical Profile of the Brazilian Male Judo Team. Journal of physiological anthropology 26:59-67.

15- Franchini, Emerson, Juliano Schwartz, and Monica Yuri Takito (2018): Maximal isometric handgrip strength: comparison between weight categories and classificatory table for adult judo athletes. J Exerc Rehabil 14(6):968-73.

16- Franchini, Emerson, Juliano Schwartz, and Monica Yuri Takito (2020): Maximal isometric handgrip strength in judo athletes from different age groups. Sport Sciences for Health 16(1):93-98.

17- Franchini, Emerson, Monica Takito, and Rômulo Bertuzzi (2005): Morphological, physiological and technical variables in high-level college judoists. Archives of Budo $1: 1-7$.

18- Fukuda, David, Jeffrey Stout, Patrick Burris, and Robert Fukuda (2011): Judo for Children and Adolescents: Benefits of Combat Sports. Strength \& Conditioning Journal 33:60-63.

19- Kamimura, T., and Y. Ikuta (2001): Evaluation of grip strength with a sustained maximal isometric contraction for 6 and 10 seconds. J Rehabil Med 33(5):225-29.

20- Katralli, Jayasudha, and Shivaprasad S. Goudar (2012): Anthropometric Profile and Special Judo Fitness levels of Indian Judo Players. Asian journal of sports medicine 3(2):113-18.

21- Kons, Rafael Lima, Juliano Dal Pupo, Jonathan Ache-Dias, Thyago Garcia, Romário Rodrigues da Silva, Luiz Felipe Guarise Katicips, and Daniele Detanico (2018): Effect of official judo matches on handgrip strength and perceptual responses. J Exerc Rehabil 14(1):93-99.

22- Lopes-Silva, João, Valéria Panissa, Ursula Julio, and Emerson Franchini (2018): Influence of Physical Fitness on Special Judo Fitness Test Performance - A Multiple Linear Regression Analysis. The Journal of Strength and Conditioning Research. doi:10.1519/JSC.0000000000002948.

23- Marques, V., V. Coswig, R. Viana, A. Leal, F. Alves, A. Alves, G. Teles, C. Vieira, M. Silva, D. Santos, and P. Gentil (2019): Physical Fitness and Anthropometric Measures of Young Brazilian Judo and Wrestling Athletes and Its Relations to Cardiorespiratory Fitness. Sports (Basel) 7(2).

24- Murata, Hiroko, Satomi Oshima, Suguru Torii, Motoko Taguchi, and Mitsuru Higuchi (2016): Characteristics of body composition and cardiometabolic risk of Japanese male heavyweight Judo athletes. Journal of physiological anthropology $35(1): 10$.

25- Nikolova, Anna, Diana Dimitrova, and Lubomir Mladenov (2020): AEROBIC CAPACITY OF JUDO PLAYERS SCALED FOR DIFFERENCES IN BODY SIZE. Journal of Applied Sports Sciences 2.

26- Sertić, Hrvoje, Stanisław Sterkowicz, and Dinko Vuleta (2009): Influence of latent motor abilities on performance in judo. Kinesiology 41:76-87.

27- Sterkowicz-Przybycień, Katarzyna, and David Fukuda (2014): Establishing 
Normative Data for the Special Judo Fitness Test in Female Athletes Using Systematic Review and Meta-Analysis. Journal of strength and conditioning research / National Strength \& Conditioning Association 28.

28- Sterkowicz-Przybycień, Katarzyna, Bianca Miarka, and David Fukuda (2016): Sex and Weight Category Differences in Time-Motion Analysis of Elite Judo Athletes: Implications for Assessment and Training. Journal of Strength and Conditioning Research 31:1.

29- Tomlin, D. L., and H. A. Wenger (2002): The relationships between aerobic fitness, power maintenance and oxygen consumption during intense intermittent exercise. J Sci Med Sport 5(3):194-203.

30- Torres-Luque, Gema, Hernández-García Raquel, Raquel Escobar-Molina, Nuria Garatachea, and Pantelis Nikolaidis (2016): Physical and Physiological Characteristics of Judo Athletes: An Update. Sports 4:20.

31- Trossman, Patricia B., and Ping-Wu Li (1989): The Effect of the Duration of Intertrial Rest Periods on Isometric Grip Strength Performance in Young Adults. The Occupational Therapy Journal of Research 9(6):362-78. 


\section{"Asuggest Vision For Establishing A Special Unit For Sports Shoes In The Faculties Of Physical Education In The Arab Republic Of Egypt In Light Of The 2030 Sustainable Development Goals"}

\section{Prof.Dr Rania Morsy Abo El-abas Abd El-aziz}

Professor of motor expression, Department of sport Administration \& Recreation, Assiut University-Faculty of Physical Education

\section{Dr. Naglaa Fathy Ahmed Hamdan}

Instructor of motor expression, Department of sport Administration \& RecreationFaculty of Physical Education - New Valley University

\section{Abstract}

The study aimed to develop a suggested vision for establishing a special unit for sports shows in the faculties of physical education in the Arab Republic of Egypt in light of the 2030 Sustainable Development Goals, the researcher used the descriptive approach, the sample included some university presidents and university agents for community service affairs, environmental development, deans, agents and faculty members in the faculties of physical education For community service and environmental development affairs, directors of the Department of Community Affairs and Environmental Development, the board of directors of some units in some Egyptian universities in the Arab Republic of Egypt which reached about (160) Individuals . The most important results is A suggested vision for establishing a special unit for sports shows included proposed vision, as it included the vision, mission, objectives of the unit, and the basic bylaw for establishing the unit, as it included (administrative regulation - technical regulation - Financial Regulation Legislative Regulation).

Key words: SPECIAL UNIT, SPORTS SHOES, COMMUNITY SERVICE, SELF-RESOURCES, THE 2030 SUSTAINABLE DEVELOPMENT.

\section{Introduction and research problem:}

The university is considered the basis for the progress of societies, as it is a beacon of science, research and culture, where it adopted society's thought and culture in various fields and disciplines, as the function of community service became one of the basic functions that the university undertakes to interact with society, its role is no longer limited to education and scientific research only.

It is the responsibility of the community service and environmental affairs sector in Egyptian universities to serve the community, as it undertakes many tasks and activities related to society, by establishing centers and special units in the fields of education, scientific research and community service, and these units have appeared officially according to law no. (345) of 1956, which was later replaced by Law no. (49) Of 1972, which approved the establishment of special units in the universities by a decision of the University Council, where these units provide training, research, environmental, and production services to various community institutions? (13:10) 
The concept of special units appears in the transformation of universities into an effective entity in the national economy, as the activity of self-resource development has become one of the university's responsibilities, especially with the current conditions the country is going through, and these units contribute to solving many problems, whether economic or social, so they work to confront Lack of financial resources, in order to advance the educational and research process that would serve the community, which contributes to reducing the burden on the state budget. ( $($ q: 96 )

The faculty of Physical Education is one of the educational institutions within the university, as it is the source of culture and sports enlightenment and upgrading the level of sports and athletes in society, and it will not be possible for them to upgrade this important and vital role except through improving and developing the quality of services provided in the sports field in particular and society in general, and the development of a mechanism To develop the activities of the faculty in the field of community service and environmental development, by activating the role of special units and centers for faculties, including the public service center, with the aim of providing financial support and self-financing to faculties and the university.

( ) r: 6)

In light of the above, Egyptian universities in general and faculties of physical education in particular have tended to establish special units as a necessity to provide various service activities to various society institutions, participate in the development of human resources and provide the needs of society and additional funding sources to improve the level of services in them to raise the efficiency of their outputs and maintain their entity, independence and legitimacy And increase the available means for the university to achieve its goals in serving the community and dealing with its various sectors.

All of that called for an attempt to create more special units of within the faculties of physical education, which contribute to the advancement of its various fields, including the field of sports shows, where sports shows have become (Abdel- Khalek; 2015) a free standing field in the fields of physical education, so Countries pay attention to it and has become a scientific method that scientists around the world take in research, development and innovation. ( $Y$ T: 35 )

Through the work of the two researchers as a member and body teaching and in the field of sports shows and as members of the Committee for Community Service and Environmental Development we noticed that the social services provided by faculties of physical education from public service centers are limited to some activities only 
(football, gymnastics, karate, swimming, boxing, and wrestling) without paying attention to the rest of the areas Including sports shows.

In light of the social and economic developments, the importance of the special units of in serving their society as an alternative to financing, and this was indicated in the study of (Mabrouk; 2019) ( $r$ r) and (zaham; 2016) $(r \cdot)$ about the necessity of establishment of the special units and their role should be activated as these units are The basic open-minded and interactive window with the community.

Hence the idea of this research came to a suggested vision for a special unit for sports shows in an attempt to search for new sources to contribute to the self-financing of the faculties of physical education through investing the activities of this unit and marketing its services to benefit the community.

\section{Importance and need for research:}

1- Contribute to providing new sources of self-resources for Physical Education Colleges.

2- Contributing to the development of fields related to sports shows and their workers.

3- Establishing new programs provided by the Faculties of Physical Education in the field of community service and environmental development.

\section{Research objectives:}

The research aims to develop a suggested vision for establishing a special unit for sports shows by identifying:

1- Unit name.

2- Seeing the unit.

3- Unity message.

4- Unit goals.

5- The basic bylaw for establishing the unit (administrative, technical, financial, legislative and legal).

\section{Research questions:}

1- What is the name of the unit?

2- What is the seeing of unity?

3 - What is the message of unity?

4-What are the unit goals?

5- What are the basic regulations for establishing the unit (administrative, technical, financial, legislative and legal)?

The terms mentioned in the research:

Sports Special Unit: (procedural definition) Centers and Special Units

These are independent administrative financial services systems in the field of sports shows in the faculties of physical education that contribute 
effectively to community service and self-financing and dependence on their financial resources in implementing their programs and activities.

\section{Some related studies:}

1- The study conducted by (AL Saad;2018) (1) aimed to: activating the role of units of a special nature in light of their goals and the experience of American universities, the researcher used the descriptive approach, the research sample included some units of a special nature in some colleges at Aim Shams University and Mansoura University and some university experiences In both the United States of America and Malaysia, and for students who benefit from its services, one of the most important results reached is that the units are created according to general and comprehensive planning linked to the overall development of the community surrounding universities and the achievement of the national interest, and that the programs and activities of the units are developed according to the needs of the beneficiaries of students To their satisfaction.

2- The study conducted by (Issa;2018) ( $\left.r^{\prime}\right)$ aimed to: identifying the relationship between Palestinian universities and local community institutions, the researcher used the descriptive approach, the research sample included the university president and heads of departments and director of the Community Partnership Institute in universities and some experts in civil society institutions and field work team coordinators In civil institutions in Palestine, and one of the most important results reached is the existence of strong relationships between universities and civil society institutions in the cultural, educational and social aspects, and civil society institutions play an important role in achieving sustainable development in the university work sector by providing material support to universities.

3- The study conducted by (Awad;2018) (11) aimed: identifying the role of university units of a special nature in community service and environmental development, the researcher used the descriptive approach, the sample included some units of a special nature that provide services to society and environment development in Egyptian universities, and from The most important results that were reached setting a proposed vision for developing the function of community service and developing the environment in Egyptian universities.

4- The study conducted by (Rajab;2018) $(r \wedge)$ aimed to: identifying the role of the social responsibility of the university and how it affected society, the researchers used the descriptive approach, the research sample included (UTM) University of Engineering Science and Technology in Malaysia, and one of the most important results that were 
reached It concluded that the fields of sports, recreation, health care, volunteer work, capacity building and social care were among the most important roles of the university's social responsibility towards society.

5- The study conducted by (Arnold;2018) (1•) aimed to: identifying the role of colleges in enhancing support for improving student transition after graduation to a professional life in society at Pepperdine University in the United States of America, the researcher used the descriptive approach, the research sample included some colleges and some departments in it That focuses on helping students on their trips to careers and some of the students in these departments, and one of the most important results reached is that one of the most important ways to support students is to integrate programs and activities across departments to improve the services provided.

\section{Comment on related studies:}

After examining the related studies and analyzing their data, Researchers were able to benefit from them in identifying:

1- Formulating goals and setting research questions.

2- The best suitable procedures that can help achieve the research objectives.

3- Choosing the means and tools of data collection appropriate for the current study.

\section{Research Methodology:}

The researcher used the descriptive approach as it suits the nature of the study.

\section{Research Population:}

The research Population consists of university presidents, university agents for community service affairs and environmental development, deans and agents of the college for community service and environmental development affairs, faculty members specializing in sports shows in the faculties of physical education, directors of community affairs follow-up and environmental development, and the board of directors of some special units to some Egyptian universities in the Arab Republic of Egypt.

\section{Research Sample:}

The research sample was randomly chosen from the research Population, and Table (1) shows the description of the research sample.

Table (1)

Description of the research sample

\begin{tabular}{c|l||c|c}
\hline \hline No. & \multicolumn{1}{|c||}{ Sample } & Fundamental & Exploratory \\
\hline \hline $\mathbf{1}$ & Heads of Egyptian universities. & $\mathbf{8}$ & $\mathbf{3}$ \\
\hline $\mathbf{2}$ & $\begin{array}{l}\text { Egyptian university agents for community service and } \\
\text { environmental development affairs in Egyptian universities. }\end{array}$ & $\mathbf{8}$ & $\mathbf{3}$ \\
\hline
\end{tabular}




\begin{tabular}{c|l||c|c}
\hline $\mathbf{3}$ & $\begin{array}{l}\text { deans of the faculties of physical education in the Egyptian } \\
\text { universities }\end{array}$ & $\mathbf{1 2}$ & $\mathbf{4}$ \\
\hline $\mathbf{4}$ & $\begin{array}{l}\text { agents of faculties of physical education for community service } \\
\text { and environmental development affairs in Egyptian universities }\end{array}$ & $\mathbf{1 2}$ & $\mathbf{4}$ \\
\hline $\mathbf{5}$ & $\begin{array}{l}\text { members of the teaching staff who specialize in sports shows in } \\
\text { faculties of physical education. }\end{array}$ & $\mathbf{3 0}$ & $\mathbf{6}$ \\
\hline $\mathbf{6}$ & $\begin{array}{l}\text { directors of the Department of Community Affairs and } \\
\text { Environmental Development in the Egyptian universities. }\end{array}$ & $\mathbf{1 0}$ & $\mathbf{5}$ \\
\hline $\mathbf{7}$ & $\begin{array}{l}\text { members of the Board of Directors of the special units in the } \\
\text { Egyptian universities. }\end{array}$ & $\mathbf{8 0}$ & $\mathbf{5}$ \\
\hline \hline & Total & $\mathbf{1 6 0}$ & $\mathbf{3 0}$ \\
\hline \hline
\end{tabular}

\section{Tools of Data collection:}

1- The regulations of some Egyptian universities and colleges for units of a special nature

2- The Egyptian Universities Organization Law and its executive regulations

3- The questionnaire:

\section{- The questionnaire:}

Based on the research problem and its objectives, the two researchers designed number (2) questionnaires to identify:

1- The name, seeing, message and goals of the unit.

2- The unit's basic bylaw (administrative - technical - financial - legal and legislative).

\section{1- The name, seeing, message and goals of the unit.}

\section{First: Defining the axes of the questionnaire:}

To determine the scientific references and related studies and some regulations for special units were analyzed, where (4) axes were reached, and then presented to the experts attached (1) to express their views on them.

Table (2)

The percentage of expert opinions on the questionnaire's axes $(n=8)$

\begin{tabular}{c|lc||c}
\hline \hline No. & \multicolumn{1}{c||}{ Suggested axes } & percentage \\
\hline \hline $\mathbf{1}$ & Unit name. & $\mathbf{1 0 0 \%}$ \\
\hline $\mathbf{2}$ & Seeing the unit. & $\mathbf{1 0 0 \%}$ \\
\hline $\mathbf{3}$ & Unity message. & $\mathbf{1 0 0 \%}$ \\
\hline $\mathbf{4}$ & Unit goals. $\quad$ ALL & $\mathbf{1 0 0 \%}$ \\
\hline \hline
\end{tabular}

Table (2) showed that the experts agree on all the proposed axes. Second: Preparing phrases of the Questionnaire:

The questionnaire was put in its initial form attachment (3), which included (4) phrases, and then it was presented to the experts Attachment (1). 
Table (3)

The percentage of expert opinions on the questionnaire's ferries $(n=8)$

\begin{tabular}{|c|c|c|c|}
\hline Axes & NO & Ferries & $\%$ \\
\hline Unit name: & 1 & Scientific Center for Sports Shows. & $100 \%$ \\
\hline $\begin{array}{c}\text { Seeing the } \\
\text { unit: }\end{array}$ & 2 & $\begin{array}{l}\text { The Scientific Center for Sports Shows is a leading center at the local and } \\
\text { regional levels in providing administrative and technical services and } \\
\text { consultations for sports shows. }\end{array}$ & $100 \%$ \\
\hline $\begin{array}{c}\text { Unity } \\
\text { message: }\end{array}$ & 3 & $\begin{array}{l}\text { The center seeks to provide services to individuals and various institutions inside } \\
\text { and outside the university in the field of Sports Shows to meet the diverse needs } \\
\text { of society. }\end{array}$ & $100 \%$ \\
\hline \multirow{4}{*}{ Unit goals: } & 4 & $\begin{array}{l}\text { Conducting scientific research in the field of sports performances } \\
\text { Marketing of Sports Shows. }\end{array}$ & $100 \%$ \\
\hline & 5 & Providing administrative and technical consultations in the field of Sports Shows. & $100 \%$ \\
\hline & 6 & Providing training programs and courses in the field of sports shows. & $100 \%$ \\
\hline & 7 & Holding scientific seminars and conferences in the field of Sports Shows. & $100 \%$ \\
\hline
\end{tabular}

Table (3) showed that the experts agree on all the all suggested phrases.

\section{Third: The Exploratory Study:}

The Researchers conducted an exploratory study on a sample of (30) from the research population and outside the basic research sample.

Fourth: The scientific transactions of the questionnaire:

\section{1- Validity:}

The Researchers applied the questionnaire to the survey sample and calculated the correlation coefficient between the degree of the single phrase and the total degree of the axis to which it belongs, as well as calculating the correlation coefficient between the degree of the single axis and the total degree of the questionnaire.

\section{Table (4)}

Correlation coefficient between phrases and the overall degree of the axis to which you belong (n $=30$ )

\begin{tabular}{|c|c|c|c|}
\hline Axes & NO & Ferries & COR. \\
\hline Unit name: & 1 & Scientific Center for Sports Shows. & $* *, \vee r q$ \\
\hline $\begin{array}{l}\text { Seeing the } \\
\text { unit: }\end{array}$ & 2 & $\begin{array}{l}\text { The Scientific Center for Sports Shows is a leading center at the local and } \\
\text { regional levels in providing administrative and technical services and } \\
\text { consultations for sports shows. }\end{array}$ & $* *,, \vee \vee 1$ \\
\hline $\begin{array}{l}\text { Unity } \\
\text { message: }\end{array}$ & 3 & $\begin{array}{l}\text { The center seeks to provide services to individuals and various institutions } \\
\text { inside and outside the university in the field of Sports Shows to meet the } \\
\text { diverse needs of society. }\end{array}$ & $* *, \wedge) 1$ \\
\hline \multirow{4}{*}{ Unit goals: } & 4 & $\begin{array}{l}\text { Conducting scientific research in the field of sports performances } \\
\text { Marketing of Sports Shows. }\end{array}$ & $* *,, \vee \neg \leq$ \\
\hline & 5 & $\begin{array}{l}\text { Providing administrative and technical consultations in the field of Sports } \\
\text { Shows. }\end{array}$ & $* *, \wedge 9 \varepsilon$ \\
\hline & 6 & Providing training programs and courses in the field of sports shows. & $* *, \wedge \neg 7$ \\
\hline & 7 & Holding scientific seminars and conferences in the field of Sports Shows. & $* *, \vee \vee \wedge \neg$ \\
\hline
\end{tabular}

It is clear from Table (4) that the correlation coefficient between the expressions and the overall degree of the axis to which it belongs ranges 
between $(\bullet, \vee \curlyvee 9 * *$ : $0 . \wedge 9 \leqslant * *)$ and all these statements are statistically significant at the level (0.05), which indicates the validity of the questionnaire.

\section{2- Stability:}

The Researchers calculated the stability coefficient for the questionnaire using the "Alpha Cronbach" factor, by calculating the alpha coefficient for each axis as well as for the questionnaire as a whole.

Table (5)

Calculation of stability using the alpha and mid-segmentation coefficients of the survey axes $(\mathbf{n}=30)$

\begin{tabular}{|c|c|c|c|c|c|}
\hline \multirow{2}{*}{ No. } & \multirow{2}{*}{ Axes } & \multirow{2}{*}{ Alpha } & \multirow{2}{*}{ COR. } & \multicolumn{2}{|c|}{ FIX.FAS. } \\
\hline & & & & SP.- BRO. & GETT \\
\hline & $\overline{\text { ALL }}$ & $\overline{c \cdot, \wedge 65}$ & $2,7,749$ & '•,857 & $\overline{c, \wedge 45}$ \\
\hline
\end{tabular}

It is clear from Table (5) which are statistically significant coefficients at (0.05) level, which indicates that the questionnaire has high stability coefficients.

\section{Fifth: The application of the questionnaire:}

After confirming the scientific transactions of the questionnaire, the questionnaire was applied in its final form attachment (4) to the basic sample in the period form $1 / 9 / r \cdot 19$ to $30 / 11 / 2019$.

2- The unit's basic bylaw (administrative - technical - financial - legal and legislative).

First: Defining the axes of the questionnaire:

To determine the scientific references and related studies were analyzed, where (4) axes were reached, and then presented to the experts attached (1) to express their views on them.

\section{Table (6)}

The percentage of expert opinions on the questionnaire's axes $(n=8)$

\begin{tabular}{|c|c|c|c|c|}
\hline No. & Suggested axes & W.S & W.S.D & percentage \\
\hline \multicolumn{2}{|c|}{ The first axis: administrative regulation } & $r, 99$ & $1, \ldots$ & $99,0 \leq$ \\
\hline 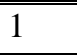 & Organizational structure of the unit & r,q1 & $\cdot, 9 \mathrm{~V}$ & qV,Ir \\
\hline 2 & Jurisdictions of the board of the unit & r, $9 \leq$ & $\cdot, 9 \wedge$ & $9 \wedge, 11$ \\
\hline \multicolumn{2}{|c|}{ Second axis: technical regulation } & r,qr & $\cdot, 9 \mathrm{~V}$ & $9 \vee, \varepsilon$. \\
\hline 3 & Establishment goals of the unit & 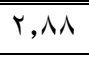 & $\cdot, 97$ & $90, \wedge r$ \\
\hline 4 & Rules and principles of the unit & r,9V & $\cdot, 99$ & 91,97 \\
\hline 5 & Tasks and activities of the unit & r,qr & $\cdot, 91$ & $9 \vee, V T$ \\
\hline \multicolumn{2}{|c|}{ Third axis: financial regulation } & $r, q \mathrm{~V}$ &., 99 & $99, \cdots$ \\
\hline \multicolumn{2}{|c|}{ Fourth axis : legislative regulation } & $r, \ldots$ & $1, \ldots$ & $1 \ldots, \ldots$ \\
\hline & ALL & $Y, 97$ & $\cdot, 99$ & $9 \wedge, 01$ \\
\hline
\end{tabular}

Table (6) showed that the percentage of experts agreeing on the axes ranged (97.12\%: 100\%), and thus all the proposed axes were approved.

\section{Second: Preparing phrases of the Questionnaire:}

The questionnaire was put in its initial form attachment (6), which 
included (90) phrases, and then it was presented to the experts Attachment (1).

Table (7)

The percentage of expert opinions on the questionnaire's ferries $(n=8)$

\begin{tabular}{|c|c|c|c|c|c|c|c|c|c|c|c|c|}
\hline Axes & NO & $\%$ & NO & $\%$ & NO & $\%$ & NO & $\%$ & NO & $\%$ & NO & $\%$ \\
\hline \multirow{4}{*}{$\begin{array}{l}\text { The first } \\
\text { axis: } \\
\text { administr } \\
\text { ative } \\
\text { regulation }\end{array}$} & 1 & $100 \%$ & 2 & $87.5 \%$ & 3 & $100 \%$ & 4 & $100 \%$ & 5 & $\% 100$ & 6 & $100 \%$ \\
\hline & 7 & $100 \%$ & 8 & $100 \%$ & 9 & $100 \%$ & 10 & $87.5 \%$ & 11 & $100 \%$ & 12 & $100 \%$ \\
\hline & 13 & $100 \%$ & 14 & $87.5 \%$ & 15 & $100 \%$ & 16 & $87.5 \%$ & 17 & $87.5 \%$ & 18 & $100 \%$ \\
\hline & 19 & $100 \%$ & 20 & $100 \%$ & 21 & $87.5 \%$ & 22 & $100 \%$ & & & & \\
\hline \multirow{6}{*}{$\begin{array}{l}\text { Second } \\
\text { axis: } \\
\text { technical } \\
\text { regulation }\end{array}$} & 23 & $100 \%$ & 24 & $100 \%$ & 25 & $100 \%$ & 26 & $100 \%$ & 27 & $100 \%$ & 28 & $100 \%$ \\
\hline & 29 & $87.5 \%$ & 30 & $87.5 \%$ & 31 & $87.5 \%$ & 32 & $100 \%$ & 33 & $100 \%$ & 34 & $100 \%$ \\
\hline & 35 & $100 \%$ & 36 & $100 \%$ & 37 & $100 \%$ & 38 & $100 \%$ & 39 & $100 \%$ & 40 & $100 \%$ \\
\hline & 41 & $100 \%$ & 42 & $100 \%$ & 43 & $100 \%$ & 44 & $100 \%$ & 45 & $100 \%$ & 46 & $100 \%$ \\
\hline & 47 & $87.5 \%$ & 48 & $100 \%$ & 49 & $100 \%$ & 50 & $87.5 \%$ & 51 & $100 \%$ & 52 & $100 \%$ \\
\hline & 53 & $100 \%$ & 54 & $100 \%$ & 55 & $100 \%$ & & & & & & \\
\hline \multirow{5}{*}{$\begin{array}{l}\text { Third axis: } \\
\text { financial } \\
\text { regulation }\end{array}$} & 56 & $100 \%$ & 57 & $100 \%$ & 58 & $87.5 \%$ & 59 & $100 \%$ & 60 & $100 \%$ & 61 & \\
\hline & 62 & $87.5 \%$ & 63 & $87.5 \%$ & 64 & $100 \%$ & 65 & $100 \%$ & 66 & $87.5 \%$ & 67 & $87.5 \%$ \\
\hline & 68 & $100 \%$ & 69 & $87.5 \%$ & 70 & $100 \%$ & 71 & $100 \%$ & 72 & $100 \%$ & 73 & $87.5 \%$ \\
\hline & 74 & $87.5 \%$ & 75 & $87.5 \%$ & 76 & $100 \%$ & 77 & $100 \%$ & 78 & $100 \%$ & 79 & $100 \%$ \\
\hline & 80 & $100 \%$ & & & & & & & & & & \\
\hline \multirow{3}{*}{$\begin{array}{l}\text { Fourth axis } \\
\text { : legislative } \\
\text { regulation }\end{array}$} & 81 & $100 \%$ & 82 & $87.5 \%$ & 83 & $100 \%$ & 84 & $87.5 \%$ & 85 & $87.5 \%$ & 86 & \\
\hline & 87 & $87.5 \%$ & 88 & $100 \%$ & 89 & $100 \%$ & 90 & $87.5 \%$ & 91 & $100 \%$ & 92 & \\
\hline & 93 & $100 \%$ & 94 & $100 \%$ & 95 & $100 \%$ & & & & & & \\
\hline
\end{tabular}

It is clear from Table (7) the percentage of expert opinions ranged between $(87.5 \%: 1 \cdots \%)$, as all the proposed phrases were agreed upon.

\section{Third: The Exploratory Study:}

The Researchers conducted an exploratory study on a sample of (30) from the research population and outside the basic research sample.

\section{Fourth: The scientific transactions of the questionnaire:}

\section{1- Validity:}

The Researchers applied the questionnaire to the survey sample and calculated the correlation coefficient between the degree of the single phrase and the total degree of the axis to which it belongs, as well as calculating the correlation coefficient between the degree of the single axis and the total degree of the questionnaire.

Table (8)

Correlation coefficient between phrases and the overall degree of the axis to which you belong (n $=30$ )

\begin{tabular}{|c|c|c|c|c|c|c|c|c|c|}
\hline NO & COR. & NO & COR. & NO & COR. & NO & COR. & NO & COR. \\
\hline \multicolumn{2}{|c|}{ Organizational } & 19 & $* *,, \vee \circ \leq \leqslant$ & rV & $* *,, \vee \vee \neg$ & \multicolumn{2}{|c|}{ financial } & $V 7$ & $* *,, \wedge \leq \varepsilon$ \\
\hline 1 & $* *, V \leq 0$ & $r$. & $* *, 9,1$ & r & $* *, \vee \vee \wedge \varepsilon$ & 07 & $* *,, \vee \wedge \varepsilon$ & $V V$ & $* *, \vee \vee \varepsilon$. \\
\hline
\end{tabular}




\begin{tabular}{|c|c|c|c|c|c|c|c|c|c|}
\hline$r$ & $* *,, \vee \circ \leq$ & YI & $* *,, \vee \circ \wedge$ & rq & $* *,, \vee 90$ & ov & $* *,, \vee \circ \leq$ & V^ & $* *,, \vee \neg 9$ \\
\hline$r$ & $* *, \wedge \cdot 1$ & rr & $* *,, \vee 0 \leq$ & \multicolumn{2}{|c|}{$\begin{array}{c}\text { Tasks and } \\
\text { activities } \\
\end{array}$} & $0 \wedge$ & 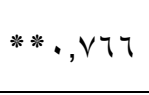 & $\vee q$ & $* *,, \vee \wedge \wedge$ \\
\hline$\varepsilon$ & $* *,, 709$ & \multicolumn{2}{|c|}{ goals } & $\varepsilon$ & $* *, \wedge r\urcorner$ & 09 & **,, ו ו & $\wedge$ & $* *,, \vee 00$ \\
\hline 0 & $* *, v \cdot 1$ & rr & $* *, V Y I$ & $\varepsilon 1$ & $* *, \wedge) \leq$ & 7. & $* *, \wedge I r$ & \multicolumn{2}{|c|}{ Legislative } \\
\hline 7 & $* *, \vee \vee \vee q$ & $r \leq$ & $* *, \vee \vee 79$ & $\varepsilon r$ & $* *,, \vee 0 \varepsilon$ & 71 & $* *, \vee \vee T 1$ & $\wedge 1$ & $* *, \wedge \leq \vee$ \\
\hline V & **, , VTr & ro & $* *, \wedge I r$ & $\varepsilon r$ & $* *, \vee \vee \wedge \wedge$ & Tr & $* *, \vee \backslash 1$ & Nr & $* *,, \vee 07$ \\
\hline$\wedge$ & $* *, \vee \vee \leqslant 9$ & $r$ & $* *, 9 \cdot 1$ & $\varepsilon \varepsilon$ & $* *, v \leq 1$ & תוד & $* *, \wedge \cdot \varepsilon$ & N & $* *, \vee \vee \wedge \varepsilon$ \\
\hline 9 & $* *, \wedge 01$ & rV & $* *, \wedge 97$ & $\varepsilon 0$ & $* *, 7 \wedge 9$ & $7 \leq$ & $* *, 9 \ldots$ & $\wedge \varepsilon$ & $* *, \wedge \wedge \varepsilon$ \\
\hline \multicolumn{2}{|c|}{ Jurisdictions } & rᄉ & $* *, \Lambda r r$ & $\leqslant 7$ & $* *$, , vor & 70 & $* *,, \uparrow \wedge \vee$ & 10 & $* *,, \vee \vee \varepsilon$ \\
\hline 1 & $* *, \vee \vee ० 9$ & rq & $* *, \vee v \leq 1$ & $\varepsilon V$ & $* *, \vee \vee 9 \wedge$ & $7 V$ & $* *, \vee \vee \wedge \varepsilon$ & 17 & $* *, 901$ \\
\hline 11 & **, • & r. & $* *,, \vee 00$ & $\varepsilon \wedge$ & $* *,, \vee 00$ & 71 & $* *$, , $\vee 07$ & $\Lambda V$ & $* *,, 70 \mathrm{~V}$ \\
\hline ir & $* *, \wedge I r$ & \multicolumn{2}{|c|}{ Rules } & $\leqslant 9$ & $* *, V Y T$ & 79 & $* *,, \vee \wedge I$ & $\wedge \wedge$ & $* *, \wedge \leq 0$ \\
\hline r & $* *, \vee \vee \backslash 0$ & ו & **, • & 0. & $* *,, \vee \neg \wedge$ & $v \cdot$ & $* *,, V \vee r$ & 19 & $* *,, \vee \circ \wedge$ \\
\hline $1 \leq$ & $* *, \wedge) \leq$ & r & $* *, \wedge \wedge r$ & 01 & **, , & $v_{1}$ & $* *, \vee \vee \vee$ & 9. & $* *, \wedge \wedge r$ \\
\hline 10 & **, • & سץ & $* *, \vee \vee \neg 7$ & or & $* *,, \vee>0$ & VY & $* *, \wedge) \leq$ & 91 & $* *,, \vee \neg 0$ \\
\hline 17 & $* *, \wedge 11$ & $r \varepsilon$ & $* *,, \vee \backslash 9$ & or & $* *,, \vee ৭ \wedge$ & $v r$ & $* *, \vee \vee ৭ 9$ & $q r$ & $* *,, \vee \circ \leq$ \\
\hline iv & $* *$, , vor & ro & $* *, \wedge \backslash \vee$ & $0 \leqslant$ & $* *, V \backslash)$ & $v \leq$ & $* *, \vee \vee \neg \wedge$ & מי & $* *, V \backslash Y$ \\
\hline \multirow[t]{2}{*}{11} & $* *, 91 \leq$ & דr & $* * \cdot, V T V$ & 00 & $* *$, VYO & vo & $* *, \wedge \leq 0$ & $9 \leq$ & $* *,, \vee \cdots$ \\
\hline & & & & & & & & 90 & $* *,, \vee \wedge \varepsilon$ \\
\hline
\end{tabular}

It is clear from Table (8) that the correlation coefficient between the expressions and the overall degree of the axis to which it belongs ranges between $(\cdot, 709 * *$ : $0.914 * *)$ and all these statements are statistically significant at the level (0.05), which indicates the validity of the questionnaire.

Table (9)

Correlation coefficient between axes and the overall score of the questionnaire $(n=30)$

\begin{tabular}{c||l||c}
\hline \hline No. & \multicolumn{1}{|c||}{ Axes } & CORR.COE \\
\hline \hline $\mathbf{1}$ & The first axis: administrative regulation. & $* * 0.884$ \\
\hline $\mathbf{2}$ & Second axis: technical regulation. & $* *,, \vee \uparrow \varepsilon$ \\
\hline $\mathbf{3}$ & Third axis: financial regulation. & $* *$, ヘ $~$ \\
\hline $\mathbf{4}$ & Fourth axis: legislative regulation. & $* *$, q) \\
\hline \hline
\end{tabular}

It is clear from Table ( 9 ) that the correlation coefficient between the expressions and the overall degree of the axis to which it belongs ranges between $\left(0.764 * *\right.$ : $\left.0.912^{* *}\right)$ and all these statements are statistically significant at the level (0.05), which indicates the validity of the questionnaire. 


\section{2- Stability:}

The Researchers calculated the stability coefficient for the questionnaire using the "Alpha Cronbach" factor, by calculating the alpha coefficient for each axis as well as for the questionnaire as a whole.

$$
\text { Table (1.) }
$$

Calculation of stability using the alpha and mid-segmentation coefficients of the survey axes $(\mathbf{n}=30)$

\begin{tabular}{|c|c|c|c|c|c|}
\hline \multirow{2}{*}{ No. } & \multirow{2}{*}{ Axes } & \multirow{2}{*}{ Alpha } & \multirow{2}{*}{ COR. } & \multicolumn{2}{|c|}{ FIX.FAS. } \\
\hline & & & & SP.- BRO. & GETT. \\
\hline$\overline{1}$ & administrative regulation & $\cdot \overline{\cdot ., \Lambda \vee r ~}$ & $\cdot, \wedge \cdot 0$ & $\cdot, \wedge 9 Y$ & $\cdot, \wedge 9 \mathrm{r}$ \\
\hline 2 & technical regulation & $\cdot, V Y \cdot$ & $\cdot, 7 \times 1$ & $\cdot, \Lambda \cdot r$ & $\cdot, \vee \vee \wedge$ \\
\hline 3 & financial regulation & $\cdot, \wedge \wedge$. & $\cdot, \vee \Gamma \wedge$ & $\cdot, \wedge \leqslant 9$ & $\cdot, \wedge \cdots$ \\
\hline 4 & legislative regulation & $\cdot, \wedge \backslash \wedge$ & $\cdot, 70 Y$ & $\cdot, \vee \vee 9$. & $\cdot, \vee \wedge \varepsilon$ \\
\hline & $\mathbf{A L L}$ & $\cdot, 9 \%$ & $\cdot, \wedge \wedge \vee$ & $\cdot, 9 \leq$. & $\cdot 949$ \\
\hline
\end{tabular}

It is clear from Table $(1 \cdot)$ that the alpha coefficient of the axes ranged between (0.652: 0.940), the midterm fragmentation ranged from $(\cdot, \wedge \cdot r: 0.940)$ using Spearman, $(\cdot, \wedge . .:$ q q) using gtman, which are statistically significant coefficients at (0.05) level, which indicates that the questionnaire has high stability coefficients.

\section{Fifth: The application of the questionnaire:}

After confirming the scientific transactions of the questionnaire, the questionnaire was applied in its final form attachment (4) to the basic sample in the period form $1 / 9 / r_{.1} 9$ to $30 / 11 / r \cdot 19$.

\section{Statistical treatments for data:}

(Percentage - correlation coefficient - alpha- Cronbach - mean - standard deviation - estimated degree).

\section{Presentation, interpretation and discussion of results:}

Within the limits of the results of the two researchers and according to the study sample and data collection tools, the discussion of the results will be presented and interpreted in a way that is consistent with the aim of the research.

\section{1-What is the name, vision, mission and objectives of the unit of a special nature for the sports shows?}

\section{Table (11)}

Weighted mean and percentage of sample opinions on the questionnaire $(n=$ 160)

\begin{tabular}{|c|c|c|c|c|c|c|c|}
\hline \multirow{2}{*}{ No. } & \multirow{2}{*}{ ferries } & \multicolumn{3}{|c|}{ opinions } & \multirow{2}{*}{ W.S } & \multirow{2}{*}{ W.S.D } & \multirow{2}{*}{ percentage } \\
\hline & & AP. & S.AP. & 1.AP & & & \\
\hline 1 & Scientific Center for Sports Shows. & 17. & - & . & r, & $1, \ldots$ & $1 \ldots \%$ \\
\hline 2 & $\begin{array}{l}\text { The Scientific Center for Sports Shows is a } \\
\text { leading center at the local and regional } \\
\text { levels in providing administrative and } \\
\text { technical services and consultations for } \\
\text { sports shows. }\end{array}$ & 17. & • & • & $r, \ldots$ & $1, \cdots$ & $1 \ldots \%$ \\
\hline
\end{tabular}




\begin{tabular}{|c|c|c|c|c|c|c|c|}
\hline 3 & $\begin{array}{l}\text { The center seeks to provide services to } \\
\text { individuals and various institutions inside } \\
\text { and outside the university in the field of } \\
\text { Sports Shows to meet the diverse needs of } \\
\text { society. }\end{array}$ & 17. & . & . & $r, .$. & $1, \ldots$ & $1 \ldots \%$ \\
\hline 4 & $\begin{array}{l}\text { Conducting scientific research in the field of } \\
\text { sports performances } \\
\text { Marketing of Sports Shows. }\end{array}$ & $1 \leq 0$ & 0 & 1. & $r, \wedge \varepsilon$ & $\cdot, 90$ & $৭ \leqslant, \vee ৭ \%$ \\
\hline 5 & $\begin{array}{l}\text { Providing administrative and technical } \\
\text { consultations in the field of Sports Shows. }\end{array}$ & TrT & IV & 1. & $r, V V$ & -,94 & $৭$ ৭, ४৭\% \\
\hline 6 & $\begin{array}{l}\text { Providing training programs and courses in } \\
\text { the field of sports shows. }\end{array}$ & IT. & 17 & $1 \varepsilon$ & $r, V r$ & $\cdot, 91$ & Q., ৯r\% \\
\hline 7 & $\begin{array}{l}\text { Holding scientific seminars and conferences } \\
\text { in the field of Sports Shows. }\end{array}$ & 17. & . & $\cdot$ & $r,$. & $1, \ldots$ & $1 \ldots \%$ \\
\hline
\end{tabular}

It is clear from table ( 11$)$ that the responses of the opinions of the research sample about the questionnaire, where the percentage of phrases ranged between ( 9 r. $99 \%$ : 100\%).

By presenting the opinions of the responses of the research sample in a table ( $\mathrm{Y}$ ), it is possible to explain and discuss some of the results that have been reached:

- A name was chosen for the unit, and a vision, mission, and goals were set forth in commensurate with it Services and activities provided by the unit.

This is in agreement with the findings of a study (Aal Saad; 2018) (1).

2- What are the basic regulations for establishing the unit (administrative, technical, financial, legislative and legal)?

Table (12)

Weighted mean and percentage of sample opinions on the questionnaire $(n=$ 160)

\begin{tabular}{|c|c|c|c|c|c|c|c|}
\hline$\overline{1}$ & Dean of the College (Chairman). & 17. & $\cdot$ & 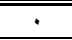 & $\bar{r}+, \cdots$ & $1, \cdots$ & $1 \cdots, \cdots$ \\
\hline 3 & Unit Director (member). & 17. & $\cdot$ & . & $r, \cdots$ & $1, \cdots$ & $1 \cdots, \cdots$ \\
\hline 6 & $\begin{array}{l}2 \text { members with technical experience in the field } \\
\text { (member). }\end{array}$ & 17. & • & · & $r, \ldots$ & $1, \ldots$ & $1 \cdots, \cdots$ \\
\hline 7 & The financial officer of the unit. & 17. & $\cdot$ & $\cdot$ & $r, \cdots$ & $1, \cdots$ & $1 \cdots, \cdots$ \\
\hline 8 & The administrative officer of the unit. & 17. & $\cdot$ & $\cdot$ & $r, \ldots$ & $1, \cdots$ & $1 \cdots, \cdots$ \\
\hline 9 & $\begin{array}{l}\text { Public Relations, Advertising, Media and Marketing } \\
\text { Unit Officer. }\end{array}$ & $1 \ldots$ & £० & 10 & r,or & $\cdot, \wedge \varepsilon$ & $\wedge \varepsilon, \Gamma \wedge$ \\
\hline 11 & $\begin{array}{l}\text { Defining the terms of reference and responsibilities and } \\
\text { describing the workers inside the unit. }\end{array}$ & 17. & · & • & $r, \ldots$ & $1, \cdots$ & $1 \cdots, \cdots$ \\
\hline 12 & $\begin{array}{l}\text { Approving the general budget project, the final } \\
\text { account, and the financial position of the unit. }\end{array}$ & 17. & • & • & $r, \ldots$ & $1, \ldots$ & $1, \ldots$ \\
\hline 13 & $\begin{array}{l}\text { Setting the annual plan for activities and programs } \\
\text { according to the needs of the community. }\end{array}$ & 17. & • & • & $r, \ldots$ & $1, \cdots$ & $1 \cdots, \cdots$ \\
\hline 14 & Carrying out all work inside the unit. & 17. & . & . & $r, \ldots$ & $1, \cdots$ & $1 \ldots, \cdots$ \\
\hline
\end{tabular}




\begin{tabular}{|c|c|c|c|c|c|c|c|}
\hline 15 & $\begin{array}{l}\text { Prepare a private database or records of activities and } \\
\text { programs. }\end{array}$ & וr. & 17 & $1 \leq$ & r, & $\cdot, 91$ & q., הr \\
\hline 16 & $\begin{array}{l}\text { Selection of the work team involved in implementing } \\
\text { programs and activities within the unit. }\end{array}$ & 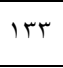 & iv & $1 \cdot$ & r,, $\mathrm{V}$ & $\cdot, 94$ & 9 १, rq \\
\hline 17 & Preparing work progress reports within the unit. & $1 \leqslant 0$ & $\circ$ & $1 \cdot$ & $r, \wedge \varepsilon$ & $\cdot, 90$ & $9 \leqslant, \vee 9$ \\
\hline 18 & $\begin{array}{l}\text { Approving the administrative, financial and technical } \\
\text { regulations within the unit. }\end{array}$ & 17. & • & • & $r, \ldots$ & $1, \ldots$ & $1, \ldots$ \\
\hline 19 & $\begin{array}{l}\text { Approval of agreements and contracts with other } \\
\text { parties after approval of the competent authorities. }\end{array}$ & iro & ro & $1 \cdot$ & r, Vr & $\cdot, 91$ & $9 \cdot, 7 r$ \\
\hline
\end{tabular}

\section{Follow Table (12)}

Weighted mean and percentage of sample opinions on the questionnaire $(n=$ 160)

\begin{tabular}{|c|c|c|c|c|c|c|c|}
\hline \multirow{2}{*}{ No. } & \multirow{2}{*}{ ferries } & \multicolumn{3}{|c|}{ opinions } & \multirow{2}{*}{ W.S } & \multirow{2}{*}{ W.S.D } & \multirow{2}{*}{ percentage } \\
\hline & & AP. & S.AP. & 1.AP & & & \\
\hline 20 & $\begin{array}{l}\text { Determine the aspects of spending for expenses and } \\
\text { revenues in light of resources. }\end{array}$ & 100 & r & r & r,97 & $\cdot, 99$ & $9 \wedge, 0 \leqslant$ \\
\hline 21 & $\begin{array}{l}\text { Propose amendments and proposals to present them to } \\
\text { the competent authorities. }\end{array}$ & IrA & it & r. & $r, 7 \uparrow$ & $\cdot, \wedge 9$ & $\wedge 9,1 \mathrm{~V}$ \\
\hline 22 & $\begin{array}{l}\text { The representative nominates the unit for assignments, } \\
\text { meetings, seminars and conferences. }\end{array}$ & $1 \ldots$ & ro & ro & $r, \leqslant V$ & $\cdot$, Ar & $\Lambda Y, r q$ \\
\hline & Jurisdictions of the board of the unit & $1 \wedge \vee 7$ & 114 & 91 & Y,А५ & $\cdot, 90$ & $90, Y V$ \\
\hline & The first axis: administrative regulation & rYOT & 101 & 1.7 & r,^q & $\cdot, 97$ & $94,0$. \\
\hline 23 & $\begin{array}{l}\text { Strengthening ties between the college and external } \\
\text { institutions and bodies. }\end{array}$ & 17. & · & · & $r, \ldots$ & $1, \ldots$ & $1 \ldots, \ldots$ \\
\hline 24 & $\begin{array}{l}\text { Contribute to the implementation of college projects in } \\
\text { the field of sports shows. }\end{array}$ & 17. & . & · & $r, \ldots$ & $1, \ldots$ & $1 \cdots, \ldots$ \\
\hline 25 & $\begin{array}{l}\text { Assisting the college in teaching and training students } \\
\text { in the field of sports shows. }\end{array}$ & $1 \leqslant V$ & IT & · & r, 9 r & $\cdot, 9 \vee$ & $9 \vee, Y q$ \\
\hline 26 & $\begin{array}{l}\text { Helping external bodies in training workers in the field } \\
\text { of sports shows }\end{array}$ & Tra & 1. & $1 \varepsilon$ & $r, V \uparrow$ & $\cdot, 94$ & $9 r, \cdot 1$ \\
\hline 27 & Conducting scientific research in the field of sports. & 90 & 10 & $\varepsilon$. & $r, r V$ & $\cdot, \times 9$ & $\vee \wedge, \wedge 9$ \\
\hline 28 & Contribute to the development of science related . & 91 & $\varepsilon$. & Tr & $r, \leqslant \wedge$ & $\cdot, \wedge r$ & NY,O. \\
\hline 29 & $\begin{array}{l}\text { Helping external bodies with scientific methods in the } \\
\text { field of sports shows. }\end{array}$ & 17. & · & • & $r, \ldots$ & $1, \ldots$ & $1 \ldots, \ldots$ \\
\hline 30 & $\begin{array}{l}\text { Contribute to training members of society through } \\
\text { scientific methods. }\end{array}$ & $1 \leqslant \Lambda$ & r & 1. & r,人 & $\cdot, 90$ & $90, \varepsilon r$ \\
\hline & Establishment goals of the unit & $11 \cdot \leq$ & $\Lambda$. & $\wedge \uparrow$ & $r, \wedge$. & $\cdot, 94$ & qr,rq \\
\hline 31 & $\begin{array}{l}\text { Supporting and maximizing the role of colleges of } \\
\text { physical education towards society and environmental } \\
\text { development. }\end{array}$ & 17. & · & · & $r, \ldots$ & $1, \ldots$ & $1, \ldots$ \\
\hline 32 & $\begin{array}{l}\text { Maximizing the role of sports shows in community } \\
\text { service and environmental development. }\end{array}$ & 17. & . & · & $r, \ldots$ & $1, \cdots$ & $1 \cdots, \ldots$ \\
\hline 33 & $\begin{array}{l}\text { Promoting the educational, research and applied } \\
\text { process in the field of sports shows. }\end{array}$ & $9 \wedge$ & 纟o & iv & $r, 01$ & $\cdot, \wedge \varepsilon$ & $\Lambda T, 0 \leqslant$ \\
\hline 34 & Linking theory to practice in sports shows. & 17. & $\cdot$ & $\cdot$ & $r, \ldots$ & $1, \cdots$ & $1 \cdots, \cdots$ \\
\hline 35 & $\begin{array}{l}\text { Highlighting the value of science and its importance in } \\
\text { working life in the field of sports shows. }\end{array}$ & 1.0 & $\varepsilon$. & 10 & r,07 & $\cdot, \wedge 0$ & $10, \leqslant Y$ \\
\hline 36 & $\begin{array}{l}\text { Increasing students' skills while studying in the field of } \\
\text { sports shows. }\end{array}$ & $1 \cdots$ & ro & ro & $r, \leqslant V$ & $\cdot, \wedge r$ & $\Lambda Y, r q$ \\
\hline 37 & Raising the efficiency of workers in the field of offers. & 100 & 0 & $\cdot$ & r,9V & $\cdot, 99$ & $9 \wedge, 97$ \\
\hline 38 & $\begin{array}{l}\text { Opening new horizons for work in the field of sports } \\
\text { shows. }\end{array}$ & 17. & · & • & $r, \ldots$ & $1, \ldots$ & $1, \ldots$ \\
\hline 39 & $\begin{array}{l}\text { Providing new resources to increase the self-resources } \\
\text { of physical education colleges. }\end{array}$ & 17. & . & - & $r,$. & $1, \cdots$ & $1, \ldots$ \\
\hline \multicolumn{2}{|r|}{ Rules and principles of the unit } & $1 Y 01$ & iro & $\Delta V$ & $r, \wedge r$ & $\cdot, 9 \leqslant$ & $9 \leqslant, \leqslant V$ \\
\hline 40 & $\begin{array}{l}\text { Conducting scientific research in the field of sports } \\
\text { shows. }\end{array}$ & 1To & 10 & 1. & $r, \mathrm{r} \wedge$ & • & $9 r, V)$ \\
\hline 41 & $\begin{array}{l}\text { Providing research consultancy in the field of sports } \\
\text { shows. }\end{array}$ & 11. & r. & r. & r,07 & $\cdot, \wedge 0$ & $10, \varepsilon r$ \\
\hline 42 & $\begin{array}{l}\text { Providing technical and administrative consultations in } \\
\text { the field of sports shows. }\end{array}$ & 17. & - & • & $r, \ldots$ & $1, \cdots$ & $1, \ldots$ \\
\hline 43 & $\begin{array}{l}\text { Providing, preparing and qualifying specialists and } \\
\text { leaders in the field of sports shows. }\end{array}$ & $10 \mathrm{~V}$ & r & 1 & r,१९ & $\cdot, 99$ & $99,1 \vee$ \\
\hline 44 & $\begin{array}{l}\text { Preparing professional development programs for } \\
\text { workers in the field of sports shows. }\end{array}$ & IrV & rt & · & r,人т & $\cdot, 90$ & $90, r_{1}$ \\
\hline
\end{tabular}




\begin{tabular}{|c|c|c|c|c|c|c|c|}
\hline 45 & $\begin{array}{l}\text { Implementing training and qualification programs for } \\
\text { workers in the field of sports shows. }\end{array}$ & 149 & 11 & 1. & $r, \wedge)$ & $\cdot, 9 \leq$ & $94,0 \leqslant$ \\
\hline 46 & Designing programs and projects for different parties. & 17. & . & $\cdot$ & $r, \ldots$ & $1, \cdots$ & $1 \cdots, \cdots$ \\
\hline 47 & $\begin{array}{l}\text { Incorporation of specialized cadres in sports shows to } \\
\text { serve the community. }\end{array}$ & 101 & r & $\cdot$ & r,१९ & $1, \cdots$ & 99,01 \\
\hline
\end{tabular}

\section{Follow Table (12)}

Weighted mean and percentage of sample opinions on the questionnaire $(n=$ 160)

\begin{tabular}{|c|c|c|c|c|c|c|c|}
\hline \multirow{2}{*}{ No. } & \multirow{2}{*}{ ferries } & \multicolumn{3}{|c|}{ opinions } & \multirow{2}{*}{ W.S } & \multirow{2}{*}{ W.S.D } & \multirow{2}{*}{ percentage } \\
\hline & & AP. & S.AP. & 1.AP & & & \\
\hline 48 & $\begin{array}{l}\text { Linking the unit to the community's developmental, } \\
\text { educational and professional needs. }\end{array}$ & $10 \mathrm{~V}$ & $r$ & • & $r, 91$ & $\cdot, 99$ & $99, \Gamma \wedge$ \\
\hline 49 & $\begin{array}{l}\text { Participate in raising awareness and spreading a culture } \\
\text { of community service. }\end{array}$ & 100 & $r$ & r & $r, 97$ & $\cdot, 99$ & $9 \wedge, 0 \leq$ \\
\hline 50 & $\begin{array}{l}\text { Holding seminars, conferences and workshops in the } \\
\text { field of sports shows. }\end{array}$ & 17. & · & . & $r, \ldots$ & $1, \ldots$ & $1 \ldots, \ldots$ \\
\hline 51 & $\begin{array}{l}\text { Providing sources of knowledge and creating databases } \\
\text { on sports shows. }\end{array}$ & $1 \leq \varepsilon$ & 1. & 7 & Y,Aт & $\cdot, 90$ & $90, \leqslant r$ \\
\hline 52 & $\begin{array}{l}\text { Providing the necessary human and material } \\
\text { capabilities to manage and organize sports shows }\end{array}$ & 17. & $\cdot$ & • & $r, \ldots$ & $1, \ldots$ & $1 \ldots, \ldots$ \\
\hline 53 & $\begin{array}{l}\text { (Participants - Design - Clothing - Instruments - Music } \\
\text { - Profiles - Directing) }\end{array}$ & 107 & $\varepsilon$ & • & $r, 91$ & $\cdot, 99$ & $99,1 \vee$ \\
\hline 54 & Establishing sports shows marketing forums. & 100 & 0 & $\cdot$ & r,qV & $\cdot, 99$ & 91,97 \\
\hline 55 & $\begin{array}{l}\text { Organizing training courses, seminars and conferences } \\
\text { to market sports shows. }\end{array}$ & 17. & • & $\cdot$ & $r, \ldots$ & $1, \ldots$ & $1 \cdots, \cdots$ \\
\hline & Tasks and activities of the unit & $r \leq \cdot r$ & 1.1 & $\leqslant 9$ & $r, 9 r$ & $\cdot, 9 \mathrm{~V}$ & qV,rr \\
\hline & Second axis: technical regulation & $\sum \vee 70$ & mir & $19 r$ & $r, \wedge \mathrm{V}$ & $\cdot, 97$ & 90,09 \\
\hline 56 & $\begin{array}{l}\text { The finance officer prepares the unit's budget plan for } \\
\text { presentation to the Board of Directors. }\end{array}$ & 100 & $\circ$ & • & r, $9 \mathrm{~V}$ & $\cdot, 99$ & $9 \wedge, 97$ \\
\hline 57 & $\begin{array}{l}\text { Budget is prepared in the style of budgets for public } \\
\text { service agencies. }\end{array}$ & 17. & • & • & $r, \cdots$ & $1, \cdots$ & $1, \ldots$ \\
\hline 58 & $\begin{array}{l}\text { It is approved by the Board of Directors for approval } \\
\text { by the University Council. }\end{array}$ & 17. & $\cdot$ & • & $r, \ldots$ & $1, \cdots$ & $1 \cdots, \cdots$ \\
\hline 59 & The budget begins and ends with the state's fiscal year. & 17. & $\cdot$ & $\cdot$ & $r, \cdots$ & $1, \cdots$ & $1 \cdots, \cdots$ \\
\hline 60 & $\begin{array}{l}\text { The plan includes the internal budget (wages - bonuses } \\
\text { - incentives - revenue). }\end{array}$ & 17. & • & • & $r, \ldots$ & $1, \ldots$ & $1 \cdots, \ldots$ \\
\hline 61 & $\begin{array}{l}\text { The plan includes the external budget after approval by } \\
\text { the University Council, which is: }\end{array}$ & 17. & $\cdot$ & • & $r, \ldots$ & $1, \cdots$ & $1 \cdots, \cdots$ \\
\hline 62 & $\begin{array}{l}\text { (Donations - donations - interest on deposits and } \\
\text { investments) }\end{array}$ & 17. & • & $\cdot$ & $r, \ldots$ & $1, \ldots$ & $1 \cdots, \cdots$ \\
\hline 63 & Unit statements and accounts are prepared. & 17. & $\cdot$ & $\cdot$ & $r, \cdots$ & $1, \ldots$ & $1 \cdots, \cdots$ \\
\hline 64 & $\begin{array}{l}\text { The calculations are subject to internal control from } \\
\text { exchange and collection. }\end{array}$ & 109 & 1 & . & r, 99 & $1, \ldots$ & $99, \vee 9$ \\
\hline 65 & $\begin{array}{l}\text { The disbursement from the unit's account is made by } \\
\text { check. }\end{array}$ & 17. & • & • & $r, \ldots$ & $1, \cdots$ & $1 \ldots, \ldots$ \\
\hline 66 & $\begin{array}{l}\text { Checks are issued after reviewing the unit's financial } \\
\text { officer and attaching all documents supporting the } \\
\text { exchange process. }\end{array}$ & 17. & • & • & $r, \ldots$ & $1, \ldots$ & $1 \ldots, \ldots$ \\
\hline 67 & $\begin{array}{l}\text { Checks are approved by signing the dean of the college } \\
\text { and the secretary of the college. }\end{array}$ & 17. & . & • & $r, \ldots$ & $1, \ldots$ & $1 \ldots, \ldots$ \\
\hline 68 & $\begin{array}{l}\text { All unit expenses are subject to taxes and stamp duty } \\
\text { according to laws. }\end{array}$ & 10. & 0 & 0 & $r, q 1$ & $\cdot, 9 \vee$ & $97, \wedge \wedge$ \\
\hline 69 & $\begin{array}{l}\text { The finance officer supplies the expenses to the } \\
\text { competent authorities in accordance with the laws. }\end{array}$ & 17. & . & . & $r, \ldots$ & $1, \cdots$ & $1 \cdots, \ldots$ \\
\hline 70 & $\begin{array}{l}\text { Supplying the percentage prescribed by the University } \\
\text { Council for each activity separately for the account of } \\
\text { the Ministry of Finance, special funds and the } \\
\text { Community Service and Environment Development } \\
\text { Fund at the university. }\end{array}$ & $10 \mathrm{~V}$ & $r$ & · & $r, 91$ & $\cdot, 99$ & $99, \Gamma \wedge$ \\
\hline 71 & $\begin{array}{l}\text { The net revenue is distributed at (5\% the Ministry of } \\
\text { Finance }-10 \% \text { of the university }-20 \% \text { of the college - } \\
20 \% \text { of unit account support }-35 \% \text { of the work team - } \\
10 \% \text { of the Board of Directors). }\end{array}$ & $1 \cdots$ & 10 & $\leq 0$ & $r, r \leqslant$ & $\cdot, \mathrm{VA}$ & $\vee \wedge, 1 \Gamma$ \\
\hline 72 & $\begin{array}{l}\text { Marketing and advertising does not exceed } 10 \% \text { of the } \\
\text { internal budget. }\end{array}$ & 1.9 & $r \cdot$ & r) & $r, \leqslant q$ & $\cdot, \wedge \Gamma$ & NY,qr \\
\hline 73 & $\begin{array}{l}\text { The financial officer is responsible for receiving the } \\
\text { permanent advance from the unit. }\end{array}$ & $11 \mathrm{~V}$ & $r$. & 14 & r, 70 & $\cdot, \wedge \wedge$ & A^,rr \\
\hline
\end{tabular}




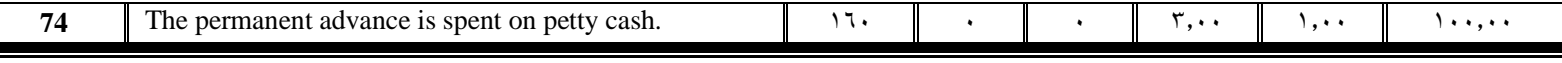

\section{Follow Table (12)}

Weighted mean and percentage of sample opinions on the questionnaire $(n=$ 160)

\begin{tabular}{|c|c|c|c|c|c|c|c|}
\hline \multirow{2}{*}{ No. } & \multirow{2}{*}{ ferries } & \multicolumn{3}{|c|}{ opinions } & \multirow{2}{*}{ W.S } & \multirow{2}{*}{ W.S.D } & \multirow{2}{*}{ percentage } \\
\hline & & AP. & S.AP. & 1.AP & & & \\
\hline 75 & $\begin{array}{l}\text { Do not use the petty cash amount for wages, incentives, } \\
\text { or rewards. }\end{array}$ & 11. & $\varepsilon \cdot$ & $1 \cdot$ & r & $\cdot, \wedge \wedge$ & $\wedge \vee, 0$ \\
\hline 76 & $\begin{array}{l}\text { Follow legal and administrative procedures in } \\
\text { disbursing and settling the permanent advance. }\end{array}$ & 17. & • & · & $r, \ldots$ & $1, \cdots$ & $1 \cdots, \cdots$ \\
\hline 77 & $\begin{array}{l}\text { The temporary advance is made in the event that the } \\
\text { checks cannot be disbursed. }\end{array}$ & $1 \cdots$ & 0. & $1 \cdot$ & r,0T & $\cdot, 10$ & 10, $\Sigma Y$ \\
\hline 78 & $\begin{array}{l}\text { The needs of the unit can be purchased by direct order, } \\
\text { tender, or practice in accordance with Law (89) for the } \\
\text { year 1998 AD in accordance with the provisions of the } \\
\text { executive regulations of the Universities Organizing } \\
\text { Law, upon a proposal from the Unit's Board of } \\
\text { Directors and approved by the President of the } \\
\text { University. }\end{array}$ & 17. & • & • & $r, \ldots$ & $1, \ldots$ & $1, \ldots$ \\
\hline 79 & $\begin{array}{l}\text { The finance officer reviews the final accounts and } \\
\text { sends them to the Special Funds Unit and the Follow- } \\
\text { up Management Unit of a special nature in the } \\
\text { university's social service sector. }\end{array}$ & 17. & • & · & $r, \ldots$ & $1, \ldots$ & $1 \cdots, \ldots$ \\
\hline 80 & $\begin{array}{l}\text { Post the surplus of the remaining revenues from the } \\
\text { ending fiscal year to the following years. }\end{array}$ & $10 \mathrm{~V}$ & r & • & r,१人 & $\cdot, 99$ & 99, ґ \\
\hline & Third axis: financial regulation & rvis & IVY & $11 \leq$ & r,q. & $\cdot, 9 \mathrm{~V}$ & $94,7 \vee$ \\
\hline 81 & $\begin{array}{l}\text { Article (307) of the executive regulations of the } \\
\text { Universities Organization Law establishing the unit in } \\
\text { an independent administrative and financial capacity by } \\
\text { a decision of the University Council. }\end{array}$ & 17. & . & • & $r, .$. & $1, \ldots$ & $1 \ldots, \ldots$ \\
\hline 82 & $\begin{array}{l}\text { Article (308) of the executive regulations of the } \\
\text { Universities Organizing Law that the unit achieves the } \\
\text { goals mentioned in the text of the article. }\end{array}$ & 17. & • & • & $r, \ldots$ & $1, \ldots$ & $1 \ldots, \ldots$ \\
\hline 83 & $\begin{array}{l}\text { Article (309) of the executive regulations of the law } \\
\text { regulating universities, each unit has a special account } \\
\text { in one of the accredited banks after the approval of the } \\
\text { university council, in which all its resources are } \\
\text { deposited. }\end{array}$ & 17. & . & · & $r, \ldots$ & $1, \ldots$ & $1 \ldots, \ldots$ \\
\hline 84 & $\begin{array}{l}\text { Article (310) of the executive regulations of the } \\
\text { Universities Organizing Law. The unit shall perform the } \\
\text { activities and activities of the college affiliated to it } \\
\text { without charge, while the rest of the authorities, whether } \\
\text { inside or outside the university, will be paid for a fee. }\end{array}$ & 17. & • & · & $r, \ldots$ & $1, \ldots$ & $1 \ldots, \ldots$ \\
\hline 85 & $\begin{array}{l}\text { Article }(311) \text { of the executive regulations of the law } \\
\text { regulating universities is managed by the unit a board of } \\
\text { directors expressing the goals that the unit seeks to } \\
\text { achieve. }\end{array}$ & 17. & • & • & $r, \ldots$ & $1, \ldots$ & $1 \ldots, \ldots$ \\
\hline 86 & $\begin{array}{l}\text { Article (311) of the executive regulations of the } \\
\text { Universities Organizing Law, the term of the council } \\
\text { ranges from three years, renewable once. }\end{array}$ & 17. & . & · & $r, \ldots$ & $1, \ldots$ & $1 \ldots, \ldots$ \\
\hline 87 & $\begin{array}{l}\text { Article (311) of the executive regulations of the law } \\
\text { regulating universities. The university president } \\
\text { appoints the director of the unit and all members are } \\
\text { nominated by the dean of the college. }\end{array}$ & 17. & . & · & $r, \ldots$ & $1, \ldots$ & $1 \ldots, \ldots$ \\
\hline 88 & $\begin{array}{l}\text { Article (311) of the executive regulations of the law } \\
\text { regulating universities must not occupy the center } \\
\text { director with any other administrative positions in the } \\
\text { college or university. }\end{array}$ & 17. & • & • & $r, \ldots$ & $1, \ldots$ & $1 \ldots, \ldots$ \\
\hline 89 & $\begin{array}{l}\text { Article (311) of the executive regulations of the Law on } \\
\text { Universities Regulation finds that the Council includes } \\
\text { members from abroad with technical expertise in the } \\
\text { field. }\end{array}$ & 17. & · & · & $r, \ldots$ & $1, \cdots$ & $1 \ldots, \ldots$ \\
\hline 90 & $\begin{array}{l}\text { Article (311) of the executive regulations of the } \\
\text { Universities Regulatory Law. The Board of Directors } \\
\text { has the dominant authority over unit affairs. }\end{array}$ & 17. & - & · & $r, .$. & $1, \ldots$ & $1 \ldots, \ldots$ \\
\hline
\end{tabular}

Follow Table (12)

Weighted mean and percentage of sample opinions on the questionnaire $(n=$ 
160)

\begin{tabular}{|c|c|c|c|c|c|c|c|}
\hline \multirow{2}{*}{ No. } & \multirow{2}{*}{ ferries } & \multicolumn{3}{|c|}{ opinions } & \multirow{2}{*}{ W.S } & \multirow{2}{*}{ W.S.D } & \multirow{2}{*}{ Per. } \\
\hline & & AP. & S.AP. & 1.AP & & & \\
\hline 91 & $\begin{array}{l}\text { Article (312) of the executive regulations of the Universities } \\
\text { Organizing Law. The decisions of the Board of Directors are } \\
\text { communicated to the Vice Chancellor for Community Affairs } \\
\text { and Environmental Development within (8) days at the most } \\
\text { from the date of its issuance for approval by the University } \\
\text { President. }\end{array}$ & 17. & • & • & $r, \ldots$ & $1, \cdots$ & $1 \cdots, \cdots$ \\
\hline 92 & $\begin{array}{l}\text { Article (313) of the executive regulations of the law } \\
\text { regulating universities is concerned with the unit's resources } \\
\text { in foreign exchange for its service of direct import through } \\
\text { the bank in which its resources are deposited. }\end{array}$ & 17. & • & • & $r, \ldots$ & $1, \cdots$ & $1 \cdots, \ldots$ \\
\hline 93 & $\begin{array}{l}\text { Article (314) of the executive regulations of the law } \\
\text { regulating universities. The unit shall have an internal } \\
\text { regulation specifying the functions of the council, the council } \\
\text { chairman, and the financial and administrative systems of the } \\
\text { unit. }\end{array}$ & 17. & • & • & $r, \ldots$ & $1, \ldots$ & $1 \ldots, \ldots$ \\
\hline 94 & $\begin{array}{l}\text { The provisions of Law No. (49) of } 1972 \text { regarding the } \\
\text { organization of universities and its regulations shall apply in } \\
\text { the absence of a special text for this unit. }\end{array}$ & 17. & • & • & $r, \ldots$ & $1, \cdots$ & $1 \ldots, \cdots$ \\
\hline 95 & $\begin{array}{l}\text { The work of the unit is subject to the supervision of the } \\
\text { university's competent bodies, the central auditing agency, } \\
\text { and the state's supervisory organs. }\end{array}$ & 17. & • & • & $r, \ldots$ & $1, \cdots$ & $1 \cdots, \cdots$ \\
\hline \multicolumn{2}{|c|}{ Fourth axis : legislative regulation } & $r \leq \ldots$ & - & · & $r, \ldots$ & $1, \ldots$ & $1 \ldots, \ldots$ \\
\hline & ALL & $1 \leq 1 \leq 0$ & $7 \varepsilon r$ & $\& 1 Y$ & r, 9 . & $\cdot, 9 V$ & $97, \vee \wedge$ \\
\hline
\end{tabular}

It is clear from table (12) that the responses of the opinions of the research sample about the questionnaire, where the percentage of phrases ranged between ( $\vee \wedge .1 \% \%$ : 100\%), and the percentage of axes as a whole ranged $(93 . r 9 \%: 1 \cdots \%)$.

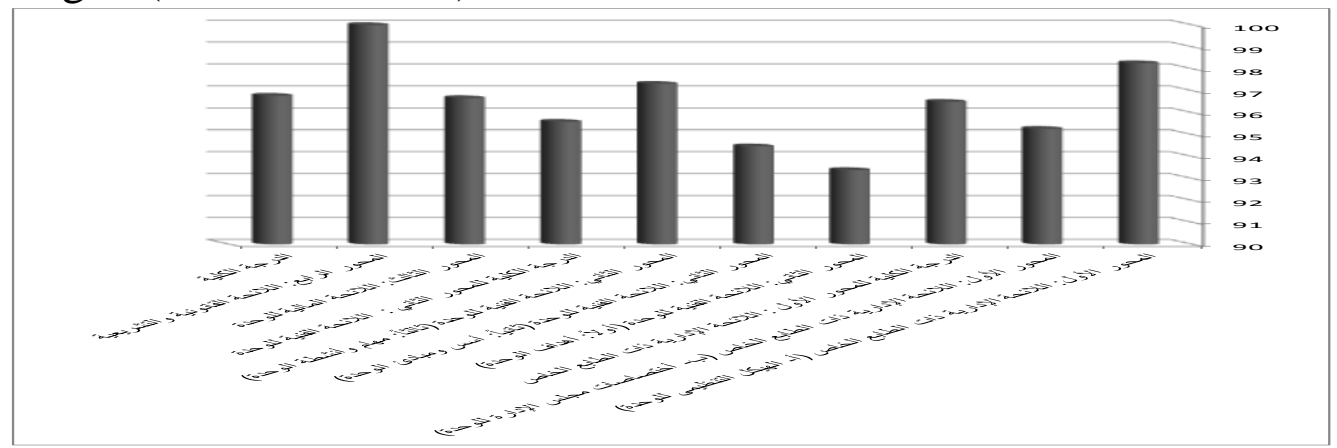

\section{Figure (1) Percentage of weighted averages of the questionnaire}

By presenting the opinions of the responses of the research sample in a table (12), it is possible to explain and discuss some of the results that have been reached:

\section{The first major axis: the administrative regulations:}

- The organizational structure of the unit consists of faculty members who specialize in the field of sports shows in the faculty and they are responsible for the workflow of the unit and the activities that will be carried out.

The board of directors is at a high level of competence in the same field of specialization, and they should be taken care of through human and 
professional development in the same field. ( 1 ^: 210)

- The board of directors of special units must also include members from outside the academic institution with experience in the same specialty of the unit, which helps to create other channels of communication with the community and meet its services, and this was confirmed by the results of (Zahm; 2016) ( $(\cdot)$.

- Public Relations, Advertising, Media and Marketing Officer for the unit, where (Al-Jamal; 2012) (9) indicates that there must be a member within the board of directors responsible for preparing the marketing plan for the tasks and activities of the special units, and that he has the ability, experience and competence in this field, as he should be a source to support the link with the community.

- The unit's board of directors is concerned with setting general policy and plans for work within the unit, as there is a clear plan to serve the community as (Muhammad; 2017) ( $Y \varepsilon$ ) indicates that they develop the community services provided by the units, and the members of the board of directors should not abuse the granted authority and obstruct the work.

\section{The second axis: Technical Regulations:}

the special units seek to achieve varied goals, as the study of (Gondaa; 2014) ( $I V$ ) and (Saad; 2018) ( 1 ) showed that universities sought to establish special units as a necessity to provide various service activities to different community institutions, and to participate in the development Its human resources, providing the community's needs for qualified and trained cadres, and providing support services for students to develop their skills and prepare them for the labor market.

- The unit seeks to provide new resources to increase the self-resources of the physical of physical education, and self-financing, as indicated by (Al-Asmai; 2019) ( $(r)$ and (Isaac; 2017) $(r)$ is all the revenues achieved by the sports authority, where these resources are numerous and differ from one sports administration to another, where the bodies strive to provide Sources of self-financing to improve the level of services in it, and the need to pay attention to spreading awareness of the importance of self-financing within student welfare offices to raise the level of various student activities.

The two researchers agrees with (Al-Hanashly;2012) $(\wedge)$ and (Abu Dhaif; 2018) ( 7 ) that relying on government funding as the main source of the annual budget of anybody or institution does not meet the necessary financial obligations to achieve the goals, so it must search for self-sources to support the budget and achieve the goals.

- The special productive and service units are adopted as the results of the study of (Al-Jamal; 2012) ( 9 ) reached in its work two pillars. The first is the actual participation in providing services and consultations and setting 
the experiences of the faculty members and their research capabilities in order to achieve the university's mission in serving the community, while the second pillar is participation in providing of financial resources for the operation of the units and the university's participation in financing its projects.

- included The tasks and activities of the unit in the field of marketing, as this requires setting up forums for training courses, conferences, seminars and conducting agreements and protocols, and this come along with the results of the (Sami; 2011) ( $\left.{ }^{\bullet}\right)$ that marketing is one of the most important areas that must be taken care of in order to make progress and development in the field of sports shows.

\section{The third axis: the financial regulations:}

- The unit derived its work from financial independence, whereby the general budget of the unit is prepared in the style of budgets for service public bodies, and the statements and accounts of the unit are prepared, and that the special units have an accounting system consistent with the goal of their establishment, and this is confirmed by the results of the study of (Salam; 2015) ( $\varepsilon$ ) and (Ghazi; 1997) (I צ) and (Al-Baz; 1990) (v).

- The unit's work is also subject to the supervision of the competent authorities of the university, the central accounting system, and the state's supervisory organs, which contributes to assessing the performance of special units for their roles and directs efforts to improve and develop the unit to meet the requirements of community development and service, and this is confirmed by the results of the study of (Selim; Al-Shaer; Abbas ; Sayed; 2018) ( $r \vee$ ) and (Abdel Bar; 2016) ( $r)$.

- The plan includes the external budget after the approval of the University Council, as (Mohammad; 2010) (30) and (Al-Abidin; 2002) ( $M$ ) indicated that it is possible to rely on the external budget such as gifts, donations, or interest in deposits and investments as sources of selffinancing for universities.

\section{Fourth Theme: Legal and Legislative Regulations:}

- special Units are based on their origin, form, activity, goals and relationships on a legal basis that represents the legal and legislative framework for these units financially, administratively and accounting, as this requires a set of laws and regulations regulating them and ensuring their legitimacy in practicing tasks and activities. ( $Y$ : 333 )

This is what the researchers followed when setting the main regulation of the unit, as it used many of the laws and regulations necessary to establish the unit, including the directory of special units (13) and the law of university organization and its executive regulations ( 7 , and this is consistent with the results of the study of each of (Saad; 
2018) (1) And (Hussein; Al-Zahri; Shalaby; 2014) (19) and (AlShafei; 2010) (7).

\section{Conclusions:}

- Support and maximize the role of faculties of physical education towards society and environmental development.

- Establishing units of a special nature to provide services that suit the requirements and needs of society.

- Putting a name, vision, mission, and goals for the unit commensurate with the activities and programs it offers.

- Preparing professional development programs for workers in the field of sports shows.

- Development of administrative, technical, financial, legal and legislative regulations for special units.

- Giving powers to the Board of Directors of the units of a special nature to manage the affairs of the unit.

- The diversity, multiplicity of specialties and experiences of members of the Board of Directors of special units.

- Preparing plans and programs to meet the requirements of the labor market in the field of sports shows.

- Preparing professional and human development programs for workers in the field of sports shows.

\section{Recommendations:}

- Activating the role of special units in serving the community and developing the environment.

- The diversity and multiplicity of activities and services provided by special units in universities.

- Reconsidering some of the regulations and laws that organizing units

- Doing more researches in the fields related to sports shows.

\section{References:}

1- Aal Saad, Iman Abdel (2018): Activating the role of special units in Egyptian universities in improving student service, Master Thesis, Girls College of Arts, Sciences and Education, Ain Shams University.

2-Abdeen, Mahmoud Abbas (2013): Education planning issues and economics between global and local, Egyptian Lebanese House, Cairo.

3-Abdel Bar, Nesma Abdel Rasoul (2016): A proposed strategy for developing financial resources in Egyptian universities in the light of the experience of the Republic of South Africa, $\mathrm{PhD}$ thesis, Faculty of Education, Benha University. 
4- Abdel Salam, Imad Abdel-Hakim (2015): The role of centers and units of a special nature at Zagazig University in the human development of the local community, Master Thesis, College of Education, Zagazig University.

5-Abdel-Samie,Heba Abdel-Aziz (2011): A Proposed Strategy for Marketing Sports Show Services, Master Thesis, Faculty of Physical Education for Girls, Zagazig University.

6- Abu Deif, Mahmoud Ahmed (2018): Self-financing and its role in advancing the services and activities of the Union of Sports Professions in the Arab Republic of Egypt, Master Thesis, Faculty of Physical Education for Boys, Helwan University.

7-Al-Baz, Mustafa Ali (1990): Development of Accounting in Units of a Special Nature in Universities, Scientific Production, Scientific Journal of Economics and Trade, No. 1, Faculty of Commerce, Ain Shams University.

8-Al-Hanashly,Ibrahim Mohamed (2018): Suggested alternatives to finance university education in the Republic of Yemen in the light of some contemporary global trends, PhD thesis, Faculty of Education, Ain Shams University.

9- Al-Jamal, Amal Abdul Mardi (2012): planning to market units of a special nature at Helwan University, scientific production, the twenty-fifth conference (the future of social service in the shadow of the modern civil state), Faculty of Social Work, University of Helwan.

10- Arnold, W William (2018): Strengthening College Support Services To Improve Student Transitioning To Careers, Journal of College Teaching \& Learning, Pepperdine University, USA, $\mathrm{V}(15), \mathrm{N}(1)$.

11- Awad, Mayada El-Sayed (2018): The role of university units of a special nature in community service and environmental development, Journal of Arab Studies in Education and Psychology, No. (104), Association of Arab Educators, Cairo.

12- Azab, Mohamed Ali (2011): University Education and Development Issues, The Anglo Egyptian Library, Cairo.

13- Bakry, Adel Abdel-Tawab، Zaghloul, Tharwat Saad (2006): The Law on Organizing Universities and its Executive Regulations, The General Authority of Al Amiria Printing Press, Cairo.

14- Directory of Specialized Units (2012): Community and Environmental Affairs Sector, Ain Shams University.

15- El-Shafei, Ayman Ahmed (2010): developing university units of a special nature in the light of contemporary administrative thought, $\mathrm{PhD}$ thesis, Faculty of Education, Beni Suef 
University.

16- Ghazi, Ahmed Ali (1997): A suggested accounting method for maximizing the role of units of a special nature through the concepts of strategic management accounting, scientific production, the Egyptian Journal of Commercial Studies, Volume (12), No. (3), Faculty of Commerce, University.

17- Gondaa, G. Mahadappa (2014): Role Of Educational Institutions In Shaping The Future Of Business And Society, Procedia Economics and Finance, N (11).

18- Haji, Ahmed Ismail ، Abdel Hamid, Hossam Hamad (2012): University and Human Development, World of Books, Cairo.

19- Hussein, Muhammad Rehan، Al-Zahri, Alaa Fathi ، Shalaby, Samah Sami (2014): The nature of units of a special nature and their importance in developing self-resources in universities, scientific production, Scientific Journal of Research and Commercial Studies, Volume (28), No. (1), College of Commerce and Business, Helwan University.

20- Ishaq,Basem Fouad (2017): A proposed model of self-financing for the care offices of university students in the Arab Republic of Egypt, Master Thesis, Faculty of Physical Education, Minia University.

21- Issa, Iman Mustafa (2018): A proposed strategy to activate the partnership between Palestinian universities in the West Bank and civil society institutions in the light of quality standards, Ph.D. thesis, Girls College of Arts and Educational Sciences, Ain Shams University.

22- Mabrouk, Ghada Adel (2019): The financial and administrative independence of some international universities and the possibility of benefiting from them at the University of the Suez Canal, Master Thesis, College of Education, Suez Canal University.

23- Mahrous, Muhammad Al-Asmai (2019): Suggested alternatives to diversify sources of financing higher education in the Arab countries in light of my visions of Egypt and Saudi Arabia 2030, scientific production, the educational journal of the Faculty of Education, No. (59), Faculty of Education, Sohag University.

24- Mohamed, Gehan Lotfy (2017): Envisioning a proposal based on the Pfeiffer model for developing societal services provided by the Faculty of Kindergarten for Child Care Institutions in Port Said Governorate, Scientific Production, Arab Research Journal in Specific Education, No. (6). 
25- Mohammad, Samah Zakariya (2010) : A Futuristic Vision For Developing The University Special Units For The Service of The Community , N(17).

26- Mostafa, Azmy Abdel-Khalek (2015): New in modern and contemporary sports festivals for the educational and private sectors, Dar Al-Maarif facility, Alexandria.

27- Salim, Mona Ahmed، Al-Shaer, Amira Mahmoud ، Abbas, Ahmed Ahmed، Abdel Basset, Sami El-Sayed (2018): Financial evaluation of units of a special nature, Faculty of Agriculture, Suez Canal University, Scientific Production, Journal of Agricultural Economics and Rural Development, Volume (4), No. (1), Scientific Society of Agricultural Sciences, Suez Canal University.

28- Shaari, Roziana، Rajab, Azizah (2018): The Impact of University Social Responsibility towards Producing Good Citizenship Evidence from Malaysia, International Journal of Organizational Leadership, Faculty of Management, University Technology Malaysia ,N (7).

29- Tolba, Jaber Mahmoud (1999): Educational Renewal for the Future of the University, Al-Iman Library, Mansoura.

30- Zaham, Radwan Ali (2016): Activating the role of the productive units in the colleges of the arts to develop awareness among the Arab community about the traditional arts of archaeological sites, scientific production, the Fourth International Conference, Faculty of Applied Arts, Cairo University.

31- Zain El-Abidine, Mohamed Shams El-Din (2002): The role of fundraising campaigns, grants and units of a special nature as sources of funding for the university, scientific production, Journal of Research in Education and Psychology, Volume (15), No. (3), Faculty of Education, Mania University. 


\title{
The Effectiveness of Core Muscle Exercises on the Muscle Strength \\ Level and Some of the Biomechanical Variables Associated with the Jump Shooting Skill Performance in Handball
}

\author{
*Asst. Prof. Dr. Ranya Mohamed Saeed Mahmoud
}

\author{
Assistant Professor, Department of Training of Physical Sports, Faculty of \\ Physical Education for Girls in Cairo - Helwan University - Egypt.
}

\begin{abstract}
:
This research aims to identify the effectiveness of core muscle Exercises on the muscle strength level (legs, trunk, and arms) and the performance level of the jump shooting skill for female handball players, as well as some biomechanical variables associated with the skill performance (performance stages time distribution, the body's movement course horizontal displacement value, the shooting hand movement horizontal displacement value, the body's gravity center height on the vertical axis at the elevation moment value, the elevated foot at the body launch moment vertical velocity components value, the shooting arm at the ball release moment horizontal velocity components value, the fixed shooting leg, the free leg, and the elevated foot joints angular change value, some body positions and parts angular change values percentages). The researcher used the descriptive approach through biomechanical analysis of the jump shooting skill, and the experimental method of one-group design on a sample of (7) female national players in the Helwan University team for handball, who performed (3) shooting attempts, before and after the application of core muscle Exercises. and the researcher used strength and muscle ability tests, and skill level tests for the jump shot skill. The Exercises program consisted of (30) units for (10) weeks period, with (3) Training units per week, and a capacity of (60) minutes per unit. The results showed improvement in the biomechanical variables (under study), strength and muscle ability measurements (legs, trunk, and arms) and the jump shooting skill performance of the research sample players.
\end{abstract}

\section{Research Terminologies:}

Core muscles, core stability, biochemical variables, jump shooting.

\section{Introduction and Research Problem:}

Bliss (2005), Dave Schmitz (2003), and Ron Jones (2003) suggest that corebody strengthening exercises have become the main key to athletes Exercises programs for all levels. It acts as a bridge that connects the upper and lower extremities, in addition to preventing force leakage, and the force resulted from the core body part is called the extremities power source.

Core body part term refers to the trunk and pelvis area, which includes the abdominal muscles (rectus, transverses, internal, external, and oblique's), the hip muscles (front, back), and the spinal muscles (Lower back muscles, and upper back muscles); these groups are connected to the legs, shoulders, and arms muscles. (Greg, B, 2003, Dean, B) It consists of (29) muscles and is located in the center of gravity of the body when the movement begins. (Prentice: 2003) 
Akuthota, and Nadler (2004) add that the core muscles work on the complete transfer of the force produced from the lower extremity through the trunk to the upper extremity and sometimes the held tool. Therefore, the core muscles weakness will not lead to a complete motor energy transfer from the lower to upper and thus poor athletic performance.

The trunk has an important effect on the shooting skill performance in handball, for when the player starts preparing for the swing, following that the torso rotates backward inverting the throwing direction until the shoulder axis crosses the pelvic axis and the left shoulder faces the goal in order to achieve the foothold of the left leg for the right player. When the trunk completes its swing, this moment is considered to be the starting moment to turn facing the direction of shooting, by transferring the movement from the trunk to the shooting arm, where the shoulders axis rotates to face the goal through the forward movement of the arm and the trunk forward rotation, followed by the whip movement of the forearm and wrist. The strength and accuracy of the shot depends on the trunk strong rotation the foothold movement on the front left foot and the arm's whip movement. (Reita, E, Mary P: 1997)

Amal Gaber (2008), Adel Abd El Basir, Ehab Adel (2007), and Laila El Sayed Farhat (2005) agree that the kinetic analysis is done with the aim of identifying the skill technical characteristics, revealing performance defects and comparing it with theoretical curves. Also the theoretical study of the sample movement and their kinetic possibilities, and the evaluation through biomechanical kinematic analysis is done through studying the skill motor course mechanical variables. This is done according to the mathematical movement laws and the resulting variables that affect motor performance, and it is the best method of objective evaluating.

Through the researcher's viewing of scientific references and Arab and foreign studies, she found lack of quality research that is concerned with linking the biomechanics fields as a scientific field and activating it to study skill performance problems in handball. This prompted the researcher to connect between the core muscle strength development as one of the most important physical components affecting the implementation of the kinematic duties of the jump shot skill, and between one of the biomechanics modern sciences and its applications in sports activity.

The jump shooting skill is a complex motor skill that requires an accurate neuromuscular compatibility of the feet, trunk and the shooting arm movement during correct skill performance. Due to the presence of some deficiencies in the interest of specialized Exercises that focuses on the physical components development of the jump shooting skill, the idea of this research occurred as an attempt to link the core muscle strength development with the long jump shooting skill biomechanical variables. Therefore, the research problem was shaped in identifying the developing core muscle strength effect on the quantitative values of some biomechanical variables for jump shooting skill, through diagnosing the handball female players' skill performance. 


\section{Research Objectives:}

The research aims to identify:

1. Biomechanical analysis of the jump shooting for handball female players.

2. Designing a group of core muscle exercises, and identifying their effect on:

a) Some biomechanical variables affecting the jump shot skill performance (performance stages time distribution, the body's movement course horizontal displacement value, the shooting hand movement horizontal displacement value, the body's gravity center height on the vertical axis at the elevation moment value, the elevated foot at the body launch moment vertical velocity components value, the shooting arm at the ball release moment horizontal velocity components value, the fixed shooting leg, the free leg, and the elevated foot joints angular change value, some body positions and parts angular change values percentages).

b) The muscle strength level (legs, trunk, and arms), as well as the jump shooting performance skill of handball female players.

\section{Research Hypothesis}

1. There are statistically significant differences between the pre and post measurements in some biomechanical variables values that affect the long jump shooting skill performance of the research sample handball female players in favor of the post measurement.

2. There are statistically significant differences between the pre and post measurements in the muscle strength level (legs, trunk, arms), as well as the jump shooting skill level of the research sample handball female players in favor of the post measurement.

\section{Research Plan and Procedures}

\section{Research Methodology}

The researcher used the descriptive method through biomechanical analysis of the jump shooting skill for handball female players, as well as the experimental method of one experimental group using the pre and post measurement to apply the proposed core strength Exercises, and to determine the biomechanical changes to measure the development of the core muscle strength effect of handball female players.

\section{Research Community}

The research community contained (27) national handball team female players in Helwan University, all of whom are registered in the Egyptian Handball Federation for the sports season (2019-2020).

\section{Research Sample}

The research sample was chosen by the intentional method from national handball team female players in Helwan University, who are students of in the 
Faculty of Physical Education for Girls in El Gezira, and their number is (7) players. Each player performed ( 3 attempts) to jump shot before and after the application of core muscle exercises Each player performed ( 3 attempts) of the jump shot before and after the application of core muscle exercises, and the best attempts of each player were chosen for the purpose of biomechanical kinematic analysis, the number of attempts under study became (14 attempts); 7 attempts before and 7 attempts after applying core muscle Exercises. Additional (20 players) were selected to conduct the pilot study, and calculate the scientific treatments for the physical and skill tests under study.

\section{Research Sample Homogeneity:}

Table (1)

Arithmetic mean, Standard deviation, and Torsion coefficient of the variables understudy - pre-measurements $(n=7)$

\begin{tabular}{|c|c|c|c|c|c|}
\hline & Variables & $\begin{array}{c}\text { Measurement } \\
\text { Unit }\end{array}$ & Mean & SD & $\begin{array}{c}\text { Torsion } \\
\text { coefficient }\end{array}$ \\
\hline \multirow{4}{*}{ 旁 } & Age & Year & 20,15 & 1,17 & $\mathbf{0 , 2 3}$ \\
\hline & Height & Meter & 171,8 & $\mathbf{0 , 6 3}$ & 0,132 \\
\hline & Weight & Kg & 65 & 1,41 & $-2,10$ \\
\hline & Exercises age & Year & 12,3 & $\mathbf{0 , 0 2}$ & 1,83 \\
\hline \multirow{12}{*}{ 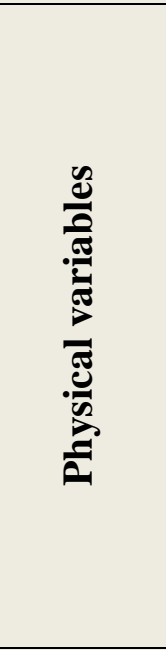 } & Legs strength in dynamometer & Kg & 68,00 & 14,49 & $\mathbf{0}$ \\
\hline & Back strength in dynamometer & Kg & 64,28 & 12,39 & $-0,17$ \\
\hline & Sit ups & Repeat & 21,57 & 4,03 & 1,17 \\
\hline & Push ups & Repeat & 18,57 & 3,10 & $-0,41$ \\
\hline & Standing broad jump & $\mathrm{Cm}$ & 148 & $\mathbf{8 , 5 2}$ & $\mathbf{1 , 0 5}$ \\
\hline & Broad jump (3 steps) & $\mathbf{C m}$ & 176,28 & 24,34 & $\mathbf{0 , 2 8}$ \\
\hline & Vertical jump with swing arms & $\mathbf{C m}$ & 22,57 & 4,96 & $-0,864$ \\
\hline & Vertical jump without swing arms & $\mathbf{C m}$ & 18,57 & 2,29 & 0,74 \\
\hline & Medicine ball trunk rotation throw & Meter & $\mathbf{5 , 3 5}$ & $\mathbf{0 , 7 8}$ & $-2,10$ \\
\hline & Medicine ball trunk rotation $(30 \mathrm{sec})$ & Repeat & 19,57 & 1,81 & $\mathbf{0 , 9 4}$ \\
\hline & $\begin{array}{l}\text { Throwing medicine ball to farthest } \\
\text { point }\end{array}$ & Meter & 7,19 & 1,45 & 1,01 \\
\hline & Strength\& stability of core muscles & Grade & 41,25 & $\mathbf{0 , 9 8}$ & $\mathbf{0 , 5 1}$ \\
\hline \multirow{2}{*}{ 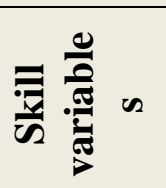 } & $\begin{array}{c}\text { Long jump shot\& calculating fly } \\
\text { distance }\end{array}$ & $\mathbf{C m}$ & 188,10 & $\mathbf{0 , 2 7}$ & $-1,37$ \\
\hline & $\begin{array}{l}\text { Long jump shot accuracy on goal } \\
\text { corners }\end{array}$ & Grade & 47,79 & $\mathbf{9 , 1 7}$ & $-1,22$ \\
\hline
\end{tabular}

\section{Data Collecting Tools}

1. Arab and foreign reference sources, previous studies, and the International Information Network:

In order to identify the biomechanical variables, the physical tests, and the skill tests of the jump shooting skill, and how to conduct the study. (Talha H. 2006) (Adel A., Ehab A. 2007) (Fathy A. 2010) (Kamal D.2002) , (Kamal A., Mohamed, S., 2010) (Mohamed K., 2004) (Mohamed S.,: 2006) (Melvin, R: 2003). 
2. An expert opinion survey form to determine: Physical and skill tests, as well as determining the general framework for implementing the proposed exercises in terms of duration - Training unit's number - Training unit time - core muscle exercises

3. The Tests used in the Research:

a) Physical Tests:

- Muscle Strength Tests:

- Legs strength in dynamometer (Mohamed, S., 2001)

- Back strength in dynamometer (Mohamed, S., 2001)

- Abdomen muscle strength (Sit ups $20 \mathrm{sec}$ ) (Mohamed, S., 2001)

- Arms muscle strength (Push-ups) (Mohamed, S., 2001)

- Leg muscles strength and ability tests in the horizontal and vertical directions

- Standing broad jump. (Kamal A., Mohamed S. 2010)

- Broad jump (3 steps) and elevating with one leg, it is similar to the jump shooting skill understudy. (Researcher Design)

- Vertical jump with swing arms. (Kamal A., Mohamed S. 2010)

- Vertical jump without swing arms with the purpose of identifying the effect of the swinging arms amount result on vertical jump. (Kamal D. 2002)

- Trunk and arms muscles strength and ability tests

- Medicine ball trunk rotations throw. (Researcher design)

- Medicine ball trunk rotation (30 sec). (Researcher design)

- Throwing medicine ball to farthest point. (Kamal D. 2002)

- Core muscles strength and stability test to measure the body's core part strength.

- (Aishe,E:2011)( www.w3c.org/TR/1999).

b) Skill Tests:

- $\quad$ Long jump shot\& calculating fly distance. (Kamal D. 2002)

- Long jump shot accuracy on goal corners. (Researcher design)

\section{Tools and Devices:}

a) Photographing devices and tools for kinematic analysis purpose:

- (Canon EOS-1DC) camera with a resolution of (18.1 Megapixels)

$(24 \mathrm{~mm}$ X36 mm) (Pixels $5184 \times 3456)$ with a frequency of $(100)$ images per second was used.

- Camera Tripod Stand.

- Memory Card, Flash memory (32 GB) to plug to the computer.

- Wooden ruler $(3 \mathrm{~m})$ to calculate the scale.

- Computer Device.

- Movie Maker Windows program to edit videos, and Any Video Converter to convert video extension to AVI.

b) Tools for measurements, tests and suggested core muscle exercises:

Rastameter to measure height, medical scale to measure weight, dynamometer to measure the back and leg muscles strength, tape measure, stop watch, medicine balls, hand balls, chalk, collars, Swiss ball, Swiss hemisphere ball, hand wheel, Roman seat, Boules balls.

\section{Research Implementation Procedures:}




\section{First Pilot Study:}

The researcher conducted the first pilot study on (20) players from the research sample original community, and they are not enrolled in the research sample, from Monday 2/9/2019 to Monday 9/9/2019 in order to ensure:

- Devices and tools used validity.

- The possibility of implementing and applying measurements and tests and its related procedures according to the established conditions.

- Assistants Exercises on implementing measurements and tests.

- Calculating the scientific treatments of the tests under study.

Tests Scientific Treatments: First Tests Validity:

Table (2)

The significance differences between the significant and insignificant groups in the physical and skill variables under study $(\mathrm{n} 1=\mathrm{n} 2=10)$

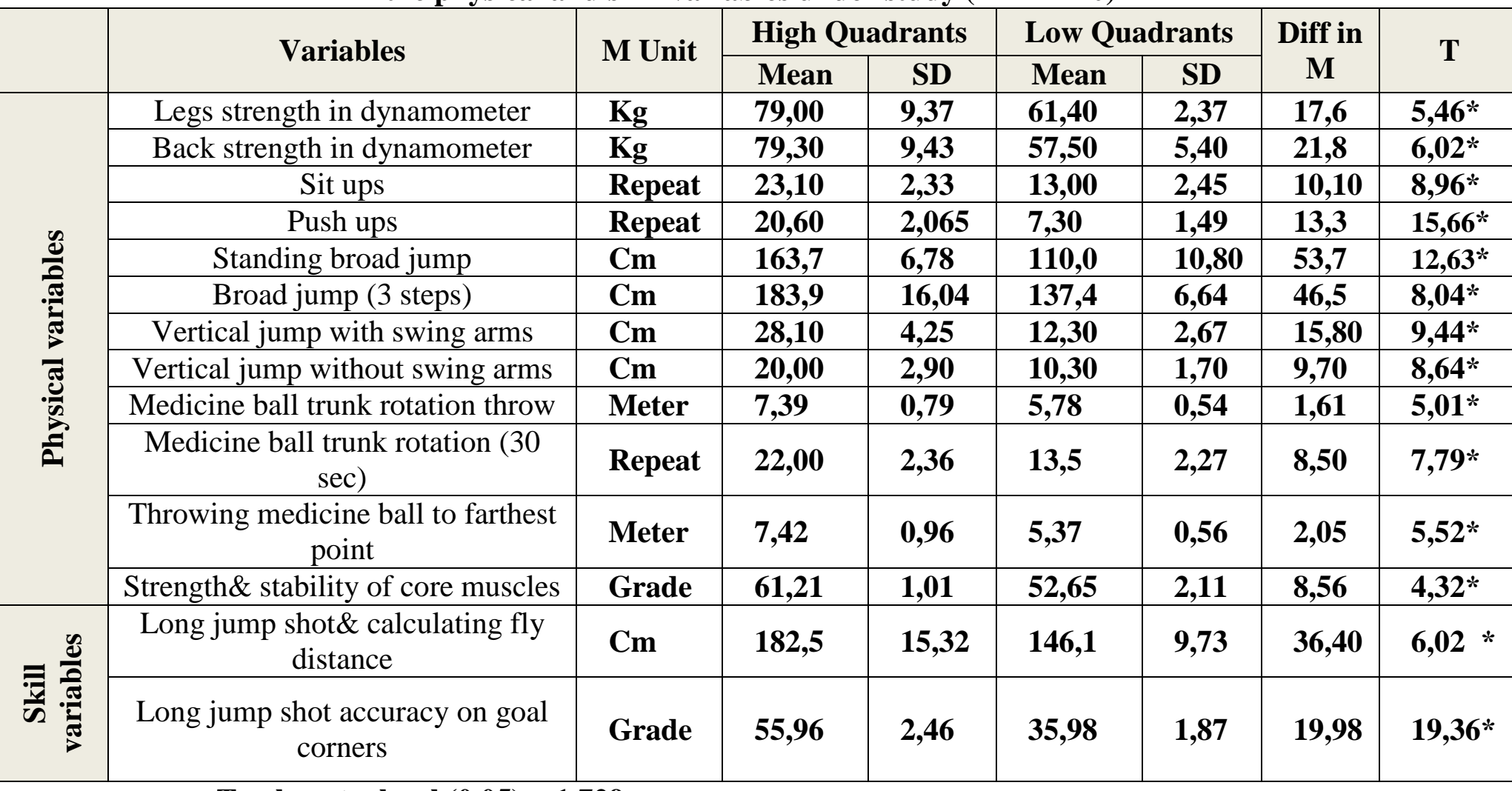

T value at a level $(0.05)=1,729$

Second Tests Stability

To verify the test stability, the researcher used the test applying method and re-applying it to the pilot sample, and used the test validity account data as the first application on Monday 2/9/2019 and the second application a week after the first application on Monday 9/9/2019. 
Table (3)

Correlation coefficient between the first and second applications in the physical and skill variables under study $(n=20)$

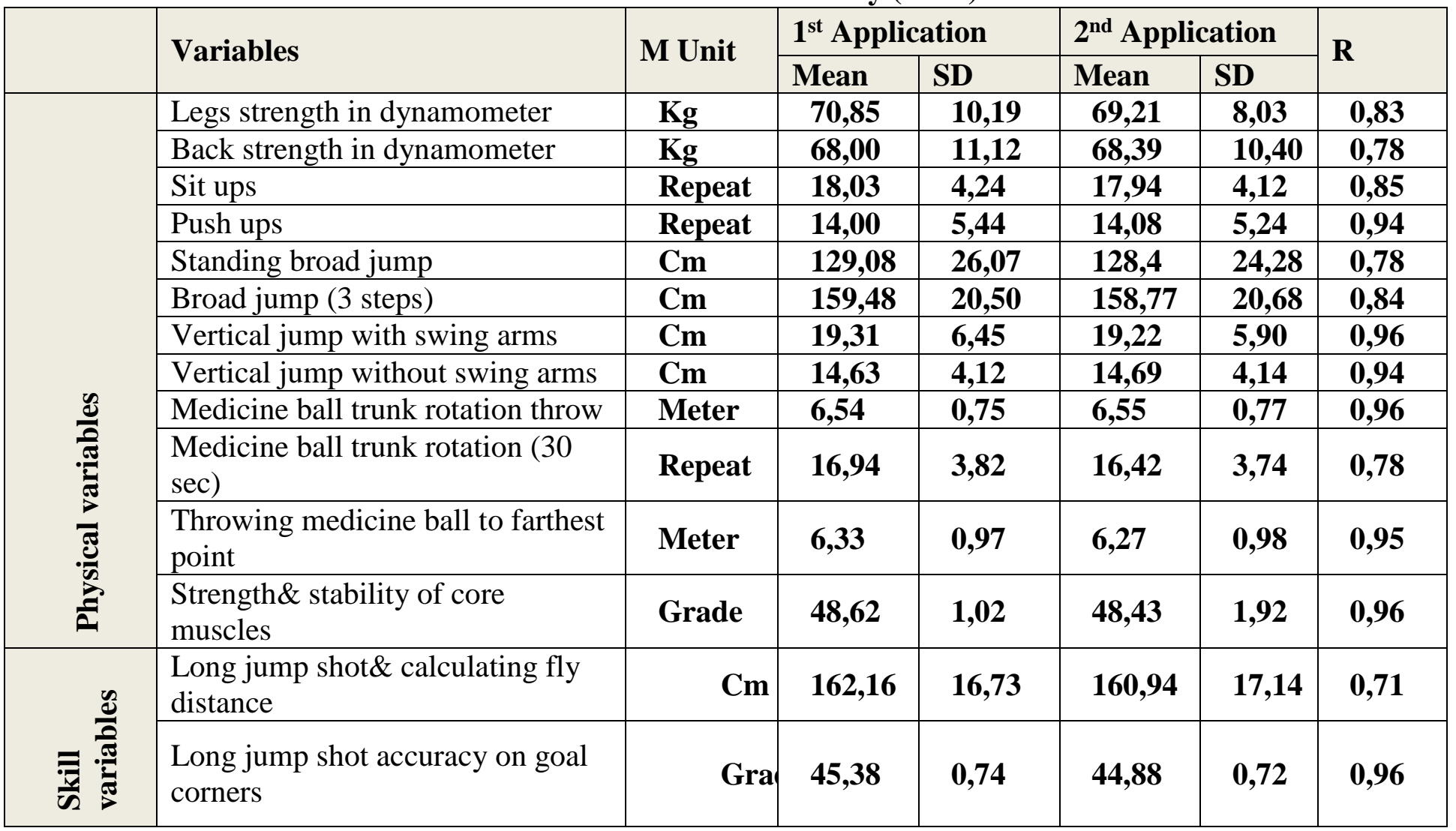

$R$ value at a level $(0.05)=0,43$

\section{Second Pilot Study}

The researcher conducted the second pilot study on (5) female players from the research community and outside the main research sample on Sunday 15/9/2019 in the handball court at Faculty of Physical Education for Girls in El Gezira, in order to prepare the filming location as follows:

- Determining the camera position location for analytical photography purpose, as the camera position was set at a distance $(10 \mathrm{~m})$ from the player's foothold and at a height of $(1.20 \mathrm{~m})$ from the ground, and the camera angle was placed so that it is perpendicular to the player's side during the performance.

- $\quad$ Set the most appropriate timing for filming the video.

- Set the camera position according to the sun movement.

- Determine the player's field motion during the skill performance to determine the sector of viewing during filming.

- Availability of an electrical source near the camera.

- Determine control marks location for the scale.

- Identify the obstacles the researcher faces during the filming process and try to overcome them, including the tripod stability on the ground, its height relative to the players, and the availability of photography aids. 


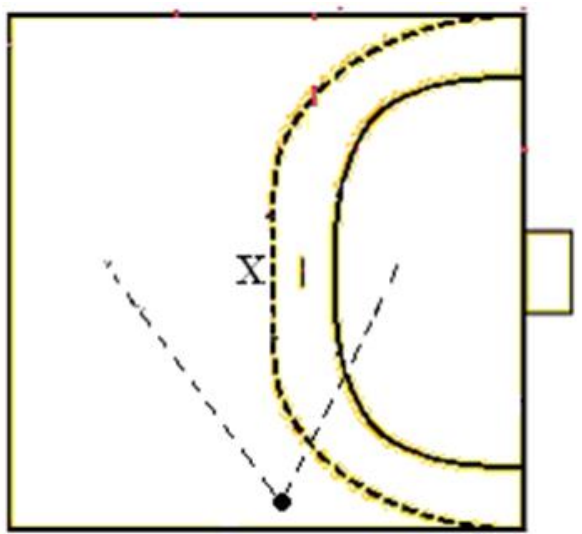

Figure (1) Camera position [*] Camera, [X] shooting player Proposed Core Muscle Exercises Program:

The proposed core muscle Exercises program aims to develop the body's core part muscles strength, and to improve the legs, arms, and trunk muscular ability to raise jump shooting skill level of the research sample female handball players by improving the skill some biomechanical variables.

\section{Proposed Program Setting Foundations}

- The exercises were developed in light of the jump shooting skill technical standards, which serve the skill's motor stages.

- Setting exercises in the light of muscular work for skill performance stages.

- Safety and security factor availability for the Exercises place and the tools used.

- Provide the necessary tools and devices to implement the program.

- Taking into account the individual differences between the research sample players.

- Pay attention to warm-up and prepare the body for Exercises.

- Gradient from easy to difficult, from simple to complex, and from stillness to movement.

\section{Program Time Division}

The program was divided into (30) training units for a period of (10) weeks, at the rate of (3) Training units per week, with a time of (60) minutes per unit, according to the experts opinion.

\section{Forming Exercises Endurance:}

The researcher gradated in the endurance intensity from medium to maximum intensity, where she divided the total endurance cycle into (10) weeks, and each week into (3) Training units, where the endurance gradate were distributed among the Exercises weeks during the Exercises program stages, to start from 55\% to 90\%. The principle of gradual increase in the endurance intensity and size during the Exercises program stages according to the objectives was in consideration, as it started from 55$65 \%$ to $75-90 \%$ of the maximum that an individual can endure.

The researcher legalized the Exercises endurance by determining the appropriate dose for each exercise by dividing the maximum number of repetitions by (2) and recording the time spent by the player in performing each exercise and its endurance, as well as recording the rest time between each exercise and the one after.

\section{Exercises Method}

The researcher used the low-intensity interval Exercises method in the program implementation first stage, and high-intensity interval Exercises in the 
second and third stages.

\section{Proposed Program Design}

The program was divided into (3) stages:

First stage:

- Stage content: initial exercises for the body's core part stability by performing the exercises in a steady position.

- Endurance intensity: 55\% - 65\%

- Duration of the stage: (2) weeks.

- Number of units: (6) units.

Second stage:

- Stage content: complex exercises to stabilize body's core part by performing exercises in a steady position with the arms and legs movement.

- Endurance intensity: 65\% - 80\%

- Duration of the stage: (4) weeks.

- Number of units: (12) units.

Third stage:

- Stage content: Initial and complex exercises and performing exercises in steady and moving position.

- Endurance intensity: $80 \%-90 \%$

- Duration of the stage: (4) weeks.

- Number of units: (12) units.

\section{Training unit Components}

a) The preparatory part (warm-up and stretching): This part achieves general preparation and stretching for all body muscles; it includes running, partridge, jumping and joint flexibility exercises. The warm-up time is (15min) from the Training unit total time.

b) The main part: This part achieves the programs' main goal and includes the proposed core muscle exercises. This part is (40 min) from Training unit total time.

c) The final part (cooling down): This part achieves the players returning to normal state through light running and cooling exercises. This part is (5 min) from the Training unit total time.

\section{Third Pilot Study}

The researcher conducted the third pilot study on (9) female players from the research community outside the main research sample on Wednesday 18/9/2019 in the handball court at Faculty of Physical Education for Girls in El Gezira, in order to test a Training unit from the program, and the study resulted in:

- Exercises suitability with the training unit time.

- Suitable exercises that fits the player's level.

- Being able to determine the actual performance time for each exercise, the average number of repetitions, and the average time between groups.

Table (4) shows a unit model for the proposed program units. 
Table (4)

The proposed program training unit model

Second week, fifth unit, training Level: (foundation) Unit time: $60 \mathrm{~min}$.

\begin{tabular}{|c|c|c|c|c|c|c|}
\hline Unit Parts & Duration & Content & Intensity & Repeat & Groups & $\begin{array}{c}\text { Rest between } \\
\text { groups }\end{array}$ \\
\hline Warm Up & 15 mins & $\begin{array}{l}\text { - Run around the handball court } \\
\text { - (Standing) jumping with feet in place } \\
\text { - (Standing) jumping with feet in place, } \\
\text { forth and back } \\
\text { - (Standing) jumping with the feet in } \\
\text { place to the right and left } \\
\text { - (Standing) jump open, join legs in } \\
\text { place } \\
\text { - Stretching exercises for the legs, trunk } \\
\text { and arms muscles }\end{array}$ & & & & \\
\hline Main Part & 40 mins & $\begin{array}{l}\text {-Push-ups (stability) } \\
\text { - Bridge Marching } \\
\text { - Sit up with leg raises } \\
\text { - Superman Exercise }\end{array}$ & $\begin{array}{c}\% 55 \\
- \\
\% 65\end{array}$ & 20 & 6 & $45 \mathrm{sec}$ \\
\hline Final Part & 5 mins & - Jogging, stretching, and breathing & & & & \\
\hline
\end{tabular}

Main Study

Pre Measurements:

Pre measurements were conducted on the variables under study according to the following order:

- Saturday 21/9/2019, measuring the research sample physical and skill tests.

- Sunday 22/9/2019 filming the jump shooting skill for the research sample of (7) female players, where each player performed (3) shooting attempts and each player best attempt was chosen based on the criteria of correct jump shooting technical performance to extract the biomechanical variables in the skill performance technical stages.

\section{Program Application}

The proposed core muscle training program was applied on the research sample over a period of (10) weeks, (3) training units per week on (Saturday, Monday, and Wednesday), and (30) training units with a capacity of (60) minutes, in the period from Monday 23/9/2019 to Monday 2/12/2019 in the handball court at Faculty of Physical Education for Girls in El Gezira.

\section{Post Measurements}

The post measurements were conducted after the proposed program implementation completion on the research sample, with the same sequence and conditions followed in the pre-measurements.

- Wednesday 4/12/2019 measuring the research sample physical and skill tests.

- Thursday 5/12/2019 filming the jump shooting skill to extract the biomechanical variables extracted in the pre-measurement.

\section{Statistical Treatments}

The researcher used the following statistical treatments:

- Arithmetic mean. 
- Median.

- Standard Deviation.

- Torsion coefficient.

- T-Test.

- Correlation coefficient Pearson.

- Improving Percentage.

- Significance differences test for small samples (parametric) using SPSS software.

- $\left(\mathrm{Q}^{2}\right)$

Results Presentation and Discussion

First: The research sample jump shoot performance most important biomechanical characteristics presentation and discussion:

1) Jump shooting skill performance stages time distribution (preparatory stage - main stage - final stage) for the research sample female players.

Table (5)

Jump shooting performance stages time distribution statistical description for the research sample female players $(n=7)$

\begin{tabular}{|c|c|c|c|c|c|c|c|}
\hline Measurement & $\begin{array}{c}\text { Performance } \\
\text { stages }\end{array}$ & $\begin{array}{c}\text { Measure } \\
\text { unit }\end{array}$ & Mean & SD & Minimum & Maximum & Range \\
\hline \multirow{6}{*}{ Pre } & Preparatory & Sec & $\mathbf{0 , 2 1 1}$ & $\mathbf{0 , 1 9 5}$ & $\mathbf{0 , 2 0}$ & $\mathbf{0 , 2 4}$ & $\mathbf{0 , 0 4}$ \\
\cline { 2 - 8 } & Main & Sec & $\mathbf{0 , 1 5 3}$ & $\mathbf{0 , 0 5 5}$ & $\mathbf{0 , 1 2}$ & $\mathbf{0 , 2 7}$ & $\mathbf{0 , 1 5}$ \\
\cline { 2 - 8 } & Follow-up & Sec & $\mathbf{0 , 0 8}$ & $\mathbf{0 , 0 0 0}$ & $\mathbf{0 , 0 8}$ & $\mathbf{0 , 0 8}$ & $\mathbf{0 , 0 0}$ \\
\hline \multirow{3}{*}{ Post } & Preparatory & Sec & $\mathbf{0 , 2 1 1}$ & $\mathbf{0 , 1 9 5}$ & $\mathbf{0 , 2 0}$ & $\mathbf{0 , 2 4}$ & $\mathbf{0 , 0 4}$ \\
\cline { 2 - 8 } & Main & Sec & $\mathbf{0 , 1 2 0}$ & $\mathbf{0 , 0 0 0}$ & $\mathbf{0 , 1 2}$ & $\mathbf{0 , 1 2}$ & $\mathbf{0 , 0 8}$ \\
\cline { 2 - 8 } & Follow-up & Sec & $\mathbf{0 , 0 8}$ & $\mathbf{0 , 0 0 0}$ & $\mathbf{0 , 0 8}$ & $\mathbf{0 , 0 8}$ & $\mathbf{0 , 0 0}$ \\
\hline
\end{tabular}

Table (6)

The significance differences between the jump shooting skill stages time distribution in both the pre and post measurements for the research sample

female players $(n=7)$

\begin{tabular}{|c|c|c|c|c|c|c|}
\hline Measurement & Groups & Groups no. & $\begin{array}{l}\text { Average } \\
\text { Range }\end{array}$ & $\mathbf{X}$ & $\begin{array}{c}\text { Freedom } \\
\text { Level }\end{array}$ & $\begin{array}{c}\text { Significance } \\
\text { diff. }\end{array}$ \\
\hline \multirow{3}{*}{ Pre } & 1 & 7 & 17,00 & \multirow{6}{*}{16,584} & \multirow{6}{*}{2} & \multirow{6}{*}{$* * * 0,000$} \\
\hline & 2 & 7 & 12,00 & & & \\
\hline & 3 & 7 & 4,00 & & & \\
\hline \multirow{3}{*}{ Post } & 1 & 7 & 18,00 & & & \\
\hline & 2 & 7 & 11,00 & & & \\
\hline & 3 & 7 & 4,00 & & & \\
\hline
\end{tabular}

Group 1=preparatory level Group 2= main level Group 3= final level

In light of the results presented in tables (5) and (6), the researcher can infer some phenomena related to performance characteristics, including:

1. The preparatory movement performance time arithmetic mean (approach steps, shooting arm preparatory swing, elevation and foot instep touching the ground) reached $(0.211 \mathrm{sec})$ and represents $(50 \%)$ of the skill total performance time, evenly for pre or post measurement. The researcher sees that the preparatory stage took a longer time than the main and follow-up stages due to its importance, as it aims to prepare for the basic movement by gathering forces and increasing speed through the shooting arm approaching 
steps and the preparatory movement invert the throwing direction and bending the elevating leg joint, which leads to the appropriate stretching of the working muscles preparing for the appropriate muscle contraction to perform the basic movement. This is in agreement with what "Amal Gaber Berekaa" (2008), "Adel Abd El Basir and Ehab Adel Abd El Basir" (2007), and "Mounir Gerges" (2004) indicated that the preparatory stage aims to well prepare for the main stage, which accomplish the basic mechanical goal, which is obtain a horizontal distance towards the goal to reach the nearest shooting point. The preparatory stage serves the main part and works to prepare the movement performance necessary strength. It is an important stage from a mechanical point of view because it is responsible for placing the shooting arm at the most appropriate point to start the basic movement in the goal direction.

2. The body's basic movement performance time (fly) and shooting arm basic movement in the shooting direction until the ball launches and releases (fly) reached $(0,153 \mathrm{sec})$ from the skill total performance time in the premeasurement, and $(0.120 \mathrm{sec})$ at a rate of $(30 \%)$ from the skill total performance time in post measurements. The researcher sees that this stage is during which the basic movement mechanical goal is achieved and the force obtained in the preparatory stage are exploited, as it represents (the effect and result) while the preparatory stage represents the cause.

3. The skill performance time final part (follow-up) reached $(0.08 \mathrm{~s})$, which was represented in the landing process to the surface from the body's flying state and restoring balance and it represents $(20 \%)$ of the skill performance total, evenly in the pre or post measurement. As the correct landing on the elevated foot followed by the other foot helped maintain the balance quickly after shooting and in a shorter period of time than the previous two stages. After the ball is launched and the player reaches the maximum height, the landing takes place by the action of gravity, where follow up importance is summarized in absorbing the performance redundant energy and making the body maintain its balance. (www.iraqacad.org)

4. There is a variation in the time distribution values, whether in the skill performance total time or the three stages time of the skill performance requirements (preparatory- main - follow-up) for most of the research sample female players between the pre and post measurements. In general, the average of shooting ball basic movement performance improved, as the basic stage average time improved from $(0.153 \mathrm{sec})$ for pre-measurement to $(0.120 \mathrm{sec})$ for post-measurement.

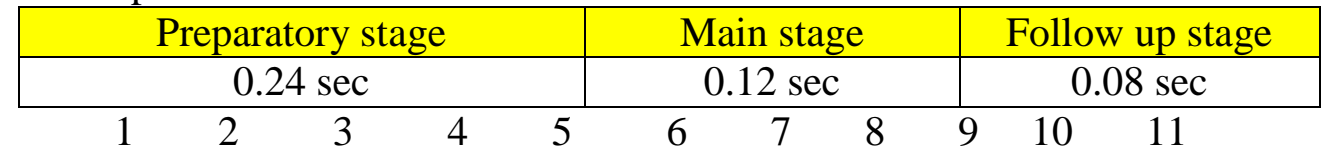

Figure (2) linear chronogram for the jump shot performance stages time distribution of the research sample

2) The horizontal displacement value of the body's motion path during the jump shot skill performance 
Table (7)

The body's movement path from the gravity center horizontal displacement $(\mathrm{cm})$ during the jump shooting skill performance in (pre/post) measurements of the

\section{research sample}

\begin{tabular}{|c|c|c|c|c|c|c|c|c|c|c|c|c|c|c|c|}
\hline \multirow[t]{2}{*}{ Statement } & \multirow{2}{*}{$\begin{array}{c}\text { Measure } \\
\text { unit }\end{array}$} & \multicolumn{2}{|c|}{ Player 1} & \multicolumn{2}{|c|}{ Player 2} & \multicolumn{2}{|c|}{ Player 3} & \multicolumn{2}{|c|}{ Player 4} & \multicolumn{2}{|c|}{ Player 5} & \multicolumn{2}{|c|}{ Player 6} & \multicolumn{2}{|c|}{ Player 7} \\
\hline & & Pre & Post & Pre & Post & Pre & Post & pre & Post & Pre & Post & Pre & Post & Pre & Post \\
\hline 0,04 & sec & 53 & 55 & 52 & 43 & 38 & 35 & 43 & 45 & 50 & 54 & 36 & 43 & 43 & 45 \\
\hline 0,08 & sec & 55 & 52 & 55 & 52 & 43 & 43 & 52 & 53 & 43 & 50 & 43 & 52 & 52 & 53 \\
\hline 0,12 & sec & 52 & 38 & 33 & 29 & 38 & 32 & 38 & 34 & 35 & 38 & 33 & 31 & 38 & 36 \\
\hline 0,16 & sec & 55 & 54 & 38 & 45 & 40 & 50 & 43 & 47 & 45 & 52 & 36 & 45 & 52 & 55 \\
\hline 0,2 & sec & 60 & 57 & 43 & 55 & 43 & 57 & 52 & 55 & 54 & 55 & 45 & 55 & 50 & 60 \\
\hline 0,24 & sec & 65 & 62 & 50 & 62 & 54 & 65 & 55 & 60 & 60 & 65 & 55 & 62 & 57 & 65 \\
\hline 0,28 & sec & 60 & 57 & 45 & 54 & 43 & 56 & 52 & 55 & 55 & 54 & 45 & 45 & 50 & 62 \\
\hline 0,32 & sec & 54 & 55 & 38 & 45 & 38 & 52 & 43 & 45 & 43 & 52 & 38 & 45 & 53 & 55 \\
\hline 0,36 & sec & 52 & 36 & 33 & 31 & 31 & 29 & 34 & 36 & 39 & 40 & 33 & 34 & 36 & 36 \\
\hline
\end{tabular}

Table (7) shows the horizontal displacement value change of the body's movement path during the jump shooting skill performance in the two measurements (pre- post), and the shaded part in the table shows the body's position at the moment the elevating foot is released to start the player's body flight, until the end of the flight and the beginning of the landing point.

In light of the results presented in the previous table, the researcher can discuss these results as follows:

1. The horizontal displacement values of the body's path movement in samples pre and post measurements were variable from the movement beginning to its end as a result of the gradual increase in the gravity center height, especially with the body's flight beginning.

2. The player's pre and post measurements highest value came at a time $(0.24$ sec), and the researcher sees that this value reflects the moment when the player is at the maximum height while performing the skill basic movement and also the shooting arm basic movement, which is the decisive moment in determining the appropriate angle to shot the ball.

3. The reduction in the horizontal displacement value in the post measurement over the pre-measurement at the elevating foot release moment in $(0.16 \mathrm{sec})$ time for some players is attributed by the researcher to the elevating foot pushing force the increase, that is presented in is the body's launch into the air starting force; Which could be a result of the core muscle exercises under study.

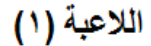

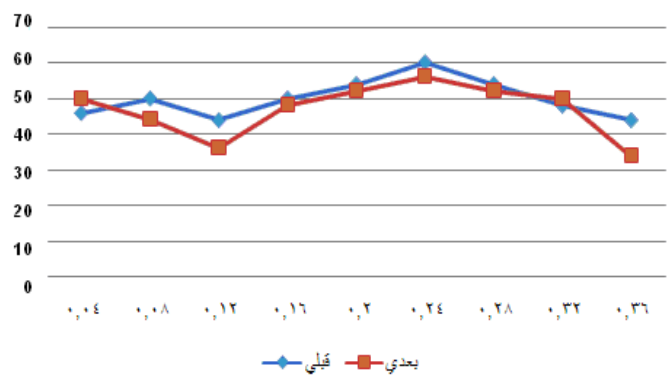



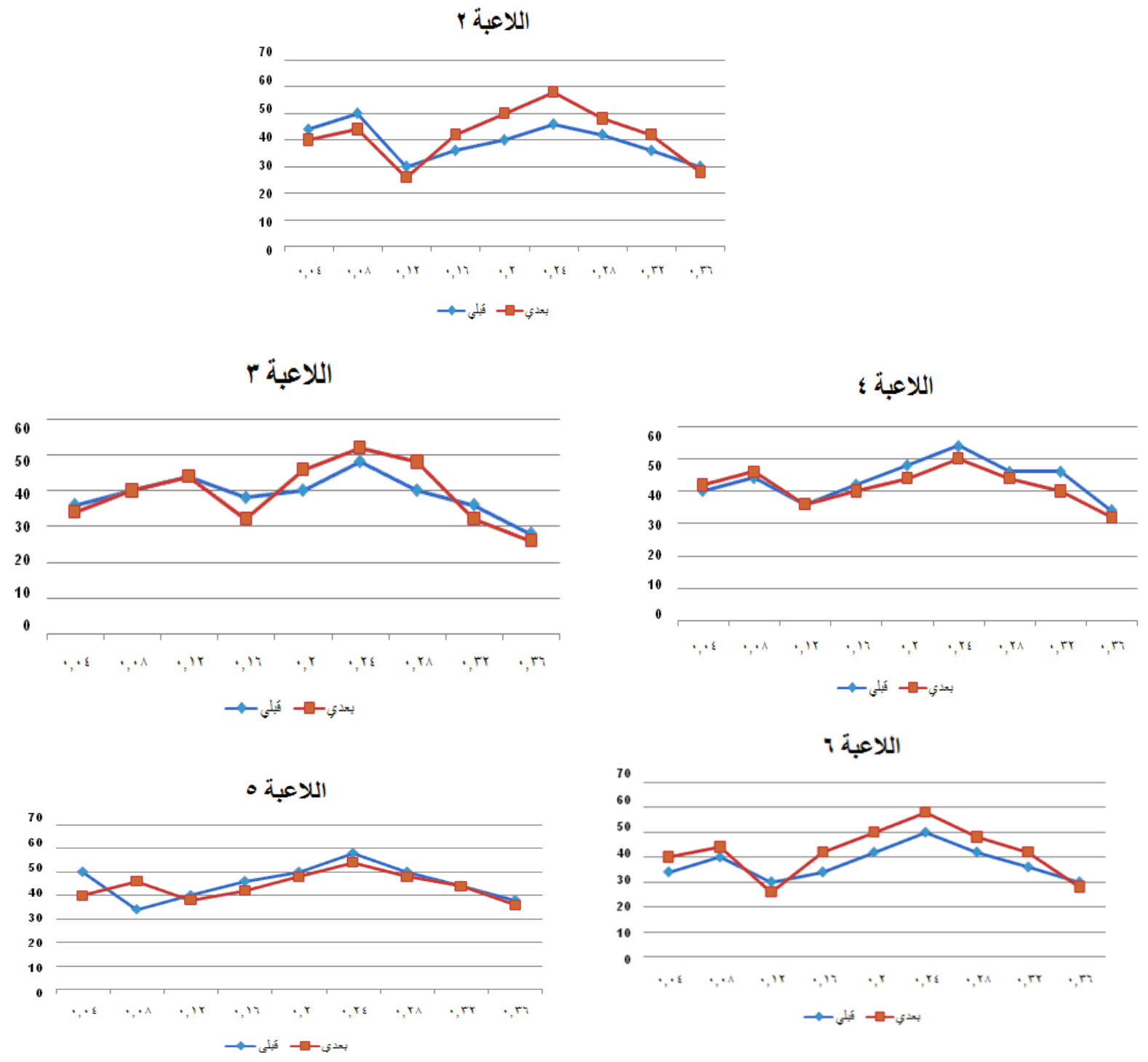

اللاعبة V

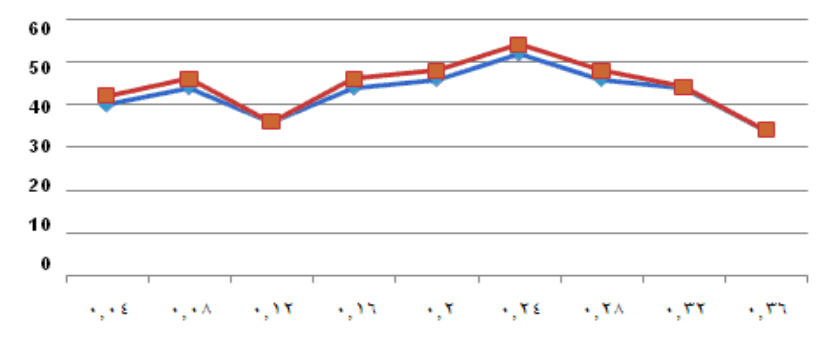

$$
\rightarrow \text { بxist }
$$

Figure (3) horizontal displacement values curve for body movement while performing the jump shooting skill in the two measurements (pre - post) for the female athletes. 


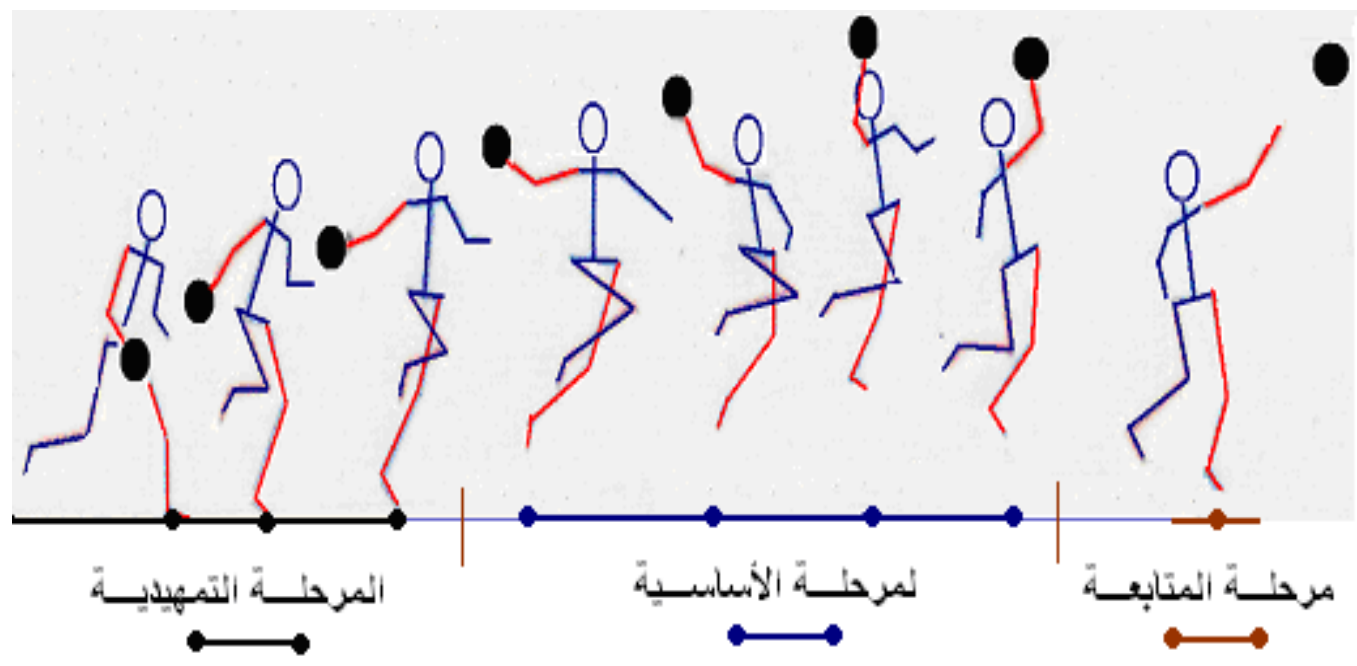

Pre Measurement

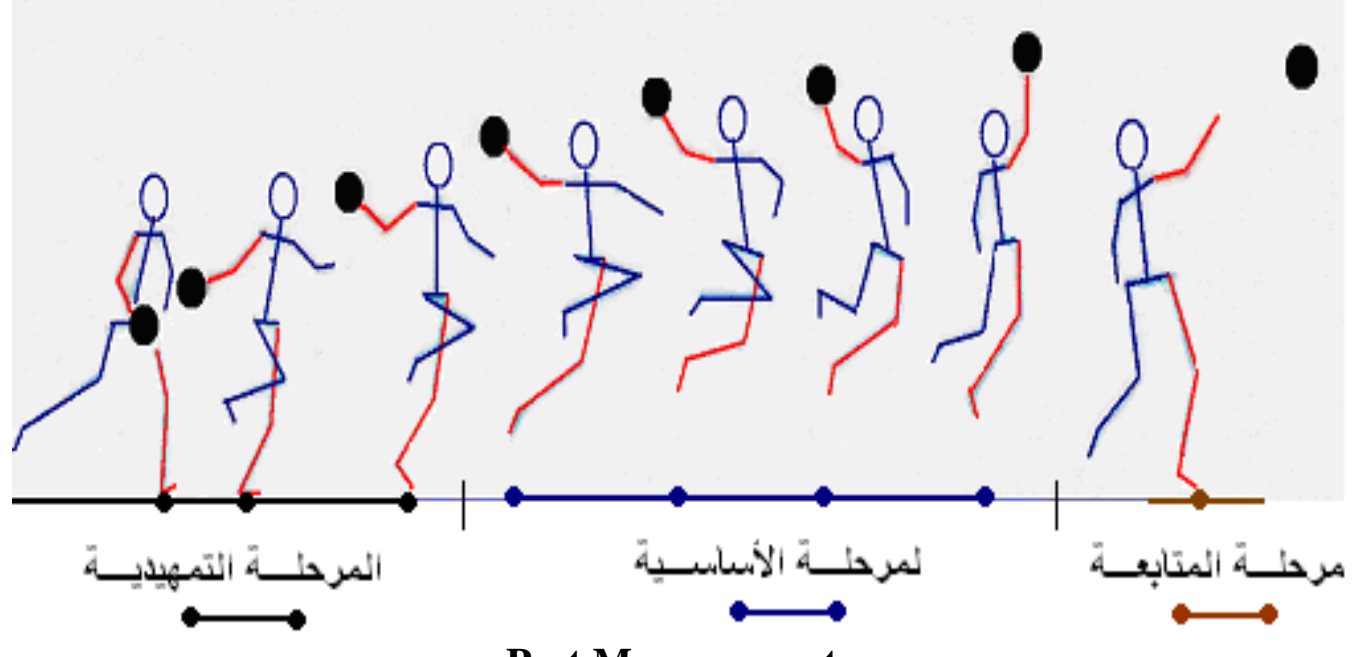

Post Measurement

Figure (4) the body parts kinematic path movement while performing the jump shooting skill in the two measurements (pre - post) of player (1)

3) Shooting arms hand movement horizontal displacement value while performing the jump shooting skill 
Table (8)

Shooting arm hand movement horizontal displacement $(\mathrm{cm})$ during the jump shot skill performance in the two measurements (pre-post) of the research sample

\begin{tabular}{|c|c|c|c|c|c|c|c|c|c|c|c|c|c|c|c|}
\hline \multirow[t]{2}{*}{ Statement } & \multirow{2}{*}{$\begin{array}{c}\text { Measure } \\
\text { unit }\end{array}$} & \multicolumn{2}{|c|}{ Player 1} & \multicolumn{2}{|c|}{ Player 2} & \multicolumn{2}{|c|}{ Player 3} & \multicolumn{2}{|c|}{ Player 4} & \multicolumn{2}{|c|}{ Player 5} & \multicolumn{2}{|c|}{ Player 6} & \multicolumn{2}{|c|}{ Player 7} \\
\hline & & Pre & Post & Pre & Post & Pre & Post & pre & Post & Pre & Post & Pre & Post & Pre & Post \\
\hline 0,04 & sec & 62 & 67 & 57 & 60 & 57 & 43 & 57 & 60 & 65 & 60 & 60 & 57 & 65 & 68 \\
\hline 0,08 & sec & 57 & 65 & 43 & 52 & 43 & 35 & 55 & 53 & 36 & 33 & 52 & 45 & 52 & 53 \\
\hline 0,12 & sec & 43 & 36 & 35 & 33 & 27 & 33 & 36 & 28 & 30 & 22 & 33 & 30 & 38 & 36 \\
\hline 0,16 & sec & 33 & 30 & 28 & 25 & 18 & 22 & 23 & 20 & 22 & 17 & 25 & 18 & 25 & 22 \\
\hline 0,2 & sec & 29 & 22 & 22 & 18 & 12 & 13 & 17 & 15 & 25 & 13 & 18 & 14 & 18 & 15 \\
\hline 0,24 & sec & 36 & 30 & 37 & 36 & 22 & 27 & 33 & 25 & 33 & 25 & 33 & 37 & 30 & 33 \\
\hline 0,28 & sec & 55 & 40 & 45 & 54 & 33 & 36 & 46 & 53 & 48 & 54 & 45 & 54 & 48 & 54 \\
\hline 0,32 & sec & 60 & 65 & 57 & 62 & 52 & 57 & 60 & 60 & 65 & 65 & 62 & 65 & 60 & 64 \\
\hline 0,36 & sec & 75 & 80 & 75 & 83 & 65 & 72 & 65 & 68 & 75 & 75 & 75 & 80 & 72 & 80 \\
\hline
\end{tabular}

Table (8) shows that the horizontal displacement change in values of the shooting arm hand movement during the jump shot skill performance in the two measurements (pre-post), and the table shaded part shows the start of the basic main movement start of the shooting arm until the moment the ball is released.

In light of the results presented in the previous table, the researcher can discuss these results as follows:

1. Shooting arm preparatory stage took two-thirds of the time to perform the arm movement from the beginning of the skill to its end. Table (8) identifies the shooting arm preparatory stage end at $(0.2 \mathrm{sec})$ time.

2. It is also noticed that there is a variation between the shooting arm hand movement horizontal displacement values between the pre and post measurements of the research sample. The researcher sees that the shooting hand movement displacement values increase in general from the beginning of the performance and then its declines with the preparatory stage end. The result of a change in the hand direction from front to backwards reversing the movement direction, and the decline in the preparatory stage post measurement values is a result of the shooting arm expanding and the increased muscle lengthening of the muscles involved in the movement, and increase the muscle stretching of the muscles involved in the movement. The more the shooting arm expands backwards the horizontal displacement values of the preparatory arm movement decline until the arm begins its backward movement with the arm main stage beginning.

3. The basic stage took a quick form of the shooting arm's hand path where the basic stage began with the arm's movement forward beginning towards the goal at a time $(0.24 \mathrm{sec})$ and ended with the launch moment (release) of the ball at a time of $(0.36 \mathrm{sec})$.

The researcher believes that the observed increase in the outputs of the main stage movement horizontal displacement values was a result of the shooting hand movement rapid transfer from back to front until the ball was launched from the player's hand, in addition to the rotation of the trunk, so the throwing process requires the participation of the rest of the body. For that the trunk helps motor transport from the lower to the upper extremities. 


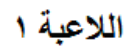

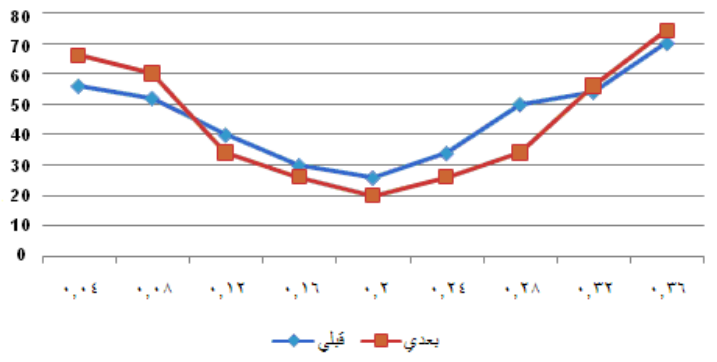

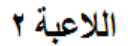
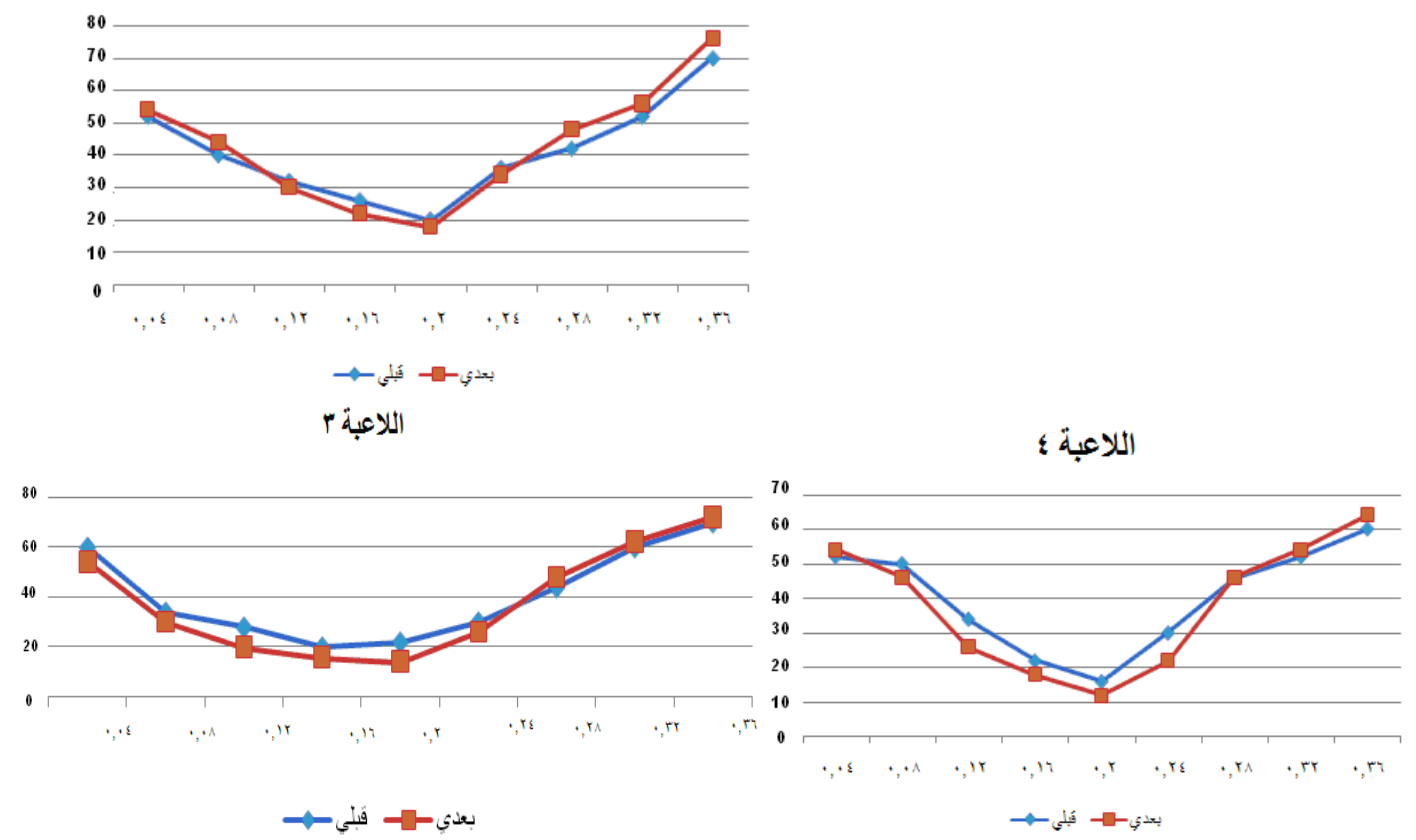

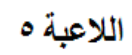
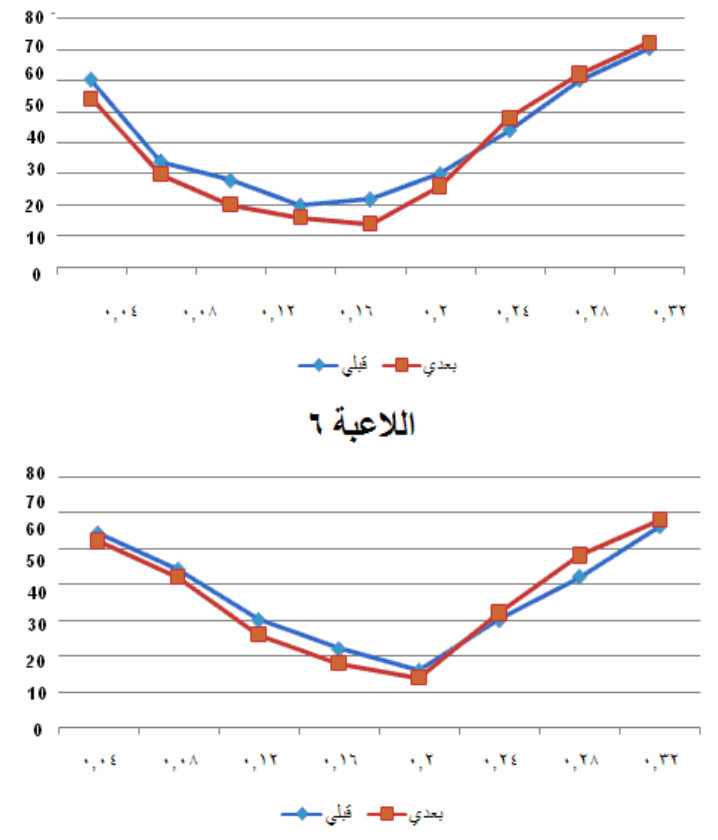


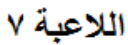

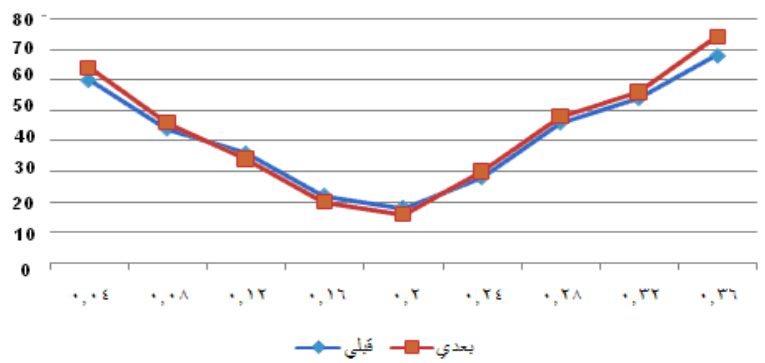

Figure (5) horizontal displacement values curve for the shooting arm's hand movement during the jump shooting skill performance in the two measurements (pre-post) for the research sample female player.

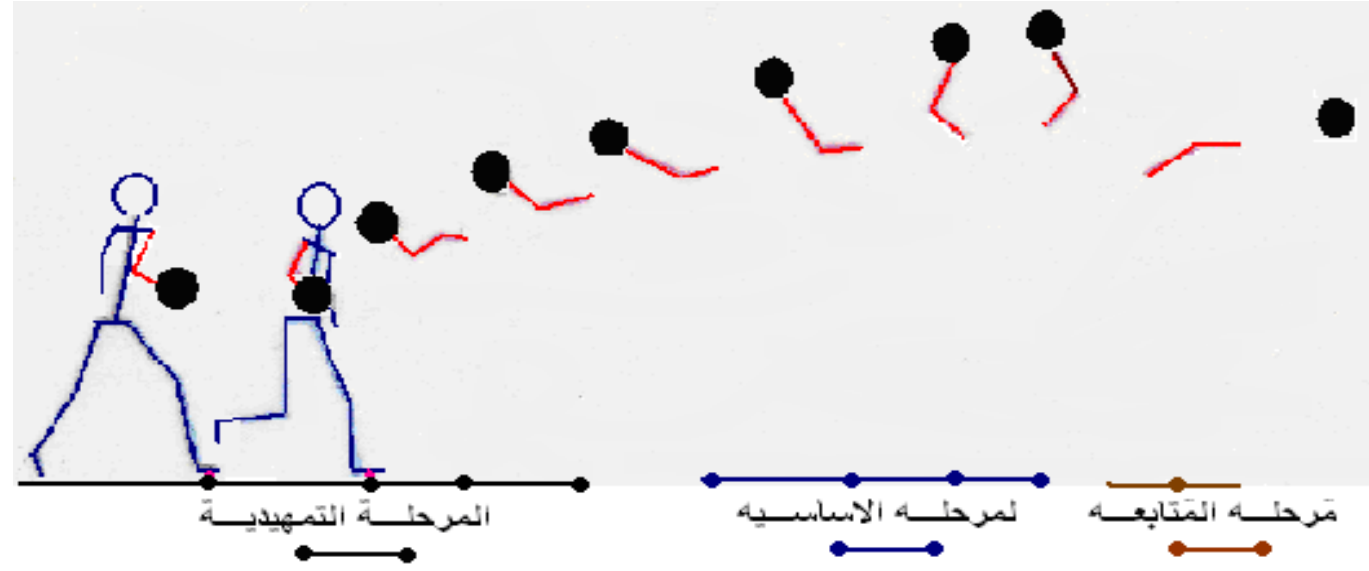

Pre Measurements

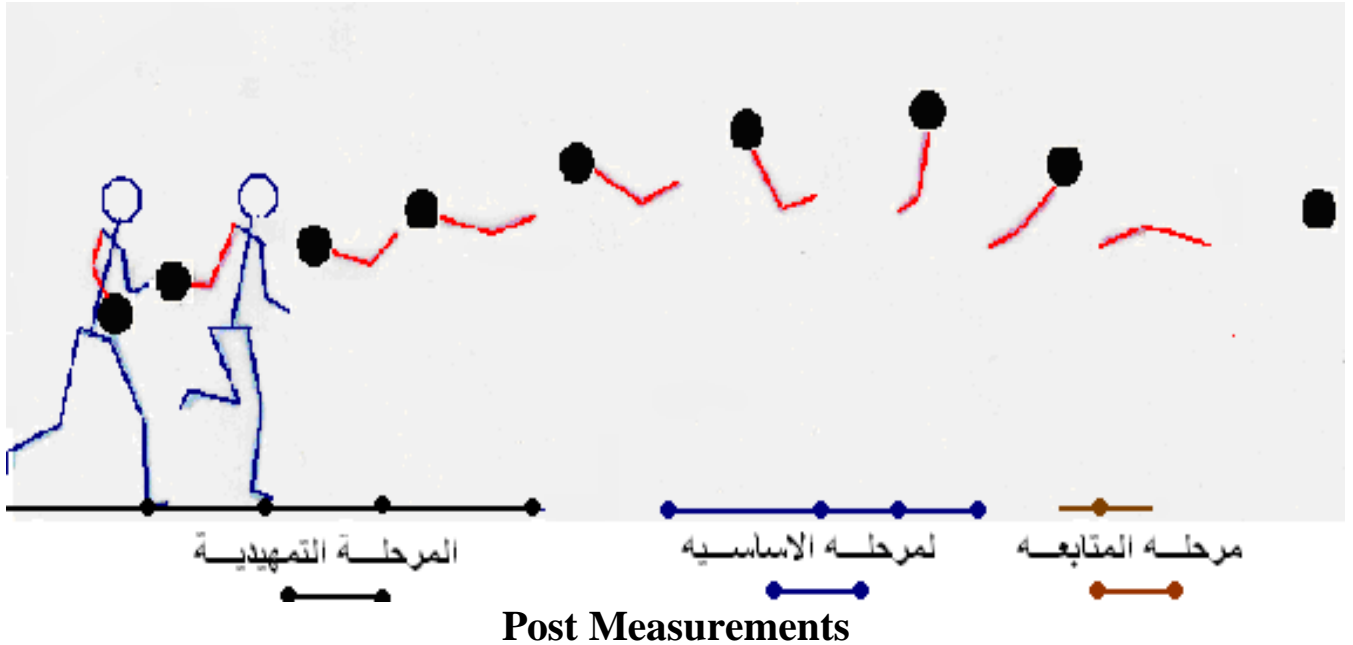

Figure (6) the kinematic path for the shooting arm movement while performing the jump shooting skill in the two measurements (before - after) for player (3)

4) Gravity center height rate on the vertical axis moment of elevating (launch) of the jump shooting skill 
Table (9)

Significant difference between the research sample pre and post measurements in the body's gravity center elevation position in the elevated foot release

moment on the vertical level (meters) $(n=7)$

\begin{tabular}{|c|c|c|c|c|}
\hline $\begin{array}{c}\text { Measuremen } \\
\text { ts }\end{array}$ & $\begin{array}{c}\text { Research sample gravity center } \\
\text { height value Mean }\end{array}$ & Minimum & Maximum & $\mathrm{Z}$ value \\
\hline Pre & $\mathbf{1 , 1 5 2}$ & $\mathbf{1 , 1 2}$ & $\mathbf{1 , 1 8}$ & \multirow{2}{*}{$\mathbf{0 , 8 5 0} *$} \\
\hline Post & $\mathbf{1 , 1 5 7}$ & $\mathbf{1 , 1 0}$ & $\mathbf{1 , 2 0}$ & \\
\hline
\end{tabular}

\section{$Z$ value at a level $(0.05)=0,773$}

By comparing the body's gravity center height values of the pre and post measurement of the research sample female players, it is noted that there is a slight variation in the gravity center height distance between the pre and post measurements, which was in the post measurement direction.

The researcher believes that the body's gravity center height at the elevation moment (launch) depends mainly on the extent of the player's ability to achieve the pushing leg full expansion at the release moment. This may be due to an improvement in the elevation foot work, especially the ankle, and this in turn is considered an improvement in the muscular work of the active muscle groups, especially the legs gastrocnemius muscle as an ankle flexor muscle. Therefore, the researcher believes that the core muscle exercises under study contributed in improving the muscular work of the active muscle groups in the process of pushing the elevation around the knee and foot joints in particular. In addition, the trunk straighten posture was improved by being in line with the pushing leg with the free leg swinging help. This is in agreement with Melvin P. Ramy (2005) in that the height of the body's center of gravity during a jump is affected by the force produced at the elevating moment. (www.iraqcad.org/forum)
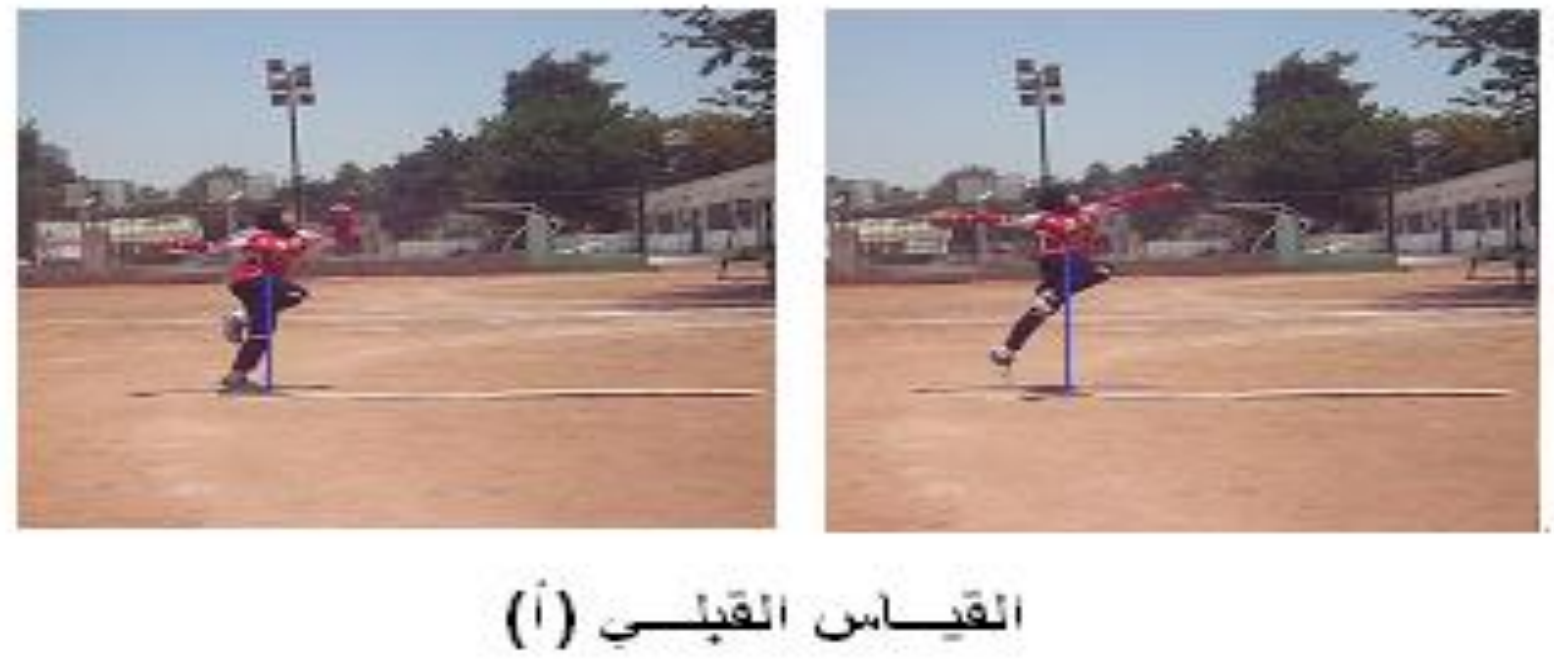

Pre Measurements (A) 

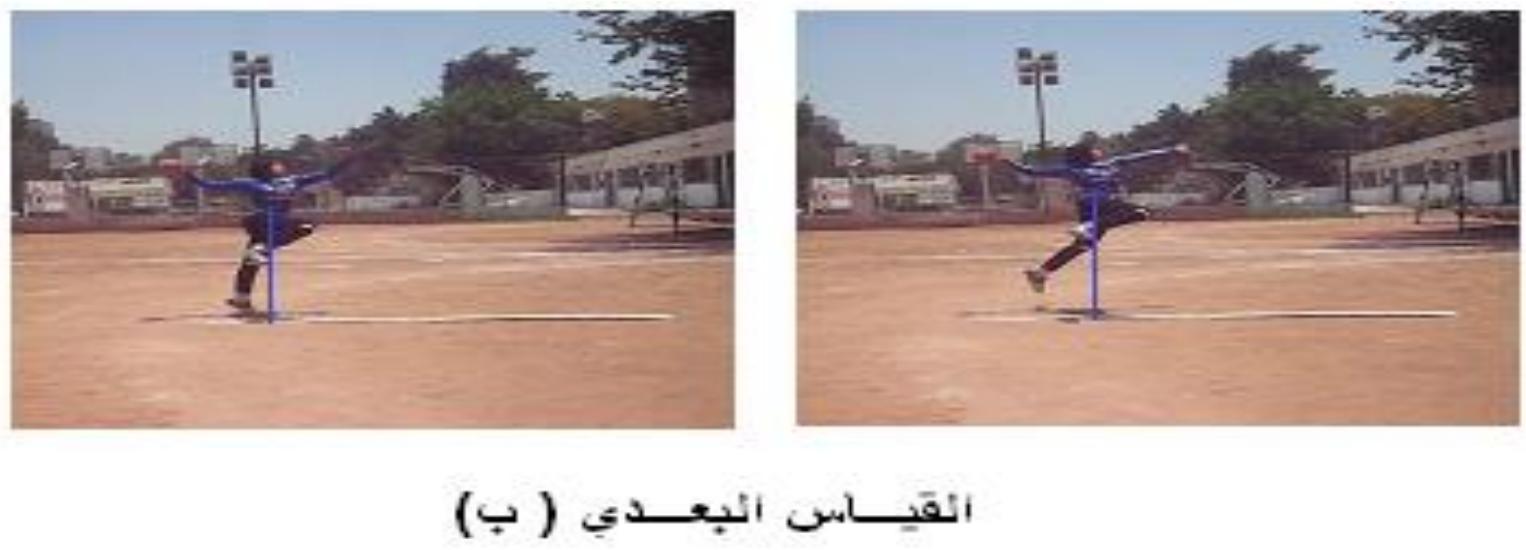

Post Measurements (B)

Figure (7) shows the difference between the body's gravity center height and the elevation moment

For pre-measurement (A) - post measurement (B)

5) The elevated foot vertical velocity components values at the body's launch moment (release) and the shooting arm horizontal velocity components at the ball launch moment (release).

Table (10)

Significance differences between the pre and post measurements of the elevated foot vertical velocity components values at the body's launch moment, and the ball horizontal velocity components at its launch moment of the research sample $(\mathrm{min} / \mathrm{sec})(\mathrm{n}=7)$

\begin{tabular}{|c|c|c|c|c|c|}
\hline \multirow{2}{*}{ Velocity Components } & \multicolumn{2}{|c|}{ Pre Measurements } & \multicolumn{2}{|c|}{$\begin{array}{c}\text { Post } \\
\text { Measurements }\end{array}$} & \multirow{2}{*}{ Z value } \\
\cline { 2 - 5 } & Mean - & SD \pm & Mean - & SD \pm & \\
\hline $\begin{array}{c}\text { Elevated foot vertical velocity } \\
\text { component launch moment }\end{array}$ & 3,735 & $\mathbf{0 , 9 1 5}$ & $\mathbf{4 , 7 9 2}$ & $\mathbf{1 , 0 1}$ & $\mathbf{2 , 3 7 1 *}$ \\
\hline $\begin{array}{c}\text { ball horizontal velocity } \\
\text { components launch moment }\end{array}$ & $\mathbf{1 0 , 4 5 7}$ & $\mathbf{1 , 3 5 2}$ & $\mathbf{2 0 , 4 4 8}$ & $\mathbf{2 , 0 9 2}$ & \multirow{2}{*}{$\mathbf{2 , 3 7 1 *}$} \\
\hline
\end{tabular}

\section{$Z$ value at a level $(0.05)=0,773$}

The researcher believes that the increase in the elevation foot at the body's launch moment instantaneous velocity for post measurement depends on the player's ability to obtain speed from the preparatory stage by taking advantage of the horizontal velocity gained from approaching and converting it into a vertical velocity at the elevating foot pushing moment.

Table (10) shows the increase in the shooting arm horizontal velocity at the ball's launching moment for post measurement. The researcher believes that this depends on increasing the shooting arm's hand motion range, as it increases the arm's movement path and increases the ball's speed in its launch moment. This, in turn, expresses the shooting arm muscular work improvement during the main stage performance (ability stage). In addition to taking advantage of the elevating foot speed, the free leg swinging and the trunk rapid rotation through the body parts kinetic transmission that works on the shooting arms movement path height and thus the ball launch quickly and forcefully in the goal direction. 
1) The angular change values of the shooting arm joints, the free leg, and the lift foot in some jump shooting performance positions.

Table (11)

The body angles value during the jump shot kinematic stages performance in pre and post measurements of the research sample $(n=7)$

\begin{tabular}{|c|c|c|c|c|c|c|c|c|c|c|c|c|c|c|c|}
\hline \multirow{2}{*}{\multicolumn{2}{|c|}{ Body angles variables }} & \multicolumn{2}{|c|}{ Player 1} & \multicolumn{2}{|c|}{ Player 2} & \multicolumn{2}{|c|}{ Player 3} & \multicolumn{2}{|c|}{ Player 4} & \multicolumn{2}{|c|}{ Player 5} & \multicolumn{2}{|c|}{ Player 6} & \multicolumn{2}{|c|}{ Player 7} \\
\hline & & Pre & Post & Pre & Post & Pre & Post & pre & Post & Pre & Post & Pre & Post & Pre & Post \\
\hline \multicolumn{2}{|c|}{$\begin{array}{l}\text { shooting arm elbow angle at the } \\
\text { preparatory motion end }\end{array}$} & 135 & 170 & 135 & 140 & 105 & 150 & 115 & 140 & 105 & 140 & 120 & 155 & 110 & 130 \\
\hline \multicolumn{2}{|c|}{ elbow angle ball release moment } & 85 & 100 & 103 & 110 & 115 & 105 & 115 & 100 & 90 & 100 & 105 & 100 & 95 & 105 \\
\hline \multicolumn{2}{|c|}{$\begin{array}{r}\text { elevation foot angles, launch moment } \\
- \text { instep touch ground }\end{array}$} & 110 & 115 & 95 & 125 & 91 & 125 & 117 & 115 & 127 & 130 & 115 & 120 & 105 & 115 \\
\hline \multicolumn{2}{|c|}{$\begin{array}{c}\text { incline angle elevating moment } \\
\text { (release })\end{array}$} & 5 & 10 & 10 & 15 & 10 & 12 & 12 & 14 & 10 & 15 & 8 & 15 & 10 & 11 \\
\hline \multirow[t]{3}{*}{ free foot angle before launch } & thigh & 45 & 70 & 60 & 38 & 45 & 57 & 30 & 50 & 35 & 45 & 45 & 40 & 40 & 130 \\
\hline & knee & 50 & 50 & 44 & 65 & 55 & 55 & 54 & 95 & 50 & 60 & 50 & 50 & 55 & 105 \\
\hline & ankle & 125 & 135 & 93 & 132 & 65 & 90 & 105 & 115 & 110 & 135 & 105 & 110 & 110 & 115 \\
\hline \multirow{3}{*}{$\begin{array}{l}\text { free foot angles at the body } \\
\text { launch in air moment }\end{array}$} & thigh & 25 & 22 & 44 & 33 & 45 & 42 & 34 & 75 & 40 & 30 & 35 & 30 & 40 & 10 \\
\hline & knee & 53 & 67 & 52 & 52 & 65 & 38 & 62 & 95 & 60 & 50 & 55 & 50 & 65 & 40 \\
\hline & ankle & 70 & 137 & 90 & 120 & 100 & 91 & 118 & 112 & 95 & 130 & 105 & 110 & 110 & 50 \\
\hline \multirow{3}{*}{$\begin{array}{c}\text { Free leg angle with the } \\
\text { shooting arm preparatory } \\
\text { end movement }\end{array}$} & thigh & 35 & 23 & 74 & 29 & 53 & 42 & 54 & 52 & 95 & 30 & 45 & 30 & 50 & 105 \\
\hline & knee & 45 & 50 & 75 & 44 & 105 & 110 & 78 & 125 & 125 & 45 & 70 & 55 & 80 & 40 \\
\hline & ankle & 65 & 135 & 110 & 134 & 110 & 135 & 130 & 140 & 90 & 142 & 110 & 105 & 115 & 55 \\
\hline \multirow{3}{*}{$\begin{array}{l}\text { Free leg angle in the body's } \\
\text { flight path top }\end{array}$} & thigh & 45 & 35 & 70 & 20 & 40 & 40 & 90 & 90 & 40 & 15 & 50 & 35 & 45 & 110 \\
\hline & knee & 28 & 55 & 68 & 45 & 70 & 52 & 117 & 115 & 60 & 35 & 70 & 60 & 65 & 45 \\
\hline & ankle & 55 & 147 & 110 & 97 & 75 & 147 & 110 & 120 & 70 & 90 & 110 & 105 & 115 & 60 \\
\hline
\end{tabular}

Table (11) shows the angular change values of some body parts joints (shooting arm - free leg - elevating foot) in some jump shooting 
As for the shooting arm elbow angle at the preparatory movement end, the obtuse angle has increased in the post measurement than in the pre measurement, since the obtuse angle gives a wider motion range for the shooting arm movement. As for the elbow angle at the moment the ball is released, it is a slightly obtuse angle compared to the elbow angle at the end of the preparatory movement, and it may be less than the same angle in the skill pre measurement for some players such as player (3), player (4) and player (6). The basic shooting arm movement appears with the start by moving the shoulder forward towards the goal, followed by the elbow, then the hand and the ball, and the elbow joint angle is reduced for some players in the post measurement, as a result of the increase in the muscular contraction force that helps to quickly get rid of the ball at the flying phase end.

The researcher believes that the strength development and core muscles ability positively affected the arm's muscular capacity, which affected the shooting arm muscular work by providing the opportunity for muscles sufficient stretching before contracting to perform the basic movement, which can be expressed as the ability stage to complete the shooting process by launching the ball towards the goal.

As for the elevating foot ankle angle at the body's launching moment and the instep touching the ground in the post measurement, was more than the amount of the same angle in the pre measurement. As the slightly obtuse angle in the post measurement is an indicator of the improvement in the elevating foot work by increasing the ankle expansion, which increases the player's ability in the elevation foot pushing the ground process. This is in agreement with "Wilf Paish" (1998) that the jump success is determined by calculating the starting angle at the last point the elevation foot contacted the ground.

The body's inclination angle at the elevation moment, increased in the post measurement than in the pre measurement. The researcher believes that the body's inclination angle at the elevation moment is what enables the player to expand the body joints (thigh, knee, ankle), that pushes the player to launch in the air. Whereas, the inclination angle is determined by the body's gravity center movement forward and upward over the elevating foot with the help of swinging the shooting arm backward, the trunk rotation and the free leg strongly upwards harmonizes with the elevating foot joints expansion (thigh, knee, and ankle), this expansion pushes the player into the air.

The free leg angular change before, at the launch moment, at the shooting arm preparatory movement end and at the flight path top was in some pre measurements exaggerated obtuse angles where the performance was marred by many errors that were corrected in the post measurements; this may be result of the core muscle training. The players were able to take appropriate joint angles for the joint involved in performance, which allows the best stretching and prepares the muscles to contract quickly and strongly, which helped in skill performance the skill in the correct mechanical way. This is in agreement with "Khairia Ibrahim El Sokar, Mohamed Gaber Berekaa" (2002) in that performing the skill in the correct mechanical way enables the player to make good use of all body joints to obtain a technically correct movement. 
Table (12)

Angular change values improvement rates of some body positions and parts for the pre and post measurements $(n=7)$

\begin{tabular}{|c|c|c|c|c|c|c|}
\hline \multicolumn{2}{|c|}{ Body angles variables } & $\begin{array}{l}\text { Reference } \\
\text { frame }\end{array}$ & $\begin{array}{c}\text { Pre } \\
\text { measurements } \\
\text { Mean }\end{array}$ & $\begin{array}{l}\text { Post } \\
\text { Measurements } \\
\text { Mean }\end{array}$ & Differences & $\%$ \\
\hline \multicolumn{2}{|c|}{$\begin{array}{c}\text { shooting arm elbow angle } \\
\text { at the preparatory motion } \\
\text { end }\end{array}$} & Relative & $119^{\circ}$ & $146^{\circ}$ & $27^{\circ}$ & 23 \\
\hline \multicolumn{2}{|c|}{$\begin{array}{c}\text { elbow angle ball release } \\
\text { moment }\end{array}$} & Relative & $101^{\circ}$ & $108^{\circ}$ & $7^{\circ}$ & 7 \\
\hline \multicolumn{2}{|c|}{$\begin{array}{l}\text { elevation foot angles, } \\
\text { launch moment - instep } \\
\text { touch ground }\end{array}$} & Relative & $113^{\circ}$ & $116^{\circ}$ & $3^{\circ}$ & 3 \\
\hline \multicolumn{2}{|c|}{$\begin{array}{c}\text { incline angle elevating } \\
\text { moment (release ) }\end{array}$} & Absolute & $10^{\circ}$ & $11^{\circ}$ & $1^{\circ}$ & 10 \\
\hline \multirow{3}{*}{$\begin{array}{l}\text { free foot angle } \\
\text { before launch }\end{array}$} & thigh & Relative & $43^{\circ}$ & $49^{\circ}$ & $6^{\circ}$ & 14 \\
\hline & knee & Relative & $51^{\circ}$ & $61^{\circ}$ & $10^{\circ}$ & 2 \\
\hline & ankle & Relative & $102^{\circ}$ & $117^{\circ}$ & $15^{\circ}$ & 15 \\
\hline \multirow{3}{*}{$\begin{array}{l}\text { free foot angles at } \\
\text { the body launch in } \\
\text { air moment }\end{array}$} & thigh & Relative & $37^{\circ}$ & $39^{\circ}$ & $2^{\circ}$ & 4 \\
\hline & knee & Relative & $48^{\circ}$ & $60^{\circ}$ & $12^{\circ}$ & 2 \\
\hline & ankle & Relative & $98^{\circ}$ & $116^{\circ}$ & $18^{\circ}$ & 18 \\
\hline \multirow{3}{*}{$\begin{array}{l}\text { Free leg angle with } \\
\text { the shooting arm } \\
\text { preparatory end } \\
\text { movement }\end{array}$} & thigh & Relative & $32^{\circ}$ & $36^{\circ}$ & $4^{\circ}$ & 12 \\
\hline & knee & Relative & $82^{\circ}$ & $90^{\circ}$ & $8^{\circ}$ & 10 \\
\hline & ankle & Relative & $104^{\circ}$ & $129^{\circ}$ & $25^{\circ}$ & 24 \\
\hline \multirow{3}{*}{$\begin{array}{l}\text { Free leg angle in } \\
\text { the body's flight } \\
\text { path top }\end{array}$} & thigh & Relative & $34^{\circ}$ & $39^{\circ}$ & $5^{\circ}$ & 15 \\
\hline & knee & Relative & $68^{\circ}$ & $70^{\circ}$ & $2^{\circ}$ & 3 \\
\hline & ankle & Relative & $92^{\circ}$ & $117^{\circ}$ & $25^{\circ}$ & 27 \\
\hline
\end{tabular}

Table (12) shows the change rate (improvement rate) for the angular change values for some body places and its parts that occurred between the research sample pre and post measurements. The improvement rates ranged between $(2 \%-27 \%)$, and the highest improvement rates were in favor of the free leg angle variable at the top of the body's flying path.

The researcher believes that the change values in favor of technical performance on one hand and the benefit from proceeds of the body core muscles muscle strength development, as well as the active body parts strength and ability development in the skill performance of jump shooting on the other side. Although the percentage values varied according to the mechanical variable pattern, the most obvious changes are the free-leg angle at the body's flight path top and the elbow joint angle (forearm- humerus) at the shooting arm preparatory movement end. This helps improve muscular work during the main stage performance (the ability stage), in addition to increasing the shooting arm hand motion range, which increases arm movement path and increases the ball speed at the launch moment in the goal direction. 


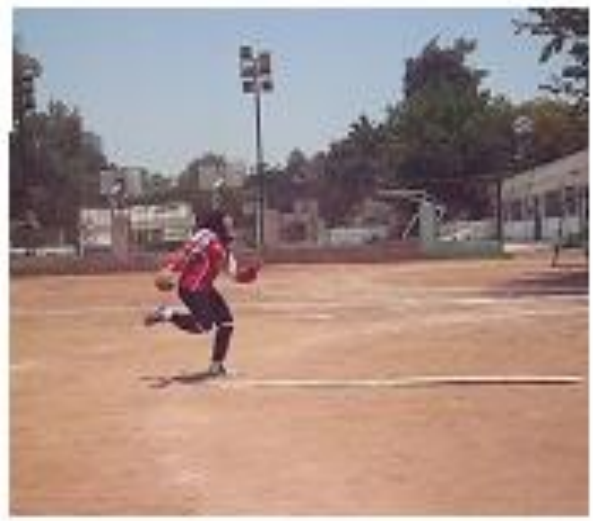

Free Leg Angles before Launch (A)

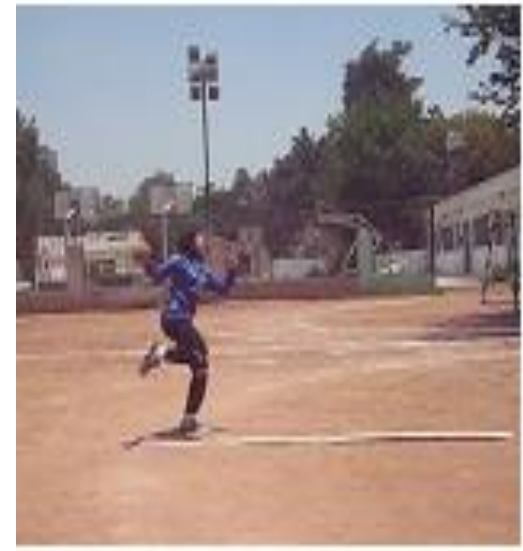

Free Leg Angles before Launch (B)

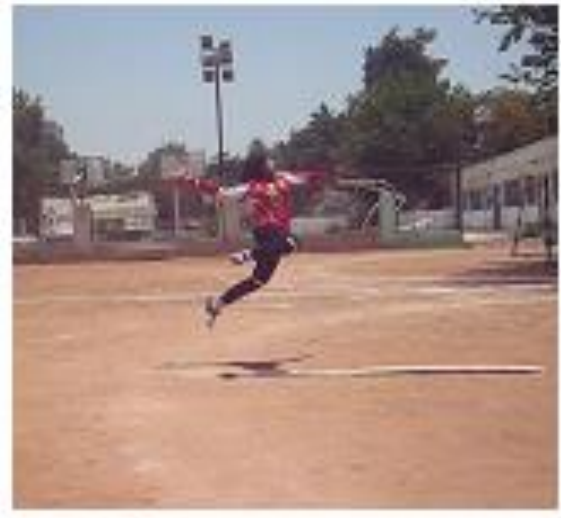

Free leg angles are at the body's

flight path top (A)

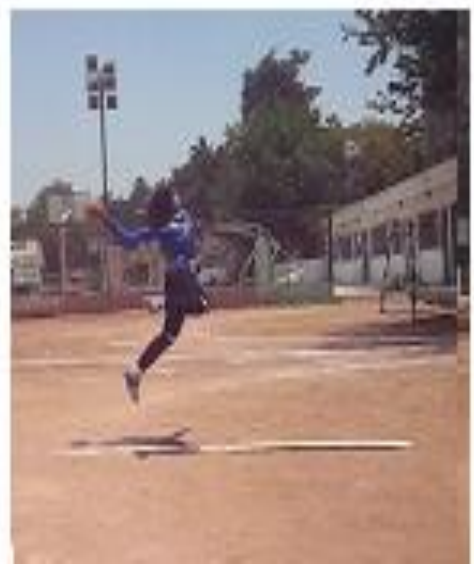

Free leg angles are at the body's

flight path top (B)

Figure (8) Pictures some body angles while performing the shooting jump kinetic stages in the pre (A) - post (B) measurements.

From the above, the first hypothesis has been partially answered, that states: There are statistically significant differences between the pre and post measurements in some biomechanical variables values that affect the long jump shooting skill performance of the research sample handball female players in favor of the post measurement.

Second: The physical and skill variables results of the research sample: 
Table (13)

Significance differences and change rate between the pre and post measurements in the physical and skill variables of the research sample $(n=7)$

\begin{tabular}{|c|c|c|c|c|c|c|c|c|c|c|}
\hline & \multirow{2}{*}{ Tests } & \multirow{2}{*}{$\begin{array}{c}\text { M } \\
\text { unit }\end{array}$} & \multicolumn{2}{|c|}{ Pre } & \multicolumn{2}{|c|}{ Post } & \multirow{2}{*}{$\begin{array}{l}\text { Avera } \\
\text { ge rate }\end{array}$} & \multirow{2}{*}{$\begin{array}{c}\mathbf{Z} \\
\text { value }\end{array}$} & \multirow{2}{*}{$\begin{array}{c}\text { Signific } \\
\text { ance }\end{array}$} & \multirow{2}{*}{$\begin{array}{l}\text { Change } \\
\text { rate \% }\end{array}$} \\
\hline & & & Mean & SD & Mean & SD & & & & \\
\hline \multirow{24}{*}{ 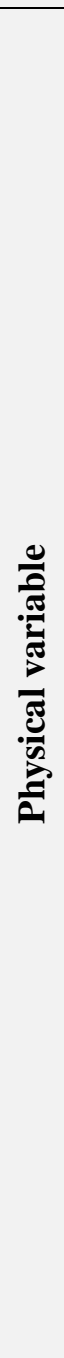 } & \multirow[b]{2}{*}{ Legs strength (Dynamometer) } & \multirow{2}{*}{ Kg } & \multirow{2}{*}{68,00} & \multirow{2}{*}{14,49} & \multirow{2}{*}{ 70,31 } & \multirow{2}{*}{2,11} & $\mathbf{0 , 0 0}$ & \multirow{2}{*}{$2,36-$} & \multirow{2}{*}{$\mathbf{0 , 0 1 7 *}$} & \multirow{2}{*}{22,48} \\
\hline & & & & & & & 4,00 & & & \\
\hline & \multirow[b]{2}{*}{ Back strength(Dynamometer) } & \multirow[b]{2}{*}{ Kg } & \multirow[b]{2}{*}{64,28} & \multirow[b]{2}{*}{12,39} & \multirow{2}{*}{71,21} & \multirow[b]{2}{*}{1,01} & $\mathbf{0 , 0 0}$ & \multirow[b]{2}{*}{$2,37-$} & \multirow{2}{*}{$0,017 *$} & \multirow[b]{2}{*}{16,25} \\
\hline & & & & & & & 4,00 & & & \\
\hline & \multirow[b]{2}{*}{ Sit ups (20 sec) } & & & & & & $\mathbf{0 , 0 0}$ & & $0017 *$ & \\
\hline & & Repeat & 21,57 & 4,03 & 35,54 & 1,11 & 4,00 & 2,37- & $0,017^{*}$ & 46,13 \\
\hline & & Repeat & 18,57 & 3,10 & 24,66 & 4,811 & $\mathbf{0 , 0 0}$ & 2,36- & $\mathbf{0 , 0 1 7 *}$ & 54,16 \\
\hline & Push ups & Repeat & $18,5 /$ & 3,10 & 24,00 & 4,811 & 4,00 & $2,90^{-}$ & $0,01 /$ & 54,10 \\
\hline & & $\mathbf{C m}$ & 148 & 852 & 1573 & 785 & $\mathbf{0 , 0 0}$ & 237 & $0.017 *$ & 63 \\
\hline & Standing broad jump & CIm & 140 & $0, \mathbf{3 z}$ & $15 /, 3$ &, $\mathbf{0 5}$ & 4,00 & $2,3 /-$ & $0,01 / \cdots$ & $\mathbf{0 , 5}$ \\
\hline & & $\mathrm{Cm}$ & 176.3 & 24.34 & 2097 & 34.80 & $\mathbf{0 , 0 0}$ & $236-$ & $0.017 *$ & 18.9 \\
\hline & Broad jump (3 steps) & & & & & & 4,00 & & & \\
\hline & & $\mathrm{Cm}$ & 2257 & 496 & 29.4 & 287 & $\mathbf{0 , 0 0}$ & $237-$ & $0.017 *$ & 307 \\
\hline & Vertical jump with swing arms & $\mathrm{Cm}$ & $22,3 /$ & 4,90 & 29,4 & $2, \mathbf{0} /$ & $\mathbf{4 , 0 0}$ & 2,3/- & & \\
\hline & & $\mathrm{Cm}$ & 18.57 & 2.29 & 23.28 & 281 & $\mathbf{0 , 0 0}$ & $237-$ & $0.017 *$ & 25.4 \\
\hline & Vertical jump without swing arms & CiII & & & & & 4,00 & & 0,011 & $2 \mathfrak{J}, \mathbf{4}$ \\
\hline & & Meter & 535 & 078 & 806 & 166 & $\mathbf{0 , 0 0}$ & 236 & $0017 *$ & 506 \\
\hline & Medicine ball trunk rotation throw & ineter & $\mathbf{5 , 3 0}$ & $0, / 0$ & $\mathbf{0 , 0 0}$ & 1,00 & 4,00 & $2,90^{-}$ & $0,01 / 4$ & 50,0 \\
\hline & & & & & & & $\mathbf{0 , 0 0}$ & & & \\
\hline & $\begin{array}{l}\text { Medicine ball trunk rotation (30 } \\
\text { sec) }\end{array}$ & Repeat & 19,57 & 1,81 & 28 & 2,64 & 4,00 & $2,41-$ & $\mathbf{0 , 0 1 5 *}$ & 43,1 \\
\hline & & & & & & & $\mathbf{0 , 0 0}$ & & & \\
\hline & $\begin{array}{l}\text { Throwing medicine ball to } \\
\text { farthest point }\end{array}$ & Meter & 7,19 & $\mathbf{1 , 4 5}$ & 9,11 & 1,92 & 4,00 & 2,36- & $\mathbf{0 , 0 1 7 *}$ & 26,7 \\
\hline & & & & & & & $\mathbf{0 , 0 0}$ & & & \\
\hline & $\begin{array}{l}\text { Strength\& stability of core } \\
\text { muscles }\end{array}$ & Grade & 41,25 & 0,98 & 71,21 & 0,54 & 4,00 & 2,36- & $0,017 *$ & 72,6 \\
\hline & & & & & & & $\mathbf{0 , 0 0}$ & & & \\
\hline $\overrightarrow{\frac{\pi}{\pi}}$ & $\begin{array}{l}\text { Long jump shot\& calculatıng fly } \\
\text { distance }\end{array}$ & $\mathrm{m}$ & $1, \mathbf{8 8}$ & $\mathbf{0 , 2 7}$ & 2,05 & $\mathbf{0 , 2 9}$ & 4,00 & 2,39- & 0,017* & $\mathbf{9 , 0 4}$ \\
\hline$\stackrel{\bar{z}}{\bar{z}}$ & Long jump shot accuracy on goal & ade & 4797 & 9.17 & 51.06 & 8.77 & $\mathbf{0 , 0 0}$ & $237-$ & $0.018 *$ & 14.4 \\
\hline$\frac{4}{\pi}$ & corners & & & & & & 4,00 & & & \\
\hline
\end{tabular}

Significance $\leq(\mathbf{0 , 0 5})$

in favor of the post measurement. It is also clear from table (13) that the improvement rates in the physical tests ranged between (72.6\% and 6.3\%), and the highest improvement rates was in favor of testing the core strength and stability.

The researcher attributes the improvement occurrence to the good planning of the core muscle training program and the training loads regulations in a scientific manner appropriate 
with the age and training phase of the research sample. She used the Swiss ball exercises, light weights and using body weight as a core strength training major part in order to develop muscular strength, where the researcher took into account the training with gradual loads during the program implementation by training the various muscle groups, especially the core part muscles.

This is in agreement with both "Skip \& Allen" (2002) that the most important benefits resulting from practicing exercises to strengthen the body's core part muscles are to increase motor efficiency during exercise, increase the body stability, and produce tremendous strength from the body's core part muscles as well as the adjacent muscles (shoulder, arms, and legs). The velocity strength characteristic improvement (muscular capacity), the activity of the rubber reflex allows excellent strength characterized transfer by velocity to the same biomechanically similar movements that require the trunk and the legs high capacity.

In this regard, Dave Schmitz (2003) points out that strong core muscles connect the lower extremities to the upper extremities, in addition to that core strength training includes multidirectional movements, making it one of the best exercises used to improve core muscle strength. (Middle body)

The table also shows statistically significant differences between the pre and post measurements in favor of the post measurement in the skill tests of the jump shot skill of the research sample. The researcher attributes this result to the core muscle training program, which led to an improvement in the legs and arms muscle strength and ability. The success of the shot skill requires the legs ability so that the player can jump forward to the maximum distance, as well as the arms strength and ability so that the shot is characterized by strength, speed and accuracy.

The core muscles exercises led to strengthening the trunk muscles, which has a great impact on the skill performance. This is in agreement with Reita (1997), who pointed that the aiming strength depends on the trunk rapid rotation, also in line with "Leith Ibrahim" (2009), who indicates that the shot skill performance skill requires many muscle groups participation beside the arms and shoulder in order to perform it with the required efficiency. This is done by transferring the force generated from the foot muscles through the trunk to end with the ball leaving the shooting palm, which requires a movement transfer in which the force is transferred between the body parts and applied in a way that ensures that the shot is stronger and faster as possible.

From the above, the first hypothesis has been partially answered, that states: There are statistically significant differences between the pre and post measurements in the muscle strength level (legs, trunk, arms), as well as the jump shooting skill level of the research sample handball female players in favor of the post measurement.

\section{Conclusions}

In light of the research objectives, within the research sample limits, from the data and information that the researcher has reached, and in statistical treatments light, the following were concluded:

1. The differences between the stages time distribution of the jump shooting skill performance in the pre and post measurements were statistically significant in both the preparatory and the main stage in favor of the post measurement, the variation in the follow-up phase time is equivalent, and the time distribution is summarized as follows:

- $\quad$ The average total time to perform the skill was approximately $(0.4 \mathrm{~s})$.

- The skill preparatory movement represented in (approach, elevate and arm movement 
aiming backward) represents approximately (50\%) of the players performance time in general according to the general situation and in particular according to the development processes during the player's training program.

- The skill basic movement, which was represented in (flying and the arm movement aiming the goal) represents $(30 \%)$ of the skill performance total time and with an ability time $(0.12 \mathrm{~s})$ for all research sample players, in the post measurement of the jump shot skill performance.

2. The core muscle exercises under study helped increase the elevating strength (pushing) and the body's launch speed.

3. Increasing the ankle range and pushing the free leg at the body launching moment is reflected in the body's gravity center height at the launch moment to complete the shot.

4. The change in values percentage variation $(\%)$ of the biomechanical variables is fitting to the job function and is in favor of performance.

5. Research sample strength and muscle ability measurements (legs - trunk - arms) were statistically significant in favor of the post measurements.

6. The change highest percentage improvement in muscular work for strength output and muscular ability among the three body parts (legs - trunk - arms) was the largest for the core area.

\section{Recommendations}

Within the research limits, its sample, and methodology used, and through the results, the researcher recommends the following:

1. Coaches making use of the research results as indicators through which to infer the player's physical performance characteristics.

2. Paying attention to the muscular work characteristic analysis and its parts during the handball skills performance generally and shooting specifically.

3. Paying attention to training the involved muscles during jump shot by applying more core muscle exercises within the training units.

4. Paying attention to training the players on the preparatory stage shot performance in a good way because of its important impact on the main stage.

5. Paying attention to developing muscle strength and ability for the trunk region for its role in the motor transport from the lower extremities to the upper extremities and achieving more motor control in the parts movement to serve the skill performance objective.

6. Increasing scientific research to support performance tests by using the mechanical variable values to evaluate the performance level.

\section{References List:}

\section{First: Arabic References}

1. Adel Abd El Basir Ali, Ihab Adel Abd El Basir (2007): Biomechanical Analysis (Integration between Theory and Practice in the Sports Field), Central Library for Printing and Publishing (394-396).

2. Amal Gaber Berikaa (2008): Biomechanics Principles and their Applications in the Sports Field, Dar Al-Wafaa Le Donia for Printing and Publishing, Alexandria. (17-60).

3. Fathy Ahmed Hady (2010): Modern Scientific Training in Handball, Horus International Foundation.

4. Kamal Abd El Hamid Ismail, Mohamed Sobhy Hassanein (2010): The Modern Handball Quad, Book Center for Publishing, Cairo. 
5. Kamal El Din Darwish, Kadri Sayed Morsy, Emad El Din Abbas (2002): Measurement, Evaluation, and Game Analysis in Handball, Theories - Applications, 1st Edition, Book Center for Publishing, Cairo. (125-130)

6. Khairia Ibrahim El Sokkari, Mohamed Gaber Berekaa (2002): Biomechanics Basic Principles in Sports Field, Part One, Knowledge Foundation in Alexandria. (120-124)

7. Laila El Sayed Farhat (2005): Measurement and Examination in Physical Education, 3rd Edition, Book Center for Publishing, Cairo. (71)

8. Leith Ibrahim Jassim Al-Azizi (2009): "Special strength and its relationship with the shot strength and accuracy during different physical effort levels for handball youth players aged (18-20)", Physical Education Science Journal, Volume Two, Issue Three, Syria. (110-133)

9. Mohamed Khalil Mohamed El Akidy (2004): Biochemical analysis of some shot skill variables from high jumping and their relationship with the handball shooting accuracy, Unpublished PhD thesis, KTR, Mosul University, Baghdad. (16)

10. Mohamed Said Soliman Abu Samra (2006): Plyometric Program Effectiveness on Some Kinematic Variables for the high jump in Hhandball for the Palestinian National Team, Unpublished Master's Thesis, Faculty of Physical Education, Tanta University.

11. Mohamed Sobhy Hassanein (2001): Measurement and Evaluation in Physical Education and Sports, 4th Edition, Arab Thought House, Cairo.

12. Mounir Gerges Ibrahim (2004): Handball for all (comprehensive training and skill excellence), Arab Thought House, Cairo. (145)

13. Talha Hossam E Din, Mohamed Fawzy Abd El Shakor, Mohamed El Sayed Helmy (2006): Motor Control (Principles - Theories - Applications), 1st Edition, Book Center for Publishing, Cairo. (75)

\section{Second: English References}

14 - Aishe El Fateh (2011): "The Effect of Core Strengthening on Physical Variables and Performance Level of Lung Among Young Female Fencers" Sport and science, National Sport Academy, Bulgira, 1000, Sofia, blv.v.levski, no75.(97-121)

15 - Akuthota, V., and S.F. Nadler. (2004): Core strengthening. Arch. Phys. Med. Rehabil. 85:86y92.(68)

16 - Allen, Skip (2002): "Core strength Training", science institute sports science Exchange roundtable, USA.(41)

17 - Bliss, Lisa S. (2005): "Core Stability the centerpiece of any training program" American college of sports medicine.(56)

18 - Dave Schmitz (2003): Functional Training Pyramids, New Truer High School, Kinetic Wellness Department, USA.(13-25)

19 - Dean Brittenham, Greg Brittenham (2003): Stronger ABC and Back, Human Kinetics, USA.(67)

20 - Melvin R. Ramey: Biomechanics of the long jump and triple jump, Department of Civil Engineering and Department of Physical Education University of California، Davis، California 95616، U.S.A.(202)

21 - Prentice, William (2003):"Arnheiem Principles of Athletic Training", Barns and Noble.(54)

22 - Reita, Eclaton, Mary Phg/D Wight (1997): Team handball Steps to Success Champaign, Human Kinetice.(33-44)

23 - Ron Jones (2003): Functional Training \#1: Introduction, Reebo Santana, Jose Carlos 
Univ. USA.(24)

24 - Wilf Paish(1998): The Complete Manual of Sports Science، A\&C Black Publishers LTD، London.(26)

\section{Third: Internet References}

25- $\quad$ http://www.w3c.org/tr/1999/rec-htm1401-1999/224/loose.dtd

26- http://www.iraqcad.org/forum/viewtopic.php.35

27- http://www.iraqacad.org/lip/uday.pdf 


\section{The Requirements of Digital Transformation and Its Economic Applications To Achieve a Competitive Advantage in Major Sports Clubs In the Arab Republic of Egypt}

\section{Assistant Prof. Dr. / Reham Amin Hamza Shehab}

Assistant Professor, Department of Sports Administration, Faculty of Physical Education for Girls, Alexandria University.

\section{Research Problem and Importance:}

Under accelerated developments of information and communication technology, many administrative directions emerged towards adopting digital transformation.

Tomas M. Siebel (2019), George Westernman (2014) defines digital transformation as a phenomenon arising from using information and communication technologies and new digital techniques synchronically to produce a lot of information to use in decision making and strategic planning. (59: 26), (47: 32)

The researcher believes that digital transformation he researcher believes that the digital transformation is changing the structure of the institution and building its strategy on digital technology and the technical capabilities it possesses to achieve value for its customers.

UNESCO (2018) and Sara Grand (2017) defines digital skills as along chain of skills of using digital appliances, communications and works applications to reach and administrate information and establishing a digital content. (41: 2), (58: 5).

Communication International Federation (2018) indicates that digital skills are subdivided to 3 levels: basic, average and advanced skills. (23: 18)

Giacomo and Antonio (2018) and Ovidiu, Peter (2013) indicate that things internet links infinite number of things via a network with availing the relevant technical support. (48: 34), (56: 167).

Bruce Sinclair (2017) indicates that computers ability to knowledge by using things internetcollected data enables us to follow up and count things. (45: 16)

Kevin L. Jackson and Scott (2018) define cloud computerization the set of computerized sources and systems on demand via internet able to avail some of integrated computer services. (54: 12)

Financial Crises of (2008) affected the confidence between governments and companies, also weak and unsafe information technologies and users' increasing fear from lack of privacy and safety resulted in the so called blue kitchen technique.

(44: 13).

David, Christophe (2019) defines blocks chain as distributing data to a great number of points spread on internet which is computers entrusted with verifying true data and operations (46: 23).

Book of Jared Tate, Andrew Knapp (2019) mentions that blocks chain consists of 4 main elements represented in: block, information. Margin and time print. (50:27)

Joel Gurin (2014) and Rob Kitchen (2014) define open data as publishing digital data on internet in an automatic legible format. (52:18), (57:17)

Julian Singh (2017) indicates that for data to be open many levels shall be considered: legal opening, technical opening and commercial opening. (53: 44).

Beshir Arnous (2007) and Srour Ali Srour (2005) defines artificial intelligence as a part of accounting science looking for developed programming methods for carrying out works and 
conclusions similar to methods alluding intelligence to human. (10: 9), (39: 26)

Mohit Sharma (2018), Khalil Abo Koura (2014) define systems of automating robot processes as non-intertwined applications requiring no technical integration with other system. (55: 11), (37: 19)

Ramadan Elmarouf (2011), Abdelsabour Elmasry (2011) and Hind Hamid (2010) define ecommerce as all business made electronically via internet. (34:34), (2: 24), (21:17)

Jim Work George Brand (2020) mentions that applying ecommerce shall depend on three factors: "E. markets, E. data exchange and internet". (51:57)

As Gil Gildner, Anya Gildner (2019) and Youssef Abo Fara (2007) define E. marketing as some efforts exerted by the company to inform purchasers of its products and services and communicating with them via internet. (49:14), (42:27)

Egypt adopter a serious direction to be a digital community as a basis of achieving integrated and permanent development, at the first step of transferring to digital economy in Egypt, the first Egyptian communication satellite, Tiba, was developed (1). (60), (68), (61: 2), (62:1).

In the sports field, there are many new attempts to attend digital transfer, as minister of youth and sports, in coordination with officials of Microsoft Egypt looked into binary cooperation in the field of digital transformation. (63:1)

Also El Ahly Club adopted the digital transformation strategy incorporated under its future plan to transfer all services provided to members electronically, also Heliopolis Club and Kuwait National Bank - Egypt signed a cooperation protocol to support and activate digital transformation system, also Smouha Club declared a protocol of cooperation with Egypt telecom to develop the internet infra-structure.

(64: 2), (65:1), (66:1), (67:2).

The researcher concluded a Pilot Study for some supreme management officials at clubs whose number reached 6 subjects to identify the status quo and procedures taken by the supreme management to make development needed for applying digital transformation. The interview results proved the supreme management's awareness of the importance of adopting digital transformation strategies.

Also the researcher concludes a second pilot study for a sample of sports clubs' employees, whose number reached (11) subjects to identify the fact of digital transformation inside sports clubs, as the results proved establishing an interactive website, the main club's data bases are being updated, the club's infrastructure is being developed and protocols of cooperating with banks are being signed to support digital transformation projects.

Also through looking into the previous studies results such as results of Nawal Abdalla (2019) (30), Hanin Abdelasalam(2019) (18), Faleh Abbas (2019) (14), Tawil Osama (2017) (40), Dina Mohamed Adel (2016) (12), digital transformation contributes to providing high quality digital governmental services, good planning for transfer to e administration in sports department is lacking.

As study of Omar Saleh (2018) (33) and Khloud Bent Salem (2019) (24) recommends that there should be an infrastructure to enable profiting from E. government services and availing human resources to develop the same and financial resources to avail systems required for concluding digital transformation.

Through the researcher open personal interviews, the survey study and the results and recommendations of previous studies, the researcher concluded the importance of activating digital transformation system in sports clubs and adopting modern communication systems to transfer all services provided to members electronically in order to achieve the satisfaction of the 
beneficiaries, and to support the competitiveness of sports clubs. Researcher to conduct the current research and its title:

This made the researcher carry out this research titled:

"The Requirements of Digital Transformation and Its Economic Applications to Achieve a Competitive Advantage in Major Sports Clubs in the Arab Republic of Egypt"

The Research Objective:

The research aims at identifying The Requirements of Digital Transformation and Its Economic Applications to Achieve a Competitive Advantage in Major Sports Clubs in the Arab Republic of Egypt via identifying:

- Digital transformation requirements: "supreme management support, digital skills, digital techniques"

- Digital transformation economic applications: "E. commerce, E. marketing"

The Research Procedures:

The research method:

The survey descriptive method was used as suitable for the research nature.

The research community:

The research community consisted of (9) great clubs from Cairo and Alexandria.

The research sample:

Table (1) Numerical Description of the Research Community Groups Subjects and the Pilot and the Main Research Sample

\begin{tabular}{|c|c|c|c|c|c|}
\hline \multirow{2}{*}{ Administrative levels } & \multirow{2}{*}{$\begin{array}{l}\text { Total research } \\
\text { community }\end{array}$} & \multirow{2}{*}{$\begin{array}{c}\text { Sample of } \\
\text { codifying } \\
\text { questionnaire } \\
\text { form }\end{array}$} & \multirow{2}{*}{ Removed forms } & \multicolumn{2}{|c|}{ Main Search Sample } \\
\hline & & & & Number & Percentages \\
\hline Supreme management : clubs boards' members & 99 & 11 & 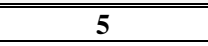 & 83 & $83.83 \%$ \\
\hline $\begin{array}{l}\text { Middle management: executive managers and } \\
\text { sports activity mangers }\end{array}$ & 25 & 6 & 3 & 18 & $64 \%$ \\
\hline Executive management: sports specialists & 123 & 21 & 13 & 89 & $72.35 \%$ \\
\hline Total & 247 & 38 & 21 & 188 & \multirow{2}{*}{$76.113 \%$} \\
\hline Percentage & $100 \%$ & $15.38 \%$ & $8.502 \%$ & $76.113 \%$ & \\
\hline
\end{tabular}

Data Collection Tools:

Questionnaire form designed by the researcher

The researcher followed the following steps to design the questionnaire form: - Results of the interview, the first and second exploratory study. - Access to the scientific references and the results of previous studies. Through this, the researcher was able to develop the factors and dimensions of the questionnaire, as it included two main factors, first factor of (3) dimensions, and second factor of (2) dimensions.

Questionnaire form scientific coefficients:

Calculating validity questionnaire form scientific coefficient:

Table (2) Correlation Coefficient between Questionnaire Dimensions and Factors $(\mathrm{N}=38)$

\begin{tabular}{|c|c|c|c|c|c|c|}
\hline \multirow{2}{*}{\multicolumn{2}{|c|}{ Factors and dimensions }} & \multicolumn{4}{|c|}{ First factor } & \multirow{3}{*}{$\begin{array}{c}\begin{array}{c}\text { Questionnaire } \\
\text { total degree }\end{array} \\
\mathbf{0 . 8 3 9} \\
\end{array}$} \\
\hline & & \multirow{2}{*}{ First factor } & \multirow{2}{*}{$\begin{array}{c}\begin{array}{c}\text { Second } \\
\text { factor }\end{array} \\
\mathbf{0 . 5 8 5} \\
\end{array}$} & \multirow{2}{*}{$\begin{array}{r}\begin{array}{r}\text { Third } \\
\text { factor }\end{array} \\
\mathbf{0 . 7 8 5} \\
\end{array}$} & \multirow{2}{*}{$\begin{array}{c}\begin{array}{c}\text { Total factors } \\
\text { degree }\end{array} \\
\mathbf{0 . 7 4 5} \\
\end{array}$} & \\
\hline First & First dimension & & & & & \\
\hline factor & Second dimension & & & 0.617 & $\mathbf{0 . 7 3 7}$ & 0.877 \\
\hline
\end{tabular}




\begin{tabular}{|c|c|c|c|c|c|}
\hline & Third dimension & & & \multirow[t]{2}{*}{0.759} & \multirow{2}{*}{$\begin{array}{l}0.851 \\
0.845 \\
\end{array}$} \\
\hline & Total degree & & & & \\
\hline \multirow{2}{*}{\multicolumn{2}{|c|}{ Factors and dimensions }} & \multicolumn{3}{|c|}{ Second factor } & Total \\
\hline & & $\begin{array}{c}\text { First } \\
\text { dimension }\end{array}$ & $\begin{array}{c}\text { Second } \\
\text { dimension }\end{array}$ & Total factors degree & $\begin{array}{c}\text { questionnaire } \\
\text { degree }\end{array}$ \\
\hline \multirow{3}{*}{$\begin{array}{l}\text { Second } \\
\text { factor }\end{array}$} & First dimension & & 0.791 & 0.534 & 0.749 \\
\hline & Second dimension & & & 0.609 & $\mathbf{0 . 8 3 0}$ \\
\hline & Total degree & & & & 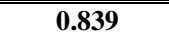 \\
\hline
\end{tabular}

Rg value $(0,05.36)=0,304$

Table (2) clarifies a statistical significant correlation at significant level (0.05) between the degree of every factor and the whole degree to prove questionnaire internal consistency.

Calculating questionnaire reliability coefficient:

Table (3) Questionnaire Reliability by Split Half and Cronbach's Alpha

\begin{tabular}{|c|c|c|c|}
\hline \multirow[b]{2}{*}{ Factors and Dimensions } & \multicolumn{2}{|c|}{ Split half } & \multirow[b]{2}{*}{ Cronbach's Alpha } \\
\hline & $\begin{array}{l}\text { Spearman } \\
\text { Brown }\end{array}$ & Guttman & \\
\hline First dimension: supreme management support & 0.716 & 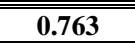 & 0.776 \\
\hline Second dimension: digital skills & 0.789 & 0.817 & 0.749 \\
\hline Third dimensions: digital technique & 0.745 & 0.736 & $\mathbf{0 . 7 0 5}$ \\
\hline $\begin{array}{l}\text { First factor: requirements of digital transformation to achieve } \\
\text { a competitive advantage at sports clubs }\end{array}$ & 0.821 & 0.755 & 0.781 \\
\hline First dimension: E. commerce & $\mathbf{0 . 7 1 5}$ & 0.873 & $\mathbf{0 . 7 7 5}$ \\
\hline Second dimension: E. marketing & $\mathbf{0 . 7 6 3}$ & 0.851 & $\mathbf{0 . 7 2 3}$ \\
\hline $\begin{array}{c}\text { Second factor: economic applications of digital transformation } \\
\text { to achieve a competitive advantage at sports clubs }\end{array}$ & 0.746 & 0.757 & 0.806 \\
\hline Total questionnaire degree & 0.721 & 0.918 & 0.881 \\
\hline
\end{tabular}

From table (3) it is clear that reliability coefficient by half split ranged between (0.715) and (0.918) and Cronbach's Alpha reliability coefficient ranged between (0.705) and (0.881) proving that the researched questionnaire has a high reliability coefficient.

Application of the questionnaire form:

The questionnaire form was applied in its final form to the basic research sample, which amounted to (188) single, during the period from (6/12/2020) to $(18 / 8 / 2020)$.

Statistical treatments:

Repetitions, percentage, spearman's rank correlation coefficient, split half for Spearman Brown and Guttman, Cronbach's Alpha reliability coefficient, outweighed percentage, arithmetic mean out weighted by weights, chi square for independent samples (cross tabulation), chi square for one sample, (Chi Square Goodness of Fit Test).

Discussing results:

Table (4) First Factor Results: Digital Transformation Requirements to Achieve the Best Competitive Advantage at Clubs (First Dimension: Supreme Management Support)

\begin{tabular}{|c|c|c|c|c|c|c|c|c|c|}
\hline $\mathbf{S}$ & Statement content & Departments & Agreeing & $\begin{array}{c}\text { To } \\
\text { a certain } \\
\text { degree }\end{array}$ & Disagreeing & $\begin{array}{c}\text { Out } \\
\text { weighted } \\
\text { percentage }\end{array}$ & Average & Attitude & Chi square \\
\hline$\overline{11}$ & & & supreme $\mathbf{m}$ & 1agement $\mathrm{s}$ & pports digital & Insformation & & & \\
\hline \multirow{4}{*}{$1 / 1$} & \multirow{4}{*}{$\begin{array}{l}\text { Looking into new } \\
\text { techniques }\end{array}$} & $\begin{array}{c}\text { Supreme } \\
\text { management }=83\end{array}$ & 66 & 9 & 8 & 89.96 & 2.70 & agreeing & \multirow{3}{*}{7.49} \\
\hline & & $\begin{array}{c}\text { Middle } \\
\text { management }=16\end{array}$ & 9 & 2 & 5 & 75.00 & 2.25 & $\begin{array}{c}\text { to a certain } \\
\text { degree }\end{array}$ & \\
\hline & & $\begin{array}{c}\text { Executive } \\
\text { management= } 89\end{array}$ & 61 & 8 & 20 & 82.02 & 2.46 & agreeing & \\
\hline & & All $=188$ & 136 & 19 & 33 & 84.93 & 2.55 & agreeing & 130.29 \\
\hline $1 / 2$ & Readiness for bearing & $\begin{array}{c}\text { Supreme } \\
\text { management }=83\end{array}$ & 62 & 13 & 8 & 88.35 & 2.65 & agreeing & $15.15 *$ \\
\hline
\end{tabular}




\begin{tabular}{|c|c|c|c|c|c|c|c|c|c|}
\hline $\mathbf{S}$ & Statement content & Departments & Agreeing & $\begin{array}{c}\text { To } \\
\text { a certain } \\
\text { degree }\end{array}$ & Disagreeing & $\begin{array}{c}\text { Out } \\
\text { weighted } \\
\text { percentage }\end{array}$ & Average & Attitude & Chi square \\
\hline & $\begin{array}{l}\text { digital transformation } \\
\text { application costs }\end{array}$ & $\begin{array}{c}\text { Middle } \\
\text { management }=16\end{array}$ & 8 & 2 & 6 & 70.83 & 2.13 & $\begin{array}{l}\text { to a certain } \\
\text { degree }\end{array}$ & \\
\hline & & $\begin{array}{c}\text { Executive } \\
\text { management }=89\end{array}$ & 54 & 7 & 28 & 76.40 & 2.29 & $\begin{array}{l}\text { to a certain } \\
\text { degree }\end{array}$ & \\
\hline & & All $=188$ & 124 & 22 & 42 & 81.21 & 2.44 & agreeing & 93.23 \\
\hline \multirow{4}{*}{$1 / 3$} & \multirow{4}{*}{$\begin{array}{l}\text { Training employees and } \\
\text { providing them with all } \\
\text { skills neede for } \\
\text { attending technique } \\
\text { permanently }\end{array}$} & $\begin{array}{c}\text { Supreme } \\
\text { management }=83\end{array}$ & 64 & 11 & 8 & 89.16 & 2.67 & agreeing & \multirow{3}{*}{$15.72 *$} \\
\hline & & $\begin{array}{c}\text { Middle } \\
\text { management }=16\end{array}$ & 9 & 1 & 6 & 72.92 & 2.19 & $\begin{array}{c}\text { to a certain } \\
\text { degree }\end{array}$ & \\
\hline & & $\begin{array}{c}\text { Executive } \\
\text { management }=89\end{array}$ & 58 & 4 & 27 & 78.28 & 2.35 & agreeing & \\
\hline & & All $=188$ & 131 & 16 & 41 & 82.62 & 2.48 & agreeing & 116.76 \\
\hline \multirow{4}{*}{$1 / 4$} & \multirow{4}{*}{$\begin{array}{l}\text { Planning for dealing } \\
\text { with restrictions of } \\
\text { using new techniques }\end{array}$} & $\begin{array}{c}\text { Supreme } \\
\text { management }=83\end{array}$ & 67 & 8 & 8 & 90.36 & 2.71 & agreeing & \multirow{3}{*}{$13.18 *$} \\
\hline & & $\begin{array}{c}\text { Middle } \\
\text { management }=16\end{array}$ & 10 & 1 & 5 & 77.08 & 2.31 & $\begin{array}{l}\text { to a certain } \\
\text { degree }\end{array}$ & \\
\hline & & $\begin{array}{c}\text { Executive } \\
\text { management }=89\end{array}$ & 51 & 13 & 25 & 76.40 & 2.29 & $\begin{array}{l}\text { to a certain } \\
\text { degree }\end{array}$ & \\
\hline & & All $=188$ & 128 & 22 & 38 & 82.62 & 2.48 & agreeing & 104.21 \\
\hline \multirow{4}{*}{2} & \multirow{4}{*}{$\begin{array}{c}\text { The club's } \\
\text { organizational structure } \\
\text { agrees with digital } \\
\text { transformation } \\
\text { application }\end{array}$} & $\begin{array}{c}\text { Supreme } \\
\text { management }=83\end{array}$ & 59 & 12 & 12 & 85.54 & 2.57 & agreeing & \multirow{3}{*}{$14.58 *$} \\
\hline & & $\begin{array}{c}\text { Middle } \\
\text { management }=16\end{array}$ & 6 & 3 & 7 & 64.58 & 1.94 & $\begin{array}{l}\text { to a certain } \\
\text { degree }\end{array}$ & \\
\hline & & $\begin{array}{c}\text { Executive } \\
\text { management }=89\end{array}$ & 44 & 12 & 33 & 70.79 & 2.12 & $\begin{array}{l}\text { to a certain } \\
\text { degree }\end{array}$ & \\
\hline & & All $=188$ & 109 & 27 & 52 & 76.77 & 2.30 & $\begin{array}{l}\text { to a certain } \\
\text { degree }\end{array}$ & 56.37 \\
\hline \multirow{4}{*}{3} & \multirow{4}{*}{$\begin{array}{c}\text { There is a specialized } \\
\text { committee or unit for } \\
\text { applying digital } \\
\text { transformation as } \\
\text { planned }\end{array}$} & $\begin{array}{c}\text { Supreme } \\
\text { management }=83\end{array}$ & 60 & 15 & 8 & 87.55 & 2.63 & Agreeing & \multirow{3}{*}{$15.41 *$} \\
\hline & & $\begin{array}{c}\text { Middle } \\
\text { management }=16\end{array}$ & 7 & 3 & 6 & 68.75 & 2.06 & $\begin{array}{l}\text { to a certain } \\
\text { degree }\end{array}$ & \\
\hline & & $\begin{array}{c}\text { Executive } \\
\text { management }=89\end{array}$ & 48 & 12 & 29 & 73.78 & 2.21 & $\begin{array}{l}\text { to a certain } \\
\text { degree }\end{array}$ & \\
\hline & & All $=\mathbf{1 8 8}$ & 115 & 30 & 43 & 79.43 & 2.38 & agreeing & 66.90 \\
\hline \multirow{4}{*}{4} & \multirow{4}{*}{$\begin{array}{l}\text { The club documents } \\
\text { services and transforms } \\
\text { paper forms to } \\
\text { electronic ones }\end{array}$} & $\begin{array}{c}\text { Supreme } \\
\text { management }=83\end{array}$ & 56 & 4 & 23 & 79.92 & 2.40 & agreeing & \multirow{3}{*}{8.82} \\
\hline & & $\begin{array}{c}\text { Middle } \\
\text { management }=16\end{array}$ & 7 & 2 & 7 & 66.67 & 2.00 & $\begin{array}{l}\text { to a certain } \\
\text { degree }\end{array}$ & \\
\hline & & $\begin{array}{c}\text { Executive } \\
\text { management }=89\end{array}$ & 45 & 14 & 30 & 72.28 & 2.17 & $\begin{array}{l}\text { to a certain } \\
\text { degree }\end{array}$ & \\
\hline & & All $=188$ & 108 & 20 & 60 & 75.18 & 2.26 & $\begin{array}{l}\text { to a certain } \\
\text { degree }\end{array}$ & 61.96 \\
\hline \multirow{2}{*}{5} & \multirow{2}{*}{$\begin{array}{l}\text { Information systems } \\
\text { used by the club are } \\
\text { integrated and } \\
\text { associated with all the }\end{array}$} & $\begin{array}{c}\text { Supreme } \\
\text { management }=83\end{array}$ & 51 & 8 & 24 & 77.51 & 2.33 & $\begin{array}{l}\text { to a certain } \\
\text { degree }\end{array}$ & \multirow{2}{*}{5.72} \\
\hline & & $\begin{array}{c}\text { Middle } \\
\text { management }=16\end{array}$ & 6 & 2 & 8 & 62.50 & 1.88 & $\begin{array}{l}\text { to a certain } \\
\text { degree }\end{array}$ & \\
\hline
\end{tabular}




\begin{tabular}{|c|c|c|c|c|c|c|c|c|c|}
\hline $\mathbf{S}$ & Statement content & Departments & Agreeing & $\begin{array}{c}\text { To } \\
\text { a certain } \\
\text { degree }\end{array}$ & Disagreeing & $\begin{array}{c}\text { Out } \\
\text { weighted } \\
\text { percentage }\end{array}$ & Average & Attitude & Chi square \\
\hline & club's units & $\begin{array}{c}\text { Executive } \\
\text { management= } 89\end{array}$ & 41 & 12 & 36 & 68.54 & 2.06 & $\begin{array}{c}\text { to a certain } \\
\text { degree }\end{array}$ & \\
\hline & & All $=188$ & 98 & 22 & 68 & 71.99 & 2.16 & $\begin{array}{l}\text { to a certain } \\
\text { degree }\end{array}$ & 46.77 \\
\hline \multirow{4}{*}{6} & \multirow{4}{*}{$\begin{array}{l}\text { Consulting investment } \\
\text { authorities and experts } \\
\text { to give information } \\
\text { about developing } \\
\text { information technology } \\
\text { fields }\end{array}$} & $\begin{array}{c}\text { Supreme } \\
\text { management }=83\end{array}$ & 60 & 2 & 21 & 82.33 & 2.47 & agreeing & \multirow{3}{*}{$15.35 *$} \\
\hline & & $\begin{array}{c}\text { Middle } \\
\text { management }=16\end{array}$ & 5 & 3 & 8 & 60.42 & 1.81 & $\begin{array}{c}\text { to a certain } \\
\text { degree }\end{array}$ & \\
\hline & & $\begin{array}{c}\text { Executive } \\
\text { management= } 89\end{array}$ & 46 & 9 & 34 & 71.16 & 2.13 & $\begin{array}{c}\text { to a certain } \\
\text { degree }\end{array}$ & \\
\hline & & All $=188$ & 111 & 14 & 63 & 75.18 & 2.26 & $\begin{array}{l}\text { to a certain } \\
\text { degree }\end{array}$ & 75.07 \\
\hline \multirow{4}{*}{7} & \multirow{4}{*}{$\begin{array}{l}\text { The club has a system } \\
\text { for evaluating } \\
\text { employees performance } \\
\text { indicating clear norms } \\
\text { of their ability to use } \\
\text { information technology } \\
\text { applications }\end{array}$} & $\begin{array}{c}\text { Supreme } \\
\text { management }=83\end{array}$ & 50 & 9 & 24 & 77.11 & 2.31 & $\begin{array}{c}\text { to a certain } \\
\text { degree }\end{array}$ & \multirow{3}{*}{5.43} \\
\hline & & $\begin{array}{c}\text { Middle } \\
\text { management }=16\end{array}$ & 5 & 2 & 9 & 58.33 & 1.75 & $\begin{array}{l}\text { to a certain } \\
\text { degree }\end{array}$ & \\
\hline & & $\begin{array}{c}\text { Executive } \\
\text { management }=89\end{array}$ & 49 & 12 & 28 & 74.53 & 2.24 & $\begin{array}{c}\text { to a certain } \\
\text { degree }\end{array}$ & \\
\hline & & All $=188$ & 104 & 23 & 61 & 74.29 & 2.23 & $\begin{array}{l}\text { to a certain } \\
\text { degree }\end{array}$ & 52.41 \\
\hline
\end{tabular}

Chi square value $(0,05,4)=9,488$, Chi square value $(0,05,2)=5,991$

Outweighed arithmetic mean: disagreeing (1: 1.66), to a certain degree (1.67: 2.33), agreeing (2.34:3)

From table (4) agreement of research sample groups on statements number $(1 / 1,4,5,7)$ was clear as the outweighed percentage of the whole sample ranged between (71.99: 84.93) as chi square ranged between (5.43: 8.82)

Results of study of Doaa Elhasban, Weaam Elhayek (2017) (13) indicate the importance of appointing an authority responsible for supervising and following up digital transformation.

Saad Shalaby and Abdellatif Bokhary (2008) (35) confirm that clubs delaying in using new technologies will lag behind other clubs.

Also the above table results proved difference between opinions of the research sample groups on statements number $(\mathbf{1 / 2}, \mathbf{1 / 3}, \mathbf{1 / 4}, \mathbf{2}, \mathbf{3}, \mathbf{6})$ at level $(0.05)$ as chi square ranged between $\left(13.18^{*}: 15.72 *\right)$ with outweighed percentage (75.18: 82.62).

Results of study of Mahmoud Ibrahim and Bassma Haddad (2018) (25), and Ashour Abdelkarim (2010) (9) found that digital transformation depends on compiling a clear strategy by some field expert.

The results of the study of Ashour Abdul Karim (2010) (9) indicate that the development of the level of employees mainly requires a review of their competence, by integrating the human resources of the institutions within the programs of raising the qualification level, with the aim of compatibility with the developments and the reality of these institutions in light of the digital transformation strategy.

The researcher concludes that the sports club management must develop plans and strategies that support the digital transformation system, the more accurately and clearly formulated, the greater the success rate of its implementation. 
Table (5) First Factor Results: Digital Transformation Requirements to Achieve a Competitive Advantage at Clubs (Second Dimension: Digital Skills) (A- Main Skills)

\begin{tabular}{|c|c|c|c|c|c|c|c|c|c|}
\hline $\mathbf{S}$ & Statement content & Departments & Agreeing & $\begin{array}{c}\text { To a } \\
\text { certain } \\
\text { degree }\end{array}$ & Disagreeing & $\begin{array}{l}\text { Out weighted } \\
\text { percentage }\end{array}$ & Average & Attitude & $\begin{array}{l}\text { Chi } \\
\text { square }\end{array}$ \\
\hline 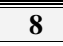 & the club's employees & ave the main digital & 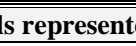 & & & & & & \multirow{4}{*}{3.63} \\
\hline \multirow{4}{*}{$8 / 1$} & \multirow{4}{*}{ Using keyboard } & $\begin{array}{c}\text { Supreme } \\
\text { management }=83\end{array}$ & 68 & 7 & 8 & 90.76 & 2.72 & agreeing & \\
\hline & & $\begin{array}{c}\text { Middle } \\
\text { management }=16\end{array}$ & 10 & 2 & 4 & 79.17 & 2.38 & agreeing & \\
\hline & & $\begin{array}{c}\text { Executive } \\
\text { management }=89\end{array}$ & 71 & 8 & 10 & 89.51 & 2.69 & agreeing & \\
\hline & & All $=188$ & 149 & 17 & 22 & 89.18 & 2.68 & agreeing & 178.61 \\
\hline \multirow{4}{*}{$8 / 2$} & \multirow{4}{*}{$\begin{array}{l}\text { Administrating } \\
\text { files in computers }\end{array}$} & $\begin{array}{c}\text { Supreme } \\
\text { management }=83\end{array}$ & 66 & 8 & 9 & 89.56 & 2.69 & agreeing & \multirow{3}{*}{8.34} \\
\hline & & $\begin{array}{c}\text { Middle } \\
\text { management }=16\end{array}$ & 9 & 1 & 6 & 72.92 & 2.19 & $\begin{array}{c}\text { to a certain } \\
\text { degree }\end{array}$ & \\
\hline & & $\begin{array}{c}\text { Executive } \\
\text { management }=89\end{array}$ & 69 & 9 & 11 & 88.39 & 2.65 & agreeing & \\
\hline & & All $=188$ & 144 & 18 & 26 & 87.59 & 2.63 & agreeing & 158.85 \\
\hline \multirow{4}{*}{$8 / 3$} & \multirow{4}{*}{$\begin{array}{l}\text { Protecting personal } \\
\text { and private data }\end{array}$} & $\begin{array}{c}\text { Supreme } \\
\text { management }=83\end{array}$ & 61 & 11 & 11 & 86.75 & 2.60 & agreeing & \multirow{3}{*}{4.02} \\
\hline & & $\begin{array}{c}\text { Middle } \\
\text { management }=16\end{array}$ & 8 & 3 & 5 & 72.92 & 2.19 & $\begin{array}{c}\text { to a certain } \\
\text { degree }\end{array}$ & \\
\hline & & $\begin{array}{c}\text { Executive } \\
\text { management }=89\end{array}$ & 62 & 12 & 15 & 84.26 & 2.53 & agreeing & \\
\hline & & All $=188$ & 131 & 26 & 31 & 84.40 & 2.53 & agreeing & 111.97 \\
\hline \multirow{4}{*}{$8 / 4$} & \multirow{4}{*}{ Using email } & $\begin{array}{c}\text { Supreme } \\
\text { management }=83\end{array}$ & 65 & 8 & 10 & 88.76 & 2.66 & agreeing & \multirow{3}{*}{$12.31 *$} \\
\hline & & $\begin{array}{c}\text { Middle } \\
\text { management }=16\end{array}$ & 8 & 1 & 7 & 68.75 & 2.06 & $\begin{array}{c}\text { to a certain } \\
\text { degree }\end{array}$ & \\
\hline & & $\begin{array}{c}\text { Executive } \\
\text { management }=89\end{array}$ & 70 & 9 & 10 & 89.14 & 2.67 & agreeing & \\
\hline & & All $=188$ & 143 & 18 & 27 & 87.23 & 2.62 & agreeing & 155.12 \\
\hline \multirow{4}{*}{$8 / 5$} & \multirow{4}{*}{$\begin{array}{l}\text { Browsing, } \\
\text { research and } \\
\text { assorting data, } \\
\text { information and } \\
\text { legal content }\end{array}$} & $\begin{array}{c}\text { Supreme } \\
\text { management }=83\end{array}$ & 67 & 6 & 10 & 89.56 & 2.69 & agreeing & \multirow{3}{*}{$9.54 *$} \\
\hline & & $\begin{array}{c}\text { Middle } \\
\text { management }=16\end{array}$ & 9 & 1 & 6 & 72.92 & 2.19 & $\begin{array}{c}\text { to a certain } \\
\text { degree }\end{array}$ & \\
\hline & & $\begin{array}{c}\text { Executive } \\
\text { management }=89\end{array}$ & 68 & 11 & 10 & 88.39 & 2.65 & agreeing & \\
\hline & & All $=188$ & 144 & 18 & 26 & 87.59 & 2.63 & agreeing & 101,01 \\
\hline \multirow{4}{*}{$8 / 6$} & \multirow{4}{*}{$\begin{array}{l}\text { Communicating } \\
\text { and working in a } \\
\text { team through } \\
\text { digital techniques }\end{array}$} & $\begin{array}{c}\text { Supreme } \\
\text { management }=\mathbf{8 3}\end{array}$ & 65 & 10 & 8 & 89.56 & 2.69 & agreeing & \multirow[t]{3}{*}{$10.59 *$} \\
\hline & & $\begin{array}{c}\text { Middle } \\
\text { management }=16\end{array}$ & 8 & 2 & 6 & 70.83 & 2.13 & $\begin{array}{r}\text { to a certain } \\
\text { degree }\end{array}$ & \\
\hline & & $\begin{array}{c}\text { Executive } \\
\text { management }=89\end{array}$ & 71 & 6 & 12 & 88.76 & 2.66 & agreeing & \\
\hline & & All $=188$ & 144 & 18 & 26 & 87.59 & 2.63 & agreeing & 101,01 \\
\hline \multirow{4}{*}{$8 / 7$} & \multirow{4}{*}{$\begin{array}{l}\text { Filling an internet } \\
\text { form }\end{array}$} & $\begin{array}{c}\text { Supreme } \\
\text { management }=83\end{array}$ & 66 & 8 & 9 & 89.56 & 2.69 & Agreeing & \multirow[t]{3}{*}{$४, \wedge 9$} \\
\hline & & $\begin{array}{c}\text { Middle } \\
\text { management }=16\end{array}$ & 8 & 3 & 5 & 72.92 & 2.19 & $\begin{array}{r}\text { to a certain } \\
\text { degree }\end{array}$ & \\
\hline & & $\begin{array}{c}\text { Executive } \\
\text { management }=89\end{array}$ & 67 & 11 & 11 & 87.64 & 2.63 & agreeing & \\
\hline & & All $=188$ & 141 & 22 & 25 & 87.23 & 2.62 & agreeing & $1 \leqslant 7,90$ \\
\hline
\end{tabular}


From table (5) there are significant differences between the research groups response on statements number $(8 / 4,8 / 5,8 / 6)$ as chi ranged between $(9.54 *: 12.31 *)$ with outweighed percentage (87.23: 87.59).

Ahmed Ghoneim (2004) states the main skills to be enjoyed by employees to achieve digital transformation including information techniques and computers (7: 73).

The sample opinions agreed upon statements number $(8 / 1,8 / 2,8 / 3,8 / 7)$

Mohamed Fathy (2008) refers to efficiencies, knowledge and skills needed by employees enabling them to use advanced knowledge and technology in fulfilling their tasks (27: 14)

The researcher believes that basic digital skills related to the use of digital devices and Internet applications have become an essential component of a new set of skills that must be available to club employees in the digital era.

\section{Table (6) Results of First Factor: Requirements of Digital Transfer to Achieve a Competitive Advantages at Clubs) (second Dimension: Digital Skills)}

\section{(B- Average Skills)}

\begin{tabular}{|c|c|c|c|c|c|c|c|c|c|}
\hline $\begin{array}{l}\text { Chi } \\
\text { square }\end{array}$ & Attitude & Average & $\begin{array}{c}\text { Out } \\
\text { weighted } \\
\text { percentage }\end{array}$ & Disagreeing & $\begin{array}{c}\text { To a } \\
\text { certain } \\
\text { degree }\end{array}$ & Agreeing & Departments & $\begin{array}{c}\text { Statement } \\
\text { content }\end{array}$ & $\mathbf{S}$ \\
\hline \multicolumn{9}{|c|}{ the club's employees has the following average digital skills } & 8 \\
\hline \multirow{3}{*}{5.45} & Agreeing & 2.47 & 82.33 & 18 & 8 & 57 & $\begin{array}{c}\text { Supreme } \\
\text { management }=83\end{array}$ & \multirow{4}{*}{$\begin{array}{l}\text { Evaluating and } \\
\text { managing data, } \\
\text { information and } \\
\text { digital contents }\end{array}$} & \multirow{4}{*}{$8 / 8$} \\
\hline & $\begin{array}{c}\text { to a certain } \\
\text { degree }\end{array}$ & 2.06 & 68.75 & 6 & 3 & 7 & $\begin{array}{c}\text { Middle } \\
\text { management }=16\end{array}$ & & \\
\hline & agreeing & 2.55 & 85.02 & 16 & 8 & 65 & $\begin{array}{c}\text { Executive } \\
\text { management }=89\end{array}$ & & \\
\hline 108.84 & agreeing & 2.47 & 82.45 & 40 & 19 & 129 & All $=188$ & & \\
\hline \multirow{3}{*}{7.38} & $\begin{array}{c}\text { to a certain } \\
\text { degree }\end{array}$ & 2.27 & 75.50 & 23 & 15 & 45 & $\begin{array}{c}\text { Supreme } \\
\text { management }=83\end{array}$ & \multirow{4}{*}{$\begin{array}{l}\text { Digital data } \\
\text { design }\end{array}$} & \multirow{4}{*}{$8 / 9$} \\
\hline & $\begin{array}{c}\text { to a certain } \\
\text { degree }\end{array}$ & 1.88 & 62.50 & 8 & 2 & 6 & $\begin{array}{c}\text { Middle } \\
\text { management }=16\end{array}$ & & \\
\hline & Agreeing & 2.45 & 81.65 & 18 & 13 & 58 & $\begin{array}{c}\text { Executive } \\
\text { management }=89\end{array}$ & & \\
\hline 54.27 & $\begin{array}{l}\text { to a certain } \\
\text { degree }\end{array}$ & 2.32 & 77.30 & 49 & 30 & 109 & All $=188$ & & \\
\hline \multirow{3}{*}{5.43} & $\begin{array}{c}\text { to a certain } \\
\text { degree }\end{array}$ & 2.34 & 77.91 & 21 & 13 & 49 & $\begin{array}{c}\text { Supreme } \\
\text { management }=83\end{array}$ & \multirow{4}{*}{ Data analysis } & \multirow{4}{*}{$8 / 10$} \\
\hline & $\begin{array}{c}\text { to a certain } \\
\text { degree }\end{array}$ & 1.88 & 62.50 & 8 & 2 & 6 & $\begin{array}{c}\text { Middle } \\
\text { management }=16\end{array}$ & & \\
\hline & Agreeing & 2.38 & 79.40 & 20 & 15 & 54 & $\begin{array}{c}\text { Executive } \\
\text { management }=89\end{array}$ & & \\
\hline 54.27 & $\begin{array}{l}\text { to a certain } \\
\text { degree }\end{array}$ & 2.32 & 77.30 & 49 & 30 & 109 & All $=188$ & & \\
\hline \multirow{3}{*}{6.81} & Agreeing & 2.36 & 78.41 & 22 & 9 & 52 & $\begin{array}{c}\text { Supreme } \\
\text { management }=83\end{array}$ & \multirow{4}{*}{$\begin{array}{c}\text { Digital } \\
\text { marketing }\end{array}$} & \multirow{4}{*}{$8 / 11$} \\
\hline & $\begin{array}{c}\text { to a certain } \\
\text { degree }\end{array}$ & 1.88 & 62.50 & 7 & 4 & 5 & $\begin{array}{c}\text { Middle } \\
\text { management }=16\end{array}$ & & \\
\hline & Agreeing & 2.38 & 79.40 & 23 & 9 & 57 & $\begin{array}{c}\text { Executive } \\
\text { management }=89\end{array}$ & & \\
\hline 70.26 & $\begin{array}{c}\text { to a certain } \\
\text { degree }\end{array}$ & 2.33 & 77.66 & 52 & 22 & 114 & All $=188$ & & \\
\hline \multirow{3}{*}{8.67} & Agreeing & 2.36 & 78.41 & 20 & 13 & 50 & $\begin{array}{c}\text { Supreme } \\
\text { management }=83\end{array}$ & \multirow{3}{*}{$\begin{array}{c}\text { Solving technical } \\
\text { problems }\end{array}$} & \multirow{3}{*}{$8 / 12$} \\
\hline & $\begin{array}{c}\text { to a certain } \\
\text { degree }\end{array}$ & 1.69 & 56.25 & 9 & 3 & 4 & $\begin{array}{c}\text { Middle } \\
\text { management }=16\end{array}$ & & \\
\hline & $\begin{array}{c}\text { to a certain } \\
\text { degree }\end{array}$ & 2.28 & 76.03 & 27 & 10 & 52 & $\begin{array}{c}\text { Executive } \\
\text { management }=89\end{array}$ & & \\
\hline
\end{tabular}




\begin{tabular}{|c|c|c|c|c|c|c|c|c|c|}
\hline $\begin{array}{c}\text { Chi } \\
\text { square }\end{array}$ & Attitude & Average & $\begin{array}{c}\text { Out } \\
\text { weighted } \\
\text { percentage }\end{array}$ & Disagreeing & $\begin{array}{c}\text { To a } \\
\text { certain } \\
\text { degree }\end{array}$ & Agreeing & Departments & $\begin{array}{c}\text { Statement } \\
\text { content }\end{array}$ & $\mathbf{S}$ \\
\hline 52.13 & $\begin{array}{c}\text { to a certain } \\
\text { degree }\end{array}$ & 2.27 & 75.53 & 56 & 26 & 106 & All $=188$ & & \\
\hline
\end{tabular}

From table (6) the research subjects responses agreed upon all statements as chi square ranged between (5.43: 8.67) with an outweighed percentage (77.66: 82.45)

International communication association (2018) mentions that average skills enabling us to use digital techniques are more profitable and feasible (23: 7).

The researcher believes that with the increase of knowledge and skills that the beneficiary acquires from the services in the clubs, the club's inability to match the benefactor increases, which requires more qualification and training for club employees. Table (7) First Factor Results: Digital Transformation Requirements to Achieve the Best
Competitive Advantage at Clubs (Second Dimension: Digital Skills)

(C-Advanced Skills)

\begin{tabular}{|c|c|c|c|c|c|c|c|c|c|}
\hline $\begin{array}{l}\text { Chi } \\
\text { square }\end{array}$ & Attitude & Average & $\begin{array}{c}\text { Out } \\
\text { weighted } \\
\text { percentage }\end{array}$ & Disagreeing & $\begin{array}{c}\text { To a } \\
\text { certain } \\
\text { degree }\end{array}$ & Agreeing & Departments & Statement content & $\mathbf{S}$ \\
\hline \multicolumn{9}{|c|}{ the club's employees have the following advanced digital skills : } & 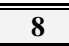 \\
\hline \multirow{3}{*}{$12.48 *$} & $\begin{array}{c}\text { to a certain } \\
\text { degree }\end{array}$ & 2.19 & 73.09 & 25 & 17 & 41 & $\begin{array}{c}\text { Supreme } \\
\text { management }=83\end{array}$ & \multirow{4}{*}{$\begin{array}{l}\text { Computerized } \\
\text { programming }\end{array}$} & \multirow{4}{*}{$8 / 13$} \\
\hline & disagreeing & 1.63 & 54.17 & 9 & 4 & 3 & $\begin{array}{c}\text { Middle } \\
\text { management }=16\end{array}$ & & \\
\hline & $\begin{array}{c}\text { to a certain } \\
\text { degree }\end{array}$ & 1.88 & 62.55 & 32 & 6 & 41 & $\begin{array}{c}\text { Executive } \\
\text { management }=89\end{array}$ & & \\
\hline 28.44 & $\begin{array}{c}\text { to a certain } \\
\text { degree }\end{array}$ & 1.99 & 66.49 & 66 & 27 & 85 & All $=188$ & & \\
\hline \multirow{3}{*}{6.29} & $\begin{array}{c}\text { to a certain } \\
\text { degree }\end{array}$ & 2.07 & 69.08 & 29 & 19 & 35 & $\begin{array}{c}\text { Supreme } \\
\text { management }=83\end{array}$ & \multirow{4}{*}{$\begin{array}{c}\text { Networks } \\
\text { management }\end{array}$} & \multirow{4}{*}{$8 / 14$} \\
\hline & disagreeing & 1.56 & 52.08 & 10 & 3 & 3 & $\begin{array}{c}\text { Middle } \\
\text { management }=16\end{array}$ & & \\
\hline & $\begin{array}{c}\text { to a certain } \\
\text { degree }\end{array}$ & 2.02 & 67.42 & 37 & 13 & 39 & $\begin{array}{c}\text { Executive } \\
\text { management }=89\end{array}$ & & \\
\hline 18.33 & $\begin{array}{l}\text { to a certain } \\
\text { degree }\end{array}$ & 2.01 & 66.84 & 76 & 35 & 77 & All $=188$ & & \\
\hline \multirow{3}{*}{6.64} & $\begin{array}{c}\text { to a certain } \\
\text { degree }\end{array}$ & 2.19 & 73.09 & 26 & 15 & 42 & $\begin{array}{c}\text { Supreme } \\
\text { management }=83\end{array}$ & \multirow{4}{*}{$\begin{array}{c}\text { Developing digital } \\
\text { content }\end{array}$} & \multirow{4}{*}{$8 / 15$} \\
\hline & disagreeing & 1.63 & 54.17 & 10 & 2 & 4 & $\begin{array}{c}\text { Middle } \\
\text { management }=16\end{array}$ & & \\
\hline & $\begin{array}{c}\text { to a certain } \\
\text { degree }\end{array}$ & 1.97 & 65.54 & 39 & 14 & 36 & $\begin{array}{c}\text { Executive } \\
\text { management }=89\end{array}$ & & \\
\hline 24.39 & $\begin{array}{l}\text { to a certain } \\
\text { degree }\end{array}$ & 2.04 & 67.91 & 75 & 31 & 82 & All $=188$ & & \\
\hline \multirow{3}{*}{2.35} & $\begin{array}{c}\begin{array}{c}\text { to a certain } \\
\text { degree }\end{array} \\
\end{array}$ & 2.06 & 68.67 & 31 & 16 & 36 & $\begin{array}{c}\text { Supreme } \\
\text { management }=83 \\
\end{array}$ & \multirow{4}{*}{$\begin{array}{l}\text { Ability to create in } \\
\text { using digital } \\
\text { techniques }\end{array}$} & \multirow{4}{*}{$8 / 16$} \\
\hline & $\begin{array}{c}\text { to a certain } \\
\text { degree }\end{array}$ & 1.69 & 56.25 & 9 & 3 & 4 & $\begin{array}{c}\text { Middle } \\
\text { management }=16\end{array}$ & & \\
\hline & $\begin{array}{c}\text { to a certain } \\
\text { degree }\end{array}$ & 2.01 & 67.04 & 36 & 16 & 37 & $\begin{array}{c}\text { Executive } \\
\text { management= 89 }\end{array}$ & & \\
\hline 18.33 & $\begin{array}{l}\text { to a certain } \\
\text { degree }\end{array}$ & 2.01 & 66.84 & 76 & 35 & 77 & All $=188$ & & \\
\hline
\end{tabular}

From table from table (7) it is clear that the research sample groups response to all statements 
agreed with an outweighed percentage between $(66.48: 67.91)$ and chi square between $(2.35$ : 6.64) with a dominant attitude disagreeing and to a certain degree upon that employees have no digital skills like managing networks, developing digital content.

But for statement number (8/13) related to enjoying digital skills by employees such as computerized programming, opinions of supreme and executive administration were to a certain degree

Communication international association (2018) mentions that advanced skills are skills needed by specialists in information technology and communication such as computerized programming and networks management (23:9).

The researcher believes that digital skills are constantly evolving with changes in technology, allowing policymakers and digital skills providers to ensure the continued relevance and up-todatedness of their programs and training curricula.

Table (8) First Factor Results: Digital Transformation Requirements to Achieve the Best Competitive Advantage at Clubs (Third Dimension: Digital Techniques) (A- Things Internet)

\begin{tabular}{|c|c|c|c|c|c|c|c|c|c|}
\hline $\begin{array}{l}\text { Chi } \\
\text { square }\end{array}$ & Attitude & Average & $\begin{array}{c}\text { Out } \\
\text { weighted } \\
\text { percentage }\end{array}$ & Disagreeing & $\begin{array}{c}\text { To a } \\
\text { certain } \\
\text { degree }\end{array}$ & Agreeing & Departments & Statement content & $\mathbf{S}$ \\
\hline \multirow{3}{*}{8.36} & agreeing & 2.65 & 88.35 & 11 & 7 & 65 & $\begin{array}{c}\text { Supreme } \\
\text { management }=83\end{array}$ & \multirow{4}{*}{$\begin{array}{c}\text { The club has } \\
\text { updated and high } \\
\text { speed internet lines }\end{array}$} & \multirow{4}{*}{9} \\
\hline & $\begin{array}{c}\text { to a } \\
\text { certain } \\
\text { degree }\end{array}$ & 2.13 & 70.83 & 6 & 2 & 8 & $\begin{array}{c}\text { Middle } \\
\text { management }=16\end{array}$ & & \\
\hline & agreeing & 2.46 & 82.02 & 17 & 14 & 58 & $\begin{array}{c}\text { Executive } \\
\text { management }=89\end{array}$ & & \\
\hline 112.73 & agreeing & 2.52 & 83.87 & 34 & 23 & 131 & All $=188$ & & \\
\hline \multirow{3}{*}{$15.36 *$} & agreeing & 2.75 & 91.57 & 8 & 5 & 70 & $\begin{array}{c}\text { Supreme } \\
\text { management }=83\end{array}$ & \multirow{4}{*}{$\begin{array}{l}\text { There is a link } \\
\text { between internet } \\
\text { and intranet }\end{array}$} & \multirow{4}{*}{10} \\
\hline & $\begin{array}{c}\text { to a } \\
\text { certain } \\
\text { degree }\end{array}$ & 2.19 & 72.92 & 6 & 1 & 9 & $\begin{array}{c}\text { Middle } \\
\text { management }=16\end{array}$ & & \\
\hline & agreeing & 2.43 & 80.90 & 18 & 15 & 56 & $\begin{array}{c}\text { Executive } \\
\text { management }=89\end{array}$ & & \\
\hline 126.20 & agreeing & 2.55 & 84.93 & 32 & 21 & 135 & All $=188$ & & \\
\hline \multirow{3}{*}{$9.62 *$} & agreeing & 2.70 & 89.96 & 9 & 7 & 67 & $\begin{array}{c}\text { Supreme } \\
\text { management }=83\end{array}$ & \multirow{4}{*}{$\begin{array}{c}\text { There are strong } \\
\text { anti-hacking } \\
\text { programs }\end{array}$} & \multirow{4}{*}{11} \\
\hline & $\begin{array}{c}\text { to a } \\
\text { certain } \\
\text { degree }\end{array}$ & 2.25 & 75.00 & 5 & 2 & 9 & $\begin{array}{c}\text { Middle } \\
\text { management }=16\end{array}$ & & \\
\hline & agreeing & 2.40 & 80.15 & 19 & 15 & 55 & $\begin{array}{c}\text { Executive } \\
\text { management }=89\end{array}$ & & \\
\hline 112.41 & agreeing & 2.52 & 84.04 & 33 & 24 & 131 & All $=188$ & & \\
\hline \multirow{3}{*}{$13.70 *$} & agreeing & 2.73 & 91.16 & 8 & 6 & 69 & $\begin{array}{c}\text { Supreme } \\
\text { management }=83\end{array}$ & \multirow{4}{*}{$\begin{array}{l}\text { The network can be } \\
\text { technically flexible }\end{array}$} & \multirow{4}{*}{12} \\
\hline & $\begin{array}{c}\text { to a } \\
\text { certain } \\
\text { degree }\end{array}$ & 2.31 & 77.08 & 5 & 1 & 10 & $\begin{array}{c}\text { Middle } \\
\text { management }=16\end{array}$ & & \\
\hline & agreeing & 2.36 & 78.65 & 21 & 15 & 53 & $\begin{array}{c}\text { Executive } \\
\text { management }=89\end{array}$ & & \\
\hline 116.21 & agreeing & 2.52 & 84.04 & 34 & 22 & 132 & All $=188$ & & \\
\hline \multicolumn{9}{|c|}{ the club has a detailed data base about : } & 13 \\
\hline
\end{tabular}




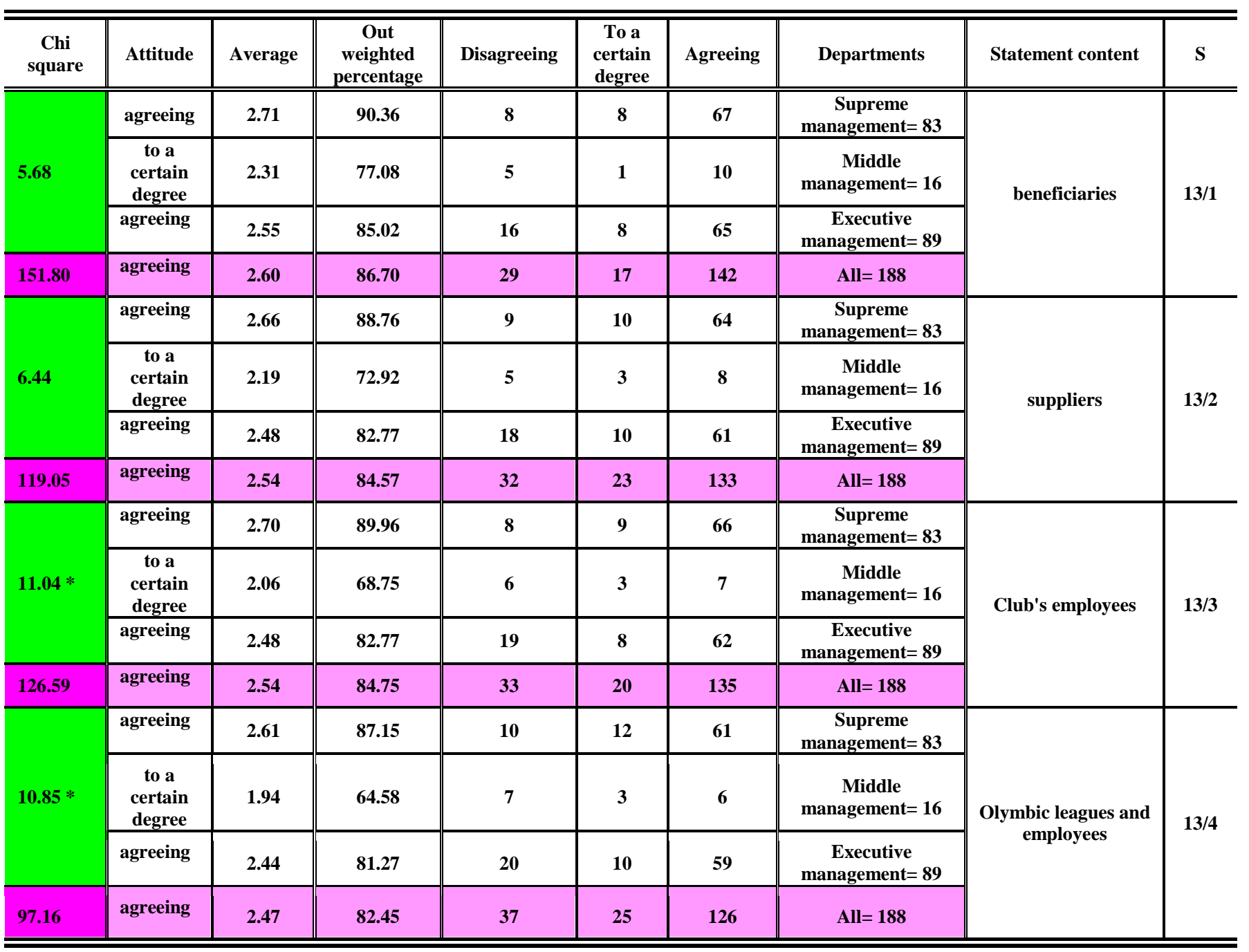

From table (8), it is clear that opinions of the research sample groups agreed upon statements number $(9,13 / 1,13 / 2)$ as the outweighed percentage reached $(83.87: 86.70)$ with chi square between $(5.68: 8.36)$

Results of Hytham Fayez (2016) (17), Ahlam Alfiki (2014) (4) agreed upon the availability of needed infra-structure helping clubs to activate modern electronic services.

But for statements number $(10,11,12,13 / 3,13 / 4)$ the research sample groups' opinion s varied between agreeing and to a certain degree.

Results of study of Tawil Osama (2017) (40) proves lack of security systems of protecting data of sports departments deals.

The researcher concludes that the activation of the Internet of things will contribute to the expansion of better services in sports clubs, which requires the availability of regular, high-speed Internet services that connect the departments to each other them within the club, as well as allow communication with other parties concerned and not concerned with sports. 
Table (9) First Factor Results: Digital Transformation Requirements to Achieve the Best Competitive Advantage at Clubs (Third Dimension: Digital Techniques) (B-Cloud computing)

\begin{tabular}{|c|c|c|c|c|c|c|c|c|c|}
\hline $\begin{array}{l}\text { Chi } \\
\text { square }\end{array}$ & Attitude & Average & $\begin{array}{c}\text { Out } \\
\text { weighted } \\
\text { percentage }\end{array}$ & Disagreeing & $\begin{array}{c}\text { To a } \\
\text { certain } \\
\text { degree }\end{array}$ & Agreeing & Departments & Statement content & $\mathbf{S}$ \\
\hline \multirow{3}{*}{$11.79 *$} & agreeing & 2.66 & 88.76 & 9 & 10 & 64 & $\begin{array}{c}\text { Supreme management }= \\
83\end{array}$ & \multirow{4}{*}{$\begin{array}{l}\text { The club uses cloud } \\
\text { computerization } \\
\text { services and } \\
\text { applications supplied } \\
\text { by service providers } \\
\text { such as Google, } \\
\text { Microsoft and Amazon }\end{array}$} & \multirow{4}{*}{14} \\
\hline & $\begin{array}{c}\text { to a } \\
\text { certain } \\
\text { degree }\end{array}$ & 2.25 & 75.00 & 5 & 2 & 9 & $\underset{16}{\text { Middle management }=}$ & & \\
\hline & $\begin{array}{l}\text { to a } \\
\text { certain } \\
\text { degree }\end{array}$ & 2.28 & 76.03 & 23 & 18 & 48 & $\begin{array}{c}\text { Executive } \\
\text { management }=89\end{array}$ & & \\
\hline 81.84 & agreeing & 2.45 & 81.56 & 37 & 30 & 121 & All $=188$ & & \\
\hline \multirow{3}{*}{$10.45 *$} & agreeing & 2.52 & 83.94 & 12 & 16 & 55 & $\begin{array}{l}\text { Supreme management }= \\
83\end{array}$ & \multirow{4}{*}{$\begin{array}{l}\text { Using cloud } \\
\text { computerization agrees } \\
\text { with the club's } \\
\text { activities }\end{array}$} & \multirow{4}{*}{15} \\
\hline & $\begin{array}{l}\text { to a } \\
\text { certain } \\
\text { degree }\end{array}$ & 1.94 & 64.58 & 7 & 3 & 6 & $\begin{array}{l}\text { Middle management }= \\
16\end{array}$ & & \\
\hline & $\begin{array}{c}\text { to a } \\
\text { certain } \\
\text { degree }\end{array}$ & 2.19 & 73.03 & 28 & 16 & 45 & $\begin{array}{c}\text { Executive } \\
\text { management }=89\end{array}$ & & \\
\hline 46.10 & $\begin{array}{c}\text { to a } \\
\text { certain } \\
\text { degree }\end{array}$ & 2.31 & 77.13 & 47 & 35 & 106 & All $=188$ & & \\
\hline \multirow{3}{*}{$10.31 *$} & agreeing & 2.58 & 85.94 & 11 & 13 & 59 & $\begin{array}{l}\text { Supreme management }= \\
83\end{array}$ & \multirow{4}{*}{$\begin{array}{l}\text { Cloud computerization } \\
\text { are used to reach } \\
\text { applications, resources, } \\
\text { data and information } \\
\text { on time }\end{array}$} & \multirow{4}{*}{16} \\
\hline & $\begin{array}{c}\text { to a } \\
\text { certain } \\
\text { degree }\end{array}$ & 2.00 & 66.67 & 7 & 2 & 7 & $\underset{16}{\text { Middle management }}=$ & & \\
\hline & $\begin{array}{l}\text { to a } \\
\text { certain } \\
\text { degree }\end{array}$ & 2.27 & 75.66 & 25 & 15 & 49 & $\begin{array}{c}\text { Executive } \\
\text { management= } 89\end{array}$ & & \\
\hline 66.90 & agreeing & 2.38 & 79.43 & 43 & 30 & 115 & All $=188$ & & \\
\hline \multirow{3}{*}{$14.44 *$} & agreeing & 2.63 & 87.55 & 9 & 13 & 61 & $\begin{array}{c}\text { Supreme management= } \\
83\end{array}$ & \multirow{4}{*}{$\begin{array}{l}\text { Cloud computerization } \\
\text { develops mechanism } \\
\text { and means of handling } \\
\text { and sharing } \\
\text { information }\end{array}$} & \multirow{4}{*}{17} \\
\hline & $\begin{array}{l}\text { to a } \\
\text { certain } \\
\text { degree }\end{array}$ & 2.06 & 68.75 & 6 & 3 & 7 & $\begin{array}{l}\text { Middle management= } \\
16\end{array}$ & & \\
\hline & $\begin{array}{l}\text { to a } \\
\text { certain } \\
\text { degree }\end{array}$ & 2.19 & 73.3 & 29 & 14 & 46 & $\begin{array}{c}\text { Executive } \\
\text { management }=89\end{array}$ & & \\
\hline 64.64 & agreeing & 2.37 & 79.08 & 44 & 30 & 114 & All $=188$ & & \\
\hline \multirow{3}{*}{$20.47 *$} & agreeing & 2.64 & 87.95 & 10 & 10 & 63 & $\begin{array}{c}\text { Supreme management= } \\
83\end{array}$ & \multirow{4}{*}{$\begin{array}{l}\text { Information safety } \\
\text { factors are available } \\
\text { for data and files } \\
\text { uploaded to the cloud }\end{array}$} & \multirow{4}{*}{18} \\
\hline & $\begin{array}{l}\text { to a } \\
\text { certain } \\
\text { degree }\end{array}$ & 1.94 & 64.58 & 7 & 3 & 6 & $\underset{16}{\text { Middle management }}=$ & & \\
\hline & $\begin{array}{l}\text { to a } \\
\text { certain } \\
\text { degree }\end{array}$ & 2.10 & 70.04 & 32 & 16 & 41 & $\begin{array}{c}\text { Executive } \\
\text { management }=89\end{array}$ & & \\
\hline 56.82 & $\begin{array}{l}\text { to a } \\
\text { certain } \\
\text { degree }\end{array}$ & 2.32 & 77.48 & 49 & 29 & 110 & All $=188$ & & \\
\hline
\end{tabular}

From table (9), there are statistical significant differences between research groups opinions on all statements as chi square ranged between $\left(10.31^{*}: 20.47^{*}\right)$ and outweighed percentage (77.13: 18.56) 
Results of study of Safaa Soliman (2019) (36), Alia Abdelmoniem (2014) (8) regarding service providers verifying quality of used network, applications and freedom fron any security gaps.

Ahmed Mahgoub (2015) (6) recommends studying service providers in details and identifying security protection supplied by service providers.

The researcher concludes that the use of cloud computing technology in clubs contributes to providing workers with access to computer resources and programs without being bound by time and place limits, and ease of communication between different departments, with the possibility of using them in cloud storage.

Table (10) First Factor Results: Digital Transformation Requirements to Achieve the Best Competitive Advantage at Clubs (Third Dimension: Digital Techniques) (C - Blocks Chain "Blue Kitchen")

\begin{tabular}{|c|c|c|c|c|c|c|c|c|c|}
\hline $\begin{array}{l}\text { Chi } \\
\text { square }\end{array}$ & Attitude & Average & $\begin{array}{c}\text { Out } \\
\text { weighted } \\
\text { percentage }\end{array}$ & Disagreeing & $\begin{array}{c}\text { To a } \\
\text { certain } \\
\text { degree } \\
\end{array}$ & Agreeing & Departments & Statement content & $\mathbf{S}$ \\
\hline \multirow{3}{*}{$10.58 *$} & agreeing & 2.69 & 89.56 & 8 & 10 & 65 & $\begin{array}{c}\text { Supreme } \\
\text { management }=83\end{array}$ & \multirow{4}{*}{$\begin{array}{l}\text { There are } \\
\text { employees } \\
\text { specialized in } \\
\text { information security } \\
\text { and protection }\end{array}$} & \multirow{4}{*}{19} \\
\hline & $\begin{array}{c}\text { to a } \\
\text { certain } \\
\text { degree }\end{array}$ & 2.19 & 72.92 & 4 & 5 & 7 & $\begin{array}{c}\text { Middle } \\
\text { management }=16\end{array}$ & & \\
\hline & agreeing & 2.44 & 81.27 & 19 & 12 & 58 & $\begin{array}{c}\text { Executive } \\
\text { management }=89\end{array}$ & & \\
\hline 108.65 & agreeing & 2.53 & 84.22 & 31 & 27 & 130 & All $=188$ & & \\
\hline \multirow{3}{*}{$12.07 *$} & agreeing & 2.64 & 87.95 & 10 & 10 & 63 & $\begin{array}{c}\text { Supreme } \\
\text { management }=83\end{array}$ & \multirow{4}{*}{$\begin{array}{l}\text { Specialists use } \\
\text { blocks chain to } \\
\text { discover and } \\
\text { describe hacking }\end{array}$} & \multirow{4}{*}{2} \\
\hline & $\begin{array}{c}\text { to a } \\
\text { certain } \\
\text { degree }\end{array}$ & 2.00 & 66.67 & 6 & 6 & 6 & $\begin{array}{c}\text { Middle } \\
\text { management }=16\end{array}$ & & \\
\hline & $\begin{array}{c}\text { to a } \\
\text { certain } \\
\text { degree }\end{array}$ & 2.33 & $\mathbf{7 7 . 5 3}$ & 22 & 51 & 51 & $\begin{array}{c}\text { Executive } \\
\text { management }=89\end{array}$ & & \\
\hline 79.19 & agreeing & 2.44 & 81.21 & 38 & 120 & 120 & All $=188$ & & \\
\hline \multirow{3}{*}{$14.45 *$} & agreeing & 2.69 & 89.56 & 8 & 65 & 65 & $\begin{array}{c}\text { Supreme } \\
\text { management }=83\end{array}$ & \multirow{4}{*}{$\begin{array}{l}\text { There are specialists } \\
\text { in observing } \\
\text { hacking at time of } \\
\text { occurrence and } \\
\text { repairing any } \\
\text { resulting defect }\end{array}$} & \multirow{4}{*}{21} \\
\hline & $\begin{array}{c}\text { to a } \\
\text { certain } \\
\text { degree }\end{array}$ & 2.13 & 70.83 & 4 & 6 & 6 & $\begin{array}{c}\text { Middle } \\
\text { management }=16\end{array}$ & & \\
\hline & agreeing & 2.37 & 79.03 & 20 & 53 & 53 & $\begin{array}{c}\text { Executive } \\
\text { management= } 89\end{array}$ & & \\
\hline 90.4 & agreeing & 2.49 & 82.98 & 32 & 124 & 124 & All $=188$ & & \\
\hline
\end{tabular}

From table (10) there are significant differences between the research group responses on all statements as chi square ranged between $\left(10.58^{*}: 14.45^{*}\right)$ with an outweighed percentage (81.21: 84.22)

Fatma Elsebaey (2019), Ehab Khalifa (2018) (22) mention that blue kitchen techniques has 2 main norms, non-centralism and international transparency in managing all deals (15:4)

The researcher considers the need to work on holding introductory courses for workers in sports clubs to learn about blockchain technology and how to deal with this technology and to urge its application and adoption because of its benefits in preserving data integrity and protecting 
information.

Table (11) First Factor Results: Digital Transformation Requirements to Achieve the Best Competitive Advantage at Clubs (Third Dimension: Digital Techniques) (D - Open Governmental Data)

\begin{tabular}{|c|c|c|c|c|c|c|c|c|c|}
\hline $\begin{array}{l}\text { Chi } \\
\text { square }\end{array}$ & Attitude & Average & $\begin{array}{c}\text { Out } \\
\text { weighted } \\
\text { percentage }\end{array}$ & Disagreeing & $\begin{array}{c}\text { To a } \\
\text { certain } \\
\text { degree } \\
\end{array}$ & Agreeing & Departments & Statement content & $\mathbf{S}$ \\
\hline \multirow{3}{*}{7.42} & agreeing & 2.53 & 84.34 & 13 & 13 & 57 & $\begin{array}{c}\text { Supreme } \\
\text { management }=83\end{array}$ & \multirow{4}{*}{$\begin{array}{l}\text { Open governmental data } \\
\text { are used in developing } \\
\text { the club's administrative } \\
\text { performance via } \\
\text { providing the content } \\
\text { with club's service } \\
\text { related data }\end{array}$} & \multirow{4}{*}{22} \\
\hline & $\begin{array}{c}\text { to a certain } \\
\text { degree }\end{array}$ & 2.06 & 68.75 & 7 & 1 & 8 & $\begin{array}{c}\text { Middle } \\
\text { management }=16\end{array}$ & & \\
\hline & agreeing & 2.35 & 78.28 & 21 & 16 & 52 & $\begin{array}{c}\text { Executive } \\
\text { management= 89 }\end{array}$ & & \\
\hline 71.63 & agreeing & 2.40 & 80.14 & 41 & 30 & 117 & All $=188$ & & \\
\hline \multirow{3}{*}{8.22} & agreeing & 2.52 & 83.94 & 12 & 16 & 55 & $\begin{array}{c}\text { Supreme } \\
\text { management }=83\end{array}$ & \multirow{4}{*}{$\begin{array}{l}\text { The club profits from } \\
\text { open governmental data } \\
\text { in statistical analysis for } \\
\text { a certain subject }\end{array}$} & \multirow{4}{*}{23} \\
\hline & $\begin{array}{l}\text { to a certain } \\
\text { degree }\end{array}$ & 2.00 & 66.67 & 7 & 2 & 7 & $\begin{array}{c}\text { Middle } \\
\text { management= } 16\end{array}$ & & \\
\hline & $\begin{array}{c}\text { to a certain } \\
\text { degree }\end{array}$ & 2.28 & 76.03 & 24 & 16 & 49 & $\begin{array}{c}\text { Executive } \\
\text { management= 89 }\end{array}$ & & \\
\hline 56.56 & agreeing & 2.36 & 78.72 & 43 & 34 & 111 & All $=188$ & & \\
\hline \multirow{3}{*}{7.46} & agreeing & 2.63 & 87.55 & 11 & 9 & 63 & $\begin{array}{c}\text { Supreme } \\
\text { management }=83\end{array}$ & \multirow{4}{*}{$\begin{array}{l}\text { Technical and } \\
\text { technological structure of } \\
\text { sites availing open data } \\
\text { are not enough }\end{array}$} & \multirow{4}{*}{24} \\
\hline & $\begin{array}{c}\text { to a certain } \\
\text { degree }\end{array}$ & 2.06 & 86.75 & 6 & 3 & 7 & $\begin{array}{c}\text { Middle } \\
\text { management }=16\end{array}$ & & \\
\hline & agreeing & 2.47 & 82.40 & 17 & 13 & 59 & $\begin{array}{c}\text { Executive } \\
\text { management }=89\end{array}$ & & \\
\hline 105.79 & agreeing & 2.51 & 83.51 & 34 & 25 & 129 & All $=188$ & & \\
\hline \multirow{3}{*}{6.79} & agreeing & 2.54 & 84.74 & 14 & 10 & 59 & $\begin{array}{c}\text { Supreme } \\
\text { management }=83\end{array}$ & \multirow{4}{*}{$\begin{array}{l}\text { Legal restrictions and } \\
\text { confident information } \\
\text { limit profiting from and } \\
\text { reuse }\end{array}$} & \multirow{4}{*}{25} \\
\hline & $\begin{array}{c}\text { to a certain } \\
\text { degree }\end{array}$ & 2.00 & 66.67 & 6 & 4 & 6 & $\begin{array}{c}\text { Middle } \\
\text { management }=16\end{array}$ & & \\
\hline & agreeing & 2.42 & 80.52 & 20 & 12 & 57 & $\begin{array}{c}\text { Executive } \\
\text { management= 89 }\end{array}$ & & \\
\hline \multirow[t]{2}{*}{85.83} & agreeing & 2.44 & 81.21 & 40 & 26 & 122 & All $=188$ & & \\
\hline & & & & & & & & $\begin{array}{l}\text { The club profits from } \\
\text { data provided by }\end{array}$ & 26 \\
\hline \multirow{3}{*}{8.28} & agreeing & 2.65 & 88.35 & 12 & 5 & 66 & $\begin{array}{c}\text { Supreme } \\
\text { management }=83\end{array}$ & \multirow{4}{*}{$\begin{array}{l}\text { Ministries and } \\
\text { authorities site }\end{array}$} & \multirow{4}{*}{$26 / 1$} \\
\hline & $\begin{array}{l}\text { to a certain } \\
\text { degree }\end{array}$ & 2.13 & 70.83 & 6 & 2 & 8 & $\begin{array}{c}\text { Middle } \\
\text { management= } 16\end{array}$ & & \\
\hline & agreeing & 2.51 & 83.52 & 16 & 12 & 61 & $\begin{array}{c}\text { Executive } \\
\text { management= } 89\end{array}$ & & \\
\hline 127.03 & agreeing & 2.54 & 84.557 & 34 & 19 & 135 & All $=188$ & & \\
\hline \multirow{3}{*}{$10.78 *$} & agreeing & 2.61 & 87.15 & 11 & 10 & 62 & $\begin{array}{c}\text { Supreme } \\
\text { management }=83\end{array}$ & \multirow{4}{*}{$\begin{array}{c}\text { Statistical central } \\
\text { authority }\end{array}$} & \multirow{4}{*}{$26 / 2$} \\
\hline & sometimes & 1.94 & 64.58 & 7 & 3 & 6 & $\begin{array}{c}\text { Middle } \\
\text { management }=16\end{array}$ & & \\
\hline & agreeing & 2.49 & 83.15 & 15 & 15 & 59 & $\begin{array}{c}\text { Executive } \\
\text { management= 89 }\end{array}$ & & \\
\hline 99.27 & agreeing & 2.50 & 83.33 & 33 & 28 & 127 & All $=188$ & & \\
\hline \multirow{2}{*}{$13.45 *$} & agreeing & 2.66 & 88.76 & 13 & 2 & 68 & $\begin{array}{c}\text { Supreme } \\
\text { management }=83\end{array}$ & \multirow{2}{*}{ Sports leagues sites } & \multirow{2}{*}{$26 / 3$} \\
\hline & $\begin{array}{c}\text { to a certain } \\
\text { degree }\end{array}$ & 2.13 & 70.83 & 6 & 2 & 8 & $\begin{array}{c}\text { Middle } \\
\text { management }=16\end{array}$ & & \\
\hline
\end{tabular}




\begin{tabular}{|c|c|c|c|c|c|c|c|c|c|}
\hline $\begin{array}{l}\text { Chi } \\
\text { square }\end{array}$ & Attitude & Average & $\begin{array}{c}\text { Out } \\
\text { weighted } \\
\text { percentage }\end{array}$ & Disagreeing & $\begin{array}{c}\text { To a } \\
\text { certain } \\
\text { degree } \\
\end{array}$ & Agreeing & Departments & Statement content & $\mathbf{S}$ \\
\hline & agreeing & 2.54 & 84.64 & 14 & 13 & 62 & $\begin{array}{c}\text { Executive } \\
\text { management }=89\end{array}$ & & \\
\hline 137.88 & agreeing & 2.56 & 85.28 & 33 & 17 & 138 & All $=188$ & & \\
\hline \multirow{3}{*}{6.32} & agreeing & 2.54 & 84.74 & 15 & 8 & 60 & $\begin{array}{c}\text { Supreme } \\
\text { management }=83\end{array}$ & \multirow{4}{*}{ Olympic committees sites } & \multirow{4}{*}{$26 / 4$} \\
\hline & $\begin{array}{c}\text { to a certain } \\
\text { degree }\end{array}$ & 2.06 & 68.75 & 6 & 3 & 7 & $\begin{array}{c}\text { Middle } \\
\text { management }=16\end{array}$ & & \\
\hline & agreeing & 2.51 & 83.52 & 15 & 14 & 60 & $\begin{array}{c}\text { Executive } \\
\text { management= 89 }\end{array}$ & & \\
\hline 100.03 & agreeing & 2.48 & 82.80 & 36 & 25 & 127 & All $=188$ & & \\
\hline
\end{tabular}

From table (11) there are differences between research groups responses to statements numbers $(26 / 2,26 / 3)$ as chi square reached $\left(10.87^{*}\right),\left(13.45^{*}\right)$ and outweighed percentage (83.33), (85.28) respectively.

As the sample opinions agreed upon statements numbers $(22,23,24,25,26 / 1,26 / 4)$ as chi square ranged between $(6.32: 8.28)$ and outweighed percentage (78.72:84.57)

The results of Khulud Bint Salem Bin Saleh (2019) (24) indicate that open governmental data must be integrated, compiled at the highest level of accuracy, and available to the largest number of users and for the broadest range of purposes without distinction of anyone and without registration conditions, and is not subject to any copyright, patents or trademarks, with easy and quick access to it in a timely manner to preserve its value.

Haroun Abdalla (2009) (19) mentions that creating a data base is the basis of governmental entrance to internet to provide people and investors with the latest information.

The researcher believes that it is necessary to develop and upgrade government databases and establish central repositories for information, considering a specific policy for informational security in accordance to international standards in this regard.

Table (12) First Factor Results: Digital Transformation Requirements to Achieve the Best Competitive Advantage at Clubs (Third Dimension: Digital Techniques) (E- Artificial Intelligence)

\begin{tabular}{|c|c|c|c|c|c|c|c|c|c|}
\hline $\begin{array}{l}\text { Chi } \\
\text { square }\end{array}$ & Attitude & Average & $\begin{array}{c}\text { Out } \\
\text { weighted } \\
\text { percentage }\end{array}$ & Disagreeing & $\begin{array}{c}\text { To a } \\
\text { certain } \\
\text { degree }\end{array}$ & Agreeing & Departments & Statement content & $\mathbf{S}$ \\
\hline & & & & & & & & $\begin{array}{l}\text { Artificial intelligence is } \\
\text { used by clubs in }\end{array}$ & 27 \\
\hline \multirow{3}{*}{8.39} & agreeing & 2.65 & 88.35 & 10 & 9 & 64 & $\begin{array}{c}\text { Supreme } \\
\text { management }=83\end{array}$ & \multirow{4}{*}{$\begin{array}{c}\text { Discovering talents } \\
\text { and expecting and } \\
\text { developing talented to } \\
\text { make sports } \\
\text { champions }\end{array}$} & \multirow{4}{*}{$27 / 1$} \\
\hline & $\begin{array}{c}\text { to a } \\
\text { certain } \\
\text { degree }\end{array}$ & 2.06 & 68.75 & 6 & 3 & 7 & $\begin{array}{c}\text { Middle } \\
\text { management }=16\end{array}$ & & \\
\hline & agreeing & 2.47 & 82.40 & 17 & 13 & 59 & $\begin{array}{c}\text { Executive } \\
\text { management }=89\end{array}$ & & \\
\hline 109.03 & agreeing & 2.52 & 83.87 & 33 & 25 & 130 & All $=188$ & & \\
\hline $14.50 *$ & agreeing & 2.65 & 88.35 & 11 & 7 & 65 & $\begin{array}{c}\text { Supreme } \\
\text { management }=83\end{array}$ & $\begin{array}{c}\text { Developing and } \\
\text { improving athletes }\end{array}$ & $27 / 2$ \\
\hline
\end{tabular}




\begin{tabular}{|c|c|c|c|c|c|c|c|c|c|}
\hline $\begin{array}{l}\text { Chi } \\
\text { square }\end{array}$ & Attitude & Average & $\begin{array}{c}\text { Out } \\
\text { weighted } \\
\text { percentage }\end{array}$ & Disagreeing & $\begin{array}{c}\text { To a } \\
\text { certain } \\
\text { degree }\end{array}$ & Agreeing & Departments & Statement content & $\mathbf{S}$ \\
\hline & $\begin{array}{c}\text { to a } \\
\text { certain } \\
\text { degree }\end{array}$ & 2.06 & 68.75 & 7 & 1 & 8 & $\begin{array}{c}\text { Middle } \\
\text { management }=16\end{array}$ & \multirow{3}{*}{$\begin{array}{l}\text { performance level by } \\
\text { analyzing as great data } \\
\text { of players and teams } \\
\text { performance as } \\
\text { possible }\end{array}$} & \\
\hline & agreeing & 2.44 & 81.27 & 16 & 18 & 55 & $\begin{array}{c}\text { Executive } \\
\text { management }=89\end{array}$ & & \\
\hline 102.68 & agreeing & 2.50 & 83.33 & 34 & 26 & 128 & All $=188$ & & \\
\hline \multirow{3}{*}{$9.86 *$} & agreeing & 2.42 & 80.72 & 18 & 12 & 53 & $\begin{array}{c}\text { Supreme } \\
\text { management }=83\end{array}$ & \multirow{4}{*}{$\begin{array}{l}\text { Shooting scenes with } \\
\text { angle } 360^{\circ} \text { for sports } \\
\text { activities details of } \\
\text { participants' faces } \\
\text {,movements and acts }\end{array}$} & \multirow{4}{*}{$27 / 3$} \\
\hline & $\begin{array}{c}\text { to a } \\
\text { certain } \\
\text { degree }\end{array}$ & 1.88 & 62.50 & 8 & 2 & 6 & $\begin{array}{c}\text { Middle } \\
\text { management }=16\end{array}$ & & \\
\hline & $\begin{array}{c}\text { to a } \\
\text { certain } \\
\text { degree }\end{array}$ & 2.19 & 73.03 & 25 & 22 & 42 & $\begin{array}{c}\text { Executive } \\
\text { management }=89\end{array}$ & & \\
\hline 36.79 & $\begin{array}{c}\text { to a } \\
\text { certain } \\
\text { degree }\end{array}$ & 2.27 & 75.53 & 51 & 36 & 101 & All $=188$ & & \\
\hline \multirow{3}{*}{$15.22 *$} & agreeing & 2.41 & 80.32 & 21 & 7 & 55 & $\begin{array}{c}\text { Supreme } \\
\text { management }=83\end{array}$ & \multirow{4}{*}{$\begin{array}{l}\text { Producing press } \\
\text { reports and videos } \\
\text { clarifying facts } \\
\text { occurred during } \\
\text { different activities }\end{array}$} & \multirow{4}{*}{$27 / 4$} \\
\hline & $\begin{array}{c}\text { to a } \\
\text { certain } \\
\text { degree } \\
\end{array}$ & 1.75 & 58.33 & 9 & 2 & 5 & $\begin{array}{c}\text { Middle } \\
\text { management= }=16\end{array}$ & & \\
\hline & $\begin{array}{c}\text { to a } \\
\text { certain } \\
\text { degree }\end{array}$ & 2.29 & 76.40 & 21 & 21 & 47 & $\begin{array}{c}\text { Executive } \\
\text { management= } 89\end{array}$ & & \\
\hline 50.56 & $\begin{array}{c}\text { to a } \\
\text { certain } \\
\text { degree }\end{array}$ & 2.30 & 76.60 & 51 & 30 & 107 & All $=188$ & & \\
\hline
\end{tabular}

From table (12) there are differences between the research groups responses to all statements except for statement number (37/1) as chi ranged between $\left(9.86^{*}: 15.22^{*}\right)$ with an outweighed percentage (75.53: 83.33).

The results of Salma Kunde (2018) (38) study indicate that the sports field has benefited greatly from information technology, represented by the emergence of new techniques to explain sports movements, the development of presentation methods, and the increase in the use of computers in reaching modern methods that enable a successfully manage of sport activity.

Studies of Salma Konda (2018) (38), Abla Zaian (2016) (3) indicates that sports field profited from information technology via emergence of new techniques of illustrating sports activities and developing display methods.

Faisal EImala (2019) mentions that international trials proved the ability of artificial intelligence to develop and improve sports performance level via analyzing as most great data as possible of players and teams. (69)

The researcher believes that it is necessary to activate the digital transformation system by introducing artificial intelligence applications within sports clubs by developing a future plan to electronically transfer all the services provided by the club, thus achieving a competitive advantage for sports clubs. 
Table (13) First Factor Results: Digital Transformation Requirements to Achieve the Best Competitive Advantage at Clubs (Third Dimension: Digital Techniques) (F- Robotic Process Automation)

\begin{tabular}{|c|c|c|c|c|c|c|c|c|c|}
\hline $\begin{array}{c}\text { Chi } \\
\text { square }\end{array}$ & Attitude & Average & $\begin{array}{c}\text { Out } \\
\text { weighted } \\
\text { percentage }\end{array}$ & Disagreeing & $\begin{array}{c}\text { To a } \\
\text { certain } \\
\text { degree }\end{array}$ & Agreeing & Departments & Statement content & $\mathbf{S}$ \\
\hline \multicolumn{9}{|c|}{ The club uses robot operations to add functional advantages represented in } & 28 \\
\hline \multirow{3}{*}{8.93} & agreeing & 2.71 & 90.36 & 9 & 6 & 68 & $\begin{array}{c}\text { Supreme } \\
\text { management }=83\end{array}$ & \multirow{4}{*}{$\begin{array}{c}\text { Managing payrolls and } \\
\text { compensations } \\
\text { registration }\end{array}$} & \multirow{4}{*}{$28 / 1$} \\
\hline & $\begin{array}{c}\text { to a } \\
\text { certain } \\
\text { degree }\end{array}$ & 2.13 & 70.83 & 6 & 2 & 8 & $\begin{array}{c}\text { Middle } \\
\text { management }=16\end{array}$ & & \\
\hline & agreeing & 2.48 & 82.77 & 19 & 8 & 62 & $\begin{array}{c}\text { Executive } \\
\text { management }=89\end{array}$ & & \\
\hline 138.43 & agreeing & 2.55 & 85.11 & 34 & 16 & 138 & All $=188$ & & \\
\hline \multirow{3}{*}{6.07} & agreeing & 2.64 & 87.95 & 11 & 8 & 64 & $\begin{array}{c}\text { Supreme } \\
\text { management }=83\end{array}$ & \multirow{4}{*}{$\begin{array}{l}\text { Managing the club's } \\
\text { employees data }\end{array}$} & \multirow{4}{*}{$28 / 2$} \\
\hline & $\begin{array}{c}\text { to a } \\
\text { certain } \\
\text { degree }\end{array}$ & 2.19 & 72.92 & 5 & 3 & 8 & $\begin{array}{c}\text { Middle } \\
\text { management }=16\end{array}$ & & \\
\hline & agreeing & 2.43 & 80.90 & 20 & 11 & 58 & $\begin{array}{c}\text { Executive } \\
\text { management }=89\end{array}$ & & \\
\hline 110.09 & agreeing & 2.50 & 83.33 & 36 & 22 & 130 & All $=188$ & & \\
\hline \multirow{3}{*}{$13.20 *$} & agreeing & 2.66 & 88.76 & 10 & 8 & 65 & $\begin{array}{c}\text { Supreme } \\
\text { management }=83\end{array}$ & \multirow{4}{*}{$\begin{array}{l}\text { Identifying credit and } \\
\text { debit accounts }\end{array}$} & \multirow{4}{*}{$28 / 3$} \\
\hline & $\begin{array}{c}\text { to a } \\
\text { certain } \\
\text { degree }\end{array}$ & 2.06 & 68.75 & 6 & 3 & 7 & $\begin{array}{c}\text { Middle } \\
\text { management }=16\end{array}$ & & \\
\hline & $\begin{array}{c}\text { to a } \\
\text { certain } \\
\text { degree }\end{array}$ & 2.31 & 77.15 & 22 & 17 & 50 & $\begin{array}{c}\text { Executive } \\
\text { management= } 89\end{array}$ & & \\
\hline 85.06 & agreeing & 2.45 & 81.56 & 38 & 28 & 122 & All $=188$ & & \\
\hline \multirow{3}{*}{$16.08 *$} & agreeing & 2.61 & 87.15 & 11 & 10 & 62 & $\begin{array}{c}\text { Supreme } \\
\text { management }=83\end{array}$ & \multirow{4}{*}{$\begin{array}{l}\text { Looking into the } \\
\text { members' complaints }\end{array}$} & \multirow{4}{*}{$28 / 4$} \\
\hline & $\begin{array}{c}\text { to a } \\
\text { certain } \\
\text { degree } \\
\end{array}$ & 1.88 & 62.50 & 7 & 4 & 5 & $\begin{array}{c}\text { Middle } \\
\text { management }=16\end{array}$ & & \\
\hline & $\begin{array}{c}\text { to a } \\
\text { certain } \\
\text { degree }\end{array}$ & 2.25 & 74.91 & 24 & 19 & 46 & $\begin{array}{c}\text { Executive } \\
\text { management= } 89\end{array}$ & & \\
\hline 61.29 & agreeing & 2.38 & 79.26 & 42 & 33 & 113 & $\mathrm{All}=\mathbf{1 8 8}$ & & \\
\hline \multirow{3}{*}{$13.59 *$} & agreeing & 2.69 & 89.56 & 9 & 8 & 66 & $\begin{array}{c}\text { Supreme } \\
\text { management }=83\end{array}$ & \multirow{4}{*}{$\begin{array}{l}\text { Managing the club's } \\
\text { members subscription } \\
\text { renewal }\end{array}$} & \multirow{4}{*}{$28 / 5$} \\
\hline & $\begin{array}{c}\text { to a } \\
\text { certain } \\
\text { degree }\end{array}$ & 2.06 & 68.75 & 7 & 1 & 8 & $\begin{array}{c}\text { Middle } \\
\text { management }=16\end{array}$ & & \\
\hline & agreeing & 2.37 & 79.03 & 21 & 14 & 54 & $\begin{array}{c}\text { Executive } \\
\text { management= 89 } \\
\end{array}$ & & \\
\hline 103.73 & agreeing & 2.48 & 82.80 & 37 & 23 & 128 & All $=188$ & & \\
\hline
\end{tabular}

From table (13) and the figure there are differences between the research groups' responses to statements numbers $(28 / 3,28 / 4,28 / 5)$ as chi square ranged between $\left(13.20^{*}: 16.08^{*}\right)$ and outweighed percentage ranged between (79.26: 82.80).

Also, the research sample opinion agreed on statements numbers $(\mathbf{2 8 / 1}, \mathbf{2 8 / 2})$ as chi square reached (8.93), (6.07) with an outweighed percentage (85.11), (83.33) respectively.

Mohit Sharma (2018) states that robotic process automation (RPA) solutions are typically 
implemented in organizations that typically depend on human resources extensively for largescale, interactive, and repetitive operations. The key processes best suited to robotic process automation tend to be extensively based on data entry, comparisons and validation. (55:10).

Abdelarahman Elour (2018) stated that to guarantee successful execution of robot operations automation through profiting from automatic control increase, the organizations shall identify and redesign their current operations. (1:4)

The researcher believes that additional robotic process automations can be used within sports clubs to conduct sensitive operations without human intervention at small costs, and to restructure human resources with work requirements, including evaluation work and rewards for workers in the affected areas.

Table (14) Second Factor Results: Digital Transformation Requirements to Achieve the Best Competitive Advantage at Clubs

(First Dimension: E. Commerce)

\begin{tabular}{|c|c|c|c|c|c|c|c|c|c|}
\hline $\begin{array}{c}\text { Chi } \\
\text { square }\end{array}$ & Attitude & Average & $\begin{array}{c}\text { Out } \\
\text { weighted } \\
\text { percentage }\end{array}$ & Disagreeing & $\begin{array}{c}\text { To a } \\
\text { certain } \\
\text { degree }\end{array}$ & Agreeing & Departments & Statement content & $\mathbf{S}$ \\
\hline & & & & & & & & $\begin{array}{l}\text { Using ecommerce by the } \\
\text { club plays a great role in }\end{array}$ & 29 \\
\hline \multirow{3}{*}{$10.83 *$} & agreeing & 2.70 & 89.96 & 8 & 9 & 66 & $\begin{array}{c}\text { Supreme } \\
\text { management }=83\end{array}$ & \multirow{4}{*}{$\begin{array}{c}\text { Achieving a competitive } \\
\text { advantage for } \\
\text { beneficiaries service }\end{array}$} & \multirow{4}{*}{$29 / 1$} \\
\hline & agreeing & 2.38 & 79.17 & 4 & 2 & 10 & $\begin{array}{c}\text { Middle } \\
\text { management }=16\end{array}$ & & \\
\hline & agreeing & 2.45 & 81.65 & 13 & 23 & 53 & $\begin{array}{c}\text { Executive } \\
\text { management }=89\end{array}$ & & \\
\hline 105.97 & agreeing & 2.55 & 85.11 & 25 & 34 & 129 & $A l l=188$ & & \\
\hline \multirow{3}{*}{$17.87 *$} & agreeing & 2.69 & 89.56 & 8 & 10 & 65 & $\begin{array}{c}\text { Supreme } \\
\text { management }=83\end{array}$ & \multirow{4}{*}{$\begin{array}{c}\text { Facilitating commercial } \\
\text { deals }\end{array}$} & \multirow{4}{*}{$29 / 2$} \\
\hline & $\begin{array}{c}\text { to a certain } \\
\text { degree }\end{array}$ & 2.13 & 70.83 & 6 & 2 & 8 & $\begin{array}{c}\text { Middle } \\
\text { management }=16\end{array}$ & & \\
\hline & agreeing & 2.44 & 81.27 & 12 & 26 & 51 & $\begin{array}{c}\text { Executive } \\
\text { management }=89\end{array}$ & & \\
\hline 91.19 & agreeing & 2.52 & 84.04 & 26 & 38 & 124 & All $=188$ & & \\
\hline \multirow{3}{*}{$12.82 *$} & agreeing & 2.63 & 87.55 & 10 & 11 & 62 & $\begin{array}{c}\text { Supreme } \\
\text { management }=83\end{array}$ & \multirow{4}{*}{$\begin{array}{l}\text { Reducing the club's } \\
\text { expenses }\end{array}$} & \multirow{4}{*}{$29 / 3$} \\
\hline & $\begin{array}{c}\text { to a certain } \\
\text { degree }\end{array}$ & 1.94 & 64.58 & 6 & 5 & 5 & $\begin{array}{c}\text { Middle } \\
\text { management }=16\end{array}$ & & \\
\hline & agreeing & 2.44 & 81.27 & 15 & 20 & 54 & $\begin{array}{c}\text { Executive } \\
\text { management }=89\end{array}$ & & \\
\hline 81.65 & agreeing & 2.48 & 82.62 & 31 & 36 & 121 & $A l l=188$ & & \\
\hline \multirow{3}{*}{$13.94 *$} & agreeing & 2.48 & 82.73 & 16 & 11 & 56 & $\begin{array}{c}\text { Supreme } \\
\text { management }=83\end{array}$ & \multirow{4}{*}{$\begin{array}{l}\text { The club provides e. } \\
\text { payment service to } \\
\text { facilitate payment and } \\
\text { reducing cash collection } \\
\text { corruption }\end{array}$} & \multirow{4}{*}{30} \\
\hline & $\begin{array}{c}\text { to a certain } \\
\text { degree }\end{array}$ & 1.69 & 56.25 & 8 & 5 & 3 & $\begin{array}{c}\text { Middle } \\
\text { management }=16\end{array}$ & & \\
\hline & agreeing & 2.37 & 79.03 & 19 & 18 & 52 & $\begin{array}{c}\text { Executive } \\
\text { management }=89\end{array}$ & & \\
\hline 56.56 & agreeing & 2.36 & 78.72 & 43 & 34 & 111 & $A l l=188$ & & \\
\hline \multirow{2}{*}{$13.75 *$} & agreeing & 2.64 & 87.95 & 10 & 10 & 63 & $\begin{array}{c}\text { Supreme } \\
\text { management }=83\end{array}$ & \multirow{2}{*}{$\begin{array}{c}\text { There is an attitude } \\
\text { towards mechanizing } \\
\text { joining championships } \\
\text { and academies to }\end{array}$} & \multirow{2}{*}{31} \\
\hline & $\begin{array}{c}\text { to a certain } \\
\text { degree }\end{array}$ & 1.88 & 62.50 & 7 & 4 & 5 & $\begin{array}{c}\text { Middle } \\
\text { management }=16\end{array}$ & & \\
\hline
\end{tabular}




\begin{tabular}{|c|c|c|c|c|c|c|c|c|c|}
\hline $\begin{array}{l}\text { Chi } \\
\text { square }\end{array}$ & Attitude & Average & $\begin{array}{c}\text { Out } \\
\text { weighted } \\
\text { percentage }\end{array}$ & Disagreeing & $\begin{array}{l}\text { To a } \\
\text { certain } \\
\text { degree }\end{array}$ & Agreeing & Departments & Statement content & $\mathbf{S}$ \\
\hline & agreeing & 2.42 & 80.52 & 18 & 16 & 55 & $\begin{array}{c}\text { Executive } \\
\text { management }=89\end{array}$ & \multirow{2}{*}{$\begin{array}{l}\text { facilitate counting } \\
\text { practices and creating } \\
\text { good data bases }\end{array}$} & \\
\hline 87.33 & agreeing & 2.47 & 82.27 & 35 & 30 & 123 & All $=188$ & & \\
\hline \multirow{3}{*}{$14.71 *$} & $\overline{\text { agreeing }}$ & 2.59 & 86.35 & 11 & 12 & 60 & $\begin{array}{c}\text { Supreme } \\
\text { management }=83\end{array}$ & \multirow{4}{*}{$\begin{array}{l}\text { ts } \\
\text { ins } \\
\text { er }\end{array}$} & \multirow{4}{*}{32} \\
\hline & $\begin{array}{c}\text { to a certain } \\
\text { degree }\end{array}$ & 1.88 & 62.50 & 6 & 6 & 4 & $\begin{array}{c}\text { Middle } \\
\text { management }=16\end{array}$ & & \\
\hline & $\begin{array}{c}\text { to a certain } \\
\text { degree }\end{array}$ & 2.31 & 77.15 & 20 & 21 & 48 & $\begin{array}{c}\text { Executive } \\
\text { management }=89\end{array}$ & & \\
\hline 58.29 & agreeing & 2.40 & 79.96 & 37 & 39 & 112 & All $=188$ & & \\
\hline \multirow{3}{*}{$14.27 *$} & agreeing & 2.59 & 86.35 & 13 & 8 & 62 & $\begin{array}{c}\text { Supreme } \\
\text { management }=83\end{array}$ & \multirow{4}{*}{$\begin{array}{l}\text { Creating a digital data } \\
\text { base according to which } \\
\text { organizations, their place } \\
\text { and types are selected }\end{array}$} & \multirow{4}{*}{33} \\
\hline & $\begin{array}{c}\text { to a certain } \\
\text { degree }\end{array}$ & 2.06 & 68.75 & 5 & 5 & 6 & $\begin{array}{c}\text { Middle } \\
\text { management }=16\end{array}$ & & \\
\hline & $\begin{array}{c}\text { to a certain } \\
\text { degree }\end{array}$ & 2.28 & 76.03 & 21 & 22 & 46 & $\begin{array}{c}\text { Executive } \\
\text { management }=89\end{array}$ & & \\
\hline 63.20 & agreeing & 2.40 & 79.96 & 39 & 35 & 114 & All $=188$ & & \\
\hline \multirow{3}{*}{$11.75 *$} & agreeing & 2.46 & 81.93 & 17 & 11 & 55 & $\begin{array}{c}\text { Supreme } \\
\text { management }=83\end{array}$ & \multirow{4}{*}{$\begin{array}{l}\text { E. control via system } \\
\text { disallowing registration } \\
\text { unless legally } \\
\text { accordingly pinpointing } \\
\text { and dealing with } \\
\text { violations }\end{array}$} & \multirow{4}{*}{34} \\
\hline & $\begin{array}{l}\text { to a certain } \\
\text { degree }\end{array}$ & 1.88 & 62.50 & 7 & 4 & 5 & $\begin{array}{c}\text { Middle } \\
\text { management }=16\end{array}$ & & \\
\hline & $\begin{array}{c}\text { to a certain } \\
\text { degree }\end{array}$ & 2.27 & 75.66 & 20 & 25 & 44 & $\begin{array}{c}\text { Executive } \\
\text { management= } 89\end{array}$ & & \\
\hline \multirow[t]{2}{*}{41.02} & $\begin{array}{l}\text { to a certain } \\
\text { degree }\end{array}$ & 2.32 & $\mathbf{7 7 . 3 0}$ & 44 & 40 & 104 & All $=188$ & & \\
\hline & & & & & & & & $\begin{array}{l}\text { Digital transformation } \\
\text { supports the club } \\
\text { administrative review } \\
\text { via: }\end{array}$ & 35 \\
\hline \multirow{3}{*}{7.13} & agreeing & 2.71 & 90.39 & 8 & 8 & 67 & $\begin{array}{c}\text { Supreme } \\
\text { management }=83\end{array}$ & \multirow{4}{*}{$\begin{array}{c}\text { Rationalizing } \\
\text { administrative decisions }\end{array}$} & \multirow{4}{*}{$35 / 1$} \\
\hline & $\begin{array}{c}\text { to a certain } \\
\text { degree }\end{array}$ & 2.31 & 77.08 & 4 & 3 & 9 & $\begin{array}{c}\text { Middle } \\
\text { management= } 16\end{array}$ & & \\
\hline & agreeing & 2.46 & 82.02 & 17 & 14 & 58 & $\begin{array}{c}\text { Executive } \\
\text { management }=89\end{array}$ & & \\
\hline 121.93 & agreeing & 2.56 & 85.25 & 29 & 25 & 134 & All $=188$ & & \\
\hline \multirow{3}{*}{$12.30 *$} & agreeing & 2.71 & 90.36 & 8 & 8 & 67 & $\begin{array}{c}\text { Supreme } \\
\text { management }=83\end{array}$ & \multirow{4}{*}{$\begin{array}{l}\text { Supporting internal } \\
\text { control system }\end{array}$} & \multirow{4}{*}{$35 / 2$} \\
\hline & $\begin{array}{c}\text { to a certain } \\
\text { degree }\end{array}$ & 2.25 & 75.00 & 4 & 4 & 8 & $\begin{array}{c}\text { Middle } \\
\text { management }=16\end{array}$ & & \\
\hline & agreeing & 2.36 & 78.65 & 20 & 17 & 52 & $\begin{array}{c}\text { Executive } \\
\text { management= } 89\end{array}$ & & \\
\hline 99.14 & agreeing & 2.51 & 83.51 & 32 & 29 & 127 & All $=188$ & & \\
\hline \multirow{3}{*}{$12.22 *$} & agreeing & 2.69 & 89.56 & 8 & 10 & 65 & $\begin{array}{c}\text { Supreme } \\
\text { management }=83\end{array}$ & \multirow{4}{*}{$\begin{array}{c}\text { Verifying observing the } \\
\text { planned administrative } \\
\text { policies }\end{array}$} & \multirow{4}{*}{$35 / 3$} \\
\hline & $\begin{array}{l}\text { to a certain } \\
\text { degree }\end{array}$ & 2.19 & 72.92 & 4 & 5 & 7 & $\begin{array}{c}\text { Middle } \\
\text { management }=16\end{array}$ & & \\
\hline & agreeing & 2.36 & 78.65 & 19 & 19 & 51 & $\begin{array}{c}\text { Executive } \\
\text { management= } 89\end{array}$ & & \\
\hline 87.20 & agreeing & 2.49 & 82.98 & 31 & 34 & 123 & All $=188$ & & \\
\hline \multirow{3}{*}{$10.31 *$} & agreeing & 2.70 & 89.96 & 8 & 9 & 66 & $\begin{array}{c}\text { Supreme } \\
\text { management }=83\end{array}$ & \multirow{3}{*}{$\begin{array}{l}\text { Verifying the financial } \\
\text { reports true information }\end{array}$} & \multirow{3}{*}{$35 / 4$} \\
\hline & $\begin{array}{c}\text { to a certain } \\
\text { degree }\end{array}$ & 2.25 & 75.00 & 4 & 4 & 8 & $\begin{array}{c}\text { Middle } \\
\text { management }=16\end{array}$ & & \\
\hline & agreeing & 2.93 & 79.78 & 18 & 18 & 53 & $\begin{array}{c}\text { Executive } \\
\text { management }=89\end{array}$ & & \\
\hline
\end{tabular}




\begin{tabular}{|c|c|c|c|c|c|c|c|c|c|}
\hline $\begin{array}{l}\text { Chi } \\
\text { square }\end{array}$ & Attitude & Average & $\begin{array}{c}\text { Out } \\
\text { weighted } \\
\text { percentage }\end{array}$ & Disagreeing & $\begin{array}{c}\text { To a } \\
\text { certain } \\
\text { degree }\end{array}$ & Agreeing & Departments & Statement content & $\mathbf{S}$ \\
\hline 99.07 & agreeing & 2.52 & 83.87 & 30 & 31 & 127 & All $=188$ & & \\
\hline \multirow{3}{*}{$12.24 *$} & agreeing & 2.63 & 87.55 & 10 & 11 & 62 & $\begin{array}{c}\text { Supreme } \\
\text { management }=83\end{array}$ & \multirow{4}{*}{$\begin{array}{l}\text { Evaluating the club' s } \\
\text { employees performance }\end{array}$} & \multirow{4}{*}{$35 / 5$} \\
\hline & sometimes & 2.00 & 66.67 & 6 & 4 & 6 & $\begin{array}{c}\text { Middle } \\
\text { management }=16\end{array}$ & & \\
\hline & sometimes & 2.33 & $\mathbf{7 7 . 5 3}$ & 20 & 20 & 49 & $\begin{array}{c}\text { Executive } \\
\text { management }=89\end{array}$ & & \\
\hline \multirow[t]{2}{*}{70.67} & agreeing & 2.43 & 81.03 & 36 & 35 & 117 & All $=188$ & & \\
\hline & & & & & & & & $\begin{array}{l}\text { E. accounting systems } \\
\text { suitable data about }\end{array}$ & 36 \\
\hline \multirow{3}{*}{$11.82 *$} & agreeing & 2.67 & 89.16 & 9 & 9 & 65 & $\begin{array}{c}\text { Supreme } \\
\text { management }=83\end{array}$ & \multirow{4}{*}{ The net club's profit } & \multirow{4}{*}{$36 / 1$} \\
\hline & $\begin{array}{c}\text { to a certain } \\
\text { degree }\end{array}$ & 2.06 & 68.75 & 5 & 5 & 6 & $\begin{array}{c}\text { Middle } \\
\text { management }=16 \\
\end{array}$ & & \\
\hline & agreeing & 2.44 & 81.27 & 18 & 14 & 57 & $\begin{array}{c}\text { Executive } \\
\text { management }=89\end{array}$ & & \\
\hline 102.30 & agreeing & 2.51 & 83.69 & 32 & 28 & 128 & All $=188$ & & \\
\hline \multirow{3}{*}{$13.54 *$} & agreeing & 2.69 & 89.56 & 9 & 8 & 66 & $\begin{array}{c}\text { Supreme } \\
\text { management }=83\end{array}$ & \multirow{4}{*}{$\begin{array}{l}\text { Average investment } \\
\text { return }\end{array}$} & \multirow{4}{*}{$36 / 2$} \\
\hline & $\begin{array}{c}\text { to a certain } \\
\text { degree }\end{array}$ & 2.00 & 66.67 & 6 & 4 & 6 & $\begin{array}{c}\text { Middle } \\
\text { management }=16\end{array}$ & & \\
\hline & agreeing & 2.40 & 80.15 & 19 & 15 & 55 & $\begin{array}{c}\text { Executive } \\
\text { management }=89\end{array}$ & & \\
\hline 99.46 & agreeing & 2.49 & 83.16 & 34 & 27 & 127 & All $=188$ & & \\
\hline \multirow{3}{*}{$14.57 *$} & agreeing & 2.65 & 88.35 & 10 & 9 & 64 & $\begin{array}{c}\text { Supreme } \\
\text { management }=83\end{array}$ & \multirow{4}{*}{$\begin{array}{c}\text { Declared liquid money } \\
\text { percentage }\end{array}$} & \multirow{4}{*}{$36 / 3$} \\
\hline & $\begin{array}{c}\text { to a certain } \\
\text { degree }\end{array}$ & 1.88 & 62.50 & 7 & 4 & 5 & $\begin{array}{c}\text { Middle } \\
\text { management }=16 \\
\end{array}$ & & \\
\hline & agreeing & 2.44 & 81.27 & 17 & 16 & 56 & $\begin{array}{c}\text { Executive } \\
\text { management }=89\end{array}$ & & \\
\hline 93.20 & agreeing & 2.48 & 82.80 & 34 & 29 & 125 & All $=188$ & & \\
\hline
\end{tabular}

From table (14) there are significant differences the research sample groups' responses for all the dimensions statements as chi square ranged between $(10.31 *: 17.87 *)$ and outweighed percentage ranged between $(77.30: 85.11)$, except for statement number $(35 / 1)$ as chi square reached (7.13).

Results of study of Omar Khalaf (2019) (32), Ahmed Adam (2014) (5) indicate that using information technology in administrative business is the aim of all organization to achieve the competitive advantage.

Nigm Aboud Nigm (2004) states e. control advantages, as permanent control is achieved instead of periodic control; and by time, reduces the importance of control depending on inputs, processes or activities in the interest of increasing results assurance $(31: 247)$.

The researcher concludes that the shift towards electronic commerce has become a necessary and vital matter, and therefore club administrations should bear this in mind in setting the club's marketing strategies, in order to reduce advertising and advertising costs, and facilitate the beneficiaries' acquaintance with the specifications of the services provided by the club, thus 
achieving a competitive advantage among different sports clubs.

\section{Table (15) Second Factor Results: Digital Transformation Requirements to Achieve the Best Competitive Advantage at Clubs}

(Second Dimension: E. Marketing) (A- The Club' Website)

\begin{tabular}{|c|c|c|c|c|c|c|c|c|c|}
\hline $\begin{array}{c}\text { Chi } \\
\text { square }\end{array}$ & Attitude & Average & $\begin{array}{c}\text { Out } \\
\text { weighted } \\
\text { percentage }\end{array}$ & Disagreeing & $\begin{array}{c}\text { To a } \\
\text { certain } \\
\text { degree }\end{array}$ & Agreeing & Departments & Statement content & $\mathbf{S}$ \\
\hline \multirow{3}{*}{4.31} & agreeing & 2.69 & 89.56 & 8 & 10 & 65 & $\begin{array}{c}\text { Supreme } \\
\text { management }=83\end{array}$ & \multirow{4}{*}{$\begin{array}{l}\text { The club has a website } \\
\text { in Arabic and English } \\
\text { to facilitate dealing } \\
\text { with and access to }\end{array}$} & \multirow{4}{*}{37} \\
\hline & $\begin{array}{c}\text { to a certain } \\
\text { degree }\end{array}$ & 2.31 & 77.08 & 4 & 3 & 9 & $\begin{array}{c}\text { Middle } \\
\text { management }=16\end{array}$ & & \\
\hline & agreeing & 2.55 & 85.02 & 13 & 14 & 62 & $\begin{array}{c}\text { Executive } \\
\text { management }=89\end{array}$ & & \\
\hline 128.76 & agreeing & 2.59 & 86.35 & 25 & 27 & 136 & All $=188$ & & \\
\hline \multirow{3}{*}{6.20} & agreeing & 2.71 & 90.63 & 8 & 8 & 67 & $\begin{array}{c}\text { Supreme } \\
\text { management }=\mathbf{8 3}\end{array}$ & \multirow{4}{*}{$\begin{array}{c}\text { The club's website is } \\
\text { characterized by easy } \\
\text { use }\end{array}$} & \multirow{4}{*}{38} \\
\hline & $\begin{array}{l}\text { to a certain } \\
\text { degree }\end{array}$ & 2.31 & 77.08 & 4 & 3 & 9 & $\begin{array}{c}\text { Middle } \\
\text { management }=16\end{array}$ & & \\
\hline & agreeing & 2.51 & 83.52 & 15 & 14 & 60 & $\begin{array}{c}\text { Executive } \\
\text { management }=89\end{array}$ & & \\
\hline 128.76 & agreeing & 2.58 & 85.99 & 27 & 25 & 136 & All $=188$ & & \\
\hline \multirow{3}{*}{6.47} & agreeing & 2.65 & 88.35 & 8 & 13 & 62 & $\begin{array}{c}\text { Supreme } \\
\text { management }=83\end{array}$ & \multirow{4}{*}{$\begin{array}{c}\text { The club's page } \\
\text { includes a description } \\
\text { of services and } \\
\text { activities provided with } \\
\text { pictures }\end{array}$} & \multirow{4}{*}{39} \\
\hline & $\begin{array}{c}\text { to a certain } \\
\text { degree }\end{array}$ & 2.19 & 72.92 & 5 & 3 & 8 & $\begin{array}{c}\text { Middle } \\
\text { management }=16\end{array}$ & & \\
\hline & agreeing & 2.46 & 82.02 & 17 & 14 & 58 & $\begin{array}{c}\text { Executive } \\
\text { management }=89\end{array}$ & & \\
\hline 102.17 & agreeing & 2.52 & 84.04 & 30 & 30 & 128 & All $=188$ & & \\
\hline \multirow{3}{*}{9.17} & agreeing & 2.66 & 88.76 & 8 & 12 & 63 & $\begin{array}{c}\text { Supreme } \\
\text { management }=83\end{array}$ & \multirow{4}{*}{$\begin{array}{c}\text { The club tops the first } \\
\text { search engine pages }\end{array}$} & \multirow{4}{*}{40} \\
\hline & $\begin{array}{l}\text { to a certain } \\
\text { degree }\end{array}$ & 2.06 & 68.75 & 6 & 3 & 7 & $\begin{array}{c}\text { Middle } \\
\text { management }=16\end{array}$ & & \\
\hline & agreeing & 2.52 & 83.90 & 15 & 13 & 61 & $\begin{array}{c}\text { Executive } \\
\text { management }=89\end{array}$ & & \\
\hline 11.78 & agreeing & 2.54 & 84.75 & 29 & 28 & 131 & All $=188$ & & \\
\hline \multirow{3}{*}{$12.30 *$} & agreeing & 2.66 & 88.76 & 9 & 10 & 64 & $\begin{array}{c}\text { Supreme } \\
\text { management }=83\end{array}$ & \multirow{4}{*}{$\begin{array}{c}\text { The club updates } \\
\text { information } \\
\text { periodically on website }\end{array}$} & \multirow{4}{*}{41} \\
\hline & $\begin{array}{c}\text { to a certain } \\
\text { degree }\end{array}$ & 2.00 & 66.67 & 7 & 2 & 7 & $\begin{array}{c}\text { Middle } \\
\text { management }=16\end{array}$ & & \\
\hline & agreeing & 2.46 & 82.02 & 16 & 16 & 57 & $\begin{array}{c}\text { Executive } \\
\text { management }=89\end{array}$ & & \\
\hline 102.30 & agreeing & 2.51 & 83.69 & 32 & 28 & 128 & All $=188$ & & \\
\hline \multirow{3}{*}{$11.55 *$} & agreeing & 2.70 & 89.96 & 8 & 9 & 66 & $\begin{array}{c}\text { Supreme } \\
\text { management }=\mathbf{8 3}\end{array}$ & \multirow{4}{*}{$\begin{array}{l}\text { Words used on the } \\
\text { club's website are } \\
\text { studied carefully by a } \\
\text { specialized department }\end{array}$} & \multirow{4}{*}{42} \\
\hline & $\begin{array}{c}\text { to a certain } \\
\text { degree }\end{array}$ & 2.13 & 70.83 & 6 & 2 & 8 & $\begin{array}{c}\text { Middle } \\
\text { management }=16\end{array}$ & & \\
\hline & agreeing & 2.42 & 80.25 & 18 & 16 & 55 & $\begin{array}{c}\text { Executive } \\
\text { management }=89\end{array}$ & & \\
\hline 105.52 & agreeing & 2.52 & 83.87 & 32 & 27 & 129 & All $=188$ & & \\
\hline \multirow{3}{*}{$14.14 *$} & agreeing & 2.69 & 89.56 & 8 & 10 & 65 & $\begin{array}{c}\text { Supreme } \\
\text { management }=83\end{array}$ & \multirow{4}{*}{$\begin{array}{l}\text { The club has many } \\
\text { specialists of } \\
\text { developing the club's } \\
\text { website }\end{array}$} & \multirow{4}{*}{43} \\
\hline & $\begin{array}{c}\text { to a certain } \\
\text { degree }\end{array}$ & 1.94 & 64.58 & 7 & 3 & 6 & $\begin{array}{c}\text { Middle } \\
\text { management }=16\end{array}$ & & \\
\hline & agreeing & 2.49 & 83.15 & 15 & 15 & 59 & $\begin{array}{c}\text { Executive } \\
\text { management }=89\end{array}$ & & \\
\hline 108.55 & agreeing & 2.53 & 84.40 & 30 & 28 & 130 & All $=188$ & & \\
\hline
\end{tabular}




\begin{tabular}{|c|c|c|c|c|c|c|c|c|c|}
\hline $\begin{array}{l}\text { Chi } \\
\text { square }\end{array}$ & Attitude & Average & $\begin{array}{c}\text { Out } \\
\text { weighted } \\
\text { percentage }\end{array}$ & Disagreeing & $\begin{array}{c}\text { To a } \\
\text { certain } \\
\text { degree }\end{array}$ & Agreeing & Departments & Statement content & $\mathbf{S}$ \\
\hline \multirow{3}{*}{$19.78 *$} & agreeing & 2.63 & 87.55 & 10 & 11 & 62 & $\begin{array}{c}\text { Supreme } \\
\text { management }=83\end{array}$ & \multirow{4}{*}{$\begin{array}{c}\text { There are financial } \\
\text { appropriations } \\
\text { allocated for searching } \\
\text { and developing the } \\
\text { website }\end{array}$} & \multirow{4}{*}{44} \\
\hline & $\begin{array}{c}\text { to a certain } \\
\text { degree }\end{array}$ & 1.75 & 58.33 & 9 & 2 & 5 & $\begin{array}{c}\text { Middle } \\
\text { management }=16\end{array}$ & & \\
\hline & agreeing & 2.36 & 78.65 & 19 & 19 & 51 & $\begin{array}{c}\text { Executive } \\
\text { management }=89\end{array}$ & & \\
\hline 73.57 & agreeing & 2.43 & 80.85 & 38 & 32 & 118 & All $=188$ & & \\
\hline \multirow{3}{*}{$15.49 *$} & agreeing & 2.66 & 88.76 & 8 & 12 & 63 & $\begin{array}{c}\text { Supreme } \\
\text { management }=83\end{array}$ & \multirow{4}{*}{$\begin{array}{l}\text { There is an icon of } \\
\text { direct communication } \\
\text { via the website to } \\
\text { provide the direct } \\
\text { support to the club's } \\
\text { beneficiaries }\end{array}$} & \multirow{4}{*}{45} \\
\hline & $\begin{array}{c}\text { to a certain } \\
\text { degree }\end{array}$ & 1.75 & 58.33 & 7 & 3 & 5 & $\begin{array}{c}\text { Middle } \\
\text { management }=16\end{array}$ & & \\
\hline & agreeing & 2.40 & 80.15 & 17 & 19 & 53 & $\begin{array}{c}\text { Executive } \\
\text { management }=89\end{array}$ & & \\
\hline 82.42 & agreeing & 2.46 & 82.09 & 32 & 34 & 121 & All $=188$ & & \\
\hline \multirow{3}{*}{$17.60 *$} & agreeing & 2.54 & 84.74 & 11 & 16 & 56 & $\begin{array}{c}\text { Supreme } \\
\text { management }=83\end{array}$ & \multirow{4}{*}{$\begin{array}{c}\text { Enabling beneficiaries } \\
\text { to update their data } \\
\text { electronically via the } \\
\text { club's website }\end{array}$} & \multirow{4}{*}{46} \\
\hline & $\begin{array}{c}\begin{array}{c}\text { to a certain } \\
\text { degree }\end{array} \\
\end{array}$ & 1.69 & 56.25 & 9 & 3 & 4 & $\begin{array}{c}\text { Middle } \\
\text { management }=16\end{array}$ & & \\
\hline & agreeing & 2.40 & 80.15 & 16 & 21 & 52 & $\begin{array}{c}\text { Executive } \\
\text { management }=89\end{array}$ & & \\
\hline 58.38 & agreeing & 2.40 & 80.14 & 36 & 40 & 112 & All $=188$ & & \\
\hline \multirow{3}{*}{$15.94 *$} & agreeing & 2.66 & 88.76 & 9 & 10 & 64 & $\begin{array}{c}\text { Supreme } \\
\text { management }=83\end{array}$ & \multirow{4}{*}{$\begin{array}{l}\text { The club focuses on } \\
\text { preparing the page } \\
\text { followers, number of } \\
\text { visits and causes of } \\
\text { their increase or } \\
\text { decrease }\end{array}$} & \multirow{4}{*}{47} \\
\hline & $\begin{array}{c}\text { to a certain } \\
\text { degree }\end{array}$ & 1.81 & 60.42 & 8 & 3 & 5 & $\begin{array}{c}\text { Middle } \\
\text { management }=16\end{array}$ & & \\
\hline & agreeing & 2.46 & 82.02 & 19 & 10 & 60 & $\begin{array}{c}\text { Executive } \\
\text { management }=89\end{array}$ & & \\
\hline 106.67 & agreeing & 2.49 & 83.16 & 36 & 23 & 129 & All $=188$ & & \\
\hline \multirow{3}{*}{$17.19 *$} & agreeing & 2.58 & 85.94 & 11 & 13 & 59 & $\begin{array}{c}\text { Supreme } \\
\text { management }=83\end{array}$ & \multirow{4}{*}{$\begin{array}{l}\text { Matches tickets are } \\
\text { offered on the club's } \\
\text { website in conformity } \\
\text { with the event } \\
\text { importance and } \\
\text { preparing the expected } \\
\text { visitors }\end{array}$} & \multirow{4}{*}{48} \\
\hline & $\begin{array}{c}\begin{array}{c}\text { to a certain } \\
\text { degree }\end{array} \\
\end{array}$ & 1.69 & 56.25 & 9 & 3 & 4 & $\begin{array}{c}\text { Middle } \\
\text { management }=16\end{array}$ & & \\
\hline & agreeing & 2.45 & 81.65 & 17 & 15 & 57 & $\begin{array}{c}\text { Executive } \\
\text { management }=89\end{array}$ & & \\
\hline 78.97 & agreeing & 2.44 & 81.38 & 37 & 31 & 120 & All $=188$ & & \\
\hline
\end{tabular}

From table (15) there are research samples groups' opinions agreement on statements numbers $(37,38,39,40)$ as chi square reached $(4.31: 9.17)$ with an outweighed percentage (84.04: 86.35).

Results of study of Zahef Mohamed (2018) (43) indicate sports organizations' keenness to availing a website and allocating an enough budget to develop e. marketing

Mohamed Ramadan (2006) clarifies that e. marketing provides the profit of investing and managing time for beneficiaries via quick searching for activities and services (28: 126).

Also from the above table, it is clear that the research sample opinions disagree on statements number (41: 48) as chi square reached $\left(11.55^{*}: 19.78^{*}\right)$ with an outweighed percentage (70.85: 84.40$)$

The results of the study of Saad Ahmed Shalaby and Abd Al-Taif Bukhara (2008) (35) indicate that most German clubs take into account the design of their web pages to ensure the management and marketing of their services to various target groups via the Internet.

Results of study of Haitham Fayez (2016) (17) proves no budget allocated for e. marketing and 
discouraging using new e. marketing means for sports activities.

The researcher concludes that the application of electronic marketing to sports clubs requires the availability of specialized human resources with the skills and qualifications that enable them to develop the club's website, with the allocation of a sufficient budget to develop its marketing activity.

Table (16) Second Factor Results: Digital Transformation Requirements to Achieve the Best Competitive Advantage at Clubs

(Second Dimension: E. Marketing) (B- the Club's E. Mail)

\begin{tabular}{|c|c|c|c|c|c|c|c|c|c|}
\hline $\begin{array}{c}\text { Chi } \\
\text { square }\end{array}$ & Attitude & Average & $\begin{array}{c}\text { Out } \\
\text { weighted } \\
\text { percentage } \\
\end{array}$ & Disagreeing & $\begin{array}{c}\text { To a } \\
\text { certain } \\
\text { degree } \\
\end{array}$ & Agreeing & Departments & Statement content & $\mathbf{S}$ \\
\hline \multirow{3}{*}{$11.11 *$} & agreeing & 2.58 & 85.94 & 12 & 11 & 60 & $\begin{array}{c}\text { Supreme } \\
\text { management }=83\end{array}$ & \multirow{4}{*}{$\begin{array}{l}\text { The club has mail } \\
\text { addresses to be used } \\
\text { in correspondences }\end{array}$} & \multirow{4}{*}{49} \\
\hline & $\begin{array}{c}\text { to a certain } \\
\text { degree }\end{array}$ & 2.00 & 66.67 & 7 & 2 & 7 & $\begin{array}{c}\text { Middle } \\
\text { management }=16\end{array}$ & & \\
\hline & $\begin{array}{l}\text { to a certain } \\
\text { degree }\end{array}$ & 2.33 & $\mathbf{7 7 . 5 3}$ & 20 & 20 & 49 & $\begin{array}{c}\text { Executive } \\
\text { management }=89\end{array}$ & & \\
\hline 68.37 & agreeing & 2.41 & 80.32 & 39 & 33 & 116 & All $=188$ & & \\
\hline \multirow{3}{*}{$12.97 *$} & agreeing & 2.54 & 84.74 & 13 & 12 & 58 & $\begin{array}{c}\text { Supreme } \\
\text { management }=83\end{array}$ & \multirow{4}{*}{$\begin{array}{c}\text { Approving the email } \\
\text { as an official method } \\
\text { of correspondences to } \\
\text { get rid of } \\
\text { documentary cycle }\end{array}$} & \multirow{4}{*}{50} \\
\hline & $\begin{array}{c}\text { to a certain } \\
\text { degree }\end{array}$ & 1.88 & 62.50 & 8 & 2 & 6 & $\begin{array}{c}\text { Middle } \\
\text { management }=16\end{array}$ & & \\
\hline & $\begin{array}{c}\text { to a certain } \\
\text { degree }\end{array}$ & 2.29 & 76.40 & 21 & 21 & 47 & $\begin{array}{c}\text { Executive } \\
\text { management }=89\end{array}$ & & \\
\hline 56.31 & agreeing & 2.37 & 78.90 & 42 & 35 & 111 & All $=188$ & & \\
\hline \multirow{3}{*}{$12.69 *$} & agreeing & 2.57 & 85.54 & 14 & 8 & 61 & $\begin{array}{c}\text { Supreme } \\
\text { management }=83\end{array}$ & \multirow{4}{*}{$\begin{array}{l}\text { The club uses the } \\
\text { email to answer the } \\
\text { beneficiaries } \\
\text { questions }\end{array}$} & \multirow{4}{*}{51} \\
\hline & $\begin{array}{l}\text { to a certain } \\
\text { degree }\end{array}$ & 1.94 & 64.58 & 7 & 3 & 6 & $\begin{array}{c}\text { Middle } \\
\text { management }=16\end{array}$ & & \\
\hline & agreeing & 2.35 & 78.28 & 19 & 20 & 50 & $\begin{array}{c}\text { Executive } \\
\text { management }=89\end{array}$ & & \\
\hline 71.31 & agreeing & 2.41 & 80.352 & 40 & 31 & 117 & All $=188$ & & \\
\hline \multirow{3}{*}{$17.56 *$} & agreeing & 2.65 & 88.35 & 9 & 11 & 63 & $\begin{array}{c}\text { Supreme } \\
\text { management }=83\end{array}$ & \multirow{4}{*}{$\begin{array}{l}\text { The beneficiaries are } \\
\text { answered quickly to } \\
\text { save time and effort }\end{array}$} & \multirow{4}{*}{52} \\
\hline & $\begin{array}{c}\text { to a certain } \\
\text { degree }\end{array}$ & 1.81 & 60.42 & 8 & 3 & 5 & $\begin{array}{c}\text { Middle } \\
\text { management }=16\end{array}$ & & \\
\hline & agreeing & 2.35 & 78.28 & 20 & 18 & 51 & $\begin{array}{c}\text { Executive } \\
\text { management }=89\end{array}$ & & \\
\hline 76.16 & agreeing & 2.44 & 81.21 & 37 & 32 & 119 & All $=188$ & & \\
\hline \multirow{3}{*}{$17.10 *$} & agreeing & 2.53 & 84.34 & 11 & 17 & 55 & $\begin{array}{c}\text { Supreme } \\
\text { management }=83\end{array}$ & \multirow{4}{*}{$\begin{array}{c}\text { There is a team } \\
\text { specialized in } \\
\text { answering the } \\
\text { beneficiaries' } \\
\text { questions via email }\end{array}$} & \multirow{4}{*}{53} \\
\hline & $\begin{array}{c}\text { to a certain } \\
\text { degree }\end{array}$ & 1.75 & 58.33 & 9 & 2 & 5 & $\begin{array}{c}\text { Middle } \\
\text { management }=16\end{array}$ & & \\
\hline & $\begin{array}{c}\text { to a certain } \\
\text { degree }\end{array}$ & 2.22 & 74.16 & 23 & 23 & 43 & $\begin{array}{c}\text { Executive } \\
\text { management }=89\end{array}$ & & \\
\hline 38.95 & $\begin{array}{c}\text { to a certain } \\
\text { degree }\end{array}$ & 2.32 & 77.30 & 43 & 42 & 103 & All $=188$ & & \\
\hline \multirow{3}{*}{$14.95 *$} & agreeing & 2.61 & 87.15 & 10 & 12 & 61 & $\begin{array}{c}\text { Supreme } \\
\text { management }=83\end{array}$ & \multirow{4}{*}{$\begin{array}{c}\text { Marketing fliers are } \\
\text { sent to the club's } \\
\text { beneficiaries via } \\
\text { email }\end{array}$} & \multirow{4}{*}{54} \\
\hline & $\begin{array}{l}\text { to a certain } \\
\text { degree }\end{array}$ & 1.94 & 64.58 & 7 & 3 & 6 & $\begin{array}{c}\text { Middle } \\
\text { management }=16\end{array}$ & & \\
\hline & $\begin{array}{c}\text { to a certain } \\
\text { degree }\end{array}$ & 2.24 & 74.53 & 24 & 20 & 45 & $\begin{array}{c}\text { Executive } \\
\text { management }=89\end{array}$ & & \\
\hline 58.54 & agreeing & 2.38 & 79.26 & 41 & 35 & 112 & All $=188$ & & \\
\hline
\end{tabular}

From table (16), there are significant differences between responses of all the research sample 
groups as chi square reached $\left(11.11^{*}: 17.56^{*}\right)$ with an outweighed percentage (77.30: 81.21$)$.

Study of Hind Elghanem (2014) (20) states that the ability of dealing with beneficiaries via email is one of the most important things introduced by knowledge and organizations digital transformation.

The researcher believes that the ability to deal with beneficiaries via e-mail and social networking services is one of the most important things that knowledge and digital transformation can provide to sports clubs in the field of receiving and responding to beneficiaries' inquiries and questions.

Table (17) Second Dimension Result: E. Marketing (C-Applications of Smart Phones and Social Media)

\begin{tabular}{|c|c|c|c|c|c|c|c|c|c|}
\hline $\begin{array}{c}\text { Chi } \\
\text { square }\end{array}$ & Attitude & Average & $\begin{array}{c}\text { Out } \\
\text { weighted } \\
\text { percentage }\end{array}$ & Disagreeing & $\begin{array}{c}\text { To a } \\
\text { certain } \\
\text { degree }\end{array}$ & Agreeing & Departments & Statement content & $\mathbf{S}$ \\
\hline \multirow{3}{*}{8.99} & agreeing & 2.49 & 83.13 & 13 & 16 & 54 & $\begin{array}{c}\text { Supreme } \\
\text { management }=83\end{array}$ & \multirow{4}{*}{$\begin{array}{l}\text { The club has smart } \\
\text { phone applications } \\
\text { helping beneficiaries } \\
\text { to communicate } \\
\text { permanently with } \\
\text { the club }\end{array}$} & \multirow{4}{*}{55} \\
\hline & $\begin{array}{c}\text { to a certain } \\
\text { degree }\end{array}$ & 1.94 & 64.58 & 7 & 3 & 6 & $\begin{array}{c}\text { Middle } \\
\text { management }=16\end{array}$ & & \\
\hline & $\begin{array}{c}\text { to a certain } \\
\text { degree }\end{array}$ & 2.25 & 74.91 & 22 & 23 & 44 & $\begin{array}{c}\text { Executive } \\
\text { management }=89\end{array}$ & & \\
\hline 40.89 & $\begin{array}{c}\text { to a certain } \\
\text { degree }\end{array}$ & 2.33 & 77.66 & 42 & 42 & 104 & $\mathrm{All}=188$ & & \\
\hline \multirow{3}{*}{5.42} & agreeing & 2.73 & 91.16 & 8 & 6 & 69 & $\begin{array}{c}\text { Supreme } \\
\text { management }=83\end{array}$ & \multirow{4}{*}{$\begin{array}{l}\text { The club uses social } \\
\text { media to advertise } \\
\text { services provided to } \\
\text { beneficiaries }\end{array}$} & \multirow{4}{*}{56} \\
\hline & $\begin{array}{c}\text { to a certain } \\
\text { degree }\end{array}$ & 2.31 & 77.08 & 5 & 1 & 10 & $\begin{array}{c}\text { Middle } \\
\text { management }=16\end{array}$ & & \\
\hline & agreeing & 2.63 & 87.64 & 13 & 7 & 69 & $\begin{array}{c}\text { Executive } \\
\text { management }=89\end{array}$ & & \\
\hline 175.45 & agreeing & 2.65 & 88.30 & 26 & 14 & 148 & All $=188$ & & \\
\hline \multirow{3}{*}{$10.35 *$} & agreeing & 2.69 & 89.56 & 10 & 6 & 67 & $\begin{array}{c}\text { Supreme } \\
\text { management }=83\end{array}$ & \multirow{4}{*}{$\begin{array}{l}\text { The club studies the } \\
\text { beneficiaries e. } \\
\text { comments to know } \\
\text { the offered services } \\
\text { advantages and } \\
\text { disadvantages }\end{array}$} & \multirow{4}{*}{57} \\
\hline & $\begin{array}{c}\text { to a certain } \\
\text { degree }\end{array}$ & 2.19 & 82.92 & 6 & 1 & 9 & $\begin{array}{c}\text { Middle } \\
\text { management }=16\end{array}$ & & \\
\hline & agreeing & 2.46 & 82.02 & 17 & 14 & 58 & $\begin{array}{c}\text { Executive } \\
\text { management }=89\end{array}$ & & \\
\hline 122.95 & agreeing & 2.54 & 84.57 & 33 & 21 & 134 & $A l l=188$ & & \\
\hline \multirow{3}{*}{8.09} & agreeing & 2.72 & 90.76 & 8 & 7 & 68 & $\begin{array}{c}\text { Supreme } \\
\text { management }=83\end{array}$ & \multirow{4}{*}{$\begin{array}{c}\text { Answering e. } \\
\text { comments may give } \\
\text { beneficiaries good } \\
\text { impression }\end{array}$} & \multirow{4}{*}{58} \\
\hline & $\begin{array}{c}\text { to a certain } \\
\text { degree }\end{array}$ & 2.25 & 75.00 & 5 & 2 & 9 & $\begin{array}{c}\text { Middle } \\
\text { management }=16\end{array}$ & & \\
\hline & agreeing & 2.55 & 85.02 & 13 & 14 & 62 & $\begin{array}{c}\text { Executive } \\
\text { management }=89\end{array}$ & & \\
\hline 139.54 & agreeing & 2.60 & 86.70 & 26 & 23 & 139 & All $=188$ & & \\
\hline \multirow{3}{*}{5.32} & agreeing & 2.48 & 82.73 & 15 & 13 & 55 & $\begin{array}{c}\text { Supreme } \\
\text { management }=83\end{array}$ & \multirow{4}{*}{$\begin{array}{l}\text { The club allows } \\
\text { using sports } \\
\text { facilities such as } \\
\text { halls and basins and } \\
\text { leasing the same via } \\
\text { smart applications }\end{array}$} & \multirow{4}{*}{59} \\
\hline & $\begin{array}{c}\text { to a certain } \\
\text { degree }\end{array}$ & 2.00 & 66.67 & 6 & 4 & 6 & $\begin{array}{c}\text { Middle } \\
\text { management }=16\end{array}$ & & \\
\hline & agreeing & 2.46 & 82.02 & 16 & 16 & 57 & $\begin{array}{c}\text { Executive } \\
\text { management }=89\end{array}$ & & \\
\hline 73.41 & agreeing & 2.43 & 81.03 & 37 & 33 & 118 & All $=188$ & & \\
\hline \multirow{2}{*}{$13.06 *$} & agreeing & 2.64 & 87.95 & 8 & 14 & 61 & $\begin{array}{c}\text { Supreme } \\
\text { management }=83\end{array}$ & \multirow{2}{*}{$\begin{array}{c}\text { The club enhances } \\
\text { its promotional } \\
\text { campaigns via face } \\
\text { book through }\end{array}$} & \multirow{2}{*}{60} \\
\hline & $\begin{array}{c}\text { to a certain } \\
\text { degree }\end{array}$ & 2.06 & 68.75 & 7 & 1 & 8 & $\begin{array}{c}\text { Middle } \\
\text { management }=16 \\
\end{array}$ & & \\
\hline
\end{tabular}




\begin{tabular}{|c|c|c|c|c|c|c|c|c|c|}
\hline $\begin{array}{l}\text { Chi } \\
\text { square }\end{array}$ & Attitude & Average & $\begin{array}{c}\text { Out } \\
\text { weighted } \\
\text { percentage }\end{array}$ & Disagreeing & $\begin{array}{c}\text { To a } \\
\text { certain } \\
\text { degree }\end{array}$ & Agreeing & Departments & Statement content & $\mathbf{S}$ \\
\hline & agreeing & 2.58 & 86.14 & 12 & 13 & 64 & $\begin{array}{c}\text { Executive } \\
\text { management= 89 }\end{array}$ & $\begin{array}{c}\text { supporting by } \\
\text { pictures and videos }\end{array}$ & \\
\hline 118.41 & agreeing & 2.56 & 85.46 & 27 & 28 & 133 & All $=188$ & & \\
\hline \multirow{3}{*}{8.85} & agreeing & 2.53 & 84.34 & 12 & 15 & 56 & $\begin{array}{c}\text { Supreme } \\
\text { management }=83\end{array}$ & \multirow{4}{*}{$\begin{array}{c}\text { The club has a } \\
\text { system of sending } \\
\text { SMS on smart } \\
\text { phones }\end{array}$} & \multirow{4}{*}{61} \\
\hline & $\begin{array}{l}\text { to a certain } \\
\text { degree }\end{array}$ & 2.00 & 66.67 & 7 & 2 & 7 & $\begin{array}{c}\text { Middle } \\
\text { management }=16\end{array}$ & & \\
\hline & agreeing & 2.53 & 84.27 & 13 & 16 & 60 & $\begin{array}{c}\text { Executive } \\
\text { management }=89\end{array}$ & & \\
\hline 87.14 & agreeing & 2.48 & 82.80 & 32 & 33 & 123 & All $=188$ & & \\
\hline
\end{tabular}

From table (17) the research sample opinions agree upon statements numbers $(55,56,58,59$, $61)$ as chi square ranged between $(5.32: 8.85)$ with an outweighed percentage $(77.66: 88.30)$ Study of Moustafa Kawal (2018) (39) indicates the importance of using the phone application in attracting clients as they enable the organization to increase its works and reduce commercial costs.

Foad Bougnana (2008) (16) mentions the importance of using email and SMS.

Also table proves the research group's opinion disagreement on the statements number (57, 60) as chi square reached $\left(10.35^{*}\right),\left(13.06^{*}\right)$ with an outweighed percentage $(84.75),(85.46)$ respectively.

Results of study of Mariam Nariman (2012) (26) prove that social media marketing is very important for consumer in pre purchase stage as many service information are available.

The results of the study of Mariam Nariman Nomar (2012) (26) indicate that marketing through social networking sites such as Facebook is of great importance to the consumer in the pre-purchase stage, where there is a lot of information available about services, their characteristics, features and prices.

The researcher believes that social networking sites have become a means accessible to various groups of society, as these sites have multiplied and are distinguished by their availability and permanent adhesion to the beneficiaries, and they are of great importance for sports clubs because of their effective role in appealing to the beneficiaries of the services provided by sports clubs.

Table (18) Second Factor Results: Digital Transformation Requirements to Achieve the Best Competitive Advantage at Clubs

(Second Dimension: E. Marketing)

(D- E. Newspapers and digital transmission stages)

\begin{tabular}{|c|c|c|c|c|c|c|c|c|c|}
\hline $\begin{array}{l}\text { Chi } \\
\text { square }\end{array}$ & Attitude & Average & $\begin{array}{c}\text { Out } \\
\text { weighted } \\
\text { percentage }\end{array}$ & Disagreeing & $\begin{array}{c}\text { To a } \\
\text { certain } \\
\text { degree }\end{array}$ & Agreeing & Departments & Statement content & $\mathbf{S}$ \\
\hline \multirow{3}{*}{7.14} & agreeing & 2.60 & 86.75 & 10 & 13 & 60 & $\begin{array}{c}\text { Supreme } \\
\text { management= } 83\end{array}$ & \multirow{4}{*}{$\begin{array}{l}\text { The club has a you tube } \\
\text { channel to transmit } \\
\text { pictures and videos } \\
\text { about the club's } \\
\text { activities }\end{array}$} & \multirow{4}{*}{6} \\
\hline & $\begin{array}{c}\text { to a certain } \\
\text { degree }\end{array}$ & 2.13 & 70.83 & 6 & 2 & 8 & $\begin{array}{c}\text { Middle } \\
\text { management }=16\end{array}$ & & \\
\hline & agreeing & 2.57 & 85.77 & 12 & 14 & 63 & $\begin{array}{c}\text { Executive } \\
\text { management= } 89\end{array}$ & & \\
\hline 111.78 & agreeing & 2.55 & 84.93 & 28 & 29 & 131 & All $=188$ & & \\
\hline 8.51 & agreeing & 2.52 & 83.94 & 13 & 14 & 56 & $\begin{array}{c}\text { Supreme } \\
\text { management }=83\end{array}$ & The club contracts with & 63 \\
\hline
\end{tabular}




\begin{tabular}{|c|c|c|c|c|c|c|c|c|c|}
\hline $\begin{array}{l}\text { Chi } \\
\text { square }\end{array}$ & Attitude & Average & $\begin{array}{c}\text { Out } \\
\text { weighted } \\
\text { percentage }\end{array}$ & Disagreeing & $\begin{array}{c}\text { To a } \\
\text { certain } \\
\text { degree }\end{array}$ & Agreeing & Departments & Statement content & $\mathbf{S}$ \\
\hline & $\begin{array}{c}\text { to a certain } \\
\text { degree }\end{array}$ & 1.88 & 62.50 & 7 & 4 & 5 & $\begin{array}{c}\text { Middle } \\
\text { management }=16\end{array}$ & \multirow{3}{*}{$\begin{array}{c}\text { e. newspapers and } \\
\text { magazines as a method } \\
\text { of propaganda and } \\
\text { advertisement }\end{array}$} & \\
\hline & agreeing & 2.39 & 79.78 & 19 & 16 & 54 & $\begin{array}{c}\text { Executive } \\
\text { management }=89\end{array}$ & & \\
\hline 65.76 & agreeing & 2.40 & 80.14 & 39 & 34 & 115 & All $=188$ & & \\
\hline \multirow{3}{*}{$17.97 *$} & agreeing & 2.61 & 87.15 & 10 & 12 & 61 & $\begin{array}{c}\text { Supreme } \\
\text { management }=83\end{array}$ & \multirow{4}{*}{$\begin{array}{l}\text { The club contracts with } \\
\text { digital transmission } \\
\text { stages to display events } \\
\text { and matches against } \\
\text { financial return }\end{array}$} & \multirow{4}{*}{64} \\
\hline & $\begin{array}{c}\text { to a certain } \\
\text { degree }\end{array}$ & 1.81 & 60.42 & 7 & 5 & 4 & $\begin{array}{c}\text { Middle } \\
\text { management }=16\end{array}$ & & \\
\hline & agreeing & 2.45 & 81.65 & 29 & 18 & 51 & $\begin{array}{c}\text { Executive } \\
\text { management }=89\end{array}$ & & \\
\hline 62.04 & agreeing & 2.47 & 82.27 & 46 & 35 & 116 & All $=188$ & & \\
\hline \multirow{3}{*}{$17.78 *$} & agreeing & 2.63 & 87.55 & 9 & 13 & 61 & $\begin{array}{c}\text { Supreme } \\
\text { management }=83\end{array}$ & \multirow{4}{*}{$\begin{array}{l}\text { The club shall compile } \\
\text { special conditions with } \\
\text { digital transmission } \\
\text { stages when covering } \\
\text { and transmitting } \\
\text { matches and } \\
\text { championships }\end{array}$} & \multirow{4}{*}{65} \\
\hline & $\begin{array}{c}\text { to a certain } \\
\text { degree }\end{array}$ & 1.75 & 58.33 & 8 & 4 & 4 & $\begin{array}{c}\text { Middle } \\
\text { management }=16\end{array}$ & & \\
\hline & agreeing & 2.38 & 79.40 & 18 & 19 & 52 & $\begin{array}{c}\text { Executive } \\
\text { management }=89\end{array}$ & & \\
\hline 70.67 & agreeing & 2.44 & 81.21 & 35 & 36 & 117 & All $=188$ & & \\
\hline
\end{tabular}

From table (18), it is clear that the research sample agree upon statements number $(62,63)$ as chi square reached (7.14), (8.51) with outweighed percentage (84.93) (80.14) respectively.

Study of Bosaina Ghadiri (2015) (11) indicates the effect of e advertising on beneficiaries under the increasing number of internet users with focusing on advertisement content and credibility.

Also the research sample opinions disagreed on statements numbers $(64,65)$ as chi square reached $(17.97 *),(17.78 *)$ with outweighed percentage $(82.27),(81.21)$

The united company of advertising services established watch at forum which declared reaching the exclusive digital rights at Egyptian series for 4 years, which enables the forum users to enjoy all goals, matches and summaries (70).

The researcher believes that sports club administrations need to pay attention to enhancing their financial returns by attracting digital broadcasting platforms towards obtaining the rights to broadcast their sporting events, especially in light of the decline of traditional broadcasting channels.

\section{Conclusions:}

- The supreme management supports digital transformation via looking into new techniques by documenting services and trying to transform paper forms to electronic forms.

- Employees are neither trained nor provide with skills needed for attending technology permanently.

- The club's organizational structure agrees with digital transformation application requirements.

- Lack of specialized committee or unit for applying digital transformation as planned.

- Employees have no advanced digital skills such as networks management, ability to create in using digital techniques, developing digital content and computerized programming.

- Weak protection programs related to anti hacking 
- The club profits from open governmental data in developing the club's performance data.

- Artificial intelligence is, to a certain degree, at clubs to develop the athletes' level.

- Ecommerce is weakly used in facilitating commercial deals.

- The club has a web site in English and Arabic and the club's page has a service and activities description.

- Law financial appropriations allocated for research and developing website.

\section{Recommendations:}

- Finishing the national project of digital transformation considered as an important tool of achieving permanent development, developing governmental work development, providing e services and applying digital economy.

- Developing legislative frames supporting digital transformation and trying to make Egypt distinctive on great data centers manufacturing chart to be a territorial centre for data centers and information banks.

- Compiling an integrated strategy to develop human resources in conformity with achieving permanent and integrated community development in conformity with the aimed digital transformation to attend international changes and new updates.

- Clubs should adopt a clear strategy towards a digital transformation and preparing a time table for applying transformation to guarantee execution in conformity with Egypt view 2030.

- Respond to beneficiaries via developing participation channels, and activating beneficiaries, participation in developing and improving the club's decisions, policies and services.

\section{Bibliography}

\section{First: Arabic Bibliography}

1 Abdelrahman Elour (2018)

2
Abdelsabour Abdelkawy (2010)

3 Abla Zaian Bouzian (2016)

4 Ahlam Elfekky (2014)
Human resources impact, routine operations and their effect on work future, federal authority of governmental human resources, issue 8 , United Arab Emirates

Elmasry

Ecommerce and Law , Dar Al Elom Publishers, Cairo

The effect of using some technologies in developing decision making level for handball

: referees, unpublished master thesis, institute of physical and sports science and techniques, al gibali bonama university, Algergria

Information and Communication Technology and its Role in Developing Sports Management, an : Unpublished Master Thesis, Faculty of Post Graduate Studies for Physical Education, Sudan University for Science and Technology. 
5
Ahmed Adam Ahmed Mohamed (2014)

6 Ahmed Mahgoub Mousa (2015)

7 Ahmed Mohamed Ghounim (2004)

8 Ala Abdelmonim Abdalla (2014)

9 Ashour Abdelkerim (2010)

10 Beshir Arnous (2007)

11 Bosaina Ghadiri (2015)

12

13

Doaa Elhosban, Weam Elhayek
(2017)

14 Faleh Abbas Lotfy (2019)

15 Fatma Elsabiy (2019)
Information Technology Role in Improving Sports Management Performance in Some Governmental and Nongovernmental Organizations a Thesis Published on Magazine of Faculty of Physical Education, January issue , Sudan University for Science and Technology.

The Effect of Computerization on Achieving E: government Purposes, Faculty of Post Graduate Studies, Al Nilin University, Sudan.

E-management, Fields of Present and Expectation of Future , the Modern Library, Saudi Arabia

Creating and developing applications to avail the same as a cloud service, faculty of commuter science and information techniques, Al Nilin University, Sudan

The role e. Management in rationalizing public service in the US and Algeria, un published master thesis , faculty of law and political science, Mantori University, Algeria

: Artificial Intelligence, Alsahab Publishers, Cairo

E. Advertisement in Directing the Consumer's Behavior, Faculty of Economic Science, - Commercial Science and Facilitation Science, Al Arabi Ben Mehidi University, Algeria

The Role of e. Management in Achieving the Competitive Advantage at Clubs, a thesis : published on Al Elmia Magazine of Physical Education, Faculty of Physical Education for Girls, Alexandria University, volume 5 issue 5.

Challenges and Opportunities Affecting E. Government Success in Jordon, a thesis published : on science, Engineering and Information Technology Magazine, first volume, issue 2, National Research Center, Palestine.

The effect of artificial intelligence on auditing quality of accounting auditing offices in Jordon , : unpublished master thesis, faculty of scientific research deanship and post graduate studies , Girsh university, Jordon

Studying strategies of attitudes of applying blue : kitchen technique in Gulf states, al Bahrain center for strategic and international studies , Bahrain 
16 Foad Abougnana (2008)

17 Haitham Fayez Mahmoud (2016)

Hanin Abdelsalam Abou Oud,

18 Aseel Ahmed Eldarat, Aly

Mohamed Abdelshahid (2019)

19 Haroun Abdalla Eissa (2009)

21 Hend Mohamed Hamed (2010)

22 Ihab Khalifa (2018)

23
International Telecommunication Union (2018)

24
Kholoud Bent Salem Bin Saleh (2019)

25
Evaluating marketing communication fact in service organizations, unpublished master thesis, faculty of facilitation sciences, Warkala university, Algeria

E. Sports Marketing Strategy at Sports Clubs in : Egypt. unpublished doctorate thesis, Faculty of Physical Education, Alexandria University

Intelligence Things Internet in the Field of Health

: Care, issue 15, Academic Research Magazine

Designing a System for Human Development in States in the Frame of the E. Government's Project by Using Open Resources, unpublished doctorate thesis, Faculty of Computer Science and Information Technology, Al Nilin University, Sudan

Behaviors of Supplicating Information Related to E. Information Bases for Teaching Staff Members, : Islamic University of Imam Mohamed Ben Saoud, thesis published on national magazine of King Fahd, volume 20 issue 1

Ecommerce in Touristic Field, Faculty of Tourism and Hotels, Helwan University Cairo

The Blue Kitchen, the Next Technological Revolution in Finance and Administration, Future for Research and Advanced Studies, issue 3 March 2018, Abo Dhabi, Emirates

Creating Abilities in a Changeable Environment for Information and Communication Technology, Communication Development Library, Geneva , Switzerland

Using Open Governmental Data by Researchers at Faculties of Human Sciences, Sultan Kabos University, unpublished master thesis, Faculty of Arts and Social Science, Sultan Kabos, Oman

Business Establishment and Digital Transformation, a thesis published on information : Egyptian magazine, Egyptian Association for Information System and Accounting Technology, issue (21) 
26 Mariam Nariman Noumar (2012)

27 Mohamed Fathy Abdelhady (2008) :

28 Mohamed Ramadan Zaho (2006)

29 Moustafa Kawal (2018)

30 Nawal Bent Aly abdalla (2019)

31 Negm Aboud Negm (2004)

32 Omar Khalaf Salem Elsaleh (2019)

33 Omar Mohamed Saleh Aly (2018)

34 Ramadan Aly Elsayed Elmarouf (2011) Saad Ahmed Shalaby, Abdellatif
Boukhary (2008)

36 Safaa Soliman Khalil (2019)
Using Social Media and their Effects on Social Relationships "Studying a Sample of Facebook : Users in Algeria" unpublished master thesis, Faculty of Media and Communication Science, Al Haj Al Akhdar University, Algeria

Knowledge and Libraries Age, first print, High Institute of Culture, Cairo

Marketing and Advertising Researches from the Perspective of Acts Globalization and Data Electronic, Faculty of Commerce, Banha University, Egypt

Suggesting Methods of Sports Promotion to Achieve Self Finance for Algerian Clubs Professionalizing Football, unpublished doctorate thesis, Mohamed Bou Diaf University, Algeria

Digital Transformation in Oman Sultanate, : unpublished master thesis, Faculty of Arts and Social Science, Sultan Kabos University, Oman

E. Management "Strategies, Functions and : Problems", Dar ALmarikh, Saudi Arabia

Factors affecting adopting ecommerce in pharmaceutical companies in Jordon, unpublished : master thesis, faculty of economy and administrative science, Al Albit University , Jordon

Developing an application by using things internet techniques : by applying to care services , unpublished master thesis, faculty of post graduate studies, Al Nilin University, Sudan

E. Commerce in Japan and How Far Egypt Could Profit From, Jazirat Alward Library, Cairo

Electronic administration and marketing at sports clubs joining the German series of football 2007 : 2008 , analytical study, a thesis published on the first international conference magazine for physical and health education

Developing electronic office systems by using cloud computerizing techniques applying : correspondence system, unpublished doctorate thesis, faculty of computer science and information techniques, Al Nilin University, Sudan 
37

Safat Salama, Khalil Abou Koura (2014)

38 Salma Kounda (2018)

39 Srour Aly Srour (2005

40 Taweel Osama (2017)

United Nation Organization for

41 Education, Science and Culture : (2018)

42 Youssef Ahmed Abou Fara (2007)

43 Zahaf Mohamed (2018)

\section{Second: Foreign Bibliography}

- Robots age challenges and ethics, emirates center

of strategic studies and research, Abo Dhabi

Media and communication technology in the field of school management, a thesis published on

: sports creation magazine, Mohamed Amin Dabaghin university, volume 9, issue 2, Algeria

Artificial intelligence, smart systems manual, al marikh publishing house, Riyadh

Electronic management and restrictions of applying to sports management, a field study at : youth and sports directorate at al masila state, unpublished master thesis, physical activities science and techniques, Mohamed bo deif

Skills for Connected World, conceptual : memorandum, the Week of Learning by Mobile Appliances, UNESCO

E. Marketing Strategies, a behavioral approach, Al Mostakbal Publishing, Oman

E. Marketing as an approach to developing marketing information systems at Algeria sports : organizations. A thesis published on sports science magazine, volume 8 , issue 24 , Masila university, Algeria
\& Alison Davis, Matthew Merle (2019)
C. Le : :

Blockchain Competitive Advantage: Whether you are an entrepreneur, investor, or established company, learn how to win the battle for blockchain competitive advantage, Fifth Era Media

¿ $\quad$ Bruce Sinclair (2017): IoT Inc

: How Your Company Can Use the Internet of Things to Win in the Outcome Economy, McGraw-Hill Education

\& $\begin{aligned} & \text { David Furlonger, Christophe } \\ & \text { Uzureau (2019) }\end{aligned}$

¿ George Westerman (2014)

$\varepsilon \wedge$
Giacomo Veneri and Capasso (2018)

The Real Business of Blockchain: How Leaders Can

: Create Value in a New Digital Age, Harvard Business Review Press

: Leading Digital: Turning Technology into Business

Transformation, Harvard Business Review Press

Hands-On Industrial Internet of Things: Create a

: powerful Industrial loT infrastructure using Industry 4.0, Packt Publishing 
¿ Gil Gildner, Anya Gildner (2019) :
๑. Jared Tate, Andrew Knapp (2019): :

Becoming a Digital Marketer: Gaining the Hard \& Soft Skills for a Tech-Driven Marketing Career, Baltika Press

Blockchain 2035: The Digital DNA of Internet 3.0,
BlueShed LLC

E-Commerce Business Model 2020: This Book

O) Jim Work George Brand (2020)

or Joel Gurin (2014)

or Julian Singh (2017)

Kevin L. Jackson and Scott
Goessling (2018):

๑o Mohit Sharma (2018)

or $\begin{aligned} & \text { Ovidiu Vermesan, Peter Friess } \\ & \text { (2013) }\end{aligned}$

ov Rob Kitchin (2014)

$\bullet \wedge \quad$ Sarah Grand-Clement (2017)

๑q Thomas M. Siebel (2019)
: Includes: Online Marketing Strategies, Dropshipping, Amazon FBA - Step-by-Step Guide with Latest Techniques to Make Money Online and Reach Financial Freedom, Independently published Open Data Now: The Secret to Hot Startups, Smart

: Investing, Savvy Marketing, and Fast Innovation, McGraw-Hill Education

: : Open Data 101: The latest trends, challenges and research in government open data, Cooee Press
: Architecting Cloud Computing Solutions: Build cloud strategies that align technology and economics while effectively managing risk, Packt Publishing How RPA will impact the future workplace for : Governments across the world and the economy, Published by the Federal Authority for Government Human Resources, UA E

Internet of Things: Converging Technologies for Smart

: Environments and Integrated Ecosystems, River Publishers

The Data Revolution: Big Data, Open Data, Data

: Infrastructures and Their Consequences, SAGE Publications Ltd

: development for a connected world, RAND Europe Digital technology's role in enabling skills Mass Extinction, Rosetta Books
: Digital Transformation: Survive and Thrive in an Era of

\section{Third: International Information Network}

60

https://www.sis.gov.eg/Story/178669/
: Website of Information Authority - 15 November 2018: The partnership between the government and private sector is a basis of permanent development objectives 
61

http://www.mcit.gov.eg/Ar/Media_Center/P ress_Room/Press_Releases/41556

62

https://www.youm7.com/story/2019/11/22

63 https://www.elwatannews.com/news/details/ $\underline{4705703}$

64 https://arabic.sport360.com/article/

65 https://www.bneconomy.com/9274

66 https://www.elwatannews.com/news/details/ 1273513

67 https://www.rosaelyoussef.com/519910

68

http://www.mcit.gov.eg/Ar/Media_Center/P ress_Room/Press_Releases/41556

69

https://www.alayam.com/Article/sportarticle/414326/

70

https://www.youm7.com/story/2019/5/27/
: Website of Ministry of Communication and Information Technology - Cairo 13 January 2020: Officially , Ministry of Planning Provides Ministry of Communication with Digital Transformation Projects

: website of Al Youm Al Sabei Newspaper 22 November 2019: for the first time Egypt operate a communication satellite to apply digital transformation

: Website of Alwatan Newspaper 18 April 2020: Sobhy discusses with Microsoft : digital transformation of projects of " youth and sports"

: Website of sport 360 - 07 November 2019: Al Ahly Club uncover strategy of digital transformation for all members' services

: Site of baladna news economic 03 August 2019: Heliopolis club and Kuwait national bank sign a cooperation protocol of digital transformation of the club in cooperation with Raya systems

: Alwatan newspaper 23 July 2016: Egypt telecom signing a protocol of cooperation with "Smoha Club"

: Website of Ros Al Yossef newspaper 30 December 2019: Dr./ Ahmed Farouk Abdelkader writes: Digital Transformation in Egyptian Sports

: Website of Ministry of Communication and Information Technology 13 January 2020: Officially, Ministry of Planning Provides Ministry of Communication with Digital Transformation Projects

: Prof. Dr. / Faisal Elmala, website of alyam newspaper sports field and artificial intelligence

: Alyom alsabei 27/05/2019, exclusively, the Egyptian serious digitally on Watch iT 


\title{
Kaizen methodology for continuous improvement as an entry point to achieve outstanding institutional performance in the Directorate of Youth and Sports in Alexandria Governorate
}

\author{
Assistant Prof. Dr./ Reham Amin Hamza Shehab
}

Assistant Professor, Sports Administration Department, Faculty of Physical Education for Girls, Alexandria University

\section{Research Problem and Importance:}

Current international challenges force organizations to convert from using traditional administrative methods to new methods to exploit human capacities, perhaps (Kaizen) methodology of improving permanent performance is one of the most important new trends suitable for leading organizations for the time being.

Ann Bisou (2016) and Robert Maurer (2012) agreed upon Kaizen as an administrative philosophy and a Japanese strategy aiming at development, permanent improvement (25: 28), (32: 9).

Kai Musashi (2016), Richard Schonberger (2012), Masaaki Imai (2012) define it as creating a slow and permanent change in work via gradual improvement, reducing costs and wastes and increasing productivity. (29: 17), (31: 157), (30: 13).

Benjamin S. Sweet (2015) says that Kaizen's methodology includes a great number of procedures including "adopting Kaizen's methodology by supreme administration, selecting leaderships qualified for applying Kaizen's culture, enhancing teamwork culture, encouraging creative thoughts and reducing wastes". (26: 39).

Charles Protzman (2016) considers method of improvement course or the so called "PDCA" as the most common method of achieving permanent improvement as it consists of four stages: planning, executing, reviewing or examining and finally correction". "Act" (27: 56)

As the researcher, in order to apply Kaizen's methodology, two main factors shall be depended on, the first is the technical one related to reducing waste in operations and improving the operation's time costs and quality, and the second one is related to social aspect while focusing on changing employees and organization's culture.

The researcher could reach the research problem via taking the first place by youth and sports directorate, Alexandria as the level of youth and sports directorates for 2018 / 2019, via contacting some employees in the directorate during executing many activities of civil training curriculum as she observed non availability of all facts for all leaderships to take administrative decisions, and disallowing employees to submit new ideas to carry out improvement operations, some of waste aspects, which made the researcher carry out a pilot study via open interview with (6) persons represented in directorate's manager, directorate's deputy manager and some managers of different departments to know how far are they familiar with permanent improvement concept " Kaizen", as the most important results were "the concept 
of permanent improvement is unclear for all employees, there is no permanent review and revaluation unit".

According to looking into many previous studies results including results of study of Qusayr Bin Odeh (2020) ( 15 ) Moamen Sharafeldin (2012) (1 '), Glover et al. (2011) (28), it was found that main requirements of Kaizen's methodology success are clear policy of desiring improvement and development while study of Nadia Abdelkhalik (2016) (1 T), Twaitia Eltaher (2017) (r3), recommends the necessity of enabling employees to join cultural courses to recognize the importance of using Kaizen's method.

Which made the researcher compile this research titled:

"Kaizen methodology for continuous improvement as an entry point to achieve outstanding institutional performance in the Directorate of Youth and Sports in Alexandria Governorate "

Research Objective:

Identifying effects of using (kaizen) methodology to improve permanent performance of achieve excellent organizational performance at youth and sports directorate in Alexandria through determining:

"The role of supreme administration in improving permanent performance, procedural steps of Kaizen's methodology, and the effect of applying Kaizen's methodology to achieving a distinctive organizational performance related to employees, operations and directorate".

Research Procedures:

Research Method: Survey descriptive method was used as it is suitable for the research nature.

Research Community and Sample:

The research sample included three groups "supreme administration" of (7) persons represented in directorate's manager, directorate's deputy manager, and (5) departments' managers under research, "middle administration" of (8) managers from,

"executive administration" of (69) sports specialist as the whole research sample reached (84) subjects as the pilot sample reached (10) subjects, and (4) forms were set aside due to non data completion; accordingly, the main research sample reached (70) subjects.

\section{Date Collection Tools:}

- Questionnaire form

Form Scientific Coefficients

A- Internal consistence validity of questionnaire form phrases

The researcher used internal consistency method by finding correlation coefficient between phrases and factors they belong to and phrase and the whole questionnaire degree as in tables (1), (2) and (3) 
Table (1) Correlation Coefficient between every Phrase and Dimensions they belong to and the First Factor Degree

$(\mathrm{N}=10)$

\begin{tabular}{|c|c|c|c|c|c|c|c|c|}
\hline \multicolumn{9}{|c|}{ Correlation coefficient of the first factor phrases } \\
\hline Serial & $\begin{array}{l}\text { With the } \\
\text { first factor }\end{array}$ & $\begin{array}{c}\text { With the } \\
\text { whole degree }\end{array}$ & Serial & $\begin{array}{c}\text { With the } \\
\text { first } \\
\text { factor }\end{array}$ & $\begin{array}{c}\text { With the } \\
\text { whole degree }\end{array}$ & Serial & $\begin{array}{l}\text { With the } \\
\text { first factor }\end{array}$ & $\begin{array}{c}\text { With the } \\
\text { whole } \\
\text { degree }\end{array}$ \\
\hline $1 / 1 / 1$ & 0.668 & 0.823 & $1 / 9 / 1$ & 0.756 & 0.767 & $1 / 17$ & 0.693 & 0.761 \\
\hline $1 / 2$ & 0.719 & 0.712 & $1 / 9 / 2$ & 0.731 & 0.783 & $1 / 18$ & 0.718 & 0.748 \\
\hline $1 / 3$ & 0.719 & 0.787 & $1 / 10$ & 0.770 & 0.800 & $1 / 18 / 1$ & 0.787 & 0.874 \\
\hline $1 / 4$ & 0.726 & 0.773 & $1 / 11$ & 0.834 & 0.755 & $1 / 18 / 2$ & 0.792 & 0.765 \\
\hline $1 / 5$ & 0.699 & 0.727 & $1 / 12$ & 0.725 & 0.781 & $1 / 18 / 3$ & 0.767 & 0.745 \\
\hline $1 / 6$ & 0.855 & 0.846 & $1 / 13$ & 0.764 & 0.702 & $1 / 18 / 4$ & 0.765 & 0.748 \\
\hline $1 / 7 / 1$ & 0.731 & 0.765 & $1 / 14$ & 0.771 & 0.754 & $1 / 18 / 5$ & 0.724 & 0.776 \\
\hline $1 / 7 / 2$ & 0.695 & 0.728 & $1 / 15$ & 0.690 & 0.683 & & & \\
\hline $1 / 8$ & 0.773 & 0.761 & $1 / 16$ & 0.697 & 0.681 & & & \\
\hline
\end{tabular}

$\operatorname{Rg}(0.05 .8)=0.632$

Table (2) Correlation Coefficient between every Phrase and Dimensions they belong to and the Second Factor Degree

$(\mathrm{N}=\mathbf{1 0})$

\begin{tabular}{|c|c|c|c|c|c|c|c|}
\hline \multicolumn{4}{|c|}{$\begin{array}{c}\text { Correlation coefficient of the first dimension } \\
\text { phrases }\end{array}$} & \multicolumn{4}{|c|}{ Correlation coefficient of the second dimension phrases } \\
\hline Serial & $\begin{array}{l}\text { With the } \\
\text { first } \\
\text { dimension }\end{array}$ & $\begin{array}{l}\text { With the } \\
\text { second } \\
\text { factor }\end{array}$ & $\begin{array}{c}\text { With the } \\
\text { whole } \\
\text { degree }\end{array}$ & Serial & $\begin{array}{l}\text { With the second } \\
\text { dimension }\end{array}$ & $\begin{array}{l}\text { With the second } \\
\text { factor }\end{array}$ & $\begin{array}{c}\text { With } \\
\text { the } \\
\text { whole } \\
\text { degree }\end{array}$ \\
\hline $2 / 1$ & 0.757 & 0.775 & 0.717 & $3 / 1$ & 0.808 & 0.717 & 0.768 \\
\hline $2 / 2$ & 0.690 & 0.960 & 0.770 & $3 / 2$ & 0.748 & 0.699 & 0.708 \\
\hline $2 / 3$ & 0.757 & 0.964 & 0.717 & $3 / 3$ & 0.875 & 0.817 & 0.835 \\
\hline $2 / 4$ & 0.860 & 0.964 & 0.800 & $3 / 4$ & 0.763 & 0.725 & 0.723 \\
\hline $2 / 5$ & 0.763 & 0.902 & 0.723 & $3 / 5$ & 0.763 & 0.822 & 0.823 \\
\hline $2 / 6$ & 0.737 & 0.710 & 0.697 & $3 / 6$ & 0.808 & 0.790 & 0.768 \\
\hline $2 / 7$ & 0.875 & 0.717 & 0.835 & $3 / 7$ & 0.761 & 0.901 & 0.741 \\
\hline $2 / 8$ & 0.763 & 0.902 & 0.732 & & & & \\
\hline $2 / 9$ & 0.840 & 0.805 & 0.700 & & & & \\
\hline \multicolumn{4}{|c|}{$\begin{array}{l}\text { Correlation coefficient of the third dimension } \\
\text { phrases }\end{array}$} & \multicolumn{4}{|c|}{ Correlation coefficient of the fourth dimension phrases } \\
\hline Serial & $\begin{array}{l}\text { With the } \\
\text { third } \\
\text { dimension }\end{array}$ & $\begin{array}{l}\text { With the } \\
\text { second } \\
\text { factor }\end{array}$ & $\begin{array}{c}\text { With the } \\
\text { whole } \\
\text { degree }\end{array}$ & Serial & $\begin{array}{l}\text { With the fourth } \\
\text { dimension }\end{array}$ & $\begin{array}{l}\text { With the second } \\
\text { factor }\end{array}$ & $\begin{array}{c}\text { With } \\
\text { the } \\
\text { whole } \\
\text { degree }\end{array}$ \\
\hline $4 / 1$ & 0.808 & 0.741 & 0.768 & $5 / 1$ & 0814 & 0.713 & 0.774 \\
\hline $4 / 2$ & 0.711 & 0.827 & 0.771 & $5 / 2$ & 0.773 & 0.750 & 0733 \\
\hline $4 / 3$ & 0.817 & 0.698 & 0.777 & $5 / 3$ & 0.694 & 0.768 & 0.684 \\
\hline $4 / 4$ & 0.774 & 0.788 & 0.734 & $5 / 4$ & 0.817 & 0.822 & 0.857 \\
\hline $4 / 5$ & 0.862 & 0.878 & 0.822 & $5 / 5$ & 0.880 & 0.900 & 0.840 \\
\hline $4 / 6$ & 0.689 & 0.765 & 0.699 & $5 / 6$ & 0.761 & 0.701 & 0.721 \\
\hline $4 / 7$ & 0.849 & 0.899 & 0.809 & & & & \\
\hline
\end{tabular}


$\operatorname{Rg}(0.05 .8)=0.632$

Table (3) Correlation Coefficient between every Phrase and Dimensions they belong to and the Third Factor Degree

$(\mathrm{N}=10)$

\begin{tabular}{|c|c|c|c|c|c|c|c|c|c|c|c|}
\hline \multicolumn{4}{|c|}{$\begin{array}{l}\text { Correlation coefficient of the first } \\
\text { dimension phrases }\end{array}$} & \multicolumn{4}{|c|}{$\begin{array}{l}\text { Correlation coefficient of the second } \\
\text { dimension phrases }\end{array}$} & \multicolumn{4}{|c|}{$\begin{array}{l}\text { Correlation coefficient of the third } \\
\text { dimension phrases }\end{array}$} \\
\hline Serial & $\begin{array}{l}\text { With the } \\
\text { first } \\
\text { dimension }\end{array}$ & $\begin{array}{l}\text { With } \\
\text { the } \\
\text { third } \\
\text { factor }\end{array}$ & $\begin{array}{c}\text { With } \\
\text { the } \\
\text { whole } \\
\text { degree }\end{array}$ & Serial & $\begin{array}{l}\text { With the } \\
\text { second } \\
\text { dimension }\end{array}$ & $\begin{array}{l}\text { With } \\
\text { the } \\
\text { third } \\
\text { factor }\end{array}$ & $\begin{array}{c}\text { With } \\
\text { the } \\
\text { whole } \\
\text { degree }\end{array}$ & Serial & $\begin{array}{l}\text { With the } \\
\text { third } \\
\text { dimension }\end{array}$ & $\begin{array}{l}\text { With } \\
\text { the } \\
\text { third } \\
\text { factor }\end{array}$ & $\begin{array}{c}\text { With } \\
\text { the } \\
\text { whole } \\
\text { degree }\end{array}$ \\
\hline $6 / 1$ & 0.751 & 0.821 & 0.811 & $7 / 1$ & 0.740 & 0.847 & 0.700 & $8 / 1$ & 0.769 & 0.802 & 0.829 \\
\hline $6 / 2$ & 0.442 & 0.756 & 0.702 & $7 / 2$ & 0.901 & 0.760 & 0.861 & $8 / 2 / 1$ & 0.734 & 0.725 & 0.694 \\
\hline $6 / 3$ & 0.833 & 0.823 & 0.793 & $7 / 3 / 1$ & 0.887 & 0.836 & 0.738 & $8 / 2 / 2$ & 0.617 & 0.822 & 0.777 \\
\hline $6 / 4$ & 0.988 & 0.786 & 0.859 & $7 / 3 / 2$ & 0.695 & 0.747 & 0.755 & $8 / 3 / 1$ & 0.742 & 0.698 & 0.802 \\
\hline $6 / 5$ & 0.964 & 0.812 & 0.924 & $7 / 3 / 3$ & 0.737 & 0.714 & 0.697 & $8 / 3 / 2$ & 0.723 & 0.860 & 0.883 \\
\hline $6 / 6$ & 0.817 & 0.822 & 0.777 & $7 / 3 / 4$ & 0.724 & 0.865 & 0.784 & $8 / 3 / 3$ & 0.738 & 0.715 & 0.698 \\
\hline $6 / 7$ & 0.722 & 0.758 & 0.782 & $7 / 4 / 1$ & 0.745 & 0.742 & 0.805 & $8 / 3 / 4$ & 0.695 & 0.767 & 0.755 \\
\hline $6 / 8$ & 0.757 & 0.912 & 0.717 & $7 / 4 / 2$ & 0.719 & 0.865 & 0.779 & $8 / 3$ & 0.698 & 0.691 & 0.758 \\
\hline \multirow[t]{5}{*}{$6 / 9$} & 0.690 & 0.690 & 0.850 & $7 / 4 / 3$ & 0.837 & 0.714 & 0.697 & $8 / 4$ & 0.827 & 0.691 & 0.787 \\
\hline & & & & $7 / 5$ & 0.742 & 0.694 & 0.702 & & & & \\
\hline & & & & $7 / 6$ & 0.775 & 0.749 & 0.735 & & & & \\
\hline & & & & $7 / 7$ & 0.745 & 0.879 & 0.805 & & & & \\
\hline & & & & $7 / 8$ & 0.877 & 0.797 & 0.837 & & & & \\
\hline
\end{tabular}

$\operatorname{Rg}(0.05 .8)=0.632$

It is clear from tables $(1,2,3)$ that there is a statistical significant correlation at significant level $(0.05)$ between degree of every phrases and dimensions belonging to.

\section{Calculating Questionnaire Reliability Coefficient:}

Table (4) Questionnaire Reliability by Split Half and Cronbach's Alpha

\begin{tabular}{|c|c|c|c|}
\hline \multirow[b]{2}{*}{ Factors and Dimensions } & \multicolumn{2}{|c|}{ Split Half } & \multirow[b]{2}{*}{$\begin{array}{c}\text { Cronbach's } \\
\text { Alpha }\end{array}$} \\
\hline & Spearman Brown & Gitman & \\
\hline $\begin{array}{c}\text { First Factor: The role of supreme administration at youth } \\
\text { and sports directorate, in Alexandria in achieving } \\
\text { permanent improvement " Kaizen" }\end{array}$ & 0.731 & 0.719 & 0.811 \\
\hline Second Factor: Kaizen's methodology procedural steps & 0.794 & 0.880 & 0.754 \\
\hline First dimension: Planning & 0.830 & 0.909 & 0.790 \\
\hline Second dimension: Execution & 0.741 & 0.737 & 0.721 \\
\hline Third dimension: Evaluation and Examination & 0.794 & 0.816 & 0.754 \\
\hline Fourth dimension: Responding to suggested improvements & 0.725 & 0.752 & 0.805 \\
\hline $\begin{array}{l}\text { Third Factor: Effect of applying Kaizen's methodology in } \\
\text { achieving distinctive organizational performance at youth } \\
\text { and sports directorate, Alexandria }\end{array}$ & 0.886 & 0.701 & 0.846 \\
\hline $\begin{array}{l}\text { First dimension: Improving performance of employees of } \\
\text { youth and sports directorate }\end{array}$ & 0.840 & 0.801 & 0.830 \\
\hline Second dimension: Improving operations performance & 0.745 & 0.755 & 0.725 \\
\hline $\begin{array}{l}\text { Third dimension: Improving performance of youth and } \\
\text { sports directorate, Alexandria }\end{array}$ & 0.812 & 0.762 & 0.772 \\
\hline
\end{tabular}


It is clear from table (4) that reliability coefficient by split half ranges between (0.701) and (0.909), and Cronbach's Alpha reliability coefficient ranges between (0.721) and (0.846), to prove that the researched questionnaire has a high reliability coefficient.

\section{Statistical Treatment}

"Repetition and percentage, split half, Cronbach's Alpha reliability coefficient, outweighed percentage, Chi square Distribution, Pearson correlation coefficient, out weighted percentages."

\section{Research Results Discussions:}

Table (5) Results of Repetition Percentage, Chi square Distribution and Outweighed Percentage of Response on the First Factor the Role of:

The Role of Supreme Administration at Youth and Sports Directorate in Alexandria Achieving Permanent Improvement "Kaizen"

\begin{tabular}{|c|c|c|c|c|c|c|c|c|c|c|}
\hline \multirow{3}{*}{ Serial } & \multirow{3}{*}{ Phrase content } & \multicolumn{4}{|c|}{$\begin{array}{l}\text { Supreme and middle } \\
\text { administration } \\
\mathrm{N}=12\end{array}$} & \multicolumn{4}{|c|}{$\begin{array}{c}\text { Supreme and middle } \\
\text { administration } \\
\mathbf{N}=\mathbf{5 8}\end{array}$} & \multirow{3}{*}{$\begin{array}{l}\text { Chi Square } \\
\text { Distribution }\end{array}$} \\
\hline & & \multicolumn{2}{|c|}{ Agreeing } & \multicolumn{2}{|c|}{$\begin{array}{c}\text { Disagreein } \\
\mathbf{g} \\
\end{array}$} & \multicolumn{2}{|c|}{ Agreeing } & \multicolumn{2}{|c|}{ Disagreeing } & \\
\hline & & $\mathrm{C}$ & $\%$ & $\mathrm{C}$ & $\%$ & $\mathrm{C}$ & $\%$ & $\mathrm{C}$ & $\%$ & \\
\hline \multicolumn{11}{|l|}{1} \\
\hline $1 / 1$ & $\begin{array}{l}\text { All departments effective } \\
\text { participation in permanent } \\
\text { improvement }\end{array}$ & 10 & 83.33 & 2 & 16.67 & 47 & 81.03 & 11 & 18.97 & 0.035 \\
\hline $1 / 2$ & $\begin{array}{l}\text { Having a business } \\
\text { improvement and } \\
\text { development plan } \\
\text { according to its view, } \\
\text { strategies and objectives }\end{array}$ & 9 & 75.00 & 3 & 25.00 & 23 & 39.66 & 35 & 60.34 & 5.005 \\
\hline $1 / 3$ & $\begin{array}{c}\text { Availing suitable } \\
\text { environmental } \\
\text { circumstances in which } \\
\text { permanent development is } \\
\text { a life style }\end{array}$ & 8 & 66.67 & 4 & 33.33 & 24 & 41.38 & 34 & 58.62 & 2.562 \\
\hline $1 / 4$ & $\begin{array}{c}\text { Allowing a budget for } \\
\text { permanent improvement } \\
\text { operations }\end{array}$ & 5 & 41.68 & 7 & 58.33 & 19 & 32.76 & 39 & 67.24 & 0.350 \\
\hline $1 / 5$ & $\begin{array}{l}\text { Availing substantial and } \\
\text { human potentials to apply } \\
\text { permanent improvement }\end{array}$ & 11 & 91.67 & 1 & 8.33 & 46 & 79.31 & 12 & 20.69 & 1.004 \\
\hline $1 / 6$ & $\begin{array}{c}\text { Graduated application of } \\
\text { permanent improvement of } \\
\text { different operations inside } \\
\text { youth and sports } \\
\text { directorate }\end{array}$ & 11 & 91.67 & 1 & 8.33 & 40 & 68.97 & 18 & 31.03 & 2.591 \\
\hline $1 / 7$ & Holding cultural courses to: & & & & & & & & & \\
\hline $1 / 7 / 1$ & $\begin{array}{l}\text { Know the importance of } \\
\text { using Kaizen method }\end{array}$ & 7 & 58.33 & 5 & 41.67 & 18 & 31.03 & 40 & 68.97 & 3.227 \\
\hline
\end{tabular}




\begin{tabular}{|c|c|c|c|c|c|c|c|c|c|c|}
\hline $1 / 7 / 2$ & $\begin{array}{l}\text { Convincing all employees of } \\
\text { different administrative } \\
\text { levels by all advantages of } \\
\text { applying Kaizen's } \\
\text { methodology }\end{array}$ & 7 & 58.33 & 5 & 41.67 & 12 & 20.69 & 46 & 79.31 & $* 7.125$ \\
\hline $1 / 8$ & $\begin{array}{l}\text { Providing all suppor, } \\
\text { training and education to all } \\
\text { the directorate's employees }\end{array}$ & 10 & 83.33 & 2 & 16.67 & 34 & 58.62 & 24 & 41.38 & 2.601 \\
\hline \multicolumn{11}{|c|}{ 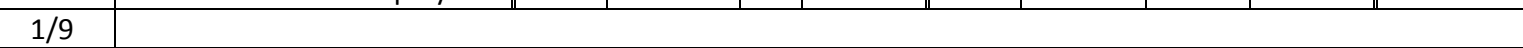 } \\
\hline $1 / 9 / 1$ & $\begin{array}{c}\text { Employees of all the } \\
\text { directorate's administrative } \\
\text { levels }\end{array}$ & 11 & 91.67 & 1 & 8.33 & 45 & 77.59 & 13 & 22.41 & 1.232 \\
\hline $1 / 9 / 2$ & Beneficiaries & 10 & 83.33 & 2 & 16.67 & 49 & 84.48 & 9 & 15.52 & 0.010 \\
\hline $1 / 10$ & $\begin{array}{l}\text { Availing all data and facts of } \\
\text { making administrative } \\
\text { decisions }\end{array}$ & 9 & 75.00 & 3 & 25.00 & 28 & 48.28 & 30 & 51.72 & 2.850 \\
\hline $1 / 11$ & $\begin{array}{l}\text { Availing new evaluation } \\
\text { methods to avoid error } \\
\text { repetition and overcoming } \\
\text { weak points }\end{array}$ & 8 & 66.67 & 4 & 33.33 & 24 & 41.38 & 34 & 58.62 & 2.562 \\
\hline $1 / 12$ & $\begin{array}{c}\text { Motivating all employees } \\
\text { creative efforts }\end{array}$ & 10 & 83.33 & 2 & 16.67 & 32 & 55.17 & 26 & 44.83 & 3.285 \\
\hline $1 / 13$ & $\begin{array}{l}\text { Rewarding the best ideas of } \\
\text { developing the directorate's } \\
\text { work }\end{array}$ & 9 & 75.00 & 3 & 25.00 & 26 & 44.83 & 32 & 55.17 & 3.621 \\
\hline $1 / 14$ & $\begin{array}{l}\text { Making employees' groups } \\
\text { "quality circuits" to solve } \\
\text { problems and obtaining } \\
\text { new ideas }\end{array}$ & 11 & 91.67 & 1 & 8.33 & 52 & 89.66 & 6 & 10.34 & 0.045 \\
\hline $1 / 15$ & $\begin{array}{l}\text { Direct supervision via } \\
\text { visiting the event's site } \\
\text { instead of problems remote } \\
\text { control "Gemba Kaizen" }\end{array}$ & 11 & 91.67 & 1 & 8.33 & 49 & 84.48 & 9 & 15.52 & 0.419 \\
\hline $1 / 16$ & $\begin{array}{l}\text { Taking all sufficient and } \\
\text { immediate preventive } \\
\text { decisions to avoid work } \\
\text { suspension }\end{array}$ & 10 & 83.33 & 2 & 16.67 & 46 & 79.31 & 12 & 20.69 & 0.101 \\
\hline $1 / 17$ & $\begin{array}{c}\text { Discussing employees ideas } \\
\text { at all departments and on a } \\
\text { regular basis to apply the } \\
\text { available ones }\end{array}$ & 10 & 83.33 & 2 & 16.67 & 21 & 36.21 & 37 & 63.79 & $* 8.950$ \\
\hline $1 / 18$ & Employees' participation in: & & & & & & & & & \\
\hline $1 / 18 / 1$ & $\begin{array}{l}\text { selecting the operation } \\
\text { required to be improved }\end{array}$ & 11 & 91.67 & 1 & 8.33 & 32 & 55.17 & 26 & 44.83 & 5.589 \\
\hline $1 / 18 / 2$ & $\begin{array}{l}\text { Looking for new means to } \\
\text { improve the directorate's } \\
\text { operations }\end{array}$ & 11 & 91.67 & 1 & 8.33 & 37 & 63.79 & 21 & 36.21 & 3.584 \\
\hline $1 / 18 / 3$ & $\begin{array}{l}\text { Executing improvement } \\
\text { operations }\end{array}$ & 11 & 91.67 & 1 & 8.33 & 42 & 72.41 & 16 & 27.59 & 2.004 \\
\hline $1 / 18 / 4$ & $\begin{array}{c}\text { Evaluating improvement } \\
\text { operations }\end{array}$ & 8 & 66.67 & 4 & 33.33 & 22 & 37.93 & 36 & 62.07 & 3.352 \\
\hline $1 / 18 / 5$ & $\begin{array}{c}\text { Documenting improvement } \\
\text { operations and informing } \\
\text { them to employees }\end{array}$ & 9 & 75.00 & 3 & 25.00 & 21 & 36.21 & 37 & 63.79 & $* 6.110$ \\
\hline
\end{tabular}

Chi square Distribution (0.05.2) = 5.991 
From table number (5) of the first factor it is clear that there are no significant difference between the research sample groups response about the first factor phrases as Chi square Distribution was less than its value at level (0.05) and ranged between (0.010:5.589) except for phrases number $(1 / 7 / 2,1 / 17,1 / 18 / 5)$

And in case of phrases number $(1 / 7 / 2,1 / 17,1 / 18 / 5)$ it is clear that how far response of research groups subjects differ and as supreme and supervisory administration agreed at percentage ranged from (58.33: $83.33 \%$ ) on that cultural courses are to held to convince all employees of advantages of applying Kaizen's methodology, discussing employees' ideas at every department, we find that executive administration.

Results of study of Rizan Salaheldin, Berzin Sheikh Mohamed (2010) (20) indicates that using Kaizen's method needs the supreme administration support; accordingly the supreme administration establishes this method as a strategy for and that applying the same is the responsibility of all administrative levels to guarantee its efficiency and success.

Results of phrases number $(1 / 1,1 / 2,1 / 3,1 / 5,1 / 6)$ indicated agreement of responses of both research groups at percentage ranged (66.67: $91.67 \%$ ) for supreme and middle administration and between (41.38: 81.03 \%) for execution administration of supreme administration concern of efficient participation of all departments in permanent improvement operations, on having an improvement plan.

Ayten Mahmoud Elmargoushy (2008) indicates that permanent development is the responsibility of administration and employees focusing on developing all the organization's activities and operations (5: 130).

Study of Maher Mohsen (2014) (1.) recommends the importance of compiling an improvement operations' budget.

From results of phrases number $(1 / 7 / 1,1 / 8,1 / 9 / 1,1 / 9 / 2)$ it is clear that there is an agreement by all responses of the two groups on holding cultural courses to Kaizen's importance, providing support and training to the directorate's employees.

This agrees with results of study of Sherihan Yehia Moursy (2017) ( ${ }^{2} 2$ ) confirming a gap between supreme administration and sports specialists of the directorate in participation in decision making process.

Also and from phrases number $(1 / 10,1 / 11,1 / 12,1 / 13,1 / 14,1 / 15,1 / 16)$ it is clear that the research sample agree at percentage between (66.67: $91.67 \%$ ) for supreme and middle administration and at (41.38: $89.66 \%$ ) for executive management provided all data and facts are available for administrative decision making, availing new evaluation methods to avoid error repetition.

Study of Dalia Taha Mahmoud Youssef (2013) (7) recommends the importance of correcting errors upon occurrence and focusing on permanent improvement.

But phrases number $(1 / 8 / 1,1 / 18 / 2,1 / 18 / 3,1 / 18 / 4)$ indicating employees participation in selecting operation required to be improved, looking for new methods of operations 
improvement, supreme and middle administration's agreement ranged between (66.67 : 91.67 $\%)$ and agreement percentage (37.93: $72.41 \%)$ for executive administration.

Ahmed Abdelsalam (2016), Nagy Ismail, Mohamed Ibrahim Meghawry (2014) indicated the importance of participating in administrating and formulating change plans for operations required to be improved ( $1: 8),(1 \leq: 114)$

The researcher indicates the importance of all administrative levels participation in planning to carry out operations of improvement.

\section{Table (6) Results of Repetition Percentage, Chi square Distribution and Outweighed Percentage for Response in the Second Factor:}

Procedures Steps of Kaizen's Methodology - First Dimension: Planning

\begin{tabular}{|c|c|c|c|c|c|c|c|c|c|c|}
\hline \multirow[t]{3}{*}{ Serial } & \multirow[t]{3}{*}{ Phrase content } & \multicolumn{4}{|c|}{$\begin{array}{l}\text { Supreme and middle } \\
\text { administration } \\
\mathrm{N}=12\end{array}$} & \multicolumn{4}{|c|}{$\begin{array}{l}\text { Supreme and middle } \\
\text { administration } \\
\mathrm{N}=\mathbf{5 8}\end{array}$} & \multirow{3}{*}{$\begin{array}{l}\text { Chi square } \\
\text { Distribution }\end{array}$} \\
\hline & & \multicolumn{2}{|c|}{ Agreeing } & \multicolumn{2}{|c|}{ Disagreeing } & \multicolumn{2}{|c|}{ Agreeing } & \multicolumn{2}{|c|}{ Disagreeing } & \\
\hline & & $\mathrm{C}$ & $\%$ & $\mathrm{C}$ & $\%$ & $\mathrm{C}$ & $\%$ & $\mathrm{C}$ & $\%$ & \\
\hline \multicolumn{11}{|l|}{2} \\
\hline $2 / 1$ & $\begin{array}{l}\text { Ordering all problems facing } \\
\text { the directorate according to } \\
\text { priority }\end{array}$ & 11 & 91.67 & 1 & 8.33 & 53 & 91.38 & 5 & 8.62 & 0.001 \\
\hline $2 / 2$ & $\begin{array}{c}\text { Collecting data and } \\
\text { information about all } \\
\text { problems and verifying real } \\
\text { causes }\end{array}$ & 10 & 83.33 & 2 & 16.67 & 44 & 75.86 & 14 & 24.14 & 0.315 \\
\hline $2 / 3$ & $\begin{array}{l}\text { Identifying causes resulted } \\
\text { in such problems }\end{array}$ & 10 & 83.33 & 2 & 16.67 & 46 & 79.31 & 12 & 20.69 & 0.101 \\
\hline $2 / 4$ & $\begin{array}{l}\text { Selecting the most critical } \\
\text { problems to be solved }\end{array}$ & 11 & 91.67 & 1 & 8.33 & 51 & 87.93 & 7 & 12.07 & 0.137 \\
\hline $2 / 5$ & $\begin{array}{l}\text { Clarifying the main problems } \\
\text { causes after separating the } \\
\text { real cause from the } \\
\text { secondary ones }\end{array}$ & 11 & 91.67 & 1 & 8.33 & 50 & 86.21 & 8 & 13.79 & 0.265 \\
\hline $2 / 6$ & $\begin{array}{l}\text { Suggesting different ideas } \\
\text { for solving such problem }\end{array}$ & 10 & 83.33 & 2 & 16.67 & 42 & 72.41 & 16 & 27.59 & 0.621 \\
\hline $2 / 7$ & $\begin{array}{c}\text { Estimating period required } \\
\text { to solve this problem }\end{array}$ & 10 & 83.33 & 2 & 16.67 & 22 & 37.93 & 36 & 62.07 & $* 8.259$ \\
\hline $2 / 8$ & $\begin{array}{l}\text { Establishing an improvement } \\
\text { plan }\end{array}$ & 11 & 91.67 & 1 & 8.33 & 49 & 84.48 & 9 & 15.52 & 0.419 \\
\hline $2 / 9$ & $\begin{array}{l}\text { Coordinating between all the } \\
\text { directorate's departments to } \\
\text { execute improvement plans } \\
\text { efficiently }\end{array}$ & 11 & 91.67 & 1 & 8.33 & 43 & 74.14 & 15 & 25.86 & 1.733 \\
\hline
\end{tabular}

Chi square Distribution (0.05.2) $=5.991$

From table number (6) of the second factor - first dimension: Planning, no differences between responses of the research sample groups about phrases of the first dimensions as Chi square Distribution was less than its tabular value at level (0.05) and ranged between (0.001: 1.733) except for phrase number (2/7) as (Ca2) value reached (8.259).

Results of phrases number $(2 / 1,2 / 2,2 / 3,2 / 4,2 / 5,2 / 6,2 / 7,2 / 8,2 / 9)$ indicated responses of the two researched groups at percentage $(83.33: 91.67 \%)$ for supreme and middle administration 
and between (72.41 : $91.38 \%$ ) for executive administration provided youth and sports directorate plans, collect data and information of all problems, selecting the most important problem, clarifying the main problem causes and suggesting problems solution.

Ahmed Abdelsalam (2016) indicates that: Analyzing the organization's environment and analyzing available internal potentials may affect suitable strategy determination $(1: 36,37)$

Table (7) Results of Repetition Percentage, Chi square Distribution and Outweighed Percentage for Response in the Second Factor:

\section{Procedures Steps of Kaizen's Methodology - Second Dimension: Execution}

\begin{tabular}{|c|c|c|c|c|c|c|c|c|c|c|}
\hline \multirow[t]{3}{*}{ Serial } & \multirow[t]{3}{*}{ Phrase content } & \multicolumn{4}{|c|}{$\begin{array}{l}\text { Supreme and middle } \\
\text { administration } \\
\mathrm{N}=12\end{array}$} & \multicolumn{4}{|c|}{$\begin{array}{c}\text { Supreme and middle } \\
\text { administration } \\
\mathrm{N}=\mathbf{5 8}\end{array}$} & \multirow{3}{*}{$\begin{array}{l}\text { Chi square } \\
\text { Distribution }\end{array}$} \\
\hline & & \multicolumn{2}{|c|}{ Agreeing } & \multicolumn{2}{|c|}{ Disagreeing } & \multicolumn{2}{|c|}{ Agreeing } & \multicolumn{2}{|c|}{ Disagreeing } & \\
\hline & & $\mathrm{C}$ & $\%$ & $\mathrm{C}$ & $\%$ & $\mathrm{C}$ & $\%$ & $\mathrm{C}$ & $\%$ & \\
\hline \multicolumn{11}{|l|}{3} \\
\hline $3 / 1$ & \begin{tabular}{l}
\multicolumn{1}{c}{ Designing a } \\
specialized unit for \\
permanent review \\
and evaluation
\end{tabular} & 4 & 33.33 & 8 & 66.67 & 13 & 22.41 & 45 & 77.59 & 0.645 \\
\hline $3 / 2$ & $\begin{array}{l}\text { Executing changes } \\
\text { needed for solving } \\
\text { problems gradually }\end{array}$ & 9 & 75.00 & 3 & 25.00 & 42 & 72.41 & 16 & 27.59 & 0.034 \\
\hline $3 / 3$ & $\begin{array}{l}\text { Availing logistic } \\
\text { materials "appliances } \\
\text { and tools" needed for } \\
\text { plans execution }\end{array}$ & 8 & 66.67 & 4 & 33.33 & 35 & 60.34 & 23 & 39.66 & 0.168 \\
\hline $3 / 4$ & $\begin{array}{c}\text { Training and } \\
\text { qualifying assigned } \\
\text { employees to execute } \\
\text { suggested plans }\end{array}$ & 5 & 41.67 & 7 & 58.33 & 21 & 36.21 & 37 & 63.79 & 0.127 \\
\hline $3 / 5$ & $\begin{array}{l}\text { Executing determined } \\
\text { corrective procedures }\end{array}$ & 7 & 58.33 & 5 & 41.67 & 31 & 53.45 & 27 & 46.55 & 0.096 \\
\hline $3 / 6$ & $\begin{array}{l}\text { Collecting information } \\
\text { to identify corrective } \\
\text { procedures efficiency }\end{array}$ & 7 & 58.33 & 5 & 41.67 & 30 & 51.72 & 28 & 48.28 & 0.174 \\
\hline $3 / 7$ & $\begin{array}{l}\text { Observing the plan } \\
\text { execution time frame }\end{array}$ & 8 & 66.67 & 4 & 33.33 & 25 & 43.10 & 33 & 56.90 & 2.215 \\
\hline
\end{tabular}

Chi square Distribution (0.05.2) $=5.991$

It is clear from table number (7) of the second factor - second dimension: Execution, there are no significant differences between the two research sample groups about phrases of the second dimension as Chi square Distribution was less than its tabular value at level (0.05) and ranged between $(0.034: 2.215)$.

And the results of phrases number $(3 / 2,3 / 3,3 / 5,3 / 6,3 / 7)$ indicated agreement of the two research responses at percentage (58.33: $75.00 \%$ ) for supreme and middle administration and at (43.10 : $72.41 \%)$ for executive administration provided the supreme administration executes and develops works gradually, availing logistic resources needed for plans execution. 
Hassan Ahmed Elshafaey (2018) indicated the importance of availing logistic resources to satisfy the organization's main functions ( $\mathrm{V}: 28)$

For phrases number $(3 / 1,3 / 4)$ it was clear that the two research groups responses agreed at (33.33\%), (41.67\%) for the first group, and $(22.41 \%),(36.21 \%)$ for the second group successively upon that supreme administration shall design a unit for permanent review and evaluation.

Ahmed Elsherif (2018) clarifies that control and follow up is the means used by organizations to follow up business execution and development. ( $r: 45)$

Table (8) Results of Repetition Percentage, Chi square Distribution and Outweighed Percentage for Response in the Second Factor:

Procedures steps of Kaizen's Methodology - Third Dimension: Evaluation and Examination

\begin{tabular}{|c|c|c|c|c|c|c|c|c|c|c|}
\hline \multirow{3}{*}{ Serial } & \multirow{3}{*}{ Phrase content } & \multicolumn{4}{|c|}{$\begin{array}{l}\text { Supreme and middle } \\
\text { administration } \\
\qquad \mathrm{N}=12\end{array}$} & \multicolumn{4}{|c|}{$\begin{array}{l}\text { Supreme and middle } \\
\text { administration } \\
\qquad \mathrm{N}=58\end{array}$} & \multirow{3}{*}{$\begin{array}{l}\text { Chi square } \\
\text { Distribution }\end{array}$} \\
\hline & & \multicolumn{2}{|c|}{ Agreeing } & \multicolumn{2}{|c|}{ Disagreeing } & \multicolumn{2}{|c|}{ Agreeing } & \multicolumn{2}{|c|}{ Disagreeing } & \\
\hline & & C & $\%$ & C & $\%$ & C & $\%$ & $C$ & $\%$ & \\
\hline 4 & & & & & & & & & & \\
\hline $4 / 1$ & $\begin{array}{l}\text { A specialized unit for } \\
\text { permanent review and } \\
\text { evaluation }\end{array}$ & 4 & 33.33 & 8 & 66.67 & 14 & 24.14 & 44 & 75.86 & 0.440 \\
\hline $4 / 2$ & $\begin{array}{c}\text { A clear performance } \\
\text { indicators to evaluate and } \\
\text { execute its plans }\end{array}$ & 8 & 66.67 & 4 & 33.33 & 27 & 46.55 & 31 & 53.45 & 1.609 \\
\hline $4 / 3$ & $\begin{array}{l}\text { Clear and written review } \\
\text { and evaluation system }\end{array}$ & 5 & 41.67 & 7 & 58.33 & 24 & 41.38 & 34 & 58.62 & 0.000 \\
\hline $4 / 4$ & $\begin{array}{l}\text { Profiting from feedback of } \\
\text { evaluation results to } \\
\text { improve its works }\end{array}$ & 10 & 83.33 & 2 & 16.67 & 38 & 65.52 & 20 & 34.48 & 1.464 \\
\hline $4 / 5$ & $\begin{array}{l}\text { Comparing data before } \\
\text { and after corrective } \\
\text { procedures }\end{array}$ & 8 & 66.67 & 4 & 33.33 & 20 & 34.48 & 38 & 65.52 & 4.291 \\
\hline $4 / 6$ & $\begin{array}{l}\text { Analyzing the gap } \\
\text { between the required } \\
\text { results and the actual } \\
\text { ones of the used } \\
\text { corrective procedures to } \\
\text { verify that new changes } \\
\text { work as planned }\end{array}$ & 9 & 75.00 & 3 & 25.00 & 22 & 37.93 & 36 & 62.07 & 5.537 \\
\hline
\end{tabular}




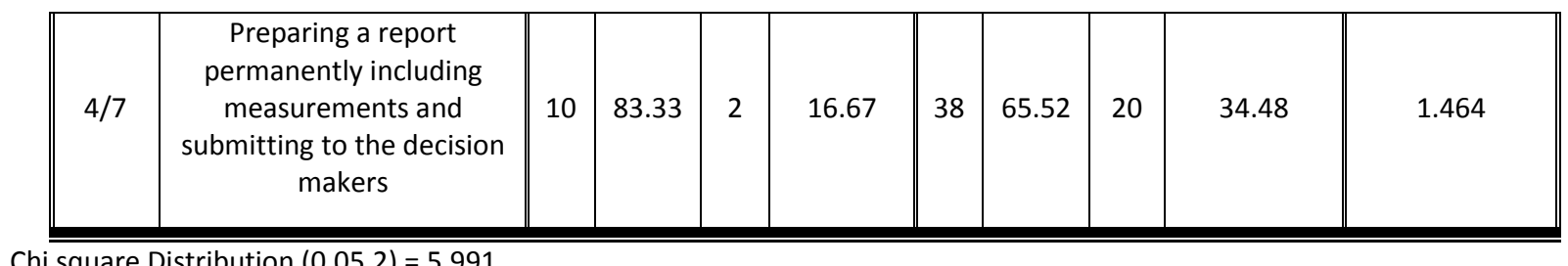

Chi square Distribution (0.05.2) $=5.991$

It is clear from table number (8) of the second factor - third dimension: evaluation and examination, there are no significant differences between the two research sample groups about phrases of the third dimension as Chi square Distribution was less than its tabular value at level (0.05) and ranged between (0.000: 5.537).

And the results of phrases number $(4 / 2,4 / 4,4 / 5,4 / 6,4 / 7)$ indicated agreement of the two research responses at percentage (66.67: $83.33 \%$ ) for supreme and middle administration and at (65.52 : $34.48 \%)$ for executive administration subject to evaluating permanent improvement of performance of youth and sports directorate via a clear performance indicators, profiting from feedback of evaluation results, analyzing the group between the requited results and the actual ones of the used corrective procedures.

Ismail Abdelfattah (2019): indicates that follow up and evaluation is a function focusing on measuring and correcting means of performance, deviations and errors. ( $9: 133$ )

Also results of study of Dalia Taha Mahmoud (2013) (") focus on improving work circumstances and correcting errors upon occurrence.

For phrases number $(4 / 1,4 / 2)$ both research groups agreed by a law percentage reached (33.33 $\%),(41.67 \%)$ "supreme and idle administration", and (24.14 \%), (41.38\%) "executive administration" respectively that evaluating permanent improvement at the directorate through a specialized unit for permanent review and evaluation.

Study of Riham Mohamed Aly (2019) (19) recommends the importance of applying control and follow system to performance on a regular basis.

The researcher considers evaluation and examination as one of the most important administrative functions as it identifies the gaps between results required to be achieved and what was reached and how far the director's sports specialists can fulfill their tasks.

Table (9) Results of Repetition Percentage, Chi square Distribution and Outweighed Percentage for Response in the Second Factor:

\section{Procedures steps of Kaizen's Methodology - Fourth Dimension: Response to Suggested Improvements}

\begin{tabular}{|c|c|c|c|c|c|c|}
\hline \multirow[t]{2}{*}{ Serial } & \multirow[t]{2}{*}{ Phrase content } & \multicolumn{2}{|c|}{$\begin{array}{l}\text { Supreme and middle } \\
\text { administration } \\
\qquad \mathrm{N}=12\end{array}$} & \multicolumn{2}{|c|}{$\begin{array}{l}\text { Supreme and middle } \\
\text { administration } \\
\qquad \mathrm{N}=58\end{array}$} & \\
\hline & & Agreeing & Disagreeing & Agreeing & Disagreeing & Chi square \\
\hline
\end{tabular}




\begin{tabular}{|c|c|c|c|c|c|c|c|c|c|c|}
\hline & & $C$ & $\%$ & C & $\%$ & $C$ & $\%$ & $\mathrm{C}$ & $\%$ & Distribution \\
\hline \multicolumn{11}{|l|}{ 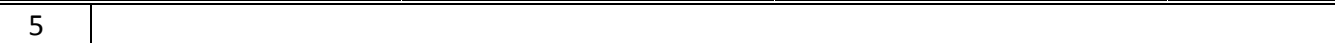 } \\
\hline $5 / 1$ & $\begin{array}{l}\text { Adopting changes } \\
\text { that achieved the } \\
\text { require results }\end{array}$ & 11 & 91.67 & 1 & 8.33 & 47 & 81.03 & 11 & 18.97 & 0.791 \\
\hline $5 / 2$ & $\begin{array}{l}\text { Taking necessary } \\
\text { procedures to } \\
\text { execute these } \\
\text { changes }\end{array}$ & 11 & 91.67 & 1 & 8.33 & 43 & 74.14 & 15 & 25.86 & 1.733 \\
\hline $5 / 3$ & $\begin{array}{c}\text { Establishing norms } \\
\text { changes }\end{array}$ & 10 & 83.33 & 2 & 16.67 & 31 & 53.45 & 27 & 46.55 & 3.660 \\
\hline $5 / 4$ & $\begin{array}{l}\text { Training employees } \\
\text { of youth and sports } \\
\text { directorate on } \\
\text { executing required } \\
\text { changes }\end{array}$ & 8 & 66.67 & 4 & 33.33 & 20 & 34.48 & 38 & 65.52 & 4.291 \\
\hline $5 / 5$ & $\begin{array}{l}\text { Correcting deviations } \\
\text { of non conformity } \\
\text { with the approved } \\
\text { performance } \\
\text { indicators }\end{array}$ & 9 & 75.00 & 3 & 25.00 & 37 & 63.79 & 21 & 36.21 & 0.554 \\
\hline $5 / 6$ & $\begin{array}{l}\text { Profiting from } \\
\text { developing } \\
\text { information } \\
\text { technology and new } \\
\text { communication } \\
\text { related to the } \\
\text { directorate's } \\
\text { business }\end{array}$ & 11 & 91.67 & 1 & 8.33 & 49 & 84.48 & 9 & 15.52 & 0.419 \\
\hline
\end{tabular}

Chi square Distribution (0.05.2) $=5.991$

It is clear from table number (9) of the second factor - forth dimension: response to improvements, there are no significant differences between the two research sample groups about phrases of the third dimension as Chi square Distribution was less than its tabular value at level (0.05) and ranged between (0.419: 4.291).

From results of phrases number $(5 / 1,5 / 2,5 / 3,5 / 4,5 / 5,5 / 6)$ it is clear that all groups' responses were that youth and sports directorate shall respond to the suggested improvements via adopting changes that achieved the required results, taking suitable procedures to achieve these changes, training employees on executing required changes, profiting from information technology and communication development at percentage (66.67 : $91.76 \%$ )for supreme and middle administration and (34.48: $84.48 \%)$ for executive administration.

Ahmed Abdelsalam Mousa (2016) clarified the importance of execution agrees with what was determined. ( $:$ :37)

The researcher believes that after evaluation and examination, the last step related to 
responding to suggested improvements arises, according to Kaizen's methodological procedures.

Table (10) results of repetition percentage, Chi square Distribution and outweighed percentage for response in the third factor: Effects of Using (Kaizen) Methodology to Improve

Permanent Performance of Achieve Excellent Organizational Performance at Youth and Sports Directorate in Alexandria - First Dimension: Improving Employees' Performance at Youth and Sports Directorate

\begin{tabular}{|c|c|c|c|c|c|c|c|c|c|c|}
\hline \multirow[t]{3}{*}{ Serial } & \multirow[t]{3}{*}{ Phrase content } & \multicolumn{4}{|c|}{$\begin{array}{l}\text { Supreme and middle } \\
\text { administration } \\
\mathrm{N}=12\end{array}$} & \multicolumn{4}{|c|}{$\begin{array}{c}\text { Supreme and middle } \\
\text { administration } \\
\mathrm{N}=\mathbf{5 8}\end{array}$} & \multirow{3}{*}{$\begin{array}{l}\text { Chi square } \\
\text { Distribution }\end{array}$} \\
\hline & & \multicolumn{2}{|c|}{ Agreeing } & \multicolumn{2}{|c|}{ Disagreeing } & \multicolumn{2}{|c|}{ Agreeing } & \multicolumn{2}{|c|}{ Disagreeing } & \\
\hline & & $\mathrm{C}$ & $\%$ & C & $\%$ & $\mathrm{C}$ & $\%$ & $\mathrm{C}$ & $\%$ & \\
\hline \multicolumn{11}{|l|}{6} \\
\hline $6 / 1$ & $\begin{array}{l}\text { Developing their } \\
\text { abilities to adapt with } \\
\text { changes and new } \\
\text { circumstances }\end{array}$ & 9 & 75.00 & 3 & 25.00 & 39 & 67.24 & 19 & 32.76 & 0.278 \\
\hline $6 / 2$ & $\begin{array}{l}\text { Changing the } \\
\text { directorate's } \\
\text { employees culture } \\
\text { through training and } \\
\text { learning }\end{array}$ & 9 & 75.00 & 3 & 25.00 & 27 & 46.55 & 31 & 53.45 & 3.221 \\
\hline $6 / 3$ & $\begin{array}{l}\text { Discovering new } \\
\text { creative potentials } \\
\text { inconformity with } \\
\text { acting according to } \\
\text { different situations } \\
\end{array}$ & 10 & 83.33 & 2 & 16.67 & 45 & 77.59 & 13 & 22.41 & 0.195 \\
\hline $6 / 4$ & $\begin{array}{l}\text { Developing employees' } \\
\text { experiences, efficiency } \\
\text { and potentials for } \\
\text { solving problems }\end{array}$ & 10 & 83.33 & 2 & 16.67 & 49 & 84.48 & 9 & 15.52 & 0.010 \\
\hline $6 / 5$ & $\begin{array}{l}\text { Enabling and } \\
\text { motivating the } \\
\text { directorate's } \\
\text { employees } \\
\end{array}$ & 9 & 75.00 & 3 & 25.00 & 41 & 70.69 & 17 & 29.31 & 0.091 \\
\hline $6 / 6$ & $\begin{array}{l}\text { Appreciating and } \\
\text { awarding creative } \\
\text { employees }\end{array}$ & 11 & 91.67 & 1 & 8.33 & 30 & 51.72 & 28 & 48.28 & $* 6.537$ \\
\hline $6 / 7$ & $\begin{array}{c}\text { Preparing a leading } \\
\text { environment } \\
\text { interactive with results } \\
\text { desiring to make } \\
\text { change }\end{array}$ & 10 & 83.33 & 2 & 16.67 & 28 & 48.28 & 30 & 51.72 & 4.924 \\
\hline $6 / 8$ & $\begin{array}{c}\text { Reducing differences } \\
\text { between } \\
\text { administrative levels at } \\
\text { youth and sports } \\
\text { directorate }\end{array}$ & 9 & 75.00 & 3 & 25.00 & 19 & 32.76 & 39 & 67.24 & $* 8.392$ \\
\hline $6 / 9$ & $\begin{array}{l}\text { Depending on group } \\
\text { work "team work" }\end{array}$ & 9 & 75.00 & 3 & 25.00 & 23 & 39.66 & 35 & 60.34 & 5.005 \\
\hline
\end{tabular}

Chi square Distribution (0.05.2) $=5.991$

It is clear from table number (10) of the third factor - first dimension: improving employees' performance, there are no significant differences between the two research sample groups about phrases of the third dimension as Chi square Distribution was less than its tabular value 
at level $(0.05)$ and ranged between $(0.010: 4.924)$ except for phrases number $(6 / 6,6 / 8)$.

Results of phrases number $(6 / 1,6 / 2,6 / 3,6 / 4,6 / 5,6 / 7,6 / 9)$ indicated agreement of the two research groups between ( $75.00: 83.33 \%$ ) for supreme and middle administration and (39.66 : $84.48 \%)$ for executive administration to indicate dependence on group work, preparing on interactive leading environment assisting in applying Kaizen's methodology to improving employees performance.

This agrees with results of study of Mohamed Gabr Elgharawy (2019) (1 ${ }^{r}$ ) indicating the importance or training courses to develop knowledge and skills related to and developing function.

Hassan Ahmed Elshafaey (2018) confirms the importance of adopting methods and behaviors enabling employees to authorizing behaviors and enhancing inferiors' potentials. $(\vee: 83)$

But for phrases number $(6 / 6,6 / 8)$ they are the most contrasted ones as supreme and supervisors administration agreed at (91.67\%), (75.00 \%) respectively on the applying Kaizen's methodology improves employees performance via appreciating and awarding creative employees, reducing difference between administrative levels while executive administration's response reached (51.72\%), (32. $67 \%)$.

Opinions of executive administration agree with study of Sherihan Yehia Moursy (2017) (21) Rihab Aly Amin, Riham Amin Hamza (2015) (16) that creative employees receive neither incentives nor awards contributing to job satisfaction.

Hoda Omar Abdalla (2018) confirms that incentives motivate employees. (^: 47)

Riham Amin Hamza (2010) (17) recommends providing training courses to sports specialists and sports field leaderships.

Table (11) Results of Repetition Percentage, Chi square Distribution and Outweighed Percentage for Response in the Third Factor: Effects of Using (Kaizen) Methodology to Improve Permanent Performance of Achieve Excellent Organizational Performance at Youth and Sports Directorate in Alexandria - Second Dimension: Improving Operations Performance

\begin{tabular}{|c|c|c|c|c|c|c|c|c|c|c|}
\hline \multirow{3}{*}{ Serial } & \multirow{3}{*}{ Phrase content } & \multicolumn{4}{|c|}{$\begin{array}{l}\text { Supreme and middle } \\
\text { administration } \\
\qquad N=12\end{array}$} & \multicolumn{4}{|c|}{$\begin{array}{l}\text { Supreme and middle } \\
\text { administration } \\
\qquad N=58\end{array}$} & \multirow{3}{*}{$\begin{array}{l}\text { Chi square } \\
\text { Distribution }\end{array}$} \\
\hline & & \multicolumn{2}{|c|}{ Agreeing } & \multicolumn{2}{|c|}{ Disagreeing } & \multicolumn{2}{|c|}{ Agreeing } & \multicolumn{2}{|c|}{ Disagreeing } & \\
\hline & & C & $\%$ & $\mathrm{C}$ & $\%$ & $C$ & $\%$ & C & $\%$ & \\
\hline \multicolumn{11}{|l|}{7} \\
\hline $7 / 1$ & $\begin{array}{c}\text { Focusing on } \\
\text { improving work } \\
\text { climate or } \\
\text { environment and any } \\
\text { factors supporting } \\
\text { change operations }\end{array}$ & 9 & 75.00 & 3 & 250.00 & 24 & 41.38 & 34 & 58.62 & 4.510 \\
\hline
\end{tabular}




\begin{tabular}{|c|c|c|c|c|c|c|c|c|c|c|}
\hline $7 / 2$ & $\begin{array}{l}\text { Identifying factors } \\
\text { supporting change } \\
\text { operations }\end{array}$ & 11 & 91.67 & 1 & 8.33 & 31 & 35.45 & 27 & 46.55 & $* 6.051$ \\
\hline \multicolumn{11}{|l|}{$7 / 3$} \\
\hline $7 / 3 / 1$ & Financial resources & 11 & 91.67 & 1 & 8.33 & 52 & 89.66 & 6 & 10.34 & 0.045 \\
\hline $7 / 3 / 2$ & Substantial potentials & 11 & 91.67 & 1 & 8.33 & 49 & 84.48 & 9 & 15.52 & 0.0419 \\
\hline $7 / 3 / 3$ & Time & 10 & 83.33 & 2 & 16.67 & 21 & 36.21 & 37 & 63.79 & $* 8.950$ \\
\hline $7 / 3 / 4$ & Operating operations & 10 & 83.33 & 2 & 16.67 & 18 & 31.03 & 40 & 68.97 & *11.331 \\
\hline \multicolumn{11}{|l|}{$7 / 4$} \\
\hline $7 / 4 / 1$ & Substantial potentials & 11 & 91.67 & 1 & 8.33 & 49 & 84.48 & 9 & 15.52 & 0.419 \\
\hline $7 / 4 / 2$ & Human potentials & 11 & 91.67 & 1 & 8.33 & 42 & 72.41 & 16 & 27.59 & 2.004 \\
\hline $7 / 4 / 3$ & Financial resources & 10 & 83.33 & 2 & 16.67 & 44 & 75.86 & 14 & 24.14 & 0.315 \\
\hline $7 / 5$ & $\begin{array}{c}\text { Identifying } \\
\text { restrictions of } \\
\text { executing quality } \\
\text { norms of every } \\
\text { department of youth } \\
\text { and sports } \\
\text { directorate }\end{array}$ & 9 & 75.00 & 3 & 25.00 & 32 & 55.71 & 26 & 44.83 & 1.611 \\
\hline $7 / 6$ & $\begin{array}{l}\text { Identifying tasks for } \\
\text { employees to be } \\
\text { trained on inside } \\
\text { every directorate's } \\
\text { department }\end{array}$ & 9 & 75.00 & 3 & 25.00 & 26 & 44.83 & 32 & 55.17 & 3.621 \\
\hline $7 / 7$ & $\begin{array}{c}\text { Creating new work } \\
\text { mechanisms }\end{array}$ & 8 & 66.67 & 4 & 33.33 & 22 & 37.93 & 36 & 62.07 & 3.352 \\
\hline $7 / 8$ & $\begin{array}{l}\text { Clarifying work } \\
\text { procedures for all } \\
\text { youth and sports } \\
\text { directorate's } \\
\text { employees }\end{array}$ & 11 & 91.67 & 1 & 8.33 & 47 & 81.03 & 11 & 18.97 & 0.791 \\
\hline
\end{tabular}

Chi square Distribution (0.05.2) $=5.991$

It is clear from table number (11) of the third factor - second dimension: improving performance of operations, there are no significant differences between the two research samples groups about phrases of the second dimension as Chi square Distribution was less than its tabular value at level $(0.05)$ and ranged between $(0.315: 4.510)$ except for phrases number $(7 / 2,7 / 3 / 3,7 / 3 / 4)$ as ( $\mathrm{Ca} 2)$ value exceeded its tabular value and ranged between (6.051 : 11.331).

For phrases number $(7 / 2,7 / 3 / 3,7 / 3 / 4)$ they are the most contrasted ones in responses of the research groups as while supreme and supervisory administrations agreed at (83.33: 91.67 \%) upon that applying Kaizen's methodology improves operations performance via identifying factors supporting change, identifying aspects of waste inside, we find that executive management achieved a percentage from 
(31.03: $53.45 \%)$.

This agreed with results of study of Riham mohamed Aly (2019 (19) indicating the increase of communication efficiency between individuals and units through coordination and integration of works between them and quick obtainment of data and information to provide services and overcome waste.

Also from results of phrases numbers $(7 / 1,7 / 3 / 1,7 / 3 / 2,7 / 4 / 1,7 / 4 / 2,7 / 4 / 3,7 / 5,7 / 6,7 / 7,7 / 8)$ it is clear that there is an agreement between most of groups response that applying Kaizen's methodology improves operations performance by focusing on improving work environment, identifying waste aspects, identifying needs of all directorate's departments of substantial and human potentials, identifying quality norms execution barriers, and crating new work mechanisms at (66.67 : $91.76 \%$ ) for supreme and middle administration and (37.93: $89.66 \%$ ) for executive administration.

This agrees with results of Dalia Taha Mahmoud Youssef (2013) (7) of that using Kaizen's method requires not only new financial resources but the best use of the organization's assets.

Table (12) Results of Repetition Percentage, Chi square Distribution and Outweighed

Percentage for Response in the Third Factor: Effects of Using (Kaizen) Methodology to Improve Permanent Performance of Achieve Excellent Organizational Performance at Youth and Sports Directorate in Alexandria - Third Dimension: Improving Performance of Youth and Sports Directorates Performance in Alexandria

\begin{tabular}{|c|c|c|c|c|c|c|c|c|c|c|}
\hline \multirow[t]{3}{*}{ Serial } & \multirow[t]{3}{*}{ Phrase content } & \multicolumn{4}{|c|}{$\begin{array}{l}\text { Supreme and middle } \\
\text { administration } \\
\mathrm{N}=12\end{array}$} & \multicolumn{4}{|c|}{$\begin{array}{l}\text { Supreme and middle } \\
\text { administration } \\
\mathrm{N}=\mathbf{5 8}\end{array}$} & \multirow{3}{*}{$\begin{array}{c}\text { Chi square } \\
\text { Distribution }\end{array}$} \\
\hline & & \multicolumn{2}{|c|}{ Agreeing } & \multicolumn{2}{|c|}{ Disagreeing } & \multicolumn{2}{|c|}{ Agreeing } & \multicolumn{2}{|c|}{ Disagreeing } & \\
\hline & & $\mathrm{C}$ & $\%$ & $\mathrm{C}$ & $\%$ & $\mathrm{C}$ & $\%$ & $\mathrm{C}$ & $\%$ & \\
\hline 8 & \multicolumn{10}{|c|}{ Youth and sports directorate is able to: } \\
\hline $8 / 1$ & $\begin{array}{l}\text { Consolidating good } \\
\text { means and norms of } \\
\text { work procedures inside } \\
\text { the directorate with } \\
\text { following international } \\
\text { norms }\end{array}$ & 8 & 66.67 & 4 & 33.33 & 24 & 41.38 & 34 & 58.62 & 2.562 \\
\hline $8 / 2$ & \multicolumn{10}{|c|}{ Responding effectively to variable: } \\
\hline $8 / 2 / 1$ & Internally & 10 & 83.33 & 2 & 16.67 & 48 & 82.76 & 10 & 17.24 & 0.002 \\
\hline $8 / 2 / 2$ & Externally & 11 & 91.67 & 1 & 8.33 & 47 & 81.03 & 11 & 18.97 & 0.791 \\
\hline $8 / 3$ & $\begin{array}{l}\text { Expecting beneficiaries } \\
\text { desires and } \\
\text { requirements through: }\end{array}$ & & & & & & & & & \\
\hline $8 / 3 / 1$ & Questionnaire from & 7 & 58.33 & 5 & 41.67 & 15 & 25.86 & 43 & 74.14 & 4.865 \\
\hline $8 / 3 / 2$ & Social media & 11 & 91.67 & 1 & 8.33 & 52 & 89.66 & 6 & 10.34 & 0.045 \\
\hline $8 / 3 / 3$ & $\begin{array}{c}\text { Complaints and } \\
\text { suggestions boxes }\end{array}$ & 10 & 83.33 & 2 & 16.67 & 43 & 74.14 & 15 & 25.86 & 0.457 \\
\hline $8 / 3 / 4$ & Interviews & 9 & 75.00 & 3 & 25.00 & 20 & 34.48 & 38 & 65.52 & $* 6.727$ \\
\hline $8 / 4$ & $\begin{array}{l}\text { Developing youth and } \\
\text { sports directorates } \\
\text { competitiveness }\end{array}$ & 10 & 83.33 & 2 & 16.67 & 47 & 81.03 & 11 & 18.97 & 0.035 \\
\hline $8 / 5$ & $\begin{array}{l}\text { Using permanent } \\
\text { improvement tools } \\
\text { efficiently }\end{array}$ & 8 & 66.67 & 4 & 33.33 & 21 & 36.21 & 37 & 63.79 & 3.802 \\
\hline
\end{tabular}


Chi square Distribution $(0.05 .2)=5.991$

It is clear from table number (12) of the third factor - third dimension: improving the directorate's performance, there are no a statistical significant differences between the two research sample groups about phrases of the second dimension as Chi square Distribution was less than its tabular value at level (0.05) and ranged between (0.002: 4.865) except for phrases number (8/3/4) as (Ca 2) value was (6.727).

Results of phrases numbers $(8 / 1,8 / 2 / 1,8 / 2 / 2,8 / 3 / 1,8 / 3 / 2,8 / 3 / 3,8 / 4,8 / 5)$ indicated agreement of all the two types responses at (66.67 : $91.76 \%)$ for supreme and middle administration at (37.93 : $89.66 \%$ ) for executive administration that youth and sports directorate is able to consolidate good methods and norms of work procedures inside the directorate, efficient response to variables in both internal and external environment, expect beneficiaries desires, increasing youth and sports directorate's competiveness, using permanent improvement tools efficiently.

Results of study of Walid Abdelhafiz (2014) (24), Aiman Abdelhamid (2013) ( $\{$ ), confirm that using information technology in administrating organizations according to beneficiary's needs develops the organization's efficiency.

Also study of Riham Amin Hamza (2017) (18) recommends the importance of having a database contributing to improvement operations.

But phrases number (8/3/4) contradictory research groups subjects responses are clear, as while supreme and supervisors administrations agreed at (75.00\%) upon that the directorate is able to expect beneficiaries desires, executive administration's opinions disapproved the same at $(34.48 \%)$.

Ahmed Mohamed Ghonim (2009) indicates establishing a database including information about beneficiaries expectations desires and identifying their tastes changes (3: 334).

The researcher believes that current international variables of the directorate's surrounding environment impose applying new scientific methods to administration to deal with such challenges and carrying out permanent improvement operations.

\section{Conclusions:}

- There are no culturing courses to convince all administrative levels employees with all advantages of applying Kaizen's methodology.

- Not constituting groups of employees "quality departments" to solve problems and reach new changes.

- Supreme administration of youth and sports directorate plans via ordering all problems facing the directorate according to priority.

- There are shortage in suggesting different ideas and suggestions to solve such problem and carry out a plan for the required improvements.

- None analyzing the gap between the required results and the actual results of the used corrective procedures to verify that new changes work as planned. 
- Weak response of youth and sports directorate to the suggested improvements and no suitable procedures are taken to execute changes.

- No waste aspects are determined inside every department of youth and sports directorate including wasting time, operation processes.

- Non effective response to variables of external and internal environment and non expecting beneficiaries' desires and requirements.

\section{Recommendation}

- Applying steps of permanent improvement, PDCA course inside youth and sports directorate as it is the means of permanent improvement by making a field study to know any dimensions needing actual application before other ones.

- Employees should be enabled to join cultural courses to know the importance of using Kaizen methodology.

- $\quad$ Focusing on permanent training of all employees as per occupational needs and measuring the training effects.

- Establishing a mechanism to motivate employees' creative efforts to encourage creation.

- Focusing on measuring beneficiaries desires and needs on a permanent basis as they are the key of change and development success at the directorate.

- There should be a unit inside the organizational structure to carry out permanent review and evaluation.

\section{Bibliography}

First: Arabic Bibliography

1 Ahmed Abdelsalam Mousa : Effects of Strategic Plan of Economic Entities on (2016) Marketing, First Print, Universities Publishing House, Cairo.

r Ahmed Elsherif (2018)

: Sports, Governance, International Direction of Sports Organization's Performance, Dar El Fekr El Araby, Cairo.

3 Ahmed Mohamed Ghonim : The Japanese Approach of Permanent Improvement and (2009) How Far Arab Organizations Profit from, Modern Library for Printing and Publishing.

\& Aiman Abdelhamid (2013) : An Executive Plan to Develop Administrative Performance, Youth and Sports Directorate, Sharkia Governorate under Requirements of Applying Norms of Quality of Sigma 6, Magazine of Faculty of Physical Education for Girls, Alexandria University.

- Ayten Mahmoud : Evaluating Organizational Performance in International Elmargoushy (2008) Public Organizations, Universities Publishing House, Cairo.

1 Dalia Taha Mahmoud : How to Use Gemba Kaizen's Method in Developing Youssef (2013) University Education in Egypt, a Research Published on Magazine of Arab Studies of Education and Psychology, Issue (35), Part (4), Egypt. 
$\checkmark$ Hassan Ahmed Elshafaey (2018)

$\wedge \quad$ Hoda Omar Abdalla (2018)

$9 \quad$ Ismail Abdelkafy (2019)

1. Maher Mohsen Marheg : Managing Integrated Quality as an Administrative (2014)

11 Moamen Sharafeldin (2012)

ir Mohamed Gabr Elgharawy : (2019)

\section{ir Nadia Abdelkhalik Ramadan : Bakr (2016)}

Is Nagy Ismail Mohamed Meghawry (2014)

15 Qusayr Bin Odeh (2020)

Manual of Organization, Organizational and Enablement Development Network, New Administration and its Theories in Physical Education, First Print, Sports World Organization, Alexandria.

Mechanism of Administrative Enablement, Faculty of Economics and Administration, King Souad University, Jeddah.

Strategy between Planning and Quality, Planning of Performance and Quality of Production, Dar El Araby, Cairo.

Development Approach, Permanent Improvement (Kaizen), Faculty of Economics, Tishreen University, Syria.

hhtps://www.researchgate.net/ publication/320840281

The Role of Administration by Operations in Improving Economic Organization's Performance, a Case Study, Nokawis Organization for Sighted, Unpublished Master Thesis, Faculty of Economic and Commercial and Managerial Science, Algeria.

Administrative Enablement and its Relationship to Occupational Satisfaction for Managers and Teachers of Physical Education, National Schools, Baghdad, Unpublished Master Thesis, Faculty of Physical for Girls, Alexandria University.

An Approach to Permanent Improvement (Kaizen) and its Effects on Organization's Performance by Applying to Egypt Electricity Holding Company, a Thesis Published on Arab Magazine for Administration, Volume (63), First Issue, Faculty of Commerce, El Azhar University.

Hamed, : Professional Administrator, First Print, New Book Center, Ibrahim Cairo.

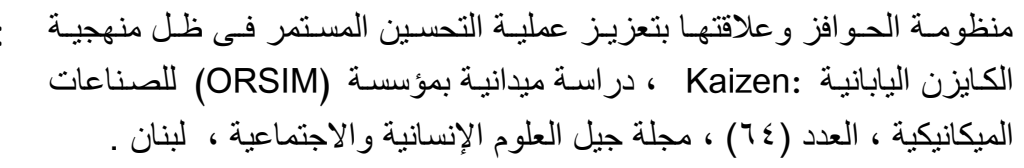

16 Rihab Aly Amin, Riham : The Relationship between Organizational Justice and Amin Hamza (2015) Specialist, Departments of Youth Care, Alexandria University, a Research Published on Faculty of Physical Education Magazine, Issue ( ), Volume ( ), Assiut University. 
17 Riham Amin Hamza (2015): : Contributions of Ministry of Youth and Sports to Achieve Permanent Development in Egypt, A Research Published on Faculty of Physical Education Magazine, Issue ( ), Volume ( ), Abo Kir - Alexandria University.

18 (2017)

19 Riham Mohamed Ibrahim (2019)

20 Rizan Salaheldin Ezzat, Berzin Sheikh Mohamed (2010)

r1 Sherihan Yehia (2017)

r2 (2017)

r3 Twaitia Eltaher (2017)

24 Walid Abdelhafiz (2014)

Second: Foreign references

Y5 Ann Bisou (2016)
Aly : A Suggested Model for Kaizen's Methodology (Permanent Improvement) to achieve Administrative Excellence, Faculty of Physical Education for Girls, Alexandria University, Unpublished Doctorate Thesis, Faculty of Physical Education for Girls, Alexandria University.

Developing Strategic Performance in Sports Clubs, a Research Published at Third International Scientific Conference, Sports and permanent Development, Faculty of Physical Education, Tanta University.

Method of Kaizen and its Relationship to Reduce Costs, a Research Published on Accounting and Financial Studies Magazine, Volume (5), Issue (10), Baghdad University.

Moursy : The Role of Administration by Enablement in Achieving Occupational Satisfaction for Employees of General Department of Youth Care, Tanta University, a Thesis Published at Third International Scientific Conference, Sports and Permanent Development, Faculty of Physical Education, Tanta University.

: Organizational Climate and its Relationship to Administrative Creation of Sports Specialist, Youth Directorates, Middle Delta Governorates, a Thesis Published at Third International Scientific Conference, Sports and Permanent Development, Faculty of Physical Education, Tanta University.

: Effects of Principles of Kaizen's Strategy in Activating the Clearer Production Technology, Case Study of Cement Company, El Maa El Abiad, Tibsa, Algeria, a Research Published on Economic Research Magazine, Volume (4), Issue (2), El Arabi Bin Mehidi University, Algeria.

: Six Sigma Method as a Suggested Model to Develop Administrative Work, youth care departments south valley and Aswan Universities, unpublished directorate thesis, Faculty of Physical Education, Asiut University.

Kaizen or How to Reach Your Goals Making Small Steps: Japanese Success Principles in Everyday Life, Amazon Digital Services LLC 
r6 Benjamin S Sweet (2015)

r7 Charles Protzman (2016)

r8 Glover et al., (2011)

r9 Kai Musashi (2016)

30 Masaaki Imai (2012)

r1 Richard Schonberger (2012)

r2 Robert Maurer (2012)
KAIZEN, the Pursuit of Continuous Improvement, Amazon Digital Services LLC

the Lean Practitioner's Field Book: Proven, Practical, Profitable and Powerful Techniques for Making Lean Really Work, Productivity Press

: A Case Study on Kaizen as a Learning Tool for a management Team. ناقص بيانات

Kaizen: How to Master Continuous Improvement and Transform Your Life One Step at a Time (Mindset, Kaizen, Continuous Improvement, Self Discipline), Amazon Digital Services LLC

Gemba Kaizen: A Commonsense Approach to a Continuous Improvement Strategy, McGraw-Hill Education; Second Edition

Best Practices in Lean Six Sigma Process Improvement: A Deeper Look, John Wiley \& Sons, Inc

The Spirit of Kaizen: Creating Lasting Excellence One Small Step at a Time, McGraw-Hill Education; 1 edition 


\title{
Effect of Online Training amidst Covid-19 Pandemic on Maintaining Physical and Technical Level for Junior Female Basketball Players
}

\section{Sara Helmy Moselhy}

Lecturer at Sports Games Training Department, Faculty of Physical Education for Girls, Helwan University, Cairo, Egypt.

\begin{abstract}
:
The world faces Covid-19 pandemic that spread to many countries around the globe. It was declared by the World Health Organization as an international health emergency requiring isolation at home and social distancing, the thing that forced players to abruptly stop their training routines at courts leading to a decline in their physical and technical performance. This study aims at identifying the effect of the online training amidst Covid-19 pandemic on maintaining the physical and technical level for junior female basketball players, using the experimental approach for two groups of female junior basketball players under 9 years old, at Wadi Degla Club - Maadi, Egypt.

The online training program including technical and physical exercises was applied at home for the experimental group $(\mathrm{n}=10)$ for (14) weeks, the duration of courts closure due to Covid-19 pandemic, using Zoom and WhatsApp applications. Whereas the control group $(n=10)$ has completely stopped training during the courts closure period. The tests used for pre and post measurements were: Alternate Hand Wall Toss Test, Pushing Medicine Ball "2kg", Standing Board Jump Test, 20-m Sprint Test, Illinois Agility Test, Shooting at Overlapping Rectangles Test, 800-m Run Test, Free Throw test, Layup Test "left and right", and Compound Technical Test. The most prominent results were, the existence of statistically significant differences between experimental and control groups in basketball physical fitness elements, except for agility and cardiorespiratory endurance elements in favor of post measurement for the experimental group. Furthermore, there are statistically significant differences between both experimental and control groups in the technical level, except for free throw skill in favor of the post measurement for the experimental group. Subsequently, it is possible to conclude that the online training amidst Covid-19 pandemic has a potent effect on maintaining the physical and technical level for junior female basketball players.
\end{abstract}

Key Words: Covid-19, online training, detraining, continuous training, maintaining sports performance.

\section{Introduction:}

The Acute Respiratory Distress Syndrome (ARDS) resulting from Corona Virus 2 (SARS CoV-2 or Covid-19), affects the world since its record in December 2019 in Wuhan, China (Gelen et al., 2020). With its rapid spread across the world (World Health Organization [WHO], 2020a), the World Health Organization (WHO) declared Covid-19 as a pandemic in March $11^{\text {th }}$, 2020 which led to the confusion and paralysis of people's everyday lives (Haleem et al., 2020; WHO, 2020b).

According to WHO recommendations, the governments imposed social distancing, curfew, and home isolation, as well as air travel ban, schools, universities, malls, restaurants, coffee shops, sports and social clubs closure in an attempt to control spreading the virus (Mattioli et al., 2020; WHO, 2020a; World Health Organization Regional Office for Africa [WHO Africa], 2020), leading to negative and devastating ramifications on all sectors (Haleem et al., 2020).

Sports sector was not excluded from the virus consequences, as many local, international, and global events were postponed and even cancelled, such as 2020 Summer Olympics in Tokyo, NBA, Wimbledon, British Open 2020, and other championship. Consequently, players of 
different ages and sports completely stopped practicing and training (Gelen et al., 2020; Sraff \& Wire Reports, 2020).

As Basketball players stop training for a while, their physical fitness decrease along with the level of adequacy of motor skill, in addition to the increase of fat mass percentage, and developing various diseases such as cardiovascular disease, atherosclerosis, diabetes, and respiratory system diseases (Al-Tikriti \& Al-Hajjar, 2012; Eirale et al., 2020; Mattioli et al., 2020; Saleh, 2019). The longer players stop training, the more their physical fitness decreases and the probability of developing chronic diseases increases (Al-Tikriti \& Al-Hajjar, 2012). This appears particularly in junior players considering the short period they already practiced the game, resulting in their physical and technical performance decrease in a short period, compared to older players who practiced the game for many years (Al-Tikriti \& Al-Hajjar, 2012; Saleh, 2019).

Maintaining and developing their physical and technical performance level, the basketball junior players need to keep up their regular training fitting to their physical and technical abilities, and consistent with their growth level and age characteristics (Al-Hajj, 2017). Persistent and regular training is the way to success and one of the essential pillars to ensure the achievement of high standards (Albasiti, 1998; Barth \& Boesing, 2010)

Regular continuous effective training means performing the training quota regulated before the declining of the previous training one, to ensure that the effect of positive training takes place and achieves stability in the adjustment process, thus guarantee load adaptation, maintain physical and technical level, and elevate organic and functional level of junior players (Albasiti, 1998).

To keep the training level for junior basketball players in a good level and prevent the decline of their physiological abilities, it is essential to avoid detraining. For the coaches, they should take into account the right relationship of load components during its formation, and not to increase training quota until making sure of reaching the adaptation stage (Albasiti, 1998). Maintaining physical and technical level mainly depends on organizing training units in terms of their intensity, duration, and repetition during the annual training program, and from year to year (Al-Tikriti \& Al-Hajjar, 2012).

With the emergence of this problem among the junior basketball female players, and by reviewing various researches addressing Covid-19 pandemic effect on psychological, physical, and mental health, it was recommended to find alternative training methods to continue training the players and practicing sports in order to reduce the effect of abrupt stopping resulting from the pandemic (Eirale et al., 2020; Mattioli et al., 2020; Wang et al., 2020).

As the author is a basketball coach for juniors, she is motivated to search for another way to continue the training process so as to limit the potential effect of detraining on the junior players' physical and technical level. This method should include preventative measures in terms of using tools individually, applying social distancing, preventing direct connection between players or between players and coach, and the continuous interaction between the players and coach and the players with each other. The researcher came up with the idea of training at home via the internet, just as what happened with home schooling; the idea of a comfortable and flexible communication via the Internet to access learning resources depending on interacting with the 
content, the teacher, and other students. It is a new social process that started as a complete alternative to both distance learning and traditional face-to-face classes, so that students can obtain knowledge to build understanding and personal growth (Ally, 2008; Hiltz \& Turoff, 2005; Moore et al., 2011).

From this aspect the idea was born, just as there is online learning, there will be online training as one of the alternative methods allowing geographical distancing for players, and in the same time keeping continuous connection. Either directly through audio and video using group video calls applications, or indirectly without contacting the coach, by having the players download the required program they need to work upon. Thus, the players train and send videos for their exercises while the coach gives her feedback using group chat applications. A physical technical training program was prepared for basketball juniors suitable to be implemented directly at home through group video calls applications, and indirectly using group chat applications. The program includes all the elements of physical fitness and skills to be acquired and maintained for this age group. This, to the researcher's knowledge, is considered a new idea that may solve such a problem.

This study aims at defining the effect of online training amidst Covid-19 pandemic on maintaining the physical and technical level for junior female basketball players.

\section{Hypothesis:}

(1) There are statistically significant differences between the experimental group (applying online training during the courts closure) and control group (not training during courts closure) amidst Covid-19 pandemic on maintaining physical level of junior female basketball players in favor of post measurement for the experimental group.

(2) There are statistically significant differences between the experimental group (applying online training during the courts closure) and control group (not training during courts closure) amidst Covid-19 pandemic on maintaining technical level of junior female basketball players in favor of post measurement for the experimental group.

\subsection{Approach}

\section{Methods:}

The study based on an experimental approach for two groups, one is experimental and the other is control, through pre and post measurement.

\subsection{Sample}

A deliberate sample was chosen from junior female players at Wadi Degla Club - Maadi, Egypt under 9 years old, who registered in the Egyptian Basketball Federation for the season 2019/2020 and received at least eight months of basketball training. The sample is composed of (25) female players, they were deliberately distributed into (10) players for the experimental group (Mean: \pm SD : age: $8.68 \pm 0.37$ years; training age: $1.12 \pm 0.34$ years; weight: $31.50 \pm 3.14$ $\mathrm{kg}$; height: $1.39 \pm 0.05 \mathrm{~cm}$ ), and (10) players for the control group (Mean: \pm SD: age: $8.61 \pm 0.38$ years; training age: $1.16 \pm 0.31$ years; weight: $30.20 \pm 3.33 \mathrm{~kg}$; height: $1.40 \pm 0.07 \mathrm{~cm}$ ), and (5)

female players for the pilot study.

Note 1: The moderation of the sample distribution under the normal curve was confirmed in the variables of height, weight, age and training age, so the values of the skewness coefficient were between $(+0.49,-0.41)$. The physical variables for basketball, the values of the skewness 
coefficient were between $(+0.35,-0.82)$. The technical variables prepared by specialists for this age group, the values of the skewness coefficient were between $(+1.08,-0.01)$; It is clear that the values of the skewness coefficient are limited to $( \pm 3)$, indicating the moderation of the sample's distribution in all the research variables.

Note 2: The conformity of the two experimental research groups to the control group was confirmed, as it was found that the $\mathrm{P}$ value $>0.05$, ensuring that there are no statistically significant differences between the two groups and that they are equivalent.

\subsection{Procedures}

- The physical tests used are, (Alternate Hand Wall Toss Test) measuring hands coordination, (pushing a medicine ball " $2 \mathrm{~kg}$ " test with one hand) measuring right and left arms power, (Standing Board Jump Test) measuring the legs power, (20-m Sprint Test) measuring speed, (Illinois Agility Test) measuring agility, (Shooting at Overlapping Rectangles Test) measuring right and left arms accuracy, (800-m Run Test) measuring cardiorespiratory endurance. Technical tests designed for this age group were applied by basketball professionals under the supervision of the Competitions Committee of the Egyptian Basketball Federation are (free throw test, layup test "left and right", compound technical test), including the following skills (dribble, behind, between, crossover, stopping, passing, receiving, layup, jump shot), however all skills are performed with both right and left hands. Physical and Technical tests described briefly as follows:

Alternate Hand Wall Toss Test The player is standing 2 meters from the wall, holding one tennis ball in her favorite hand, she then tosses the ball with the preferred hand from the bottom towards the wall and receives with the other hand; the ball is tossed with the other hand and received by preferred hand. The performance continues in this way for 30 seconds and the player scores the number of times the ball is caught in this period.

Pushing a medicine ball " $2 \mathrm{~kg}$ " test with one hand The player stands behind the starting line, puts the medical ball $2 \mathrm{~kg}$ on one hand and then pushes the ball once so that it does not cross the starting line with the right hand and with the left hand once, the distance is recorded from the nearest point of medicine ball landing towards the starting line.

Standing Board Jump Test The player stands behind the starting line, feet slightly apart; the player jumps in front of the farthest possible distance. The distance is recorded from the nearest point of the player's legs landing towards the starting line.

20-m Sprint Test The player stands in the high starting position, directly behind the starting line, after hearing the whistle. She runs at full speed to the finish line, which is 20 meters away. The time for each player is recorded to the nearest $1 / 10$ of a second.

Illinois Agility Test The player stands in the high starting position, directly behind the starting line, and when the whistle is heard, she runs at full speed following the arrow as shown in Figure 1 from the starting 
point to the finish point. The time for each player is recorded to the nearest $1 / 10$ of a second.

\section{Test}

Rectangles Test

of the wall painted by

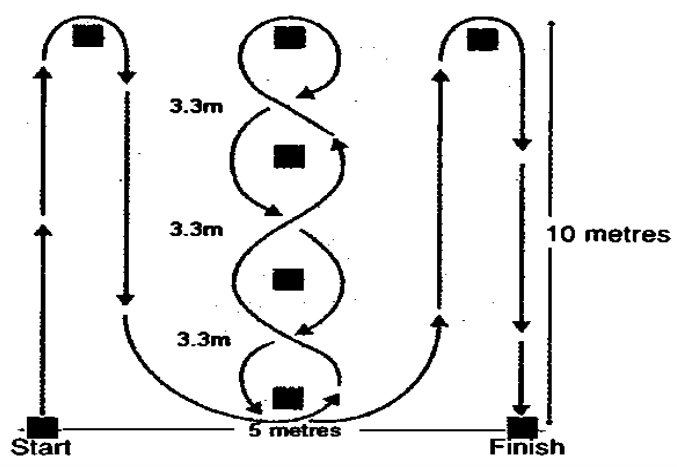

Figure 1. Illinois Agility

Shooting at Overlapping

The player stands in front the overlapping rectangles and behind the starting line, which is 5 meters away, holding a tennis ball in her hand. She shoots five times at overlapping rectangles in an attempt to hit the inner rectangle. The player has the right to use either hand when shooting. The scores recorded three points when hitting the inner rectangle, two points when hitting the middle rectangle, one point when hitting the outer rectangle, and zero points when touching the tennis ball outside the three

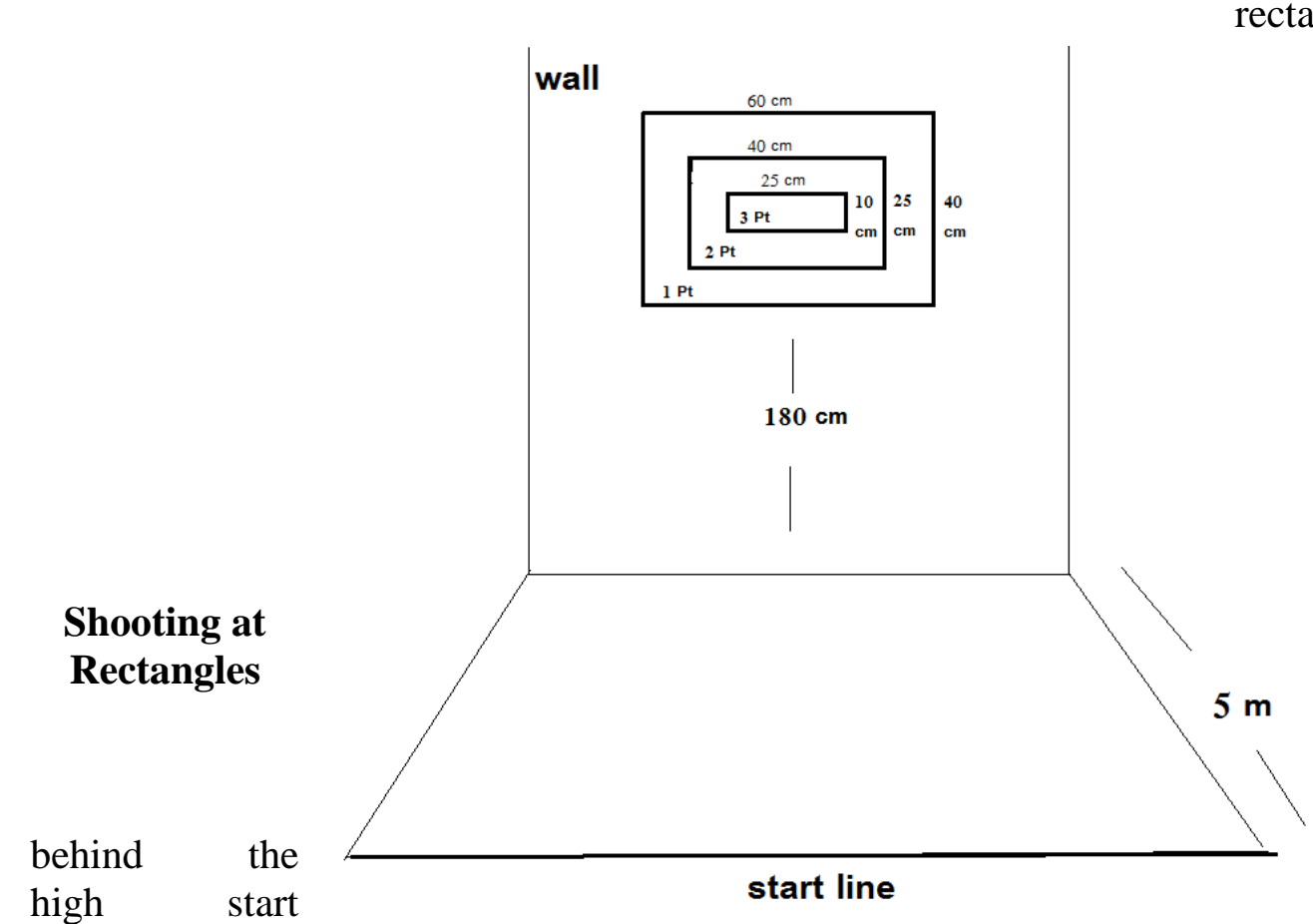

rectangles as in Figure 2.

Figure 2.

Overlapping

Test

800-m Run Test

The player stands starting line in the

position, and upon hearing the whistle, she runs two laps around the 400-meters running track until she reaches the finish line. The time for each player is recorded.

Free throw test 
The player stands behind the line 3.5 meters away and holding a basketball size 5, she shoots two consecutive free throws in the hoop, which is 2.60 meters from the ground. Successful free throws are recorded for each player.

Layup test The team stands on the center line of the basketball court and the first player starts when she hears the whistle to perform layup shot on the 2.60 meters high hoop using a size 5 basketball, and when she crosses the 3 points shooting arc, her teammate begins; The performance lasts 3 minutes for layup with the right hand and 3 minutes for layup with the left hand. The number of successful layup shots for the team (right hand - left hand) are recorded and canceled any shot with an error in the steps- hand or a legal violation.

\section{Compound technical test}

The player stands behind the starting line holding a basketball size 5, and when she hears the whistle, she dribbles with the left hand in the direction of the first cone to do behind back with left hand; between with right hand at the second cone; crossover with left hand at the third cone; stopping jump stop at fourth cone; passing chest pass to the teammate then run without the ball; receiving the ball at fifth cone; right layup; jump shot with left hand; then do all this skills again from other side of basketball court with the opposite hand to the first performance of each skills, as in Figure 3.

The final score of the test is of 200 points divided by 20 points for the left and right dribbling, 20 points for left and right behind back, 20 points for left and right between, 20 points for left and right crossover, 20 points for left and right jump stop, 20 points for left and right pass, 20 points for left and right receiving, 20 points for left and right layups, 40 points for left and right jump shots. Each skill evaluated on two criteria: looking up and controlling the ball.

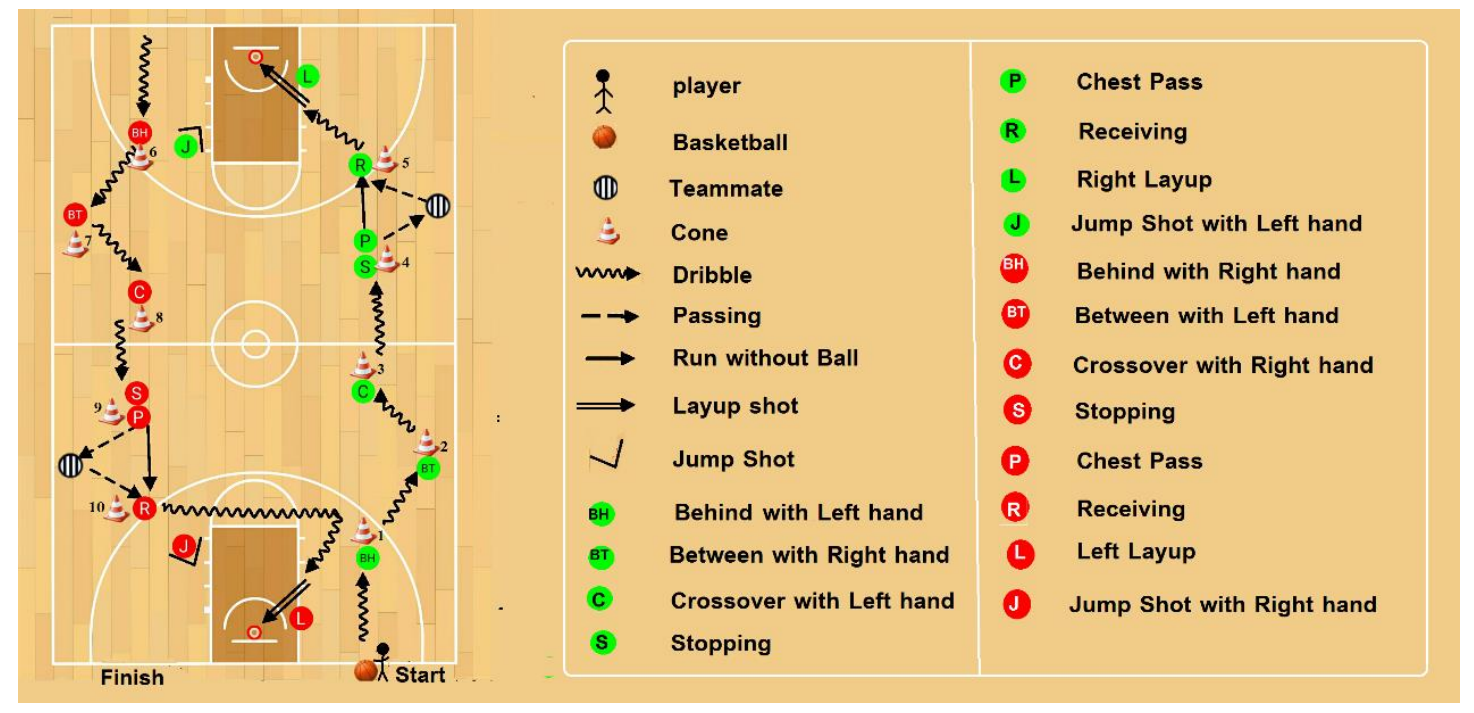

Figure 3. Compound technical test

- The validity of all physical tests are confirmed (Abdulhamid \& Hassanein, 1997; Allawi \& Radwan, 2001; Al-Tikriti \& Al-Hajjar, 2012; Barth \& Boesing, 2010; Gambetta, 2007), also the technical tests (Egyptian basketball federation, 2020) applied in the research using the 
content validity through scanning scientific references. Also, the reliability of the tests were confirmed through Test-Retest with a time interval of (14) days between the first and second application on a sample chosen randomly from the research community and outside the research sample of (5) players "pilot sample".

- A first pilot study was conducted on February $19^{\text {th }}$ and $20^{\text {th }}, 2020$, aiming at identifying the extent of the physical and technical tests compatibility with reality, and their suitability for this age group. The pilot experiment showed that all the applied tests, either physical or technical, are valid and appropriate for the age group.

- A second pilot study was conducted on March $14^{\text {th }}$ and $15^{\text {th }}, 2020$, aiming at identifying the possibility of applying online training for this age group, determining which amount of time is more appropriate online, is it (30) minutes or (60) or more? Should online training take place directly through group video calls or indirectly through group chat? Should training be on daily basis, i.e. six times a week or three times are sufficient? How suitable are physical and technical exercises prepared and designed to be applied at home in a small space in terms of actual reality? In addition to the problems and obstacles that may occur during the implementation of training units and finding appropriate solutions to them. The pilot experiment showed the following:

- It is possible to provide online training for this age group, as they know how to use the applications used in the research.

- The online training unit should be 60 minutes and not 30, so that the unit includes both the physical and technical parts, and the junior players manage to implement them. This agrees with what WHO indicated for this age group, that the physical activity practiced for this age group is of a period of 60 minutes (WHO, 2010).

- It is better to provide online training directly through group video calls three times a week using (Zoom) application, and indirectly through group chat applications three times a week using (WhatsApp group), in order to overcome internet connection problems that may occur during online video calls for some players, thus they won't obtain their full training with high efficiency. Therefore, it is better to diversify the use of the online training methods (direct and indirect) to achieve the highest benefit from the training, therefore six times a week. This is consistent with what the WHO indicated, that it is better for this age group to perform daily physical activity to achieve higher benefit and reduce the effects of detraining on their physical, mental and psychological health (WHO, 2010).

- The exercises prepared and designed by the researcher to be applied at home are appropriate, in terms of implementation. They also added suspense, enjoyment, and challenge elements for female basketball juniors.

- Pre measurements (technical - physical) were applied on junior female basketball players, the experimental and control research group, before implementing the online training program on March $7^{\text {th }}$ and $8^{\text {th }}, 2020$. Post measurements (technical - physical) were applied on female junior basketball players, the experimental and control research group, after finishing the online training program implementation for the experimental group that lasted for three months and a half, on July $4^{\text {th }}$ and $5^{\text {th }}, 2020$. It was taken into account that the players do not participate in the training 24 hours prior to the tests. Warm ups were performed before the tests. The test always started at 4 p.m.

- All tests took place in basketball courts at Wadi Degla Club - Maadi branch, Egypt. 


\subsection{Training Program}

- The suggested online training program was applied on the experimental group during the stopping period of training in courts due to Covid-19 pandemic in the supplementary preparation period for the second preparation period of the training season after canceling the second half of the season competitions. The program's implementation took three months and a half, i.e. (14) weeks, (6) training units per week, divided into (3) online training units directly using group video calls application (Zoom), and (3) online training units indirectly using group chat application (WhatsApp). The training unit duration was (60) minutes, with the total of (5040) minutes, from March $16^{\text {th }}, 2020$ to June $30^{\text {th }}, 2020$. It included a collection of exercises for basketball physical fitness elements and the chosen and proper skills for this age group, prepared and designed for home in small spaces, and eligible to be applied via the internet, as shown in tables 1 and 2. The control group did not perform any physical or technical activity during the stopping period at clubs and courts closure due to Covid-19 pandemic.

Note 1: the online training program for the experimental group included teaching, learning, and developing only the physical and technical aspects, excluding the tactical aspect, as this age group in the basketball scientific references (the research group) is at the end of the fundamental learning stage and the beginning of the learning for training stage (Saleh, 2019). Therefore, this age group is only allowed to obtain some physical abilities and skills appropriate for its age, excluding addressing the tactical aspect (AlFaith, 2014; American sport Education program, 2007; Khuraibet \& Abdel Fattah, 2016; Saleh, 2019).

- Implementing the training program for junior female basketball players (experimental group) at home through online training.

- Using low intensity interval training method, ranging between (60:80\%) and high intensity interval training method, ranging between $(80: 90 \%)$, so that in the program medium, less than maximum, and maximum loads are used. The weekly load cycle used is (1:3), as it is the most appropriate for juniors (Saleh, 2019).

- Defining the percentage for each training contents (physical preparation - technical preparation) over the months of the annual training season with the individual competition system, "as competitions for the second half of the training season were canceled due to Covid-19 pandemic, so the season was modified to individual competition system", befitting this age group, under 9 years old (the research group), according to the scientific references specialized in the field of sports training. The numbers' ratios for the months in which the detraining occurred due to the Covid-19 pandemic from mid-March to the end of June were calculated, which is the same period the online training program was applied for the experimental group. Physical preparation percentage was (40\%) and technical preparation was (60\%) in both March and April. Physical preparation percentage was $(25 \%)$ and technical preparation was $(75 \%)$ in both May and June (Albasiti, 1998).

- Warm up duration is (10) minutes and cool down duration is (5) minutes, according to scientific references specialized in basketball and sports training (Albasiti, 1998; American sport Education program, 2007; Radwan, 2017).

Table 1

Basketball Physical Elements and Exercises used for it in the Online Training Program for 


\section{the Experimental Group}

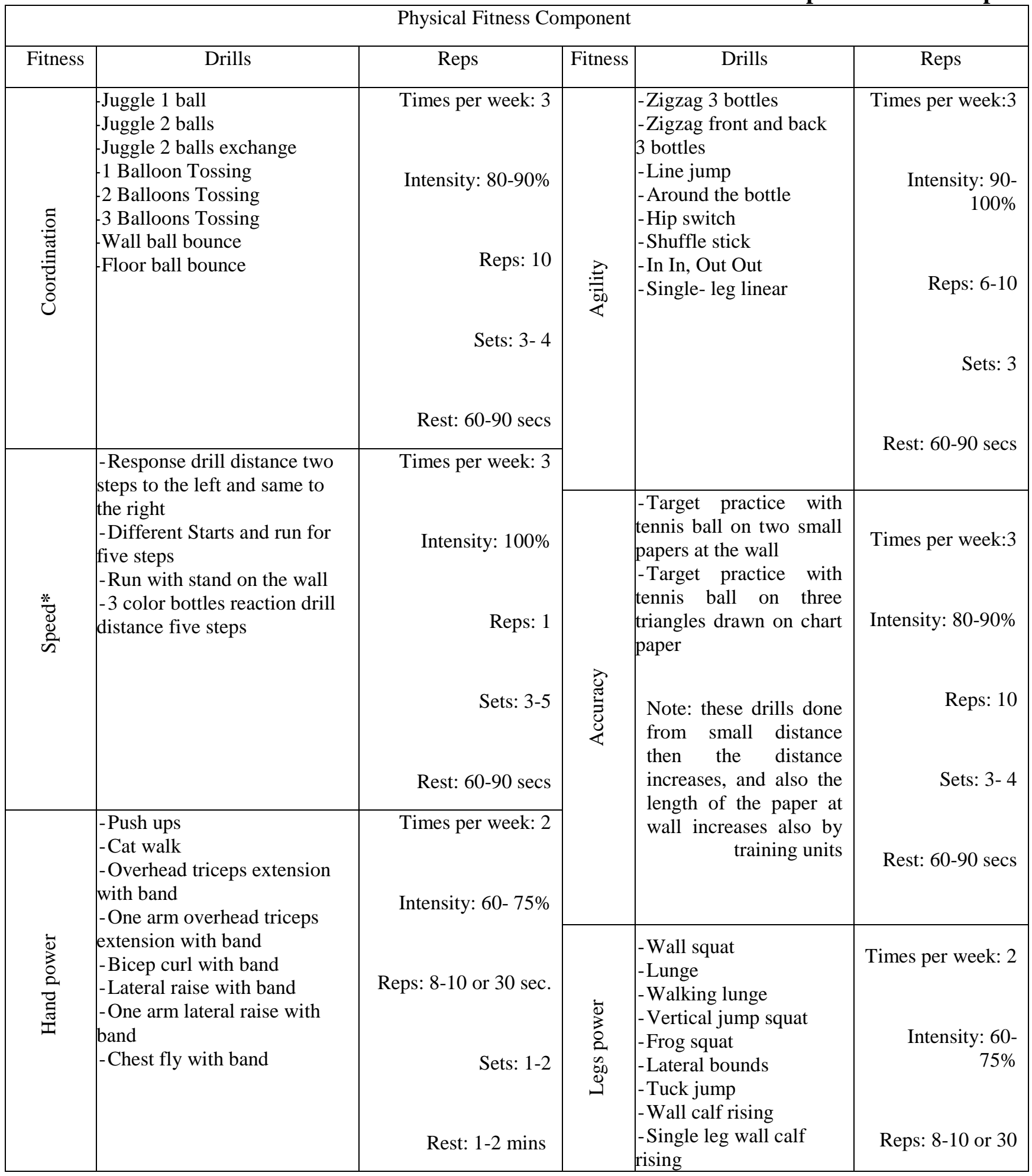




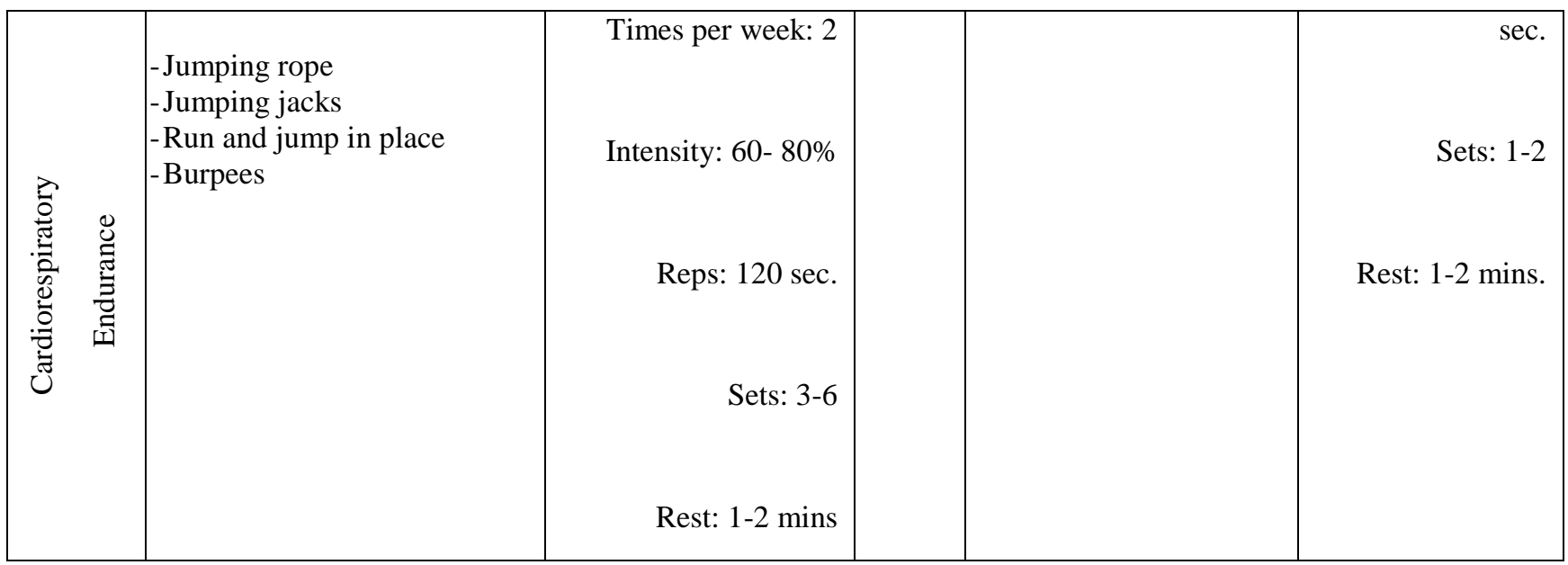

Note: (*) perform reaction and response speed exercises instead of transition speed exercises, as they are more suitable to apply at home.

Table 2

Skills and Exercises used for it in the Online Training Program for the Experimental

\begin{tabular}{|c|c|c|c|}
\hline \multicolumn{4}{|c|}{ Technical Component } \\
\hline Skills & Drills & Skills & Drills \\
\hline 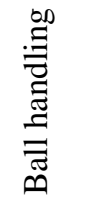 & $\begin{array}{l}\text { Rotate basketball around head, chest, legs } \\
\text { from stability and movement. } \\
\text {-Figure } 8 \text { between legs. }\end{array}$ & \multirow{2}{*}{ 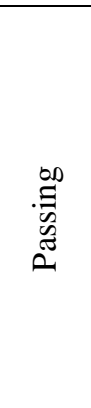 } & $\begin{array}{l}\text { - Chest pass on the wall } \\
\text { - Bounce pass on the wall } \\
\text { - Overhead pass on the wall } \\
\text { Join passing with one or two skills, before } \\
\text { or after it. }\end{array}$ \\
\hline \multirow{3}{*}{ 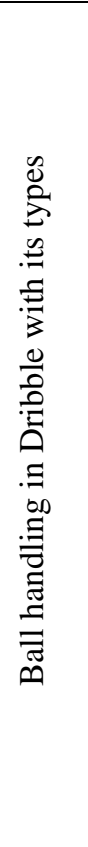 } & \multirow{3}{*}{$\begin{array}{l}\text { Ball handling in dribble with tennis ball. } \\
\text { Ball handling in dribble with two tennis } \\
\text { balls. } \\
\text { Ball handling in dribble with basketball. } \\
\text { Ball handling in dribble using basketball } \\
\text { with tossing one balloon. } \\
\text { Ball handling in dribble using basketball } \\
\text { with tossing two balloons. } \\
\text { Ball handling in dribble using basketball } \\
\text { while putting covering the eyes. } \\
\text { Ball handling in dribble using basketball } \\
\text { with tennis ball juggle. } \\
\text { Zigzag dribble } \\
\text { Join dribble skill with one or two skills, } \\
\text { before or after it. } \\
\text { Note: All drills are performed from stability } \\
\text { and movement. } \\
\text { All types of dribble are used in every } \\
\text { exercise. }\end{array}$} & & $\begin{array}{l}\text { Note: the performance passing from a } \\
\text { distance of two steps and then gradually } \\
\text { increase the distance up to } 4 \text { steps }\end{array}$ \\
\hline & & 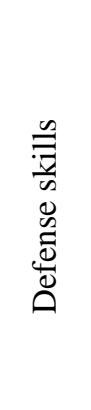 & $\begin{array}{l}\text { - Run two steps and do stance front chair } \\
\text { - Defense feet works in different directions } \\
\text { - Defense against dribbler with using chair. } \\
\text { - Defense against passer with using chair. } \\
\text { - Defense against shooter with using chair. }\end{array}$ \\
\hline & & 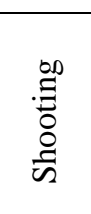 & $\begin{array}{l}\text { - Free throw on small rectangle at the wall } \\
\text { from one step : } 5 \text { steps } \\
\text { - Layup from left and right side, shooting } \\
\text { on rectangle at the wall } \\
\text { - Jump shot on small rectangle at the wall }\end{array}$ \\
\hline
\end{tabular}




\begin{tabular}{|c|c|c|}
\hline 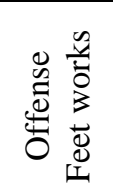 & $\begin{array}{l}\text { - Drills for stopping one and two counts } \\
\text { - Fake front chair } \\
\text { - Join skill with one or two skills, before or } \\
\text { after it. }\end{array}$ & $\begin{array}{l}\text { from one step up to } 5 \text { steps. } \\
\text { - Join skill with one or two skills, before or } \\
\text { after it except free throw skill. }\end{array}$ \\
\hline
\end{tabular}

Note: Intensity: 60- 80\%, Reps: 8-10, Sets: 3-4, Rest: 1-2 min.

\subsection{Statistical Analysis}

IBM SPSS, version (24), was used to conduct the research statistical processing. Prior to this, the normality of the research sample was checked using Shapiro-Wilk test to determine parametric or nonparametric statistic usage, (significance level is $\mathrm{P}$-value) for the research sample "experimental and control" in the variations of "height, weight, age, training age, coordination, right arm power, left arm power, the legs power, speed, agility, right arm accuracy, left arm accuracy, cardiorespiratory endurance, right layup, left layup, free throw, compound technical variable" $=(0.22,0.34,0.00,0.00,0.06,0.07,0.34,0.06,0.16,0.21,0.13,0.00,0.02$, $0.00,0.00,0.00,0.08)$. Hence, it was perceived that P-value sig. $>0.05$ in most variables, meaning using parametric statistic "Independent Samples T-Test" to calculate the differences between the experimental and control groups, and "Paired Samples T-Test" to calculate the differences between pre and post measurement for any experimental and control groups.

\section{Results:}

\section{1- Physical level for junior female basketball players:}

Table 3

Means, Standard Deviations, "t - test" and percentage of the change in the physical variables for the experimental group $(n=10)$

\begin{tabular}{|c|c|c|c|c|c|c|c|c|}
\hline \multirow{2}{*}{ Physical Variables (Units) } & \multicolumn{2}{|c|}{$\begin{array}{c}\text { Pre- } \\
\text { measurement }\end{array}$} & \multicolumn{2}{|c|}{$\begin{array}{c}\text { Post- } \\
\text { measurement }\end{array}$} & \multirow{2}{*}{$\begin{array}{c}\text { Mean } \\
\text { differences }\end{array}$} & \multirow{2}{*}{$\mathrm{t}$} & \multirow{2}{*}{$\mathrm{P}$} & \multirow{2}{*}{$\%$} \\
\hline & M & SD & M & SD & & & & \\
\hline Coordination (n/ 30s) & 10.00 & 3.92 & 14.00 & 5.12 & -4.00 & -2.44 & $0.04^{*}$ & $40 \%$ \\
\hline Right Arm power (m) & 2.97 & 0.46 & 2.86 & 0.40 & 0.11 & 0.54 & 0.60 & - \\
\hline Left Arm power (m) & 2.41 & 0.55 & 2.83 & 0.28 & -0.42 & -2.07 & 0.07 & - \\
\hline Legs power (m) & 1.27 & 0.16 & 1.36 & 0.20 & -0.09 & -2.43 & $0.04 *$ & $7.09 \%$ \\
\hline Speed (s) & 6.13 & 0.65 & 5.16 & 0.47 & 0.97 & 5.76 & $0.00 *$ & $15.82 \%$ \\
\hline Agility (s) & 22.52 & 1.53 & 23.14 & 1.75 & -0.62 & -3.55 & $0.01 *$ & $2.75 \%$ \\
\hline Right Arm accuracy (Pt) & 7.90 & 5.09 & 7.50 & 4.62 & 0.40 & 0.23 & 0.82 & - \\
\hline Left Arm accuracy (Pt) & 2.60 & 2.07 & 2.80 & 2.86 & -0.20 & -0.26 & 0.80 & - \\
\hline $\begin{array}{l}\text { cardiorespiratory } \\
\text { endurance (min) }\end{array}$ & 6.24 & 0.71 & 6.28 & 0.79 & -0.04 & -0.12 & 0.91 & - \\
\hline
\end{tabular}

* Significant difference between pre and post measurements $p \leq 0.05$ $\%=$ percent change in performance

Table 3 indicates statistically significant differences between the pre and post measurement of 
the experimental group in the variables (coordination, both legs power, speed, agility). It is clear that $(\mathrm{P}$ Value $<0.05)$, indicating the statistically significant differences in favor of the post measurement of the experimental group in the variable of coordination, legs power, and the speed, and with an improvement rate in the coordination by $(40 \%)$. Both legs power by $(7.09 \%)$ and speed by $(15.82 \%)$. As for the agility variable, it appears that the differences are in favor of

the pre measurement of the experimental group, with a decrease in the agility by $(2.75 \%)$.

Table 3 also indicates that there are non-statistically significant differences between the pre and post measurement of the experimental group in the variables (arms power "right-left", arms accuracy "right-left", and the cardiorespiratory endurance), as it becomes clear that (P value>

$0.05)$ indicating non-statistically significant differences.

Table 4

Means, Standard Deviations, "t - test" and percentage of the change in the physical variables for the control group $(n=10)$

\begin{tabular}{|c|c|c|c|c|c|c|c|c|}
\hline \multirow{2}{*}{ Physical Variables (Units) } & \multicolumn{2}{|c|}{$\begin{array}{c}\text { Pre- } \\
\text { measurement }\end{array}$} & \multicolumn{2}{|c|}{$\begin{array}{c}\text { Post- } \\
\text { measurement }\end{array}$} & \multirow{2}{*}{$\begin{array}{c}\text { Mean } \\
\text { differences }\end{array}$} & \multirow[t]{2}{*}{$\mathrm{t}$} & \multirow{2}{*}{$\mathrm{P}$} & \multirow{2}{*}{$\%$} \\
\hline & $\mathrm{M}$ & SD & $\mathrm{M}$ & SD & & & & \\
\hline Coordination (n/ 30s) & 9.70 & 4.35 & 6.20 & 4.52 & 3.50 & 2.95 & $0.02 *$ & $36.08 \%$ \\
\hline Right Arm power (m) & 2.80 & 0.42 & 2.32 & 0.48 & 0.48 & 3.26 & $0.01 *$ & $17.14 \%$ \\
\hline Left Arm power (m) & 2.50 & 0.81 & 1.94 & 0.67 & 0.56 & 2.37 & $0.04 *$ & $22.4 \%$ \\
\hline Legs power $(\mathrm{m})$ & 1.31 & 0.16 & 1.18 & 0.18 & 0.13 & 3.10 & $0.01 *$ & $9.92 \%$ \\
\hline Speed (s) & 5.53 & 0.89 & 6.20 & 0.86 & -0.67 & -2.85 & $0.02 *$ & $12.11 \%$ \\
\hline Agility (s) & 22.03 & 1.04 & 23.65 & 1.94 & -1.62 & -2.65 & $0.03 *$ & $7.35 \%$ \\
\hline Right Arm accuracy $(\mathrm{Pt})$ & 6.30 & 3.30 & 2.50 & 2.32 & 3.80 & 3.77 & $0.00 *$ & $60.31 \%$ \\
\hline Left Arm accuracy (Pt) & 3.20 & 2.82 & 0.60 & 1.26 & 2.60 & 3.07 & $0.01 *$ & $81.25 \%$ \\
\hline $\begin{array}{l}\text { cardiorespiratory } \\
\text { endurance (min) }\end{array}$ & 6.26 & 0.52 & 6.61 & 0.72 & -0.35 & -2.84 & $0.02 *$ & $5.59 \%$ \\
\hline
\end{tabular}

* Significant difference between pre and post measurements $p \leq 0.05$ $\%=$ percent change in performance

Table 4 indicates statistically significant differences between the pre and post measurement of the control group in the variables (coordination, arms power "left - right", legs power, speed, agility, arms accuracy "right- left", cardiorespiratory endurance). It is clear that (P Value $<0.05)$, indicating statistically significant differences in favor of the pre measurement of the control group with a decrease rate in the variables. The order of magnitude of the decrease in left arm accuracy $(81.25 \%)$, right arm accuracy $(60.31 \%)$, coordination $(36.08 \%)$, left arm power (22.4\%), right arm power (17.14\%), speed (12.11\%), legs power (9.92\%), agility (7.35\%), cardiorespiratory endurance $(5.59 \%)$.

Table 5

Means, Standard Deviations and "t - test" in the physical variables for experimental and control groups 


\begin{tabular}{|c|c|c|c|c|c|c|c|}
\hline \multirow{3}{*}{ Physical Variables (Units) } & \multirow{2}{*}{\multicolumn{2}{|c|}{$\begin{array}{l}\text { Experimental group } \\
\qquad(\mathrm{n}=10) \\
\text { Post- measurement }\end{array}$}} & \multirow{2}{*}{\multicolumn{2}{|c|}{$\begin{array}{l}\text { Control group } \\
\quad(\mathrm{n}=10)\end{array}$}} & \multirow{3}{*}{$\begin{array}{c}\text { Mean } \\
\text { differences }\end{array}$} & \multirow{3}{*}{$\mathrm{t}$} & \multirow{3}{*}{$\mathrm{P}$} \\
\hline & & & & & & & \\
\hline & M & SD & $\mathrm{M}$ & SD & & & \\
\hline Coordination (n/ 30s) & 14.00 & 5.12 & 6.20 & 4.52 & 7.80 & 3.61 & $0.00 *$ \\
\hline Right Arm power (m) & 2.86 & 0.40 & 2.32 & 0.48 & 0.54 & 2.75 & $0.01 *$ \\
\hline Left Arm power (m) & 2.83 & 0.28 & 1.94 & 0.67 & 0.89 & 3.92 & $0.00 *$ \\
\hline Legs power $(\mathrm{m})$ & 1.36 & 0.20 & 1.18 & 0.18 & 0.18 & 2.12 & $0.05^{*}$ \\
\hline Speed (s) & 5.16 & 0.47 & 6.20 & 0.86 & -1.04 & -3.38 & $0.01 *$ \\
\hline Agility (s) & 23.14 & 1.75 & 23.65 & 1.94 & -0.51 & -0.61 & 0.55 \\
\hline Right Arm accuracy (Pt) & 7.50 & 4.62 & 2.50 & 2.32 & 5.00 & 3.06 & $0.01 *$ \\
\hline Left Arm accuracy (Pt) & 2.80 & 2.86 & 0.60 & 1.26 & 2.20 & 2.22 & $0.03 *$ \\
\hline $\begin{array}{l}\text { cardiorespiratory } \\
\text { endurance (min) }\end{array}$ & 6.28 & 0.79 & 6.61 & 0.72 & -0.33 & -0.98 & 0.34 \\
\hline
\end{tabular}

* Significant difference between experimental and control groups $p \leq 0.05$ $\%=$ percent change in performance

Table 5 indicates statistically significant differences between both post measurements for the experimental and control group in variables (coordination, arms power "left - right", legs power, speed, arms accuracy "left - right"). It is clear that (P Value $\leq 0.05$ ) indicating statistically significant differences in favor of the post measurement of the experimental group.

Table 5 also indicates non-statistically significant differences between both post measurements for the experimental and control group in variables (agility, cardiorespiratory endurance), as it is clear that $(\mathrm{P}$ value $>0.05)$ indicating a non-statistically significant differences.

\section{2- Technical level for junior female basketball players:}

Table 6

Means, Standard Deviations, "t - test" and percentage of the change in the Technical variables for the experimental group $(n=10)$

\begin{tabular}{|c|c|c|c|c|c|c|c|c|}
\hline \multirow{2}{*}{ Variables (Units) } & \multicolumn{2}{|c|}{ Pre-measurement } & \multicolumn{2}{|c|}{ Post-measurement } & \multirow{2}{*}{$\begin{array}{c}\text { Mean } \\
\text { differences }\end{array}$} & \multirow{2}{*}{$\mathrm{t}$} & \multirow{2}{*}{$\mathrm{P}$} & \multirow{2}{*}{$\%$} \\
\hline & $\mathrm{M}$ & SD & $\mathrm{M}$ & SD & & & & \\
\hline Right Layup Test (Pt) & 1.00 & 0.67 & 1.10 & 0.57 & -0.10 & -0.56 & 0.59 & - \\
\hline Left Layup Test $(\mathrm{Pt})$ & 0.50 & 0.85 & 0.90 & 0.74 & -0.40 & -1.81 & 0.10 & - \\
\hline Free throw Test $(\mathrm{Pt})$ & 0.40 & 0.52 & 0.10 & 0.32 & 0.30 & 1.96 & 0.08 & - \\
\hline $\begin{array}{r}\text { compound technical Test } \\
\text { (total score) }\end{array}$ & 144.60 & 12.72 & 163.70 & 20.07 & -19.10 & -5.19 & $0.00^{*}$ & $13.20 \%$ \\
\hline
\end{tabular}

* Significant difference between pre and post measurements $p \leq 0.05$ $\%=$ percent change in performance

Table 6 indicates statistically significant differences between the pre and post measurement of 
the experimental group in the (compound technical variable). It is clear that ( $\mathrm{P}$ value $<0.05)$ indicating statistically significant differences in favor of post measurement for experimental group, and with improvement rate in the compound technical variable by $(13.20 \%)$.

Table 6 also indicates non-statistically significant differences between pre and post measurement for the experimental group in variables (layup "right - left", free throw), as it is clear that $(\mathrm{P}$ value $>0.05)$ indicating non-statistical significant differences.

Table 7

Means, Standard Deviations, "t - test" and percentage of the change in the Technical variables for the control group $(n=10)$

\begin{tabular}{|c|c|c|c|c|c|c|c|c|}
\hline \multirow{2}{*}{ Technical Variables (Units) } & \multicolumn{2}{|c|}{ Pre-measurement } & \multicolumn{2}{|c|}{ Post-measurement } & \multirow{2}{*}{$\begin{array}{c}\text { Mean } \\
\text { differences }\end{array}$} & \multirow{2}{*}{$\mathrm{t}$} & \multirow{2}{*}{$\mathrm{P}$} & \multirow{2}{*}{$\%$} \\
\hline & $\mathrm{M}$ & SD & $\mathrm{M}$ & SD & & & & \\
\hline Right Layup Test $(\mathrm{Pt})$ & 1.10 & 0.57 & 0.40 & 0.70 & 0.70 & 2.69 & $0.03^{*}$ & $63.63 \%$ \\
\hline Left Layup Test (Pt) & 0.70 & 0.82 & 0.10 & 0.32 & 0.60 & 2.25 & $0.05^{*}$ & $85.71 \%$ \\
\hline Free throw Test $(\mathrm{Pt})$ & 0.60 & 0.84 & 0.00 & 0.00 & 0.60 & 2.25 & $0.05^{*}$ & $100 \%$ \\
\hline $\begin{array}{r}\text { compound technical Test } \\
\text { (total score) }\end{array}$ & 148.10 & 24.14 & 134.70 & 31.19 & 13.40 & 3.70 & $0.01 *$ & $9.04 \%$ \\
\hline
\end{tabular}

* Significant difference between pre and post measurements $p \leq 0.05$

$\%=$ percent change in performance

Table 7 indicates statistically significant differences between the pre and post measurement of the control group in the variables (layup "right - left", free throw, compound technical variable). It is clear that $(\mathrm{P}$ value $\leq 0.05$ ) indicating statistically significant differences in favor of pre measurement for the control group, with decrease rate in the variables by organizing the decrease magnitude in the free throw shot by $(100 \%)$, left layup by $(85.71 \%)$, right layup by $(63.63 \%)$, compound technical variable by $(9.04 \%)$.

Table 8

Means, Standard Deviations and "t - test" in the Technical variables for experimental and control groups

\begin{tabular}{rccccccc}
\hline & $\begin{array}{c}\text { Experimental group } \\
(\mathrm{n}=10)\end{array}$ & \multicolumn{2}{c}{$\begin{array}{c}\text { Control group } \\
(\mathrm{n}=10)\end{array}$} & & & \\
Technical Variables (Units) & Post- measurement & \multicolumn{2}{c}{$\begin{array}{c}\text { Post-measurement } \\
\text { differences }\end{array}$} & $\mathrm{t}$ & $\mathrm{P}$ \\
\cline { 2 - 6 } & $\mathrm{M}$ & $\mathrm{SD}$ & $\mathrm{M}$ & $\mathrm{SD}$ & & & \\
\hline Right Layup Test (Pt) & 1.10 & 0.57 & 0.40 & 0.70 & 0.70 & 2.46 & $0.02^{*}$ \\
Left Layup Test (Pt) & 0.90 & 0.74 & 0.10 & 0.32 & 0.80 & 3.15 & $0.01^{*}$ \\
\hline
\end{tabular}




\begin{tabular}{|c|c|c|c|c|c|c|c|}
\hline Free throw Test $(\mathrm{Pt})$ & 0.10 & 0.32 & 0.00 & 0.00 & 0.10 & 1.00 & 0.34 \\
\hline $\begin{array}{r}\text { compound technical Test } \\
\text { (total score) }\end{array}$ & 163.70 & 20.07 & 134.70 & 31.19 & 29.00 & 2.47 & $0.02 *$ \\
\hline
\end{tabular}

Table 8 indicates statistically significant differences between both post measurements of the experimental and control groups in the variables (layup "right - left", compound technical variable). It is clear that ( $\mathrm{P}$ value $<0.05)$ indicating statistically significant differences in favor of post measurement for the experimental group.

Table 8 also indicates non-statistically difference between both post measurements for the experimental and control groups in the variable (free throw), as it is clear that ( $\mathrm{P}$ value $>0.05$ ) indicating non-statistically significant differences.

\section{Discussion:}

\section{1- Physical level for junior female basketball players:}

Tables 3, 4 and 5 conclude that physical level decreases for the control group who didn't exercise during the mandatory detraining period due to Covid-19 pandemic in all basketball physical fitness elements compared to those before stopping. Whereas the experimental group who subjected to online training during the mandatory detraining period has improved in the physical level for coordination, legs power, and speed elements unlike before. The group also kept up the physical level in arms power "left - right" and arms accuracy "right -left" elements, and reduced the decrease in both agility and cardiorespiratory endurance elements.

These results came as the control group did not participate in the physical activity at home for a period of 14 weeks during the mandatory detraining period in courts due to Covid-19 pandemic. This led to low level of physical performance unlike what the group had before stopping, represented in coordination, arms power "left - right", legs power, speed, agility, arms accuracy "left - right" and the cardiorespiratory endurance with a significant decrease percentage, ranging between $(5.59 \%: 81.25 \%)$.

These findings are consistent with Ammar et al. (2020) and Maugeri et al. (2020), who indicate that the significant decrease in the physical activity between pre and post Covid-19 in different age groups.

Moreover, Yousif et al. (2019), Joo (2018), Tran et al. (2017), Khudor (2016), Faigenbaum et al. (2013), and Khaleel (2008) all confirm that stopping and detraining lead to the decrease of fitness elements level. The magnitude of declining varies according to the duration and amount of obtaining the element before detraining.

In this regard, AlFaith (2016) points out that detraining may be caused by studying or other, however this affects negatively the player's physical abilities level.

Al-Tikriti and Al-Hajjar (2012) clarify that detraining for a certain period of time can weaken the physical fitness elements value, and the longer the detraining period the more the player loses physical fitness compared to the first training shape. 
These results are attributed to the experimental group for continuing online training from home throughout the mandatory detraining period, which had a positive effect in improving coordination element by $40 \%$, legs power by $7.09 \%$, and speed by $15.82 \%$ compared to before training. Also, it helped in keeping physical level that the player obtained before stopping in arms power "right - left", and arms accuracy "right - left" elements, and reducing the decrease in agility and cardiorespiratory endurance elements.

These findings are consistent with Maugeri et al. (2020) recommendations, that keeping regular exercise routine during the mandatory lockdown period, as the current state of emergency, is a major strategy for maintaining physical and mental health.

This is also consistent with the recommendations of Narici et al. (2020) that detraining harmful effects and stopping activities can be reduced and loss rate decreased through practicing routine exercises.

AlFaith (2016) points out that training continuity is considered one of the important factors necessary to ensure the rise in the level of physical attributes or at least maintain the level reached by the player.

This is because the online training program included various exercises for the basketball physical fitness elements suitable for home. These exercises were distributed over the training units taking into account their intensity and duration, so they lasted for (60) minutes, (6) times per week, to fit the same weekly load given to the players before stopping training in courts.

This agrees with the recommendations of Narici et al. (2020) that low to medium magnitude resistance exercises that can be easily performed at home, will have positive effects.

In this regard, Al-Tikriti and Al-Hajjar (2012) indicate, that maintaining what has been acquired of physical fitness and motor level depends mainly on organizing training units from their intensity, duration, and frequency during the annual training program and from year to another.

The reason behind agility decrease for the experimental group lies behind the fact that the players, before stopping their training at courts, used to train on this element three times a week, with exercises that take a large space in the court ranging between 10:15 meters, with a lot of changing directions. This space was not available during online training at home, despite the attempt to diversify the exercises, but they were performed on a small space not exceeding 5 meters and with very limited changes in directions to suit the training requirements at home.

This complies with the conclusion of Saleh (2019), who indicated that developing agility element is affected by place contrast, like distance and direction.

Saleh (2019) also mentioned that one of the factors influencing agility element development and making it more effective is a set of determinants (physical, motor duty, and environmental). He assumed that environmental determinants include the court dimensions, surface, the place for competition and colleagues, temperature, etc.

As for the cardiorespiratory endurance reduction for the experimental group players, despite 
that the online training program included exercises for its development, especially rope jumping to help preserving endurance ability for both circulatory and respiratory systems. Although these exercises helped reducing the element decrease by a large degree, compared to the control group, which had a significant decrease in this element, yet they did not help stopping the decline, neither helped in maintaining and developing cardiorespiratory endurance, which requires a long period of continuous aerobic performance. However, this cannot be reached through rope jumping and aerobic exercises in the limited space and poor ventilation at home.

This comports with what Hammad (2004) indicated, that rope jumping helps in largely improving cardiorespiratory endurance. However, it is difficult to continue performing jumping movements with a medium rhythm for enough time to build cardiorespiratory endurance, as the player will suffer from rapid leg fatigue, high pulse rates, and loss of enjoyment of the exercise.

Recently, Gelen et al. (2020) indicated that training at home during Covid-19 pandemic makes athletes go through a disturbed time in terms of performance and health. Low load training may affect the player's physical level, and body systems such as the muscular nervous system, cardiovascular system, respiratory or musculoskeletal system, due to requirements such as the training area, training equipment, and training environment.

Through the previous presentation of Tables 3, 4 and 5, it is clear that the first hypothesis has been partially fulfilled.

\section{2- Technical level for junior female basketball players:}

Tables 6, 7 and 8 conclude that technical level decrease for the control group that didn't exercise during the mandatory detraining period due to Covid-19 pandemic in layup "right left", free throw, and compound technical Test, compared to the time before stopping. Whereas the experimental group that applied the online training has improved in the technical level for the compound technical Test. The group also preserved its level in layup "right - left" and reduced the decrease in free throw level.

Such a decrease in the technical level of the control group, which ranged at a significant low rate between (9.04\%: 100\%), is due to the sudden detraining and their lack of practice of the acquired skills before stopping, which led to a very significant decrease in the technical skills.

These findings agree with Khaleel (2008), indicating that detraining has affected the game's basic skills. The percentage of the basic skills declining rate was close throughout the four weeks.

Moreover, the current results are in agreement with what Mujika and Padilla (2003) who pointed out that the detraining period has a negative effect on the player's technical performance level. This resulted in a partial or complete decrease in the acquired adaptations before stopping, which harmed the sports performance.

The experimental group findings are attributed to its continuity in online training during the mandatory detraining period, which included technical exercises for all learned and acquired skills before stopping. All available resources were used at home, such as using the wall for passing the ball, designing overlapping rectangular paper charts to help in layup shooting "indirect shot" and increase accuracy, using chairs as cones, performing difficult exercises to 
increase the players' ball control. So all types of dribbling were performed using a tennis ball, and two tennis balls, as well as a basketball with a tennis ball, and a tennis ball with balloon tossing. Also all types of dribbling control exercises using a basketball while covering the eyes. All this helped in improving compound technical Test by (13.20\%), including the following skills ball handling during dribble such as (crossover, behind, between), and stopping, passing, receiving, layup, jump shot, however all skills are performed with both right and left hands, and in preserving layup "right - left" and reducing free throw skill decrease.

These findings agree with what Abu Jamil (2015) referred to, that players keep developing in the technical skills or at least preserve it by continuing training and avoid detraining.

Moreover, this comply with what Gelen et al. (2020) referred to, that amidst Covid-19 pandemic it is not possible for all athletes to presume their usual training program in courts, being in a mandatory home isolation following the government's regulations. That is why the coach has to set a training plan as befitting these circumstances to reduce the huge impact of detraining on the players' physical, technical, and mental states. Training has positive effects on energy regeneration system, improving coordination and the technical, tactical, mental and psychological characteristics of the athlete.

Online training offered the experimental group a chance to continually connect with the coach using video calls application such as Zoom and group chat application such as WhatsApp group. This helped the players learn about the training program and exercise properly in terms of the load magnitude, also receive a feedback and correct and amend their mistakes, which positively affected their technical level.

GELEN et al. (2020) and Jakobsson et al.(2020) point out in this regard, that athletes training at home during COVID-19 pandemic should be planned through connecting them with sports coach or strength and conditioning coach, using technology (video calls, e-mails, phones, text messages) to obtain the proper training program.

Although the experimental group used an aiming chart in the form of overlapping rectangles hanged up on the wall, to help in developing shooting skill, yet it did not help in preserving free throw skill and reducing its performance level. For the form and course of the home training according to the resources there, the indirect shooting is totally different from the shape and course of the free throw "direct shot", i.e. the ball in the court is directly shot at the basket, hence the decrease in the performance level.

This is consistent with Fawzy (2004) mentions that one of the factors influencing the free throw accuracy is the shooting point. During free throw training, the ball has to be aimed at the upper edge of the front part of the hoop facing the player "direct shot".

Through the previous presentation of Tables 6,7 and 8 , it is clear that the second hypothesis has been partially fulfilled.

\section{Conclusion:}

In light of the objectives and hypotheses of the research and the approach used as well as obtained results. It is possible to conclude that the online training program at home, for a period 
of 14 weeks during detraining resulted from lockdown related to the Covid-19 pandemic, proved to have an effective and positive impact on the physical level of junior female basketball players. Through developing the following physical elements (coordination, speed, and legs power), preserving the following elements (arms power "right -left", arms accuracy "right - left"), and reducing the decline of the following elements (agility and cardiorespiratory endurance). It also has a positive impact on the technical level of junior female basketball players through developing the compound technical level performance, maintaining layup "right - left", and reducing free throw skill decrease to some extent.

It is possible to conclude that the sudden detraining for 14 weeks has a negative effect on the physical and technical level for junior female basketball players, as all basketball physical fitness elements have decreased, in addition to the decrease in the players' technical performance of the learned and acquired skills before stopping.

Online training is recommended to players using video call applications such as Zoom and group chat applications such as WhatsApp. In addition, continuous connection with the coach offer a proper training program and give outstanding opportuning for the trainee to receive follow up and feedback to correct the performance. This is suitable to face any other emergencies like a new wave of COVID-19 pandemic or any other pandemics requiring mandatory home isolation or examinations or even illness or other problems requiring the players to stay at home. It is very important for the players to maintain their physical and technical level and reduce declining in performance.

\section{Reference:}

Abdulhamid, K., \& Hassanein, M. S. (1997). Physical fitness and its components: theoretical foundations - physical preparation - methods of measurement. Cairo, Egypt: Dar Elfikr Elarabi.

Abu Jamil, E. A. (2015). Training in sports activities. Cairo, Egypt: Modern Book Center.

Albasiti, A. A. (1998). Rules and foundations of sports training and its application. Alexandria, Egypt: Al Maarif

AlFaith, W. M. (2014). The scientific encyclopedia for training juniors in the sports field. Cairo, Egypt: Arab Science and Culture Foundation.

AlFaith, W. M. (2016). Science and knowledge series for sports training (3) - The foundations of sports training for juniors' stage (a modern technical vision).Cairo, Egypt: Arab Science and Culture Foundation.

Al-Hajj, KH. T. (2017). Sport Training Basics. Amman, Jordan: Dar Aljanadria

Allawi, M. H., \& Radwan, M. N. (2001). Kinetic Performance Tests. Cairo, Egypt: Dar Elfikr Elarabi.

Ally, M. (2008). Foundations of educational theory for online learning. In T. Anderson (Ed.). 
The Theory and Practice of Online Learning (2nd ed., pp. 15-44). Edmonton: AU Press, Athabasca University

Al-Tikriti, W. Y., \& Al-Hajjar, Y. T. (2012). The complete encyclopedia in the physical preparation for women. Alexandria, Egypt: Dar Alwafaa

American sport Education program. (2007). Coaching youth basketball. Unites States: Human Kinetics.

Ammar, A., Brach, M., Trabelsi, K., Chtourou, H., Boukhris, O., Masmoudi, L., ... Hoekelmann, A. (2020). Effects of COVID-19 Home Confinement on Eating Behaviour and Physical Activity: Results of the ECLB-COVID19 International Online Survey. Nutrients, 12(6), 1583. https://doi.org/10.3390/nu12061583

Barth, K., \& Boesing, L. (2010). Training basketball. UK: Meyer \& Meyer sport.

Egyptian basketball federation (2020). Mini Basketball Rules. Cairo, Egypt: Egyptian basketball federation press

Eirale, C., Bisciotti, G., Corsini, A., Baudot, C., Saillant, G., \& Chalabi, H. (2020). Medical recommendations for home-confined footballers' training during the COVID-19 pandemic: from evidence to practical application. Biology of sport,37(2), 203-207. https://doi.org/10.5114/biolsport.2020.94348

Faigenbaum, A. D., Farrell, A. C., Fabiano, M., Radler, T. A., Naclerio, F., Ratamess, N. A., ... Myer, G. D. (2013). Effects of detraining on fitness performance in 7-year-old children. Journal of Strength \& Conditioning Research,27(2), 323-330. https://doi.org/10.1519/JSC.0b013e31827e135b

Fawzy, A. A. (2004). Junior Basketball. Alexandria, Egypt: The Egyptian Library.

Gambetta, V. (2007). Athletic Development: The Art and Science of Functional Sports Conditioning. Human Kinetics

Gelen, M., Eler, S., \& Eler, N. (2020). DETRAINING: COVID-19 VE ÜST DÜZEY PERFORMANS [DETRAINING: COVID-19 AND HIGH LEVEL PERFORMANCE]. Milli Eğitim Dergisi, 49 (227), 447-464. https://dergipark.org.tr/tr/pub/milliegitim/issue/56322/747508

Haleem, A., Javaid, M., \& Vaishya, R. (2020). Effects of COVID-19 pandemic in daily life. Current medicine research and practice, 10(2), 78-79. https://doi.org/10.1016/j.cmrp.2020.03.011

Hammad, M. I. (2004). Physical Fitness: Health Road and sports championship. Cairo, Egypt.

Hiltz, S. R., \& Turoff, M. (2005). Education goes digital: The evolution of online learning and the revolution in higher education. Communications of the ACM, 48(10), 59-64. https://doi.org/10.1145/1089107.1089139 
Jakobsson, J., Malm, C., Furberg, M., Ekelund, U., \& Svensson, M. (2020). Physical Activity During the Coronavirus (COVID-19) Pandemic: Prevention of a Decline in Metabolic and Immunological Functions. Frontiers in Sports and Active Living, 2, 57. https://doi.org/10.3389/fspor.2020.00057

Joo, C. H. (2018). The effects of short term detraining and retraining on physical fitness in elite soccer players. PloS one, 13(5), e0196212. https://doi.org/10.1371/journal.pone.0196212

Khaleel, A. M. (2008). The effect of stop-training on some elements of special physical health and some basic skills of badminton game. Al-Rafidain Journal for Sport Sciences, 14(48), 194-215. https://doi.org/10.33899/rajsport.2008.50034

Khudor, R. M. (2016). The Effects of the Stoppage of Training on the Cyclers' Speed, Speed Endurance, Aerobic Endurance, and Certain Other Functional Variables. Journal of Physical Education Sciences, 9(5), 63-98. Retrieved from https://www.iasj.net/iasj/article/125618

Khuraibet، R., \& Abdel Fattah, A. (2016). Sports Training. Cairo, Egypt: Book Center for Publishing.

Mattioli, A.V., Ballerini Puviani, M., Nasi, M., Farinetti, A. (2020). COVID-19 pandemic: the effects of quarantine on cardiovascular risk. European Journal of Clinical Nutrition, 74, 852855. https://doi.org/10.1038/s41430-020-0646-z

Maugeri, G., Castrogiovanni, P., Battaglia, G., Pippi, R., D'Agata, V., Palma, A., ... Musumeci, G. (2020). The impact of physical activity on psychological health during Covid-19 pandemic in Italy. Heliyon, 6(6), e04315. https://doi.org/10.1016/j.heliyon.2020.e04315

Moore, J. L., Dickson-Deane, C., \& Galyen, K. (2011). e-Learning, online learning, and distance learning environments: Are they the same?. The Internet and Higher Education, 14(2), 129135. https://doi.org/10.1016/j.iheduc.2010.10.001

Mujika, I., \& Padilla, S. (2003). Physiological and performance consequences of training cessation in athletes: detraining. In W. R. Frontera (Ed.). Rehabilitation of sports injuries: Scientific basis (pp. 117-143). UK: Black Well Science Ltd.

Narici, M., De Vito, G., Franchi, M., Paoli, A., Moro, T., Marcolin, G., ... Di Girolamo, F. G. (2020). Impact of sedentarism due to the COVID-19 home confinement on neuromuscular, cardiovascular and metabolic health: Physiological and pathophysiological implications and recommendations for physical and nutritional countermeasures. European Journal of Sport Science, 1-22. https://doi.org/10.1080/17461391.2020.1761076

Radwan, A. SH. (2017). Modern tools and methods in basketball. Alexandria, Egypt: World Sports Foundation.

Saleh, M. (2019). Sports training strategies for young people. Cairo, Egypt: Modern Book Center. 
STAFF AND WIRE REPORTS. (2020, March 30). How the coronavirus is affecting sports leagues and events. Available at: https://www.latimes.com/sports/story/2020-0309/coronavirus-latest-news-sports-world; accessed on 15.7.2020

Tran, T. T., Lundgren, L., Secomb, J., Farley, O. R., Haff, G. G., Nimphius, S., ... Sheppard, J. M. (2017). Effect of four weeks detraining on strength, power, and sensorimotor ability of adolescent surfers. The Open Sports Sciences Journal, 10(1). 71-80. https://doi.org/10.2174/1875399X01710010071

Wang, G., Zhang, Y., Zhao, J., Zhang, J., \& Jiang, F. (2020). Mitigate the effects of home confinement on children during the COVID-19 outbreak. Lancet, 395(10228), 945-947. https://doi.org/10.1016/S0140-6736(20)30547-X

World Health Organization [WHO]. (2010). Global Recommendations on Physical Activity for Health. Geneva, Switzerland: WHO Press

World Health Organization [WHO]. (2020a). Coronavirus disease 2019 (COVID-19): situation report, 72. Available at: https://apps.who.int/iris/handle/10665/331685; accessed on 05.9.2020

World Health Organization [WHO]. (2020b, March 11). WHO Director-General's opening remarks at the media briefing on COVID-19 - 11 March 2020. Available at: https://www.who.int/dg/speeches/detail/who-director-general-s-opening-remarks-at-the-mediabriefing-on-covid-19---11-march-2020; accessed on 11.4.2020

World Health Organization Regional Office for Africa [WHO Africa]. (2020). The Corona Virus Disease 2019 (COVID-19): Strategic Response Plan for the WHO African Region. Available at: https://www.afro.who.int/sites/default/files/2020-06/SPRP\%20BUDGET\%200520_01.pdf; accessed on 10.9.2020

Yousif, M. A., Farhan, Z. M., \& Hussain, A. A. (2019). The Effect of Stopping Training in Some Physical and Functional Variables and Sending Table Tennis. Indian Journal of Public Health Research \& Development, 10(10), 2969-2974. 